\title{
Outcome following ten years coronary artery bypass surgery : risk factors for early and late mortality and morbidity
}

Citation for published version (APA):

van Straten, A. H. (2010). Outcome following ten years coronary artery bypass surgery : risk factors for early and late mortality and morbidity. [Doctoral Thesis, Maastricht University]. Datawyse / Universitaire Pers Maastricht. https://doi.org/10.26481/dis.20100408as

Document status and date:

Published: 01/01/2010

DOI:

10.26481/dis.20100408as

Document Version:

Publisher's PDF, also known as Version of record

\section{Please check the document version of this publication:}

- A submitted manuscript is the version of the article upon submission and before peer-review. There can be important differences between the submitted version and the official published version of record.

People interested in the research are advised to contact the author for the final version of the publication, or visit the DOI to the publisher's website.

- The final author version and the galley proof are versions of the publication after peer review.

- The final published version features the final layout of the paper including the volume, issue and page numbers.

Link to publication

\footnotetext{
General rights rights.

- You may freely distribute the URL identifying the publication in the public portal. please follow below link for the End User Agreement:

www.umlib.nl/taverne-license

Take down policy

If you believe that this document breaches copyright please contact us at:

repository@maastrichtuniversity.nl

providing details and we will investigate your claim.
}

Copyright and moral rights for the publications made accessible in the public portal are retained by the authors and/or other copyright owners and it is a condition of accessing publications that users recognise and abide by the legal requirements associated with these

- Users may download and print one copy of any publication from the public portal for the purpose of private study or research.

- You may not further distribute the material or use it for any profit-making activity or commercial gain

If the publication is distributed under the terms of Article $25 \mathrm{fa}$ of the Dutch Copyright Act, indicated by the "Taverne" license above, 


\section{Outcome Following Ten Years \\ Coronary Artery Bypass Surgery}

Risk factors for early and late mortality and morbidity 
Cover illustration: Heart of Gold, Science Photo Library

(C) A.H.M. van Straten, Maastricht 2010

All rights reserved. No parts of this book may be reproduced without the priorwritten permission of the copyright holder.

ISBN 9789052789248 


\title{
Outcome Following Ten Years \\ Coronary Artery Bypass Surgery
}

\author{
Risk factors for early and late \\ mortality and morbidity
}

Proefschrift

Ter verkrijging van graad van doctor aan de Universiteit Maastricht, op gezag van de Rector Magnificus Prof. mr. G.P.M.F. Mols volgens het besluit van het College van Decanen

In het openbaar te verdedigen op donderdag 8 april 2010 om 14.00 uur

door

Albert Hendrikus Maria van Straten

Geboren 14 februari 1955 te Oirschot

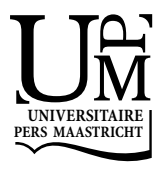




\section{Promotores}

Prof. dr. J.G. Maessen

Prof. dr. A.A.J. van Zundert

\section{Copromotor}

Prof. dr. O.C.K.M. Penn

\section{Beoordelingscommissie}

Prof. dr. H. ten Cate (voorzitter)

Prof. dr. B.A.J.M. de Mol (Academisch Medisch Centrum Universiteit van Amsterdam) Prof. dr.N.H.J. Pijls (Catharina-ziekenhuis)

Prof. dr. M. Prins

Prof. dr. J.H. Zwaveling

Financial support by The Catharina Hospital and Sorin for the publication and distribution of this thesis is gratefully acknowledged. 
Voor mijn moeder, Toos, Bart, Danielle en Mark Ter nagedachtenis aan mijn vader. 


\section{Abbreviations}

$\begin{array}{ll}\text { AUC } & \text { area under the ROC curve } \\ \text { BMI } & \text { Body Mass Index } \\ \text { BSA } & \text { Body Surface Area } \\ \text { CABG } & \text { Coronary artery bypass graft(ing) } \\ \text { CBS } & \text { Central Bureau of Statistics } \\ \text { CCS } & \text { Canedian Cardiovascular Society } \\ \text { CI } & \text { Confidence Interval } \\ \text { CKD } & \text { Chronic Kidney Disease } \\ \text { COPD } & \text { Chronic Obstructive Pulmonary Disease } \\ \text { CrCl } & \text { creatinine clearance } \\ \text { CRP } & \text { C-reactive protein } \\ \text { e-GFR } & \text { estimated glomerular filtration rate } \\ \text { ECC } & \text { Extra-corporeal circulation } \\ \text { EF } & \text { Ejection Fraction } \\ \text { EuroSCORE } & \text { European System for Cardiac Operative Risk Evaluation } \\ \text { FFP } & \text { Fresh Frozen Plasma } \\ \text { GFR } & \text { glomerular filtration rate } \\ \text { Hb } & \text { hemoglobin } \\ \text { HR } & \text { Hazard Ratio } \\ \text { HSMR } & \text { Hospital Standardized Mortality Ratio } \\ \text { IABP } & \text { intra-aortic balloon pump } \\ \text { LVEF } & \text { left ventricular ejection fraction } \\ \text { MDRD } & \text { Modification of diet in renal disease } \\ \text { OPCAB } & \text { off-pump coronary artery bypass } \\ \text { OR } & \text { Odds Ratio } \\ \text { PCI } & \text { percutaneous coronary intervention } \\ \text { Periop MI } & \text { perioperative myocardial infarction } \\ \text { RBC } & \text { Red Blood Cells } \\ \text { Redo } & \text { previous cardiac surgery } \\ \text { PVD } & \text { Peripheral Vascular Disease } \\ \text { ROC } & \text { Receivers Operating Characteristics } \\ \text { SeCr } & \text { serum creatinine level } \\ \text { SPSS } & \text { Statistical Product and Services Solutions } \\ \text { STS } & \text { Sociaty of Thoracic Surgeons } \\ \text { VLAD } & \text { Variable Life Adjusted Display } \\ \text { WHO } & \text { World Health Organisation } \\ & \end{array}$




\section{Contents}

Chapter 1 Introduction. 9

Chapter 2 Evaluation of the EuroSCORE risk scoring model for patients 27 undergoing coronary artery bypass graft surgery: a word of caution.

Accepted for publication: Neth Heart J

Chapter 3 Preoperative renal function as a predictor of survival after coronary artery bypass grafting: comparison with a matched general population.

J Thorac Cardiovasc Surg. 2009;138(4):971-6

Chapter 4 Risk factors for deterioration of renal function after coronary artery bypass grafting.

Eur J Cardio-thorac Surg 2010;37:106-111

Chapter 5 Which method of estimating renal function is the best predictor of early and late mortality after coronary artery bypass surgery?

Submitted

Chapter 6 Transfusion of red blood cells: the impact on short-term and long-term survival after coronary artery bypass grafting, a ten year follow-up.

Interact Cardiovasc Thorac Surg.2010;10:37-42

Chapter 7 Risk factors for red blood cell transfusion after coronary artery bypass grafting.

Accepted for publication: J Cardiothorac Vasc Anesth

Chapter 8 Effect of duration of red blood cell storage on early and late mortality after coronary artery bypass grafting.

Submitted

Chapter 9 Effect of storage time of transfused plasma on early and late mortality after coronary artery bypass grafting.

Submitted 
Chapter 10 Preoperative c-reactive protein levels to predict early and late mortality after coronary artery bypass surgery: 8 years' followup.

J Thorac Cardiovasc Surg. 2009;138(4):954-8

Chapter 11 Preoperative hemoglobin level as a predictor of survival after coronary artery bypass grafting, a comparison with the matched general population.

Circulation. 2009;120(2):118-25.

Chapter 12 Effect of body mass index on early and late mortality after coronary artery bypass grafting.

Ann Thorac Surg 2010:89:30-37

Chapter 13 Diabetes and survival after coronary artery bypass grafting: comparison with an age and sex matched population. Eur J Cardiothorac Surg. 2009 Dec 23. [Epub ahead of print]PMID: 20036136

Chapter 14 Peripheral vascular disease as a predictor of survival after coronary artery bypass grafting: Comparison with an age and sex matched general population.

Ann Thorac Surg 2010;89:414-20

Chapter 15 General discussion

Chapter 17 Nederlandstalige samenvatting

Chapter 18 Conclusions and recommendations 
Chapter 1

\section{Introduction}

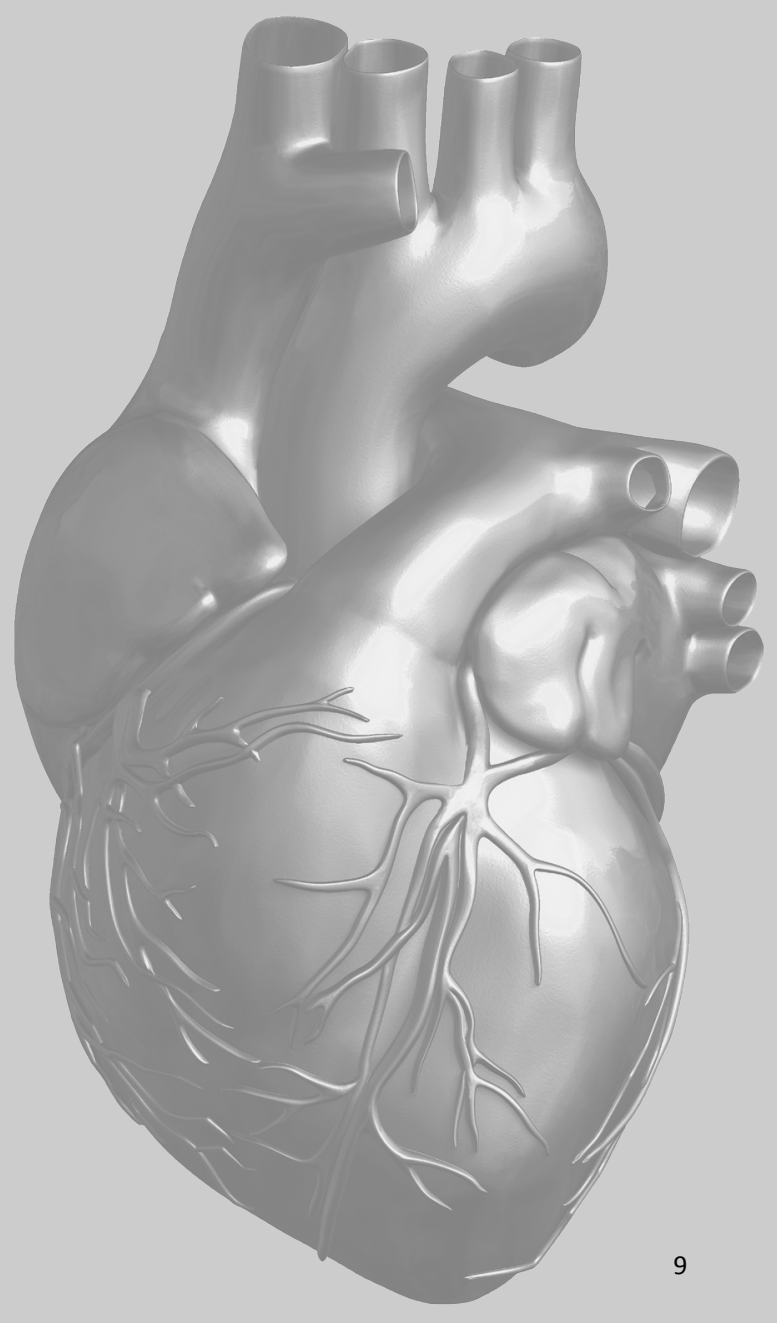





\section{Introduction}

The first open heart operation in the Catharina Hospital in Eindhoven was performed in 1978. Starting from January 1992, preoperative, operative and postoperative data of all heart surgery patients were collected in a computerized database. In 1998, the database was restructured and made more comparable with the database of the Society of Thoracic Surgeons (STS). We have prospectively calculated the additive and logistic EuroSCORE since January 2004. Before that time we used another (our own) risk scoring system named CRASH (Catharina Risk Assessment System for Heart surgery) that was a modification of the Parsonnet score.

\section{Purpose of the database}

From the beginning it was the intention to use our database to compare our results with those of other cardiac surgery centers and to use historical data to estimate the risk for future patients and to identify modifiable risk factors. Once those risk factors are identified, modification may lead to improved outcome. A yearly report is generated to inform our referral cardiologists, hospital management, other Dutch cardiothoracic surgeons, insurance companies, health inspection and others about the quality and quantity of cardio-thoracic surgical care yearly delivered by our department.

\section{Collection of data}

The preoperative data are collected from the information send to us by the referral cardiologist. This information is used to determine the indication for surgical therapy. On admission, patients' preoperative data are checked and missing data are added to the database. In the operating theatre, the surgeon writes an operation report by filling in the necessary operative items in the database. The computer generates the report. Only after all the necessary items are added the report will be generated and the surgeon has to add his signature to the report. This can be considered as a check for the accuracy and completeness of the data. Before discharge, all the postoperative data, including the complications, must be added to the database in order to generate a computerized discharge letter. This is mainly done by nurse-practitioners. The surgeon has to deliver his signature on the discharge letter as a sign that he agrees with the items scored in the database and shown in the discharge letter. After discharge, a last check is performed by a specially trained secretary and the remaining missing data are added if needed. In case of any doubt to score an item, the decision is always made by one of the staff surgeons. (In almost all cases the writer of this thesis). Yearly checks 
are performed for data entry mistakes such as false dates (date of birth, admission date, discharge date etc.). Since 2007, it was possible to make connections between our database and other databases in our hospital such as the laboratory database, the database of the hospital blood bank, the database from the ECHO lab, the database from the health insurance companies and recently the database from the pharmacological department.

In 2008, we studied the long-term survival of all cardiac surgery patients, i.e. more than 16000 patients, who were operated in our institution between January 1998 and December 2007. It proved to be a major task to obtain reliable mortality data over that time period. We started checking our data with the data in the database of health insurance companies. We assumed that if a patient was paying his health insurance fees at a certain date he must be alive 3 month before that date. Almost $90 \%$ of the patients could be followed up in this way. When we checked the mortality dates from the database of the health insurance companies with our own mortality dates, we had a complete match. For the remaining 1400 patients, we contacted the referral cardiologist, patient's home physician and sometimes the pharmacist in the home town of the patients. In our search, we noticed that the pharmacists had sometimes more and better electronic information of patients than the home physicians. When the patients had moved in the meantime it took sometimes some detective work to get the proper information. Of some 400 patients we could not get the information we needed in this way. For those patients we contacted the city authorities of the home towns of the patients. If the patient had moved in the meantime, we had to ask two or even more city authorities for the necessary information. The response of the city authorities varied from not willing to co-operate (only 2 out of 60 ) to sending official documents ("uittreksel bevolkings register"). Sometimes, we had to pay for the document ( $€ 1,5-$ $11,50)$ and sometimes it was for free. We finally succeeded to obtain information of all 16000 patients except for 172 .

For comparison of our patients' survival with that of the general Dutch population, we used the mortality data of the Dutch Central Bureau of Statistics (CBS) which are available through the internet (www.CBS.nl). Since the beginning of the $20^{\text {th }}$ century, the CBS delivers yearly age and sex specific mortality rates of the Dutch population. In our yearly report we mentioned the results of these comparisons in order to show the impact of several cardiac surgery procedures on long-term survival compared to the normal Dutch survival. We consider this information important for patients as well health insurance companies and health policy makers. Since 1992, the writer of this thesis was the supervisor of the database, responsible for the proper connection between the different databases and writer of the yearly reports. 


\section{The importance of accurate risk scoring models for patients}

A balanced decision about the best therapeutic option can only be made when the impact of risk factors of mortality and morbidity is well-addressed. This is also mandatory for taking a true informed consent from the patient.

\section{The importance of accurate risk scoring models for doctors and institutions}

Nowadays, results of medical care given by different institutions and doctors are increasingly scrutinised, and the production of hospital league tables is widespread. Such league tables usually fail to account for case mix, and great caution should be exercised in their interpretation. Operative mortality is considered to be an indicator of the quality of cardiac surgery. Comparing different institutions or surgeons on the basis of crude operative mortality figures may be misleading as mortality is affected by various preoperative patient characteristics (1). Hospital Standardized Mortality Ratio (HSMR) as first described by Jarman et al. $(2,3)$ uses administrative data that are readily available in every hospital such as: year, age, sex, ICD-9 code, Charlson index for comorbidity, social-economic status of the patient, urgency, length of hospital stay. The HSMR to measure quality of healthcare has been debated in the Dutch literature (4-13) and is considered inaccurate as it has many flaws. Various models have been developed for use in cardiac surgery. The first to become popular was the Parsonnet risk stratification system (14) which was developed in the USA in the 1980s. Subsequently, many other risk scoring models have been developed such as: Cleveland Clinic score (15), French score (16), Pons score (17) and the Ontario Province score (18). Currently the most used risk stratification models are the EuroSCORE and the Society of Thoracic Surgeons (STS) score. The European system for cardiac operative risk evaluation (EuroSCORE) has been first described in $1999(8,9)$. In the next chapter the EuroSCORE will be explained in more detail. In the recently developed national Dutch cardiac surgery database the EuroSCORE is used as the risk scoring system. Table 1 shows which variables are considered in the different scoring models. 
Table 1 Variables in different risk scoring models.

\begin{tabular}{|c|c|c|c|c|c|c|}
\hline & $\begin{array}{c}\text { Parso-nnet } \\
\text { Score (2) }\end{array}$ & $\begin{array}{c}\text { Cleveland } \\
\text { Clinicscore (6) }\end{array}$ & $\begin{array}{c}\text { French score } \\
\text { (7) }\end{array}$ & $\begin{array}{c}\text { Euro score } \\
(8,9)\end{array}$ & $\begin{array}{c}\text { Pons score } \\
\text { (10) }\end{array}$ & $\begin{array}{c}\text { Ontario } \\
\text { Province } \\
\text { score (11) }\end{array}$ \\
\hline \multicolumn{7}{|l|}{ Patient data } \\
\hline Age & $x$ & $x$ & $x$ & $x$ & $x$ & $x$ \\
\hline Gender & $x$ & & & $x$ & & $x$ \\
\hline Body weight & $x$ & $x$ & & & & \\
\hline \multicolumn{7}{|l|}{ Cardiac } \\
\hline Unstable agina & & & & $x$ & & \\
\hline Aortic stenosis & $x$ & $x$ & & & & \\
\hline Active endocarditis & & & & $x$ & & \\
\hline Congenital heart defect & $x$ & & & & & \\
\hline Hypertension, arterial & $x$ & & & & & \\
\hline Hypertension, pulmonary & $x$ & & & $x$ & & \\
\hline LV aneurysm & $x$ & & & & $x$ & \\
\hline LV ejection fraction & $x$ & $x$ & $x$ & $\mathrm{X}$ & & $x$ \\
\hline Mitral insufficiency & & $x$ & & & & \\
\hline Myocardial infarction (MI) & & & $x$ & $x$ & $x$ & \\
\hline NYHA & & & & & $x$ & \\
\hline Post MI VSD & & & $x$ & $x$ & & \\
\hline VT/VF & & & $x$ & $x$ & & \\
\hline \multicolumn{7}{|l|}{ Pulmonary } \\
\hline Asthma & $x$ & & & $x$ & & \\
\hline COPD & & $x$ & & $x$ & & \\
\hline \multicolumn{7}{|l|}{ Renal } \\
\hline Dialysis & $x$ & & $x$ & & & \\
\hline Creatinine & & $x$ & $x$ & $x$ & $x$ & \\
\hline Acute renal failure & $\mathrm{x}$ & & & $x$ & & \\
\hline \multicolumn{7}{|l|}{ Other } \\
\hline Anemia & & $x$ & & & & \\
\hline Diabetes & $\mathrm{X}$ & $x$ & & & & \\
\hline Liver disease & & & & & $x$ & \\
\hline History of TIA, stroke & & $x$ & & $x$ & & \\
\hline Paraplegia & $x$ & & & & & \\
\hline Pacemaker & $x$ & & & & & \\
\hline \multicolumn{7}{|l|}{ Vascular } \\
\hline Aortic dissection, acute & & & $x$ & & & \\
\hline Peripheral arterial disease & & & & $x$ & & \\
\hline History of vascular surgery & & $x$ & & $x$ & & \\
\hline \multicolumn{7}{|l|}{ Preoperative } \\
\hline Ventilation & & & $x$ & $x$ & $x$ & \\
\hline IABP & $x$ & & & $x$ & & \\
\hline Inotropes & & & & $x$ & & \\
\hline Resuscitation & & & & $x$ & & \\
\hline Cardiogenic shock & $x$ & & & & $x$ & \\
\hline \multicolumn{7}{|l|}{ Operation } \\
\hline Combined surgery & $x$ & & $x$ & $x$ & $x$ & $x$ \\
\hline Urgent/emergency & $x$ & $x$ & & $x$ & $x$ & $x$ \\
\hline Reoperation & $x$ & $\mathrm{X}$ & $x$ & $x$ & $\mathrm{x}$ & $x$ \\
\hline
\end{tabular}




\section{Long-term survival}

Several risk factors may lead to impaired long-term survival. In most studies the survival of patients with a certain risk factor is compared to the survival of patients without that specific risk factor. Results of these studies are of course valuable en can be used to inform patients about their prognosis. Patients with a certain risk factor have a worse prognosis than those without that risk factor. For a patient it might be more informative if we could tell him or her about the effect of certain risk factors on their prognosis compared to an age and sex matched general population group. Patients might wonder if their disease (in our study all patients had coronary artery disease) together with other risk factors will lead to premature mortality compared to age and sex matched people (wife or husband, friends, family etc). Only a few studies report about the long-term survival of CABG compared to the background population $(17,19)$. Knowledge about modifiable risk factors for late mortality may lead to improved longterm survival. However the impact of many risk factors on late survival after CABG has not been fully described yet.

\section{Objective of this thesis}

There are 3 main objectives: to base the validity of current systems for risk stratification upon our findings, to define new items for risk stratification and survival prediction and to find ways to improve risk factors in order to improve survival.

In the second chapter we evaluated the accuracy of the EuroSCORE as a risk scooring system in patients undergoing CABG.

In the third chapter we investigated renal function as a predictor of early and late mortality.

Severe renal dysfunction, particularly dysfunction requiring renal replacement therapy, has been identified as a risk factor for worse outcome after CABG (20-22). Renal dysfunction not requiring dialysis also has been identified as a predictor of poor outcome (23-27). Recently, the effect of preoperative and postoperative renal function on late survival has been described in large patient groups (28-29). In these studies, a strong correlation was found between age and deterioration of renal function. Since advanced age has a strong influence on late survival after CABG, interpretation of longterm survival curves comparing groups of patients stratified by renal function might be difficult, despite appropriate statistical tests. Postoperative survival varies not only with age but also according to gender, year of surgery, and country. We therefore studied early and late survival of our Dutch CABG patients stratified by preoperative 
creatinine clearance, in comparison to a general Dutch population that was matched for age, gender, and year of operation.

In the fourth chapter, we investigeted the risk factors for deterioration of renal function after CABG. Several risk factors for impairment of renal function after CABG have been identified, of which female gender, age, diabetes mellitus, hypertension, preoperative creatinine clearance $<50 \mathrm{ml} / \mathrm{min}$, impaired left ventricular function, need for intra aortic balloon pump (IABP) and re-exploration are most often mentioned (30-33). Several studies state that deterioration of renal function occurs more often after conventional coronary artery bypass operation with the use of extracorporeal circulation (ECC) than after off-pump coronary artery bypass (OPCAB) (34-38) although others could not confirm this statement $(32,33,39)$. Recently, deterioration of renal function has been described as a predictor of poor long-term survival (40). We analysed our data to determine risk factors for deterioration of creatinine clearance after CABG adding some variables which, to our knowledge have not yet been described as such.

In the fifth chapter, we investigated which method of estimation of renal function is the best predictor of early and late mortality after CABG. Renal insufficiency is associated with an increased risk of complications and mortality after CABG (41-43). The gold standard to determine renal function is the measurement of the glomerular filtration rate (GFR), represented by the clearance of an exogenous inert substance such as inulin. This is a cumbersome and time-consuming way to determine GFR and hence some more practical formulas have been developed to estimate the GFR. The CockcroftGault formula is used to estimate the creatinine clearance $(\mathrm{CrCl})(44)$ and more recently the Modification of Diet in Renal Disease (MDRD) has been introduced to estimate the glomular filtration rate (e-GFR). Definitions of impairment of renal function after CABG vary in the literature. Serum creatinine levels $(\mathrm{SeCr})(45,46), \mathrm{CrCl}(46-48)$ and e-GFR $(46,47,49)$ were used, describing renal function as a risk factor for mortality after CABG. We analyzed preoperative and postoperative renal function data from all patients undergoing isolated CABG in our hospital from 1998 until 2007, using three different definitions of renal function ( $\mathrm{SeCr}, \mathrm{CrCl}$ and e-GFR) in order to investigate the relationship between these parameters and early and late mortality and to evaluate their predictive value.

In the sixth chapter, we studied the impact of transfusion of red blood cells on early and late mortality after CABG. Transfusion of red blood cells (RBC) in patients undergoing CABG is associated with increased mortality and morbidity (50-53). Transfusion of $\mathrm{RBC}$ as a risk factor for early mortality has been well established whereas the effect of $\mathrm{RBC}$ transfusion on late mortality has been less well described. This study analyzes the effect of peri-operative transfusion of RBCs on short- and long-term mortality after 
CABG in our centre and compares survival rates with expected survival, based on the general Dutch population.

In the seventh chapter, we studied the risk factors for red blood cell transfusion after CABG. We analyzed the patient characteristics and sought for a correlation between these characteristics and the number of RBC's received after CABG.

In the eighth chapter, we studied the effect of duration of red blood cell storage on early and late mortality after CABG. Critically ill patients, including those who undergo cardiac surgery, experience more severe complications if they receive blood transfusions (54-56). The storage time of RBC may affect the risk of experiencing those complications (57-65) because RBCs undergo structural and functional changes that reduce function and viability after transfusion (66-69). Recently, some (70-71) but not all (7274 ) investigators have expressed their concern about using older RBCs for transfusion during or after cardiac surgery. In those reports, several endpoints in heterogeneous patient populations were mentioned. We therefore investigated whether longer storage of transfused RBCs increased the risk of early or late mortality in a large group of patients who underwent CABG.

In the ninth chapter, we investigated the effect of storage time of transfused plasma on early and late mortality. The transfusion of fresh-frozen plasma from female donors can lead to transfusion-related acute lung injury (75-83). To our knowledge, no data regarding the effect of the storage time of transfused fresh-frozen plasma on early and late outcomes after coronary artery bypass grafting are available.

In the tenth chapter, we investigated the preoperative level of C-reactive protein as a predictor for early and late mortality after CABG. Increased levels of C-reactive protein (CRP) are associated with an increased incidence of coronary and cardiac events after percutaneous coronary intervention (84). In patients with chronic heart failure, CRP levels form a major prognostic factor (85). A few reports address the correlation between elevated levels of preoperative CRP and early (86) and late mortality (87) after CABG. In one study, a correlation was found between elevated levels of CRP and early graft occlusion (88).

In the eleventh chapter, we evaluated the preoperative hemoglobin level as a risk factor for mortality after CABG. The role of preoperative hemoglobin as a predictor of short-term and long-term outcomes after CABG has not been well established. According to the World Health Organization (WHO), anemia is defined as hemoglobin $<13$ $\mathrm{g} / \mathrm{dL}$ for men and $<12 \mathrm{~g} / \mathrm{dL}$ for women. Several cut-off points for preoperative hemoglobin as a risk factor for poor early outcomes have been described, including 10 
$\mathrm{g} / \mathrm{dL}(89), 11 \mathrm{~g} / \mathrm{dL}(90)$, and $12 \mathrm{~g} / \mathrm{dL}(91)$. It is not clear whether poor outcomes are caused by the low hemoglobin level itself or by other risk factors that are frequently present in anemic patients. To our knowledge, no data are available on the association between low preoperative hemoglobin levels and long-term outcomes in patients undergoing $C A B G$. We therefore analyzed the data of patients undergoing CABG in a single center to determine the predictive value of low hemoglobin level in combination with comorbidities on early and late mortality.

In the twelfth chapter, we investigated the impact of body mass index in early and late mortality after CABG. Obesity in the Western world has achieved alarming proportions and is related to morbidity such as diabetes, hypertension and coronary artery disease, reduced life expectancy, impaired quality of life, and increased health-care costs. (9295) However, it remains controversial whether obesity is related to increased longterm mortality after CABG (96-101). In a recent meta-analysis, Oreopoulos and colleagues (102) showed that overweight and obesity are associated with a neutral or even beneficial effect on all-cause mortality after coronary revascularization. This controversial finding is described as the "obesity paradox." Because obesity is a potentially treatable condition, the identification of obesity as a risk factor for reduced life expectancy after CABG is an important issue. The objective of this study was to determine the effect of body mass index on 30-day and late mortality after CABG.

In the thirteenth chapter, we investigated diabetes as a risk factor for early and late mortality after CABG. Diabetes is a risk factor for poor outcomes after surgical myocardial revascularization (103-109). In patients undergoing CABG, the incidence of diabetes ranges from $12 \%$ to $38 \%(110-114)$. Reports addressing the long-term mortality of diabetic patients after CABG vary, with an incidence ranging from $1.3 \%$ to $6.5 \%$ per patient-year (112-116). In diabetic patients, revascularization appears to provide better long-term survival than percutaneous interventions does (114-116). In some studies, diabetes has also been described as a predictor of early mortality (117-119), but others could not confirm this finding $(111,120)$. On the other hand, little is known about the long-term post-CABG survival of patients with and without diabetes compared to the survival of the general population. In this study, we evaluated the effect of diabetes on early and late mortality after CABG. We also compared the long-term survival of diabetic and non-diabetic patients to the survival of cohorts of the general population in the Netherlands matched for age and sex (normal Dutch survival).

In the fourteenth chapter, we evaluated peripheral vascular disease as a risk factor for early and late mortality after CABG. The prevalence of PVD in patients with coronary artery disease varied in several studies between 26\% and 71\% (121-124). PVD was found to increase twofold to three-fold the risk of cardiovascular mortality (125). The 
operative mortality with CABG is estimated to be 1.6 to 2.9 - fold higher in patients with PVD $(126,127)$. In 1999, the EuroSCORE was introduced in Europe (9) and started to be widely used as a scoring system to predict early mortality in cardiac surgical patients. The standard EuroSCORE underestimated the risk in certain very high-risk patients; therefore in 2003 a more precise logistic regression model was introduced (128). In both calculating methods, the extracardiac arteriopathy (limb arteries or carotid pathology) is identified as a risk factor for early mortality in cardiac surgical patients. The value of PVD as an independent predictor for early mortality after CABG demonstrated in a non-contemporaneous series (121), can be debated considering the results of more recent cohorts (129). These results still sustain the fact that PVD is an important predictor for increased late mortality. To our knowledge there are no large recent studies assessing the impact of PVD on early and late survival after CABG. Therefore we analyzed PVD as a risk factor for early and late mortality in a large group of patients with isolated CABG operated in our department between 1998 and 2008.

\section{References}

1. DuBois RW, Rogers WH, Moxley JH, et al. Hospital inpatients mortality: is it a predictor of quality. $N$ Engl J Med 1987;317:1674-1680

2. Parsonnet $V$, Dean $D$, Bernstein, $A D$. A method of uniform stratification of risk for evaluating the results of surgery in acquired adult heart disease. Circulation 1989;701(suppl):13-112

3. Allen A, Forsyth AT. Risk stratification in open heart surgery [letter]. BMJ 1992;305:1500-1501

4. Spiegelhalter DJ. Risk stratification for open heart surgery [letter]. BMJ 1992;305:1500.

5. Treasure T. Risks and results of surgery. Br Heart J 1995;74:11-12

6. Higgins T.L., Estafanous F.G., Loop F.D., Beck G.J., Blum J.M., Paranandi L. Stratification of morbidity and mortality outcome by preoperative risk factors in coronary artery bypass patients. J Am Med Assoc 1992;267:2344-2348.

7. Roques F., Gabrielle F., Michel P., de Vincentiis C., David M., Baudet E. Quality of care in adult heart surgery: proposal for a self-assessment approach based on a French multicenter study. Eur J Cardiothorac Surg 1995;9:433-440.

8. Roques F., Nashef S.A.M., Michel P., Gauducheau E., de Vincentiis C., Baudet E., Cortina J., David M., Faichney A., Gabrielle F., Gams E., Harjula A., Jones M.T., Pinna Pintor P., Salamon R., Thulin L. Risk factors and outcome in European cardiac surgery: analysis of the EuroSCORE multinational database of 0 patients. Eur J Cardio-thorac Surg 1999;15:816-823.

9. Nashef S.A.M., Roques F., Michel P., Gauducheau E., Lemeshow S., Salamon R. European system for cardiac operative risk evaluation (EuroSCORE). Eur J Cardio-thorac Surg 1999;16:9-13.

10. Pons J.M.V., Granados A., Espinas J.A., Borras J.M., Martin I., Moreno V. Assessing open heart surgery mortality in Catalonia (Spain) through a predictive risk model. Eur J Cardio-thorac Surg 1997;11:415423.

11. Tu J.V., Jaglal S.B., Naylor C.D. Multicenter validation of a risk index for mortality, intensive care unit stay, and overall hospital length of stay after cardiac surgery. Circulation 1995;91:677-684.

12. Ad N, Barnett SD, Speir AM. The performance of the EuroSCORE and the Society of Thoracic Surgeans mortality risk score: the gender factor. Interact CardioVasc Thorac Surg 2007;7:192-195. 
13. Nilsson J, Algotsson L, Hoglund P, Luhrs C, Brandt J. Early mortality in coronary artery bypass surgery: the EuroSCORE versus the Sociaty of Thoracic Surgens risk algorithm. Ann Thorac Surg 2004;77:123539.

14. Swets JA. Measuring the accuracy of diagnostic systems. Science 1988;240:1285-1293.

15. Geissler HJ, Holzl P, Marohl S, Kuhn-Regnier F, Mehlhorn U, Sudkamp M, Rainer de Vivie E. Risk stratification in heart surgery: comparison of six score systems. Eur J of Cardiothorac Surg 200;17:400-406

16. Lovegrove J, Valencia O, Treasure T, Sherlaw-Johnson C, Gallivan S. Monitoring the results of cardiac surgery by variable life-adjusted display.Lancet. 1997 Oct 18;350(9085):1128-30.

17. Ketonen $M$, Pajunen $P$, Koukkunen $H$, Immonen-Raiha $P$, Mustonen J, Mähönen $M$, Niemelä $M$, Kuulasmaa K, Palomäki P, Arstila M, Vuorenmaa T, Lehtonen A, Lehto S, Miettinen H, Torppa J, Tuomilehto J, Airaksinen J, Pyörälä K, Salomaa V; FINMONICA/FINAMI Study Group. Long-term prognosis after coronary artey bypass surgery. Int J Cardiol. 2008;124:72-79.

18. Rahimtoola SH, Grunkemeier GL, Star A. Ten year survival after coronary artery bypass surgery for angina in patients aged 65 years and older. Circulation 1986;74:509-517.

19. Toumpoulis IK, Anagnostopoulos CE, DeRose JJ, Swistel DG.European system for cardiac operative risk evaluation predicts long-term survival in patients with coronary artery bypass grafting. Eur J Cardiothorac Surg. 2004 Jan;25(1):51-8.

20. Nakayama L, Sakata R, Ura M, Miyamoto TA. Coronary artery bypass grafting in dialysis patients. Ann Thorac Surg 1999;68:1257-61.

21. Rinehart AL, Herzog CS, Collins AJ, Flack JM, Ma JZ, Opsahl JA. A comparison of coronary angioplasty and coronary artery bypass grafting outcomes in chronic dialysis patients. Am J Kidney Dis 1995;25:281-90.

22. Labrousse L, de Vincentiis C, Madonna F, Deville C, Roques X, Baudet E. Early and long-term results of coronary artery bypass grafts in patients with dialysis dependent renal failure. Eur J Cardiothorac Surg 1999;15:691-6.

23. Rao V, Weisel RD, Buth KJ, Cohen G, Borger MA, Shiono N, et al. Coronary artery bypass grafting in patients with non-dialysis-dependent renal insufficiency. Circulation 1997;96 (suppl II):38-43.

24. Weerasinghe A, Hornick P, Smith P, Taylor K, Ratnatunga C. Coronary artery bypass grafting in nondialysis-dependent mild-to-moderate renal dysfunction. J Thorac Cardiovasc Surg 2000;121:1083-9.

25. Nakayama Y, Sakata R, Ura M, Itoh T. Long-term results of coronary artery bypass grafting in patients with renal insufficiency. Ann Thorac Surg 2003;75:496-500.

26. Hirose H, Amano A, Takahashi A. Nagano, N. Coronary artery bypass grafting for patients with nondialysis-dependent renal dysfunction (serum creatinine $2.0 \mathrm{mg} / \mathrm{dl}$ ). Eur J Cardiothorac Surg 2000; 20:565-72.

27. Szczech LA, Best PJ, Crowley E, Brooks MM, Berger PB, Bittner V, et al, for the Bypass Angioplasty Revascularization Investigation (BARI) Investigators. Outcomes of patients with chronic renal insufficiency in the Bypass Angioplasty Revascularization Investigation. Circulation 2002;105: 2253-8.

28. Howell NJ, Keogh BE, Bonser RS, Graham TR, Mascaro J, at al. Mild renal dysfunction predicts inhospital mortality and post-discharge survival following cardiac surgery. Eur J Cardiothorac Surg 2008;34:390-5.

29. Brown JR, Cochran RP, Mackenzie TA, Furnary AP, Kunzelman KS, Ross CS, et al. Long-term survival after cardiac surgery is predicted by estimated glomerular filtration rate. Ann Thorac Surg 2008;86:4-11.

30. Ascione R, Nason G, Al-Ruzzeh S, Ko C, Ciulli F, Angelini GD. Coronary revascularisation with or without cardiopulmonary bypass in patients with preoperative nondialysis-dependent renal insufficiency. Ann Thorac Surg. 2001; 72:2020-5.

31. Gerritsen WB, van Boven WJ, Driessen AH, Haas FJ, Aarts LP. Off-pump versus on-pump coronary artery bypass grafting: oxidative stress and renal function. Eur J Cardiothorac Surg. 2001; 20:923-9. 
32. Gamoso MG, Phillips-Bute B, Landolfo KP, Newman MF, Stafford-Smith M. Off-pump versus on-pump coronary artery bypass surgery and postoperative renal dysfunction. Anesth Analg. 2000; 91:1080.

33. Asimakopoulos G, Karagounis AP, Valencia O, Alexander N, Howlader M, Sarsam MA, Chandrasekaran $V$. Renal function after cardiac surgery off- versus on-pump coronary artery bypass: analysis using the Cockroft-Gault formula for estimating creatinine clearance. Ann Thorac Surg. 2005; 79:2024-31.

34. Ascione R, Lloyd CT, Underwood MJ, Gomes WJ, Angelini GD. On-pump versus off-pump coronary revascularization: evaluation of renal function. Ann Thorac Surg 1999; 68:493-8.

35. Ogawa M, Yaku H, Doi K, Okano T, Yamada Y, Hayashida K, Fukumoto A. Does off-pump coronary artery bypass beneficially affect renal function? ANZ J Surg. 2005; 75:675-9.

36. Sellke FW, DiMaio JM, Caplan LR, Ferguson TB, Gardner TJ, Hiratzka LF, Isselbacher EM, Lytle BW, Mack MJ, Murkin JM, Robbins RC; American Heart Association. Comparing on-pump and off-pump coronary artery bypass grafting: numerous studies but few conclusions: a scientific statement from the American Heart Association council on cardiovascular surgery and anesthesia in collaboration with the interdisciplinary working group on quality of care and outcomes research. Circulation. 2005; 111:2858-64.

37. Celik JB, Gormus N, Topal A, Okesli S, Solak H. Effect of off-pump and on-pump coronary artery bypass grafting on renal function. Ren Fail. 2005; 27:183-8.

38. Ascione R, Lloyd CT, Underwood MJ, Gomes WJ, Angelini GD. On-pump versus off-pump coronary revascularization: evaluation of renal function. Ann Thorac Surg. 1999;68(2):493-8.

39. Tang AT, Knott J, Nanson J, Hsu J, Haw MP, Ohri SK. A prospective randomized study to evaluate the renoprotective action of beating heart coronary surgery in low risk patients. Eur J Cardiothorac Surg. 2002; 22:118-23.

40. Brown JR, Cochran RP, MacKenzie TA, Furnary AO, Kunzelman KS, Ross CS, Langner CW, Charlesworth DC, Leavitt BJ, Dacey LJ, Helm RE, Braxton JH, Clough RA, Dunton RF, O'Connor GT. Long-term survival after cardiac surgery is predicted by estimated glomerular filtration rate. Ann Thorac Surg 2008;86:412.

41. Brown JR, Cochran RP, MacKenzie TD, Furnary AP, Kunzelman KS, Ros CS, Dacey LJ, Helm RE, Braxton JH, Clough RA, Dunton RF, O'Connor GT; for the Northern New England Cardiovascular Disease Study Group. Long-term survival after cardiac surgery is predicted by estimated glomerular filtration rate. Ann Thorac Surg 2008;86:4-12.

42. Cooper WA, O'Brien SM, Thourani VH, Guyton RA, Bridges CR, Szczech LA, Petersen R, Peterson ED. Impact of renal dysunction on outcomes of coronary artery bypass surgery. Circulation. 2006; 113:1063-1070

43. Chertow GM, Levy EM, Hammermeister KE, Grover F, Daley J. Independent association between acute renal failure and mortality following cardiac surgery. Am J Med. 1998;104:343-48.

44. Cockroft DW, Gault MH. Prediction of creatinine clearance from serum creatinine. Nephron 1976; 16:31-41.

45. Holtzmann MJ, Hammar N, Ahnve S, Nordqvist T, Phersson K, Ivert T. Renal insufficiency and long-term mortality and incidence of myocardial infarction in patients undergoing coronary artery bypass grafting. European Heart Journal 2007; 28:865-71.

46. Levey AS, Coresh J, Balk E, Kausz AT, Levin A, Steffes MW, Hogg RJ, Perrone RD, Lau J, Eknoyan G; National Kidney Foundation. National Kidney Foundation practice guidelines for chronic kidney disease : evaluation, classification and stratification. Ann Intern Med 2003;139:137-47.

47. Ye Lin, Zhe Zheng, Yan Li, Xin Yuan, Jianfeng Hou, Shiju Zhang, Hongguang Fan, Yang Wang, Wie Li, Shengshou Hu. Impact of renal dysfunction on long-term survival after isolated coronary artery bypass surgery. Ann Thorac Surg. 2009;87:1079-84.

48. Zakeri R, Freemantle N, Barnett V, Lipkin GW, Bonser RS, Graham TR, Rooney SJ, Wilson IC, Cramb R, Keogh BE, Pagano D. Relation between mild renal dysfunction and outcomes after coronary artery bypass grafting. Circulation.2005; 112 [suppl] 
49. Jin R, Grunkemeier GL, Brown JR, Furnary AP. Estimated glomular filtration rate and renal function. Ann Thorac Surg. 2008;86:1-3.

50. Rawn JD. Blood transfusion in cardiac surgery. A silent epidemic revisited. Circulation 2007;116:25232524

51. Koch CG, Khandwala F, Li L, Estafanous FG, Loop FD, Blackstone EH. Persistent effect of red cell transfusion on health-related quality of life after cardiac surgery. Ann Thorac Surg 2006;82:13-20

52. Kuduvalli M, Oo AY, Newall N, Grayson AD, Jackson M, Desmond MJ, Fabri BM, Rashid A. Effect of perioperative red blood cell transfusion on 30-day and 1-year mortality following coronary artery bypass surgery. Eur J Cardio-Thorac Surg 2005;27(4):592-598

53. Koch CG, Li L, Duncan Al, Mihaljevic T, Loop FD, Starr NJ, Blackstone EH. Transfusion in coronary artery bypass grafting is associated with reduced long-term survival. Ann Thorac Surg 2006;81:1650-1657.

54. Robinson WP 3rd, Ahn J, Stiffler A, Rutherford EJ, Hurd H, Zarzaur BL, Baker CC, Meyer AA, Rich PB. Blood transfusion is an independent predictor of increased mortality in nonoperatively managed blunt hepatic and splenic injuries. J Trauma. 2005; 58:437-444; discussion 444-445.

55. Taylor RW, Manganaro L, O'Brien J, Trottier SJ, Parkar N, Veremakis C. Impact of allogenic packed red blood cell transfusion on nosocomial infection rates in the critically ill patient. Crit Care Med. 2002; 30:2249-2254

56. .Malone DL, Dunne J, Tracy JK, Putnam AT, Scalea TM, Napolitano LM. Blood transfusion, independent of shock severity, is associated with worse outcome in trauma. J Trauma. 2003; 54:898-905; discussion 905-907.

57. Koch CG, Li L, Duncan Al, Mihaljevic T, Cosgrove DM, Loop FD, Starr NJ, Blackstone EH. Morbidity and mortality risk associated with red blood cell and blood-component transfusion in isolated coronary artery bypass grafting. Crit Care Med. 2006; 34:1608-1616.

58. Kuduvalli M, Oo AY, Newall N, Grayson AD, Jackson M, Desmond MJ, Fabri BM, Rashid A. Effect of perioperative red blood cell transfusion on 30-day and 1-year mortality following coronary artery bypass surgery. Eur J Cardiothorac Surg. 2005; 27:592-598.

59. Leal-Noval SR, Rincón-Ferrari MD, García-Curiel A, Herruzo-Avilés A, Camacho-Laraña P, GarnachoMontero J, Amaya-Villar R. Transfusion of blood components and postoperative infection in patients undergoing cardiac surgery. Chest. 2001; 119:1461-1468.

60. Engoren MC, Habib RH, Zacharias A, Schwann TA, Riordan CJ, Durham SJ. Effect of blood transfusion on long-term survival after cardiac operation. Ann Thorac Surg. 2002; 74:1180-1186.

61. Zallen G, Offner PJ, Moore EE, Blackwell J, Ciesla DJ, Gabriel J, Denny C, Silliman CC. Age of transfused blood is an independent risk factor for postinjury multiple organ failure. Am J Surg. 1999; 178:570-572.

62. Mynster T, Nielsen HJ; Danish RANX05 Colorectal Cancer Study Group. Storage time of transfused blood and disease recurrence after colorectal cancer surgery. Dis Colon Rectum. 2001; 44:955-964.

63. Offner PJ, Moore EE, BiffI WL, Johnson JL, Silliman CC. Increased rate of infection associated with transfusion of old blood after severe injury. Arch Surg. 2002; 137:711-716; discussion 716-717.

64. Purdy FR, Tweeddale MG, Merrick PM. Association of mortality with age of blood transfused in septic ICU patients. Can J Anaesth. 1997; 44:1256-1261.

65. Tinmouth A, Fergusson D, Yee IC, Hébert PC; ABLE Investigators; Canadian Critical Care Trials Group. Clinical consequences of red cell storage in the critically ill. Transfusion. 2006; 46:2014-2027.

66. Wolfe LC. Oxidative injuries to the red cell membrane during conventional blood preservation. Semin Hematol. 1989; 26:307-312.

67. Berezina TL, Zaets SB, Morgan C, Spillert CR, Kamiyama M, Spolarics Z, Deitch EA, Machiedo GW. Influence of storage on red blood cell rheological properties. J Surg Res. 2002; 102:6-12.

68. d'Almeida MS, Jagger J, Duggan M, White M, Ellis C, Chin-Yee IH. A comparison of biochemical and functional alterations of rat and human erythrocytes stored in CPDA-1 for 29 days: implications for animal models of transfusion. Transfus Med. 2000; 10:291-303. 
69. Kirkpatrick UJ, Adams RA, Lardi A, McCollum CN. Rheological properties and function of blood cells in stored bank blood and salvaged blood. Br J Haematol. 1998; 101:364-368.

70. Koch CG, Li L, Sessler DI, Figueroa P, Hoeltge GA, Mihaljevic T, Blackstone EH. Duration of red-cell storage and complications after cardiac surgery. N Engl J Med. 2008; 358:1229-1239.

71. Basran S, Frumento RJ, Cohen A, Lee S, Du Y, Nishanian E, Kaplan HS, Stafford-Smith M, BennettGuerrero $\mathrm{E}$. The association between duration of storage of transfused red blood cells and morbidity and mortality after reoperative cardiac surgery. Anesth Analg. 2006 Jul;103(1):15-20, table of contents. Retraction in: Shafer SL. Anesth Analg. 2009; 108:1953.

72. Vamvakas EC, Carven JH. Length of storage of transfused red cells and postoperative morbidity in patients undergoing coronary artery bypass graft surgery. Transfusion. 2000; 40:101-109.

73. van de Watering L, Lorinser J, Versteegh M, Westendord R, Brand A. Effects of storage time of red blood cell transfusions on the prognosis of coronary artery bypass graft patients. Transfusion. 2006; 46:1712-1718.

74. Yap CH, Lau L, Krishnaswamy M, Gaskell M, Yii M. Age of transfused red cells and early outcomes after cardiac surgery. Ann Thorac Surg. 2008; 86:554-559.

75. Chapman CE, Stainsby D, Jones H, Love E, Massey E, Win N, Navarrete C, Lucas G, Soni N, Morgan C, Choo L, Cohen H, Williamson LM; Serious Hazards of Transfusion Steering Group. Ten years of hemovigilance reports of transfusion-related acute lung injury in the United Kingdom and the impact of preferential use of male donor plasma. Transfusion 2009;49:440-52.

76. Wiersum-Osselton JC, Porcelijn L, van Stein D, Vlaar AP, Beckers EA, Schipperus MR. Transfusionrelated acute lung injury (TRALI) in the Netherlands in 2002-2005 [in Dutch]. Ned Tijdschr Geneeskd 2008;152:1784-8.

77. Middelburg RA, van Stein D, Briët E, van der Bom JG. The role of donor antibodies in the pathogenesis of transfusion-related acute lung injury: a systematic review. Transfusion 2008;48:2167-76.

78. Wright SE, Snowden CP, Athey SC, Leaver AA, Clarkson JM, Chapman CE, Roberts DR, Wallis JP. Acute lung injury after ruptured abdominal aortic aneurysm repair: the effect of excluding donations from females from the production of fresh frozen plasma. Crit Care Med 2008;36:1796-802.

79. Sachs UJ. Pathophysiology of TRALI: current concepts. Intensive Care Med 2007;33:S3-S11.

80. Win N, Massey E, Lucas G, Sage D, Brown C, Green A, Contreras M, Navarrete C. Ninety-six suspected transfusion related acute lung injury cases: investigation findings and clinical outcome. Hematology 2007;12:461-9.

81. Gajic O, Yilmaz M, Iscimen R, Kor DJ, Winters JL, Moore SB, Afessa B. Transfusion from male-only versus female donors in critically ill recipients of high plasma volume components. Crit Care Med 2007;35:1645-8.

82. Eder AF, Herron R, Strupp A, Dy B, Notari EP, Chambers LA, Dodd RY, Benjamin RJ. Transfusion-related acute lung injury surveillance (2003-2005) and the potential impact of the selective use of plasma from male donors in the American Red Cross. Transfusion 2007;47:599-607.

83. Bux J, Sachs UJ. The pathogenesis of transfusion-related acute lung injury (TRALI). Br J Haematol 2007;136:788-99

84. Bassuk SS, Rifai N, Ridker PM. High-sensitivity C-reactive protein: clinical importance. Curr Probl Cardiol 2004;29s:439-93.

85. Yin WH, Chen JW, Jen HL, Chiang MC, Huang WP, Feng AN, et al. Independent prognostic value of elevated high-sensitivity C-reactive protein in chronic heart failure. Am Heart J 2004;147:931-8.

86. Biancari F, Lahtinen J, Lepojärvi S, Rainio P, Salmela E, Pokela R, et al. Preoperative C-reactive protein and outcome after coronary artery bypass surgery. Ann Thorac Surg 2003;76:2007-12.

87. Kangasniemi OP, Biancari F, Luukkonen J, Vuorisalo S, Satta J, Pokela R, et al. Preoperative C-reactive protein is predictive of long-term outcome after coronary artery bypass surgery. Eur J Cardiothorac Surg 2006;29:983-5. 
88. Hedman A, Larsson PT, Alam M, Wallen NH, Nordlander R, Samad BA. CRP, IL-6 and endothelin-1 levels in patients undergoing coronary artery bypass grafting. Do preoperative inflammatory parameters predict early graft occlusion and late cardiovascular events? Int J Cardiol. 2007;120:108-14.

89. Bell ML, Grunwald GK, Baltz JH, McDonald GO, Bell MR, Grover FL, Shroyer LW. Does preoperative hemoglobin independently predict short-term outcomes after coronary artery bypass graft surgery? Ann Thorac Surg. 2008; 86:1415-1423.

90. Kulier A, Levin J, Moser R, Rumpold-Seitlinger G, Tudor IC, Snyder-Ramos SA, Moehnle P, Mangano DT; Investigators of the Multicenter Study of Perioperative Ischemia Research Group. Impact of preoperative anemia on outcome in patients undergoing coronary artery bypass graft surgery. Circulation. 2007; 116:471-479.

91. Cladellas M, Bruguera J, Comín J, Vila J, de Jaime E, Martí J, Gomez M. Is pre-operative anaemia a risk marker for in-hospital mortality and morbidity after valve replacement? Eur Heart J. 2006; 27:10931099.

92. Poirier P, Giles TD, Bray GA, et al; American Heart Association; Obesity Committee of the Council on nutrition, Physical Activity, and Metabolism. Obesity and cardiovascular disease: pathophysiology, evaluation, and effect of weight loss: an update of the 1997 American Heart Association Scientific Statement on Obesity and Heart Disease from the Obesity Committee of the Council on Nutrition, Physical Activity, and Metabolism. Circulation. 2006; 113:898-918.

93. Potapov EV, Loebe M, Anker S, et al. Impact of body mass index on outcome in patients after coronary artery bypass grafting with and without valve surgery. Eur Heart J. 2003; 24:1933-1941.

94. Flegal KM, Graubard BI, Williamson DF, Gail MH. Cause-specific excess deaths associated with underweight, overweight, and obesity. JAMA. 2007; 298:2028-2037.

95. Adams KF, Schatzkin A, Harris TB, et al. Overweight, obesity, and mortality in a large prospective cohort of persons 50 to 71 years old. N Engl J Med. 2006; 355:763-778.

96. Engelman DT, Adams DH, Byrne JG, et al. Impact of body mass index and albumin on morbidity and mortality after cardiac surgery. J Thorac Cardiovasc Surg. 1999; 118:866-873

97. Habib RH, Zacharias A, Schwann TA, Riordan CJ, Durham SJ, Shah A. Effects of obesity and small body size on operative and long-term outcomes of coronary artery bypass surgery: a propensity-matched analysis. Ann Thorac Surg. 2005; 79:1976-1986.

98. Jin R, Grunkemeier GL, Furnary AP, Handy JR Jr. Is obesity a risk factor for mortality in coronary artery bypass surgery? Circulation. 2005; 111:3359-3365.

99. Prabhakar G, Haan CK, Peterson ED, Coombs LP, Cruzzavala JL, Murray GF. The risks of moderate and extreme obesity for coronary artery bypass grafting outcomes: a study from the Society of Thoracic Surgeons' database. Ann Thorac Surg. 2002; 74:1125-1130; discussion, 1130-1131.

100. Reeves BC, Ascione R, Chamberlain MH, Angelini GD. Effect of body mass index on early outcomes in patients undergoing coronary artery bypass surgery. J Am Coll Cardiol. 2003; 42:668-676.

101. Schwann TA, Habib RH, Zacharias A, et al. Effects of body size on operative, intermediate, and longterm outcomes after coronary artery bypass operation. Ann Thorac Surg. 2001; 71:521-530; discussion, 530-531

102. Oreopoulos A, Padwal R, Norris CM, Mullen JC, Pretorius V, Kalantar-Zadeh K. Effect of obesity on short- and long-term mortality postcoronary revascularization: a meta-analysis. Obesity (Silver Spring). 2008; 16:442-450.

103. Wells S. Postoperative recovery: how diabetes complicates care. J Cardiovasc Nurs 1993;7:47-58

104. Yamazaki K, Kato H, Tsujimoto S, Kitamura R. Diabetes mellitus, internal thoracic artery grafting, and risk of an elevated hemidiaphragm after coronary artery bypass surgery. J Cardiothorac Vasc Anesth. 1994;8:437-40.

105. Slaughter MS, Olson MM, Lee JT Jr, Ward HB. A fifteen-year wound surveillance study after coronary artery bypass. Ann Thorac Surg. 1993;56:1063-8 
106. Stein B, Weintraub WS, Gebhart SP, Cohen-Bernstein CL, Grosswald R, Liberman HA, Douglas JS Jr, Morris DC, King SB 3rd. Influence of diabetes mellitus on early and late outcome after percutaneous transluminal coronary angioplasty. Circulation. 1995;91(4):979-89.

107. Smith LR, Harrell FE Jr, Rankin JS, Califf RM, Pryor DB, Muhlbaier LH, Lee KL, Mark DB, Jones RH, Oldham HN, Glower DD, Reves JG, Sabiston DC Jr. Determinants of early versus late cardiac death in patients undergoing coronary artery bypass graft surgery. Circulation 1991;84(suppl 5):III245-53.

108. Calafiore AM, Di Mauro M, Di Giammarco G, Contini M, Vitolla G, lacò AL, Canosa C, D'Alessandro S. Effect of diabetes on early and late survival after isolated first coronary bypass surgery in multivessel disease. J Thorac Cardiovasc Surg. 2003;125(1):144-54.

109. Leavitt BJ, Sheppard L, Maloney C, Clough RA, Braxton JH, Charlesworth DC, Weintraub RM, Hernandez F, Olmstead EM, Nugent WC, O'Connor GT, Ross CS. Effect of diabetes and associated conditions on long-term survival after coronary artery bypass graft surgery. Circulation 2004;110(11 suppl 1):II41-4

110. Whang W, Bigger JT Jr. Diabetes and outcomes of coronary artery bypass graft surgery in patients with severe left ventricular dysfunction: results from The CABG Patch Trial database. The CABG Patch Trial Investigators and Coordinators. J Am Coll Cardiol. 2000 Oct;36(4):1166-72. Erratum in: J Am Coll Cardiol 2001;37:2012.

111. Szabó Z, Håkanson E, Svedjeholm R. Early postoperative outcome and medium-term survival in 540 diabetic and 2239 non-diabetic patients undergoing coronary artery bypass grafting. Ann Thorac Surg 2002;74:712-9.

112. Barsness GW, Peterson ED, Ohman EM, Nelson CL, DeLong ER, Reves GJ, Smith PK, Anderson RD, JonesvRH, Mark DB, Califf RM. Relationship between diabetes mellitus and long-term survival after coronary bypass and angioplasty. Circulation 1997;96:2551-6.

113. Clough RA, Leavitt BJ, Morton JR, Plume SK, Hernandez F, Nugent W, Lahey SJ, Ross CS, O'Connor GT. The effect of comorbid illness on mortality outcomes in cardiac surgery. Arch Surg 2002;137:428-32; discussion 432-3.

114. Niles NW, McGrath PD, Malenka D, Quinton H, Wennberg D, Shubrooks SJ, Tryzelaar JF, Clough R, Hearne MJ, Hernandez F Jr, Watkins MW, O'Connor GT; Northern New England Cardiovascular Disease Study Group. Survival of patients with diabetes and multivessel coronary artery disease after surgical or percutaneous coronary revascularization: results of a large regional prospective study. Northern New England Cardiovascular Disease Study Group. J Am Coll Cardiol 2001;37:1008-15

115. Detre KM, Guo P, Holubkov R, Califf RM, Sopko G, Bach R, Brooks MM, Bourassa MG, Shemin RJ, Rosen $A D$, Krone RJ, Frye RL, Feit F. Coronary revascularization in diabetic patients: a comparison of the randomized and observational components of the Bypass Angioplasty Revascularization Investigation (BARI). Circulation 1999;99:633-40.

116. [No authors listed] Comparison of coronary bypass surgery with angioplasty in patients with multivessel disease. The Bypass Angioplasty Revascularization Investigation (BARI) Investigators. N Engl J Med 1996;335:217-25. Erratum in: N Engl J Med 1997;336:147.

117. Herlitz J, Wognsen GB, Karlson BW, Sjöland H, Karlsson T, Caidahl K, Hartford M, Haglid M. Mortality, mode of death and risk indicators for death during 5 years after coronary artery bypass grafting among patients with and without a history of diabetes mellitus. Coron Artery Dis 2000;11:339-46.

118. Thourani VH, Weintraub WS, Stein B, Gebhart SS, Craver JM, Jones EL, Guyton RA. Influence of diabetes mellitus on early and late outcome after coronary artery bypass grafting. Ann Thorac Surg 1999;67:1045-52.

119. Carson JL, Scholz PM, Chen AY, Peterson ED, Gold J, Schneider SH. Diabetes mellitus increases shortterm mortality and morbidity in patients undergoing coronary artery bypass graft surgery. J Am Coll Cardiol. 2002;40:418-23.

120. Rajakaruna C, Rogers CA, Suranimala C, Angelini GD, Ascione R. The effect of diabetes mellitus on patients undergoing coronary surgery: a risk-adjusted analysis. J Thorac Cardiovasc Surg. 2006;132:802-10. 
121. Birkmeyer JD, O'Connor GT, Quinton HB, Ricci MA, Morton JR, Leavitt BJ, Charlesworth DC, Hernandez $F$, McDaniel MD. The effect of peripheral vascular disease on in-hospital mortality rates with coronary artery bypass surgery. Northern New England Cardiovascular Disease Study Group. J Vasc Surg. 1995;21(3):445-52

122. Sukhija R, Aronow WS, Yalamanchili K, Sinha N, Babu S. Prevalence of coronary artery disease, lower extremity peripheral arterial disease, and cerebrovascular disease in 110 men with an abdominal aortic aneurysm. Am J Cardiol. 2004;94(10):1358-9

123. Dieter RS, Tomasson J, Gudjonsson T, Brown RL, Vitcenda M, Einerson J, McBride PE. Lower extremity peripheral arterial disease in hospitalized patients with coronary artery disease. Vasc Med. 2003;8(4):233-6.

124. Poredos $\mathrm{P}$, Jug $\mathrm{B}$. The prevalence of peripheral arterial disease in high risk subjects and coronary or cerebrovascular patients. Angiology. 2007;58(3):309-15.

125. McDermott MM. The magnitude of the problem of peripheral arterial disease: epidemiology and clinical significance. Cleve Clin J Med. 2006;73 Suppl 4:S2-7

126. Higgins TL, Estafanous FG, Loop FD, Beck GJ, Blum JM, Paranandi L. Stratification of morbidity and mortality outcome by preoperative risk factors in coronary artery bypass patients. A clinical severity score. JAMA. 1992;267(17):2344-8.

127. O'Connor GT, Plume SK, Olmstead EM, Coffin LH, Morton JR, Maloney CT, Nowicki ER, Levy DG, Tryzelaar JF, Hernandez F. Multivariate prediction of in-hospital mortality associated with coronary artery bypass graft surgery. Northern New England Cardiovascular Disease Study Group. Circulation 1992;85(6):2110-8.

128. Michel P, Roques F, Nashef SA; EuroSCORE Project Group. Logistic or additive EuroSCORE for high-risk patients? Eur J Cardiothorac Surg. 2003;23(5):684-7; discussion 687.

129. Chu D, Bakaeen FG, Wang XL, Dao TK, LeMaire SA, Coselli JS, Huh J. The impact of peripheral vascular disease on long-term survival after coronary artery bypass graft surgery. Ann Thorac Surg. 2008;86(4):1175-80. 


\section{Chapter 2}

Evaluation of the EuroSCORE risk scoring model for patients undergoing coronary artery bypass graft surgery: a word of caution

Accepted for publication: Neth Heart J

Authors:

Albert HM van Straten Erwin MESH Tan Mohamed A Soliman Hamad Elisabeth J Martens André AJ van Zundert

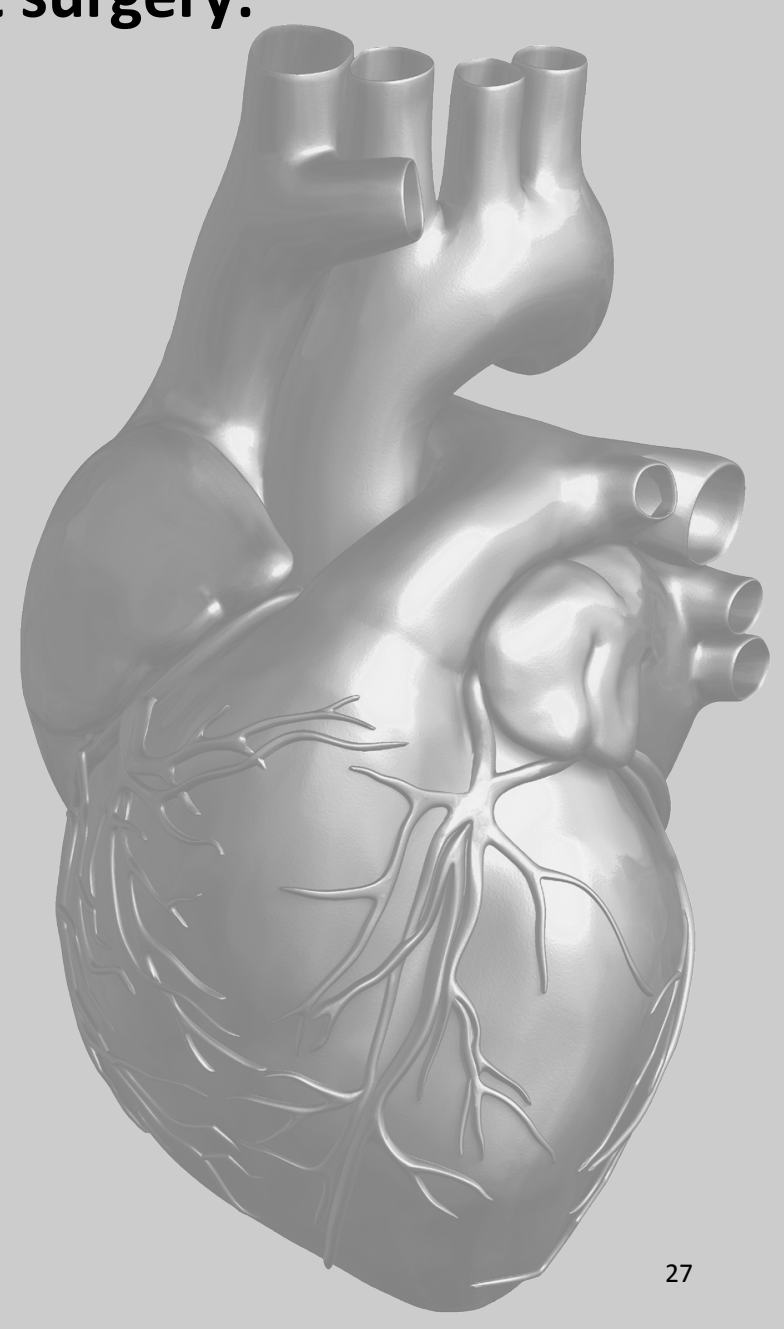




\begin{abstract}

\section{Background}

Risk adjusted mortality rates are used to compare quality of care of different hospitals. We evaluated the EuroSCORE (European System for Cardiac Operative Risk Evaluation) in patients undergoing isolated coronary artery bypass grafting (CABG).
\end{abstract}

\title{
Patients and methods
}

Data of all CABG patients from January 2004 until December 2008 were analyzed. Receiver Operating Characteristics (ROC) curves for the additive and logistic EuroSCOREs and the areas under the ROC-curve were calculated. Predicted probability of hospital mortality was calculated using logistic regression analyses and compared with the EuroSCORE Cusum analyses were performed for the EUROscore and the actual hospital mortality.

\section{Results}

5249 Patients underwent CABG, of which 89(1,7\%) died. The mean additive EuroSCORE was $3,5 \pm 2,5(0-17)$ (median $=3,0$ ) and the mean logistic EuroSCORE was 4,0 $\pm 5,5(0-73$ ) (median $=2,4$ ). The area under the ROC curve was 0,80 $\pm 0,02$ (95 percent confidence interval $(\mathrm{Cl}) 0,76-0,84)$ for the additive and $0,81 \pm 0,02(0,77-0,85)$ for the logistic EuroSCORE. The predicted probability (hazard ratio) was different from the additive and logistic EuroSCOREs. The hospital mortality was half of the EuroSCOREs, resulting in positive Variable Life Adjusted Display curves.

\section{Conclusions}

Both the additive and the logistic EuroSCORE are overestimating the in-hospital mortality risk in low risk CABG patients. The logistic EuroSCORE is more accurate in high risk patients compared to the additive EuroSCORE. Until a more accurate risk scoring system is available, we suggest being careful with comparing quality of care of different centres based on risk-adjusted mortality rates. 


\section{Introduction}

\section{The importance of accurate risk scoring models for patients}

In order to decide which therapeutic option (surgery, percutaneous intervention or medical therapy) is the best for patients with coronary artery disease, a cost benefit evaluation has to be performed for each therapeutic option. On the benefit side is the relief of symptoms and possible better long-term survival. On the cost side there is operative and postoperative morbidity and mortality. Several demographic data and preoperative, operative and postoperative variables (risk factors) may have an impact on the results of the different therapies. Only when the impact of risk factors on morbidity and early and late mortality is known, a balanced decision about the best therapeutic option can be made and a true informed consent of patients can be obtained.

\section{The importance of accurate risk scoring models for doctors and institutions}

Nowadays, results of medical care given by different institutions and doctors are increasingly scrutinised, and the production of hospital league tables is now widespread. Such league tables usually fail to account for case mix, and great caution should be exercised in their interpretation. The development of tools to allow results from different hospitals and surgeons to be compared in a meaningful way is obviously an important goal. Operative mortality is an indicator of the quality of cardiac surgery. Comparing different institutions or surgeons on the basis of crude mortality figures may be misleading as mortality is affected by various preoperative characteristics of the patients (1). Hospital Standardized Mortality Ratio (HSMR) as first described by Jarman et al. $(2,3)$ uses administrative data that are readily available in every hospital such as: year, age, sex, ICD-9 code, Charlson index for co-morbidity, social-economic status of the patient, urgency, length of stay in the hospital. The use of HSMR to measure quality of healthcare has been debated in the Dutch literature (4-13) as it has many flaws and is considered inaccurate. The ideal risk stratification model should be easy to implement, objective, an accurate predictor of observed mortality, and in widespread use. Various models have been developed for use in cardiac surgery, and the first to become popular was the Parsonnet risk stratification system (14) which was developed in the USA in the 1980s. Thereafter, many other risk scoring models have been developed such as: Cleveland Clinic score (15), French score (16), Pons score (17) and the Ontario Province score (18). Nowadays, the most used risk stratification models are the EuroSCORE and the Society of Thoracic Surgeons (STS) score. 


\section{EuroSCORE}

The European System for Cardiac Operative Risk Evaluation (EuroSCORE) has been first described in $1999(19,20)$. Nearly twenty thousand consecutive patients from 128 hospitals in eight European countries were studied. Information was collected on 97 risk factors in all patients. The outcome (survival or death) was related to the preoperative risk factors. In the newly developed Dutch national database, the data of every Dutch cardio-thoracic centre is collected including the EuroSCORE and the hospital mortality. The variables that are used to calculate the EuroSCORE are shown in table 1. Two risk calculators are available: in the simple additive EuroSCORE, the weights (score in table 1) are added to give an approximate percentage of predicted mortality. This simple additive EuroSCORE model is now well-established and has been validated in many cardiac surgery patient populations across the world. It is very valuable in quality control in cardiac surgery and gives a useful estimate of risk in individual patients. However, particularly in very high risk patients, the simple additive model may sometimes underestimate the risk when certain combinations of risk factors co-exist. The logistic version of EuroSCORE produces more accurate risk prediction for a particular high risk patient using the "Beta" from table 1 for its calculation. Its main disadvantage is that the risk has to be calculated in a complex way.

When the STS risk scoring model is compared to the EuroSCORE in CABG patients, Ad et al. (21) found both models to be good predictors of operative mortality with a slight advantage for the STS model. However, Nilsson et al. (22) found that the additive EuroSCORE had a better discriminatory power compared to the STS risk model.

The goal of this study was to evaluate the EuroSCORE as a risk stratification model for patients undergoing CABG using the data we collected in our computerized database.

\section{Patients and Methods}

Since January 2004, we collected the EuroSCORE of all cardiac surgery patients in the Catharina Hospital, Eindhoven, the Netherlands. We analyzed the data of all patients undergoing isolated CABG from January 2004 till December 2008. We measured the discriminatory power of the EuroSCORE for operative mortality. For this we calculated the Receiver Operating Characteristics (ROC) curve and the area under the ROC curve. We calculated the cumulative summation of the EuroSCORE of all consecutive patients (CUSUM) and the cumulative hospital mortality as defined by mortality during the same hospital stay as the operation. From this we calculated the variable life-adjusted display (VLAD) curve as described by Lovegrove et al. in 1997 (23). In constructing the VLAD curves, the EuroSCORE minus the mortality per patient are cumulative summarized. Logistic regression analyses were used to calculate the predicted probability per EuroSCORE value, which reflects the actual hospital mortality. 


\section{Results}

During the five year study period, 5249 Patients underwent CABG of which $89(1,7 \%)$ died. The mean additive EuroSCORE was 3,5 $\pm 2,5(0-17)$ and the mean logistic EuroSCORE was 4,0 $\pm 5,5(0-73)$. The median additive EuroSCORE was 3,0 and the median logistic EuroSCORE was 2,4. The numbers of patients per additive and logostic EuroSCORE are shown in figure 1.
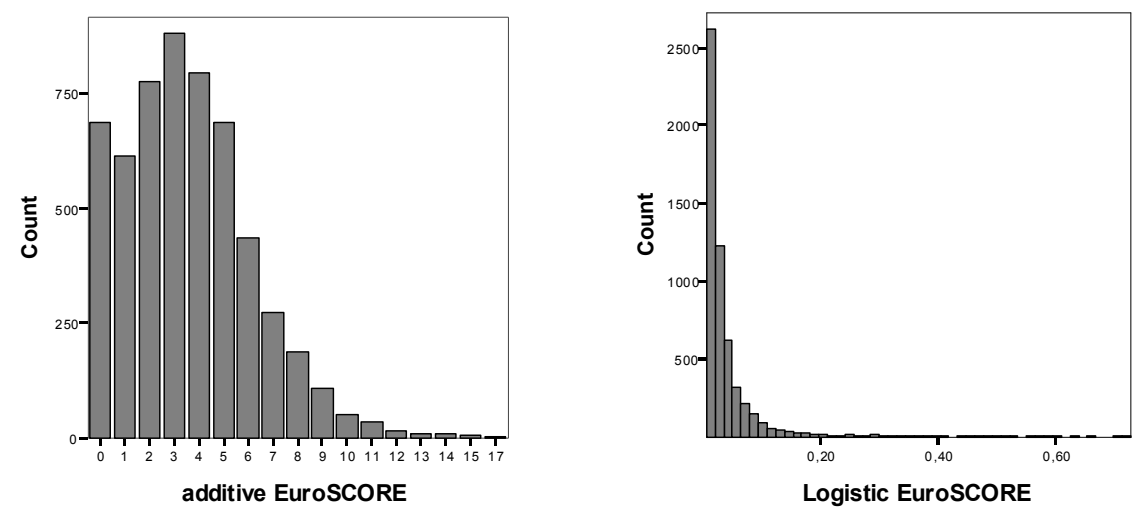

Figure 1 Distribution of additive and logistic EuroSCORE

The ROC curve of both the additive and the logistic EuroSCORE are shown in figure 2. The area under the ROC curve was $0,80 \pm 0,02$ (95 percent confidence interval $(\mathrm{Cl})$ 0,76$0,84)$ for the additive EuroSCORE and $0,81 \pm 0,02(0,77-0,85)$ for the logistic EuroSCORE.

ROC Curve

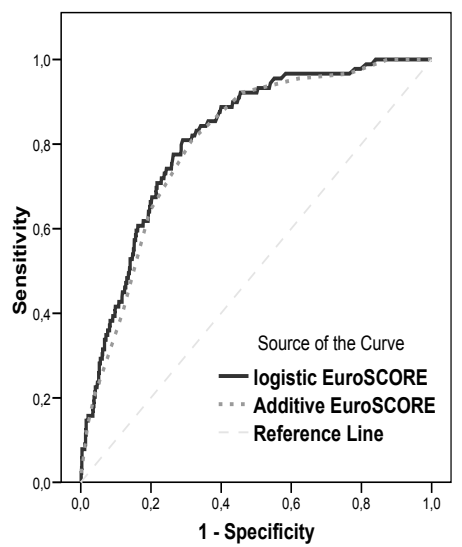

Figure 2 Receiver Operating Characteristics (ROC) Curve 
The predicted probability (actual mortality) was different from the additive and the logistic EuroSCORE (figure 3).

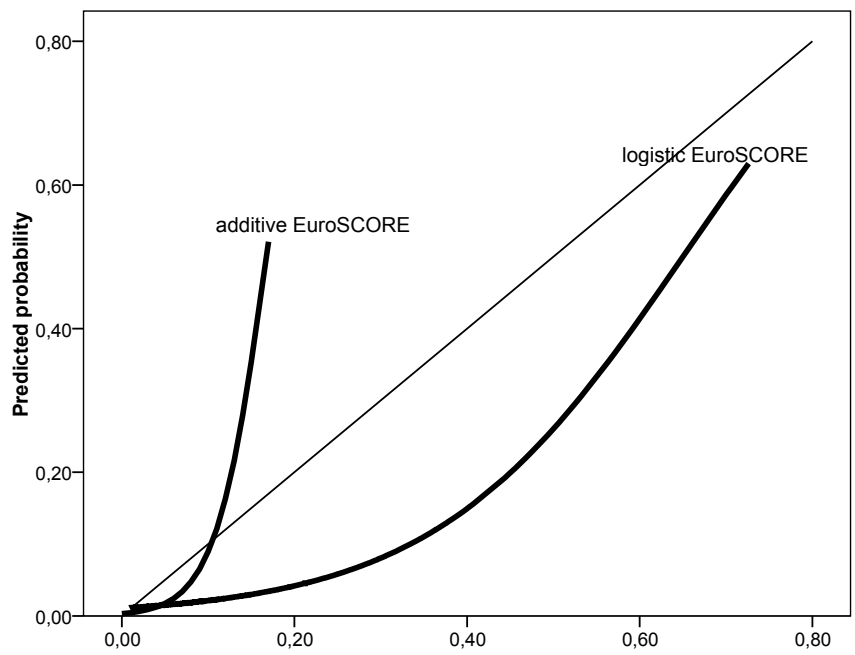

Figure 3 Predicted probability for hospital mortality and EuroSCORE

The cumulative additive EuroSCORE, logistic EuroSCORE and the hospital mortality are depicted in figure 4.

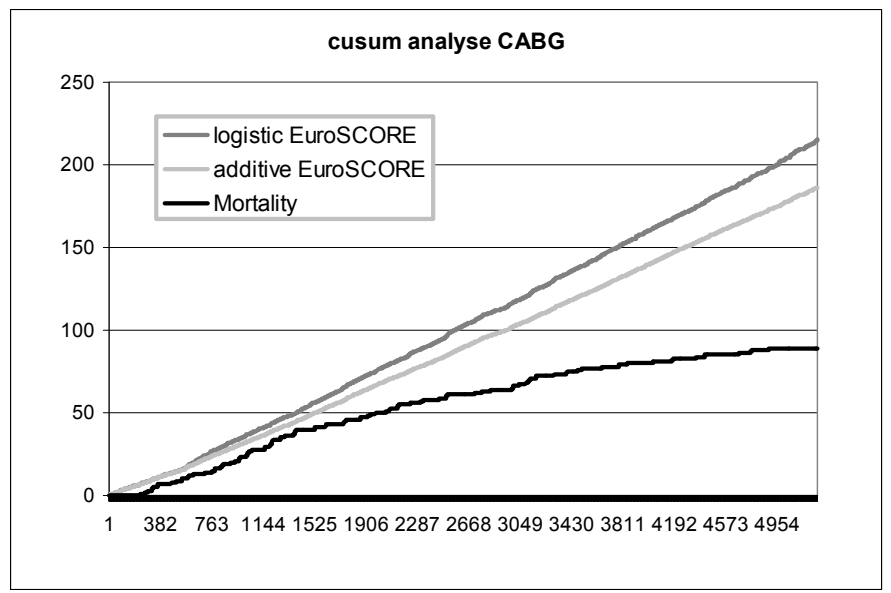

Figure 4 Cumulative additive, logistic EuroSCORE and hospital mortality. 
The cumulative mortality is half of the mortality as predicted by the EuroSCORE . The Variable Life-Adjusted Display (VLAD) curve was positive indicating that lives were spared (Figure 5).

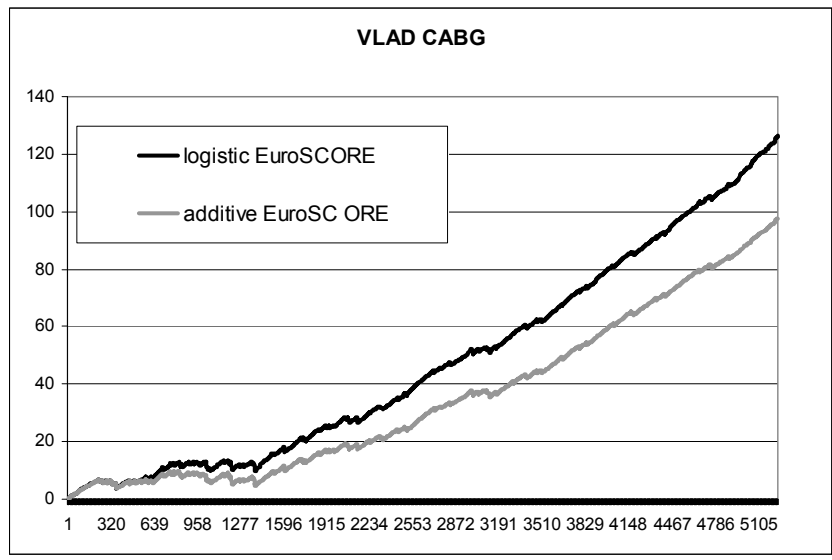

Figure 5 Variable life-adjusted display (VLAD) curves

\section{Discussion}

In our patients studied the EurOSCORE has a high discriminatory power, showed by an area under the ROC curve of 0,80 for the additive EuroSCORE and of 0.81 for the logistic EuroSCORE indicating that most patients that have died had a high EuroSCORE. The area under the ROC curve is considered to be an indicator for the discriminatory power of the model. The discriminatory power is thought to be excellent if the area under the ROC curve is $>0,80$, very good if $>0,75$, and good if $>0,70$ (23). Others found the similar results (22) in a group of 4497 patients undergoing CABG. When they made a comparison with the STS score they found an area under the ROC curve of $0,85(95 \% \mathrm{Cl} 0,80$ $0,88)$ for the EuroSCORE compared to $0,71(95 \% \mathrm{Cl} 0,66-0,77)$ for the STS risk scoring system. They concluded that the EuroSCORE showed a larger discriminatory power compared to the STS risk scoring system. Geisler et al. (24) reported an area under the ROC curve for the EuroSCORE of 0.78 in a group of 505 patients undergoing all kinds of heart surgery. When we plot the predicted probability calculated with logistic regression analyses in our CABG patients against the additive and logistic EuroSCORE (Figure 3 ), it is clear that the logistic EuroSCORE is a better predictor of hospital mortality especially in patients with a higher score. For lower logistic EuroSCOREs there was an overestimation of the risk. The additive EuroSCORE underestimates the risk in high risk patients. For a perfect risk scoring system, the picture should show a diagonal straight 
line. One can conclude that the EuroSCORE model though having a very good discriminatory power is not accurate in predicting hospital mortality in CABG patients.

Recently, data of all cardiac surgery patients including the EuroSCORE, the EuroSCORE variables and the hospital mortality, are collected in a Dutch national database. The CABG patients form an important and large group in this database. In order to compare the results of different centres using risk adjusted mortality rates, we need reliable and accurate risk stratification models. If the calculated risk score is not accurate, comparison of risk adjusted mortality may lead to wrong conclusions. If, for example the risk model underestimates the risk in high risk patients and overestimates the risk in low risk patients as is the case in our CABG patients, the results of the comparison will always be in favour of the centres that are performing operations with the lowest risk scores. The variable life-adjusted display (VLAD) curve will be more positive in centres with more low risk patients. Improvement of the VLAD curve can be easily accomplished by denying operations to high risk patients. Especially when the results of the VLAD curves are being made public, this issue will become more important. Reevaluation of the variables used in the EuroSCORE and considering new ones in order to improve the accuracy of the scoring system is warranted. Only when a more accurate scoring system for CABG (and for all other cardiac operations) has been developed as has been suggested by Nissinen et al., publication of VLAD curves per centre can be done more accurate without the risk that hospital who are offering operations to the highest risk patients will be unfairly accused of "bad quality".

\section{Conclusions}

Both the additive EuroSCORE and the logistic EuroSCORE are overestimating the hospital mortality risk in low risk patients undergoing CABG. The logistic EuroSCORE is more accurate in high risk patients compared to the additive EuroSCORE. Until a more accurate risk scoring system is available, we must be careful with comparing quality of care of different cardiac surgery centres based on risk-adjusted mortality rates.

\section{References}

1. DuBois RW, Rogers WH, Moxley JH, et al. Hospital inpatients mortality: is it a predictor of quality. $\mathrm{N}$ Engl J Med 1987;317:1674-1680

2. Jarman et al. Explaining differences in English hospital death rates using routinely collected data. BMJ 1999;318:1515-20.

3. Jarman B, Bottle A, Aylin P, Browne M. Monitoring changes in hospital standardised mortality ratios. BMJ 2005; 330; 329.

4. van den Bosch WF, Roozendaal KJ, Silberbusch J. Schommelende sterftcijfers. Medisch Contact nr. 3132, 30 juli 2009. 
5. Crommentuyn R. 'Levens redden wil iedereen'. Britten tonen dat verlagen sterftecijfer niet moeilijk is. Medisch Contact nr. 26, 25 juni 2009.

6. den Ouden AL, van der Wal G. Het gestandaardiseerde ziekenhuissterftecijfer (HSMR) bruikbaar voor het volgen van ziekenhuissterfte. Nederlands Tijdschrift voor Geneeskunde, 2008;152:1191-2.

7. van den Bosch WF, Graafmans WC, Pieter D, Westert GP. Hartcentra en het effect van bijzondere medische verrichtingen op het gestandaardiseerde ziekenhuissterftecijfer. Nederlands Tijdschrift voor Geneeskunde, 2008;152:1221-7.

8. Den Ouden AL, Nugteren WAH, Haeck J, Van den Berg, JMJ. Sterftecijfer niet afserveren. Medisch Contact, 63(13): 561; 28 maart 2008.

9. Geelkerken RH, Mastboom WJB, Bertelink BP, Van der Palen J, Berg M, Kingma JH. Een onrijp instrument. Sterftecijfer niet geschikt als maat voor ziekenhuiskwaliteit. Medisch Contact 63(9):370-379; 29 februari 2008.

10. Kool RB, Van der Veen AA, Westert GP. Sterftemaat is valide instrument. Medisch Contact 2007; 62(50): 2090-91.

11. Van der Voort PHJ, De Jonge E. Sterfte als maat voor kwaliteit. Medisch Contact 62(43): 1766-1767; 26 oktober 2007.

12. Pronk E. Mortaliteit als maat - Sterftecijfers geven kwaliteit ziekenhuiszorg weer. Medisch Contact 2005; 60 (21): 876-879.

13. Heijink R, Koolman X, Pieter D, Van der Veen A, Jarman B, Westert G. Measuring and explaining mortality in Dutch hospitals; the Hospital Standardized Mortality Rate between 2003 and 2005. BMC Health Services Research 2008, 8:73.

14. Parsonnet $V$, Dean $D$, Bernstein, $A D$. A method of uniform stratification of risk for evaluating the results of surgery in acquired adult heart disease. Circulation 1989;701(suppl):13-112

15. Higgins T.L., Estafanous F.G., Loop F.D., Beck G.J., Blum J.M., Paranandi L. Stratification of morbidity and mortality outcome by preoperative risk factors in coronary artery bypass patients. J Am Med Assoc 1992;267:2344-2348.

16. Roques F., Gabrielle F., Michel P., de Vincentiis C., David M., Baudet E. Quality of care in adult heart surgery: proposal for a self-assessment approach based on a French multicenter study. Eur J Cardiothorac Surg 1995;9:433-440.

17. Pons J.M.V., Granados A., Espinas J.A., Borras J.M., Martin I., Moreno V. Assessing open heart surgery mortality in Catalonia (Spain) through a predictive risk model. Eur J Cardio-thorac Surg 1997;11:415423.

18. Tu J.V., Jaglal S.B., Naylor C.D. Multicenter validation of a risk index for mortality, intensive care unit stay, and overall hospital length of stay after cardiac surgery. Circulation 1995;91:677-684.

19. Roques F., Nashef S.A.M., Michel P., Gauducheau E., de Vincentiis C., Baudet E., Cortina J., David M., Faichney A., Gabrielle F., Gams E., Harjula A., Jones M.T., Pinna Pintor P., Salamon R., Thulin L. Risk factors and outcome in European cardiac surgery: analysis of the EuroSCORE multinational database of 0 patients. Eur J Cardio-thorac Surg 1999;15:816-823.

20. Nashef S.A.M., Roques F., Michel P., Gauducheau E., Lemeshow S., Salamon R. European system for cardiac operative risk evaluation (EuroSCORE). Eur J Cardio-thorac Surg 1999;16:9-13.

21. Ad N, Barnett SD, Speir AM. The performance of the EuroSCORE and the Society of Thoracic Surgeans mortality risk score: the gender factor. Interact CardioVasc Thorac Surg 2007;7:192-195.

22. Nilsson J, Algotsson L, Hoglund P, Luhrs C, Brandt J. Early mortality in coronary artery bypass surgery: the EuroSCORE versus the Sociaty of Thoracic Surgens risk algorithm. Ann Thorac Surg 2004;77:123539.

23. Lovegrove J, Valencia O, Treasure T, Sherlaw-Johnson C, Gallivan S. Monitoring the results of cardiac surgery by variable life-adjusted display.Lancet. 1997 Oct 18;350(9085):1128-30.

24. Swets JA. Measuring the accuracy of diagnostic systems. Science 1988;240:1285-1293. 
25. Geissler HJ, Holzl P, Marohl S, Kuhn-Regnier F, Mehlhorn U, Sudkamp M, Rainer de Vivie E. Risk stratification in heart surgery: comparison of six score systems. Eur J of Cardiothorac Surg 200;17:400-406

26. Nissinen J, Biancari F, Wistbacka JO, Loponen P, Teittinen K, Tarkiainen P, Koivisto SP, Tarkka M. Is it possible to improve the accuracy of EuroSCORE? Eur J Cardiothorac Surg 2009;june 10 (Epub ehead of print) 


\section{Chapter 3}

\section{Preoperative Renal Function as a Predictor of Survival after Coronary Artery Bypass Grafting: Comparison with a Matched General Population}

J Thorac Cardiovasc Surg. 2009;138(4):971-6.

\section{Authors}

Albert H. M. van Straten ${ }^{1}$; Mohamed A. Soliman Hamad ${ }^{1}$ André A. J. van Zundert ${ }^{2}$ Elisabeth J. Martens ${ }^{3}$ Jacques P. A. M. Schönberger ${ }^{1}$ Andre M. de Wolf, MD ${ }^{4}$

1 Department of Cardio-Thoracic Surgery, Catharina Hospital, Eindhoven, The Netherlands.

2 Department of Anesthesiology, Catharina Hospital - Brabant Medical School, Eindhoven, The Netherlands \& University Hospital Ghent, Ghent, Belgium.

3 Department of Education and Research, Catharina Hospital, Eindhoven, The Netherlands \& Center of Research on Psychology in Somatic diseases, Department of Medical Psychology, Tilburg University, The Netherlands.

4 Department of Anesthesiology, The Feinberg School of Medicine, Northwestern University, Chicago, Illinois, USA 


\begin{abstract}
Objectives

Preoperative renal dysfunction is an established risk factor for early and late mortality after revascularization. We studied how renal function affects long-term survival of patients after coronary artery bypass grafting.

\section{Methods}

Early and late mortality were determined retrospectively among consecutive patients undergoing isolated coronary bypass at a single Dutch institution between January 1998 and December 2007. Patients were stratified into four groups according to preoperative renal function. Expected survival was gauged using a general Dutch population group which was obtained from the database of the Dutch Central Bureau for Statistics; for each of our renal function groups, a general population group was assembled by matching for age, gender and year of operation.
\end{abstract}

\title{
Results
}

After excluding 122 patients lost to follow-up, 10626 patients were studied; in 10,359, preoperative creatinine clearance could be calculated. Multivariate logistic regression and Cox regression analysis identified renal dysfunction as a predictor for early and late mortality. When long-term survival of patient groups were compared to expected survival, only patients with a creatinine clearance less than $30 \mathrm{~mL} \cdot \mathrm{min}^{-1}$ showed a worse outcome. Patients with a creatinine clearance between 60 and $90 \mathrm{~mL} \cdot \mathrm{min}^{-1}$ had a long-term survival exceeding the expected survival.

\section{Conclusions}

Severity of renal dysfunction was related to poor survival. When compared to expected survival, however, our coronary bypass patients had a worse outcome only when severe preoperative renal dysfunction was present. 


\section{Introduction}

Severe renal dysfunction, particularly dysfunction requiring renal replacement therapy, has been identified as a risk factor for worse outcome after coronary artery bypass grafting (CABG) (1-3). Renal dysfunction not requiring dialysis also has been identified as a predictor of poor outcome (4-8). Recently, the effect of preoperative and postoperative renal function on late survival has been described in large patient groups $(9,10)$. In these studies, a strong correlation was found between age and deterioration of renal function. Since advanced age has a strong influence on late survival after $C A B G$, interpretation of long-term survival curves comparing groups of patients stratified by renal function might be difficult, despite appropriate statistical tests. Postoperative survival varies not only with age but also according to gender, year of surgery, and country. We therefore studied early and late survival of our Dutch post-CABG patients stratified by preoperative creatinine clearance, in comparison to a general Dutch population that were matched for age, gender, and year of operation.

\section{Patients and Methods}

\section{Patients}

We analyzed data concerning consecutive patients undergoing isolated CABG in a single center between January 1998 and December 2007. Approval for this study was obtained from the institution's research review board. Starting in 1998, clinical data including demographic information, risk factors, and complications were collected prospectively in a database. Preoperative serum creatinine concentrations were retrieved from the hospital laboratory database. To obtain survival information for general-population CABG groups matched with our patient groups for age, gender, and year of operation, we used the database of the Dutch Central Bureau for Statistics, which can be downloaded online (www.CBS.nl). We considered this generalpopulation data to represent expected survival for our patient groups.

\section{Operative techniques}

All patients received short-acting anesthetic drugs to facilitate early extubation. Extracorporeal circulation (ECC) was performed using normothermic nonpulsatile flow. Cold antegrade crystalloid cardioplegia (St Thomas solution) or warm intermittent antegrade blood cardioplegia was used according to the surgeon's preference to induce and maintain cardioplegic arrest. All patients undergoing CABG with use of extracorporeal circulation (ECC) received a low dose of aprotinin ( 2 million kallikrein-inactivating units, or KIU) administered in the priming solution for ECC. Patients undergoing offpump surgery did not receive aprotinin. 


\section{Estimation of renal function}

Renal function was determined by calculating creatinine clearance $(\mathrm{CrCl})$, using the Cockcroft and Gault formula (11), which differs between men [(140 - age) $x$ weight/(serum creatinine $x$ 72)] and women [(140-age) $x$ weight/(serum creatinine $x$ 72) $\times 0.85]$. The latest available preoperative serum creatinine concentration was used for calculation. Patients were grouped according to chronic kidney disease (CKD) class as defined by the National Kidney Foundation Disease Outcome Quality Initiative Advisory Board (12). Patients with $\mathrm{CrCl}$ above $90 \mathrm{~mL} \cdot \mathrm{min}^{-1}$ were placed in class 1 (normal function); 60 to $90 \mathrm{~mL} \cdot \mathrm{min}^{-1}$, class 2 (mild dysfunction); 30 to $59 \mathrm{~mL} \cdot \mathrm{min}^{-1}$, class 3 (moderate dysfunction); and 15 to $29 \mathrm{~mL} \cdot \mathrm{min}^{-1}$, class 4 (severe dysfunction). Patients with $\mathrm{CrCl}$ below $15 \mathrm{~mL} \cdot \mathrm{min}^{-1}$ and those treated with dialysis were excluded from this study.

\section{Follow-up}

Follow-up data concerning mortality were gathered using databases of health insurance companies. Initially data for $9 \%$ of our total patient group could not be retrieved from these databases; we then contacted patients' general practitioners to obtain information about mortality, and if necessary government authorities in the cities where patients lived at the time of the operation. Early mortality was defined as mortality occurring up to 30 days postoperatively for any cause, while late mortality was defined as mortality from any cause occurring after 30 days.

\section{Statistical analyses}

Discrete variables were compared with the chi-squared test and are presented as numbers and percentages of patients. Continuous variables were compared with $t$ test and analysis of variance (ANOVA), and are presented as the mean \pm standard deviation. Univariate and multivariate logistic regression analyses were performed to investigate the impact of biomedical variables on early mortality. Univariate analyses were used to test for the potentially confounding effect of biomedical and demographic factors on outcome. Cox proportional hazard regression analyses, which are designed for analysis of time until an event, were performed to identify risk factors for late mortality. If significant at $p$ below 0.05 , confounding variables were included in the multivariate logistic and Cox regression analyses to predict mortality. The cumulative incidence of death was depicted using the Kaplan-Meier method, comparing differences between preoperative CKD classes with log-rank statistics. "Time zero" was used to designate the time of CABG. For all tests, a $p$ value below 0.05 was taken as indicating statistical significance. Hazard ratios (HR) are reported with $95 \%$ confidence intervals (CI). All statistical analyses were performed using SSPS version 15.0 (Chicago, IL). 


\section{Results}

Between January 1998 and December 2007, 10626 patients underwent isolated CABG at our hospital. In 267 patients, either preoperative creatinine clearance or weight was lacking. After excluding patients who were lost to follow up ( $n=122)$, a total number of 10057 patients was evaluated. Almost all patients lost to follow-up were citizens of foreign countries or were living abroad. The minimum follow-up interval for surviving patients was 60 days. The mean follow-up period was $1696 \pm 1026$ days (range, 0 to 3708 , with 0 days representing operative death). Sixty-six patients (0.6\%) needed postoperative dialysis.

Baseline characteristics stratified by preoperative CKD class are shown in Table 1. Patients with impaired preoperative renal function (classes 2 to 4) were older, more often female, more likely to have diabetes, hypertension, chronic obstructive pulmonary disease (COPD), or peripheral vascular disease (PVD), more likely to have a left ventricular ejection fraction (EF) below 35\%, and more likely to require perioperative intra-aortic balloon pump support (IABP). The number of off-pump coronary artery bypass (OPCAB) operations was less in patients with renal impairment.

Early and late mortality were greater in higher CKD classes (Table 2).

Risk factors for early mortality identified by univariate and multivariate logistic regression analyses are shown in Table 3.

Univariate logistic regression analysis identified preoperative $\mathrm{CrCl}$, considered as a continuous variable, as a risk factor for early mortality. Other patient-related risk factors indicated by univariate analysis included, age, female gender, COPD, diabetes, EF below 35\%, PVD, previous cardiac surgery, year of operation and emergency circumstances of CABG. Perioperative complications such as myocardial infarction need for $I A B P$, and re-exploration also were identified as risk factors for early mortality. On the other hand, hypertension, use of extracorporeal circulation, and cold crystalloid versus warm intermittend blood cardioplegia were not identified as risk factors for early mortality.

All preoperative risk factors identified by univariate logistic regression analysis were entered in the multivariate logistic regression model. Preoperative $\mathrm{CrCl}$, considered as a continuous variable, proved to be an independent risk factor for early mortality; others were age, COPD, diabetes, EF below 35\%, previous cardiac surgery, and emergency CABG, but not PVD or the year of operation. 
Table 1. Baseline characteristics stratified by preoperative CKD class

\begin{tabular}{llllll}
\hline & $\begin{array}{l}\text { Class 1 } \\
(\mathrm{n}=2324)\end{array}$ & $\begin{array}{l}\text { Class 2 } \\
(\mathrm{n}=4819)\end{array}$ & $\begin{array}{l}\text { Class } 3 \\
(\mathrm{n}=2798)\end{array}$ & $\begin{array}{l}\text { Class 4 } \\
(\mathrm{n}=116)\end{array}$ & p value \\
\hline Age (mean \pm SD) & $55.7 \pm 8.3$ & $64.4 \pm 7.8$ & $71.8 \pm 6.4$ & $74.8 \pm 6.0$ & $<0.0001$ \\
Male & $2113(90.9)$ & $3929(81.5)$ & $1660(59.3)$ & $51(44.0)$ & $<0.0001$ \\
Diabetes & $486(20.9)$ & $932(19.3)$ & $650(23.2)$ & $42(36.2)$ & $<0.0001$ \\
Hypertension & $946(40.7)$ & $1885(39.1)$ & $1279(45.7)$ & $73(62.9)$ & $<0.0001$ \\
COPD & $231(9.9)$ & $578(12.0)$ & $420(15.0)$ & $17(14.7)$ & $<0.0001$ \\
PVD & $201(8.6)$ & $496(10.3)$ & $439(15.7)$ & $26(22.4)$ & $<0.0001$ \\
LVEF <35\% & $46(2.0)$ & $139(3.0)$ & $133(4.9)$ & $12(10.6)$ & $<0.0001$ \\
Emergency CABG & $97(4.2)$ & $165(3.4)$ & $98(3.5)$ & $8(6.9)$ & $<0.0001$ \\
Off-pump & $298(12.4)$ & $411(8.5)$ & $186(6.6)$ & $4(3.4)$ & $<0.0001$ \\
Cristaloid cardiopl & $797(33.8)$ & $2035(41.8)$ & $1368(48.5)$ & $55(46.6)$ & $<0.0001$ \\
Blood cardioplegia & $1184(50.2)$ & $2212(45.4)$ & $1154(40.9)$ & $54(45.8)$ & $<0.0001$ \\
Prev cardiac surg & $98(4.2)$ & $294(6.1)$ & $205(7.3)$ & $10(8.6)$ & $<0.0001$ \\
IABP & $33(1.4)$ & $83(1.7)$ & $86(3.1)$ & $5(4.3)$ & $<0.0001$ \\
Re-exploration & $102(4.4)$ & $253(5.3)$ & $181(6.5)$ & $4(3.4)$ & 0.007 \\
Periop MI & $52(2.2)$ & $144(3.0)$ & $87(3.1)$ & $6(5.2)$ & 0.096 \\
\hline
\end{tabular}

Values are expressed as number of patients (percentage) unless otherwise mentioned. BMI, body mass index; CKD. chronic kidney disease; COPD, chronic obstructive pulmonary disease; PVD, peripheral vascular disease; LVEF, left ventricular ejection fraction; IABP, intra-aortic balloon pump support; Periop MI, perioperative myocardial infarction.

Table 2. Early and late mortality stratified by preoperative CKD class

\begin{tabular}{llllll}
\hline & Class 1 & Class 2 & Class 3 & Class 4 & p-value \\
& $(\mathrm{n}=2324)$ & $(\mathrm{n}=4819)$ & $(\mathrm{n}=2798)$ & $(\mathrm{n}=116)$ & \\
\hline Early mortality & $14(0.6 \%)$ & $86(1.8 \%)$ & $112(4.0 \%)$ & $13(11.2 \%)$ & $<0.0001$ \\
Late mortality & $85(3.7 \%)$ & $438(9.1 \%)$ & $535(19.1 \%)$ & $52(44.8 \%)$ & $<0.0001$ \\
\hline
\end{tabular}


Table 3. Predictors of early mortality ( $\leq 30$ days after $C A B G$ ) by univariate and multivariate logistic regression analyses.

\begin{tabular}{lllll}
\hline & \multicolumn{2}{l}{ Univariate analysis } & & Multivariate analysis \\
\hline Risk factor & $\mathrm{HR}(95 \% \mathrm{Cl})$ & $\mathrm{p}$ value & $\mathrm{HR}(95 \% \mathrm{Cl})$ & $\mathrm{p}$ value \\
& & & & \\
Preop CrCl* & $0.965(0.958-0.972)$ & $<0.0001$ & $0.980(0.971-0.990)$ & $<0.0001$ \\
Year of operation & $0.944(0.901-0.989$ & 0.015 & $0.965(0.917-1.016)$ & 0.175 \\
Age* & $1.083(1.065-1.102)$ & $<0.0001$ & $1.055(1.031-1.079)$ & $<0.0001$ \\
COPD & $2.06(1.49-2.84)$ & $<0.0001$ & $1.78(1.26-2.50)$ & .001 \\
Diabetes & $1.51(1.12-2.02)$ & 0.006 & $1.49(1,08-2.04)$ & 0.013 \\
LVEF <35\% & $6.15(4.18-0.04)$ & $<0.0001$ & $4.19(2.76-6.36)$ & $<0.0001$ \\
PVD & $1.62(1.14-2.30)$ & 0.007 & $1.30(0.89-1.90)$ & 0.171 \\
Prev cardiac surg & $4.26(3.11-5.83)$ & $<0.0001$ & $2.49(1.66-3.74)$ & $<0.0001$ \\
Emergency & $6.56(4.21-8.70)$ & $<0.0001$ & $3.73(2.30-6.04)$ & $<0.0001$ \\
Periop MI & $6.42(4.35-9.49)$ & $<0.0001$ & & \\
Re-exploration & $5.29(3.81-7.36)$ & $<0.0001$ & & \\
IABP & $14.41(10.01-20.74)$ & $<0.0001$ & & \\
Male gender & $0.74(0.55-0.99)$ & 0.047 & $1.15(0.83-1.61)$ & 0.385 \\
Hypertension & $0.97(0.74-1.27)$ & 0.745 & & \\
Crist cardioplegia & $1.18(0.89-1.57)$ & 0.242 & & \\
Off pump & $0.67(0.39-1.17)$ & 0.163 & & \\
\hline
\end{tabular}

*entered as a continuous variable. $C O P D=$ chronic obstructive pulmonary disease; $H R$ = hazard ratio; $I A B P=$ intra-aortic balloon pump support; LVEF = left ventricular ejection fraction; PeriopMI = perioperative myocardial infarction; Preop $\mathrm{CrCl}$ = preoperative creatinine clearance; PVD = peripheral vascular disease.

Results of Cox regression analyses to identify risk factors for late mortality are shown in Table 4. Univariate analysis identified preoperative $\mathrm{CrCl}$ as a risk factor for late mortality. Other patient-related risk factors identified included age, year of operation, COPD, diabetes, EF below 35\%, PVD, female gender, hypertension, previous cardiac surgery and emergency CABG. Perioperative complications representing risk factors for early mortality also were identified as risk factors for late mortality.

All preoperative risk factors that were identified by univariate analysis were entered into the multivariate Cox regression model. Preoperative $\mathrm{CrCl}$ considered as a continuous variable was identified as an independent risk factor for late mortality. Other risk factors were age, COPD, year of operation, diabetes, EF below 35\%, PVD, male gender, and emergency operation. Hypertension and previous cardiac surgery were not identified as independent risk factors. 
Table 4. Predictors of late mortality ( $>30$ days after $C A B G$ ) by univariate and multivariate Cox regression analyses.

\begin{tabular}{|c|c|c|c|c|}
\hline & Univariate analysis & & Multivariate analysis & \\
\hline Risk factor & $\mathrm{HR}(95 \% \mathrm{Cl})$ & $p$ value & $\mathrm{HR}(95 \% \mathrm{Cl})$ & $p$ value \\
\hline Preop $\mathrm{CrCl}^{*}$ & $0.966(0.964-0.969)$ & $<0.0001$ & $0.984(0.980-0.988)$ & $<0.0001$ \\
\hline Year of operation & $0.954(0.931-0.978)$ & $<0.0001$ & $0.952(0.928-0.977)$ & $<0.0001$ \\
\hline Age* & 1.092 (1.084-1.099) & $<0.0001$ & 1.067 (1.057-1.077) & $<0.0001$ \\
\hline COPD & $1.95(1.71-2.23)$ & $<0.0001$ & $1.66(1.45-1.90)$ & $<0.0001$ \\
\hline Diabetes & 1.68 (1.49-1.89) & $<0.0001$ & $1.52(1.34-1.72)$ & $<0.0001$ \\
\hline LVEF $<35 \%$ & $3.15(2.59-3.83)$ & $<0.0001$ & $2.58(2.12-3.15)$ & $<0.0001$ \\
\hline PVD & $2.12(1.85-2.43)$ & $<0.0001$ & $1.61(1.40-1.86)$ & $<0.0001$ \\
\hline Male gender & $0.84(0.75-0.95)$ & 0.008 & 1.39 (1.22-1.59) & $<0.0001$ \\
\hline Hypertension & $1.17(1.04-1.30)$ & 0.005 & $1.07(0.96-1.20)$ & 0.201 \\
\hline Previous cardiac surg & $1.95(1.66-2.31)$ & $<0.0001$ & $1.47(1.23-1.20)$ & $<0.0001$ \\
\hline Emergency CABG & $1.95(1.58-2.41)$ & $<0.0001$ & $1.92(0.50-2.47)$ & $<0.0001$ \\
\hline Off pump & $0.69(0.54-0.88)$ & 0.003 & & \\
\hline Periop MI & $2.61(2.09-3.27)$ & $<0.0001$ & & \\
\hline Re-exploration & $1.96(1.64-2.35)$ & $<0.0001$ & & \\
\hline Crist cardioplegia & $1.10(0.98-1.23)$ & 0.097 & & \\
\hline IABP & 3.69 (2.96-4.61) & $<0.0001$ & & \\
\hline
\end{tabular}

*entered as a continuous variable. $C O P D=$ chronic obstructive pulmonary disease; $H R$ = hazard ratio; IABP = intra-aortic balloon pump support; LVEF = left ventricular ejection fraction; Periop $\mathrm{MI}=$ perioperative myocardial infarction; Preop $\mathrm{CrCl}$ = preoperative creatinine clearance; PVD = peripheral vascular disease.

Figure 1 shows long-term survival stratified by preoperative CKD class.

The log-rank test yielded a $\mathrm{p}$ value below 0.001 , indicating significant differences in long-term survival between all groups. When long-term survival of patients in classes 1 and 2 was compared to the expected survival (Figure 2), survival of patients with normal function (class 1 ) was similar to that expected, with a $p$ value of 0.323 . Survival of patients in with mild impairment (class 2 ) was better than the expected survival, with a $p$ value of 0.002 . Compared to the expected survival, long-term survival of patients with moderate impairment (class 3; Figure 3) was similar, with a $p$ value of 0.385 . However, survival of patients with severe impairment (class 4; Figure 3) was worse than the expected survival ( $p<0.0001$; log-rank test). 


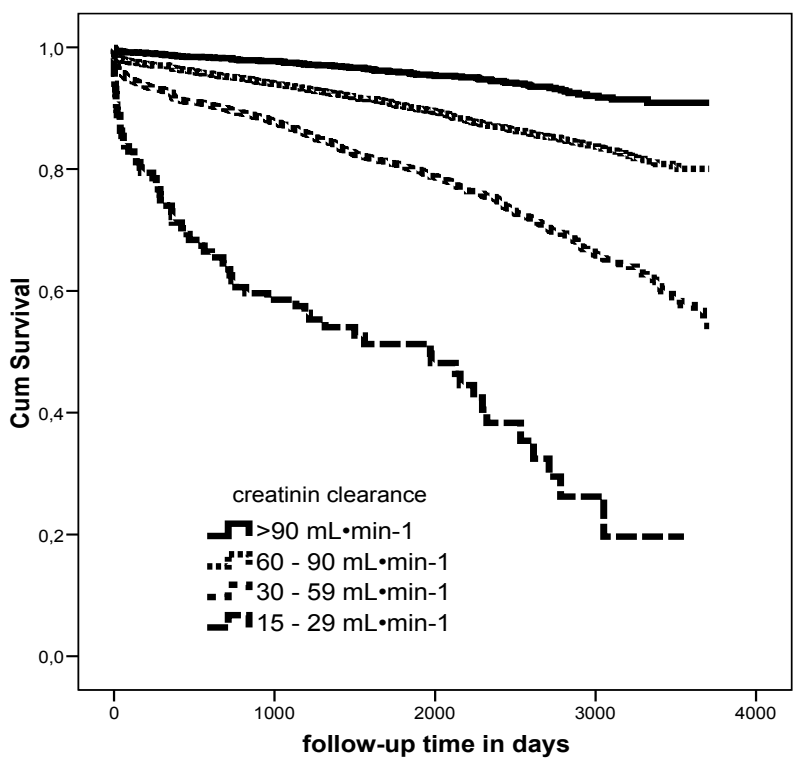

Figure 1. Kaplan -Meier survival curves stratified by preoperative CKD class.

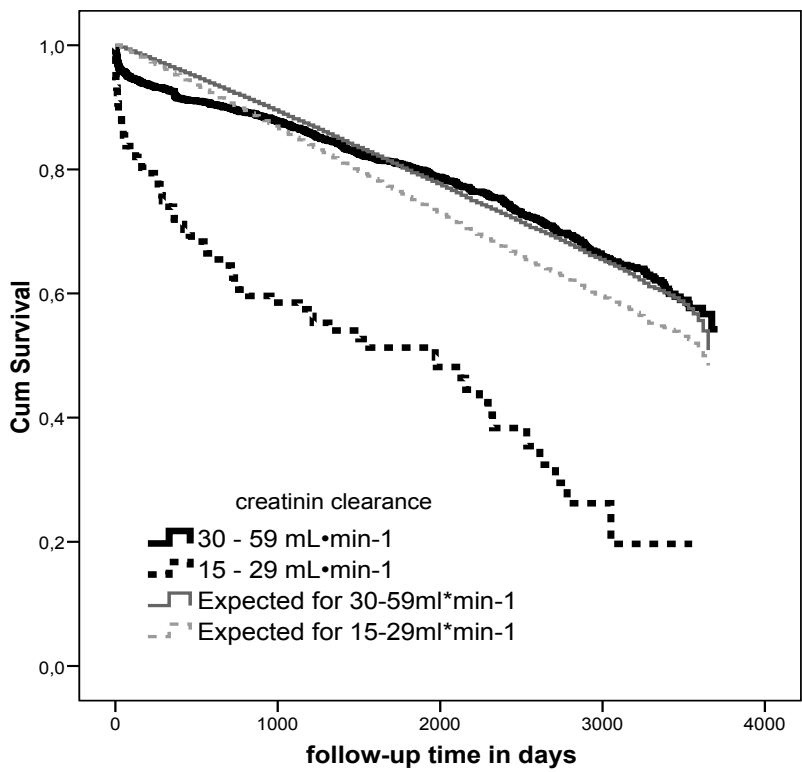

Figure 2. Kaplan-Meier curves for CKD class 1 and 2 patients and the matched general population groups 


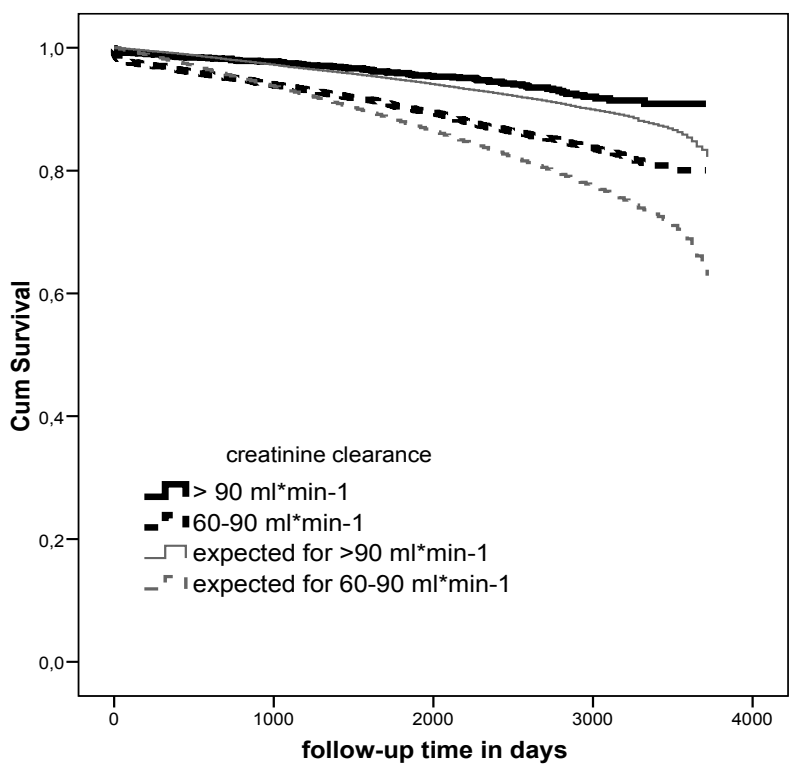

Figure 3. Kaplan-Meier curves for CKD class 3 and 4 patients compared to matched general population groups.

Table 5 shows 1-, 5-, and 10-year survival rates corresponding to the Kaplan-Meier curves.

Table 5. Survival rates (\%) for 1,5 , and 10 years, stratified by CKD class

\begin{tabular}{llll}
\hline & 1-year & 5-year & 10-year \\
\hline Class 1 & $98.1 \pm 0.3$ & $94.9 \pm 0.6$ & $90.1 \pm 1.4$ \\
Class 2 & $95.0 \pm 0.3$ & $86.0 \pm 0.2$ & $79.4 \pm 1.2$ \\
Class 3 & $89.5 \pm 0.6$ & $76.7 \pm 1.0$ & $53.2 \pm 3.8$ \\
Class 4 & $62.4 \pm 4.3$ & $44.3 \pm 5.4$ & $*$ \\
\hline
\end{tabular}

$*$ No patient in CKD class 4 survived for 10 years

\section{Discussion}

Preoperative renal impairment is a well-established predictor of adverse outcome in patients undergoing CABG (4-9), as was confirmed in this study. However, when compared to expected survival, only severe renal impairment led to worse outcome, while patients with moderate renal impairment had an outcome similar to that expected. 


\section{Renal impairment and early mortality}

Renal impairment is a well-established risk factor for early mortality. Currently used risk stratification algorithms use a serum creatinine concentration exceeding 200 $\mu \mathrm{mol} / \mathrm{L}$ as a cutoff point (13), but recent studies suggest that even mild renal dysfunction predicts poor early outcome after CABG (4-9). This finding was confirmed in our study. How renal dysfunction is related to poor early outcome after CABG has not been well established. Possibly, renal dysfunction could be a result of myocardial dysfunction or other systemic diseases. Earlier reports (14) stated that patients with renal dysfunction have a high prevalence of traditional cardiovascular risk factors. In our study, the percentages of patients with impaired left ventricular function, peripheral vascular disease, and diabetes were much higher in class 4 than in other classes. The need for postoperative dialysis in the entire study population was $0.6 \%$. This finding is in a accordance with previous reports (14). New risk stratification models should incorporate preoperative creatinine clearance as a continuous but nonlinear variable.

\section{Renal impairment and late mortality}

In agreement with others (9), we noted that patients in a higher preoperative CKD class had poorer late survival. Renal impairment has been described as a strong risk factor for development of cardiovascular disease $(15,16)$. It occurs more often in advanced age and in patients with a number of other important cardiovascular risk factors including hypercoagulability (17), endothelial dysfunction (18), arteriosclerosis (19) and left ventricular hypertrophy (20). This means increased incidence of new cardiovascular events for those who survive the postoperative period. Holzmann et al (21) showed an $8 \%$ incidence of myocardial infarction in patients with renal dysfunction within 5 years after CABG. In $35 \%$ of the cases death was the outcome within one month. It is also possible that in the presence of renal dysfunction, traditional risk factors such as smoking, hyperlipidemia, hypertension, and diabetes will have a different qualitative relationship with cardiovascular events (22). Our data show that higher CKD class is associated with greater mean age. In our study, we found that no patients of the Class 4 group survived 10 years and less than $50 \%$ survived 5 years although the same operative and perioperative techniques were adopted in all groups. These results must be weighed against alternative procedures, namely percutaneous coronary intervention $(\mathrm{PCl})$. Prior $\mathrm{PCl}$ studies have found that although procedural success rates tend to be high in patients with renal dysfunction, these patients face higher risks for mortality, morbidity, and restenosis $(23,24)$. The risk of revascularization has also to be weighed against the long-term hazards of conservative treatment in patients with coronary artery disease. In this regard, Hemmelgarn et al (25) reported worse 8-year adjusted survival rates for kidney disease patients not on dialysis who were medically managed after catheterization compared with those who underwent revascularization (54.9\% for CABG, $32.7 \%$ for $\mathrm{PCl}$, versus $29.7 \%$ for no revascularization. 
Although appropriate statistical tests can be used to distinguish between effects caused by age and by renal function, interpretation of survival curves remains difficult. Life expectancy also may vary with age, gender and race. Changing life expectancy over the years has been well documented in the Netherlands by the Central Bureau for Statistics (CBS), which keeps track of mortality rates for the entire Dutch population. We used the CBS database, which can be downloaded online (www.CBS.nl), to calculate survival in the general population groups. We compared late survival of patients stratified by CKD class with general population groups matched for age, gender, and year of operation. Patients in CKD class 1 were relatively young, and survival was similar to that in a matched general population (expected survival). Kaplan-Meyer curves and log-rank tests suggested that patients in class 2 had survival even better than the expected survival. Patients in class 3 were older than patients in class 2 and showed worse survival, but one that still was similar to the expected survival (Kaplan-Meyer curves and log-rank test). For patients in class 4, survival was far worse than the expected survival.

Caution to interpret these results is needed, because the CBS database contains data of the total Dutch population including patients described in this study as well as patients who were treated in other Dutch cardiac surgery centres. If differences between groups are found, the results of the general population group shift towards the average of the patient group, making the differences smaller than what our study shows. In comparing late survival of our patients with outcome in a matched group from the general population, we should take into account that a certain but unknown percentage of the general population suffers from renal impairment and coronary disease. One also may assume that our patients were adequately treated for their coronary problem and postoperatively treated with aspirin, hypocholesterolemic drugs, and medications for underlying diseases such as hypertension. This treatment, as well as protection by revascularization, may contribute to improved survival and explain why patients in CKD classes 1,2 , and 3 had a similar or even better survival than matched general population groups. Further, before undergoing CABG, patients are screened for severe underlying disease. If severe underlying disease is present, treatment alternatives to CABG are considered, thus biasing the CABG group.

\section{Conclusions}

Renal impairment was confirmed to be a risk factor for early mortality after CABG. Concerning late outcome, low creatinine clearance was associated with a poor survival. When compared to groups from the general population matched for age, gender, and year of CABG, only patients with a creatinine clearance of 15 to $30 \mathrm{~mL} \cdot \mathrm{min}^{-1}$ had a 
worse long-term survival, while patients with a creatinine clearance of over 30 $\mathrm{mL} \cdot \mathrm{min}^{-1}$ had a similar or better outcome than expected.

\section{Study limitations}

This study had a retrospective design. Some patients were lost to follow up and some data were unobtainable, making results less accurate.

\section{References}

1. Nakayama L, Sakata R, Ura M, Miyamoto TA. Coronary artery bypass grafting in dialysis patients. Ann Thorac Surg 1999;68:1257-61.

2. Rinehart AL, Herzog CS, Collins AJ, Flack JM, Ma JZ, Opsahl JA. A comparison of coronary angioplasty and coronary artery bypass grafting outcomes in chronic dialysis patients. Am J Kidney Dis 1995;25:281-90.

3. Labrousse L, de Vincentiis C, Madonna F, Deville C, Roques X, Baudet E. Early and long-term results of coronary artery bypass grafts in patients with dialysis dependent renal failure. Eur J Cardiothorac Surg 1999;15:691-6.

4. Rao V, Weisel RD, Buth KJ, Cohen G, Borger MA, Shiono N, et al. Coronary artery bypass grafting in patients with non-dialysis-dependent renal insufficiency. Circulation 1997;96 (suppl II):38-43.

5. Weerasinghe A, Hornick P, Smith P, Taylor K, Ratnatunga C. Coronary artery bypass grafting in nondialysis-dependent mild-to-moderate renal dysfunction. J Thorac Cardiovasc Surg 2000;121:1083-9.

6. Nakayama $\mathrm{Y}$, Sakata R, Ura M, Itoh T. Long-term results of coronary artery bypass grafting in patients with renal insufficiency. Ann Thorac Surg 2003;75:496-500.

7. Hirose H, Amano A, Takahashi A. Nagano, N. Coronary artery bypass grafting for patients with nondialysis-dependent renal dysfunction (serum creatinine $\geq 2.0 \mathrm{mg} / \mathrm{dl}$ ). Eur J Cardiothorac Surg 2000; 20:565-72.

8. Szczech LA, Best PJ, Crowley E, Brooks MM, Berger PB, Bittner V, et al, for the Bypass Angioplasty Revascularization Investigation (BARI) Investigators. Outcomes of patients with chronic renal insufficiency in the Bypass Angioplasty Revascularization Investigation. Circulation 2002;105: 2253-8.

9. Howell NJ, Keogh BE, Bonser RS, Graham TR, Mascaro J, at al. Mild renal dysfunction predicts inhospital mortality and post-discharge survival following cardiac surgery. Eur J Cardiothorac Surg 2008;34:390-5.

10. Brown JR, Cochran RP, Mackenzie TA, Furnary AP, Kunzelman KS, Ross CS, et al. Long-term survival after cardiac surgery is predicted by estimated glomerular filtration rate. Ann Thorac Surg 2008;86:411.

11. Cockcroft DW, Gault MH. Prediction of creatinine clearance from serum creatinine. Nephron 1976;16:31-41.

12. National Kidney Foundation. K/DOQI clinical practice guidelines for chronic kidney disease: evaluation, classification, and stratification. Am J Kidney Dis 2002; 39 (suppl 1):1-266.

13. Nashef SAM, Roques F, Michel P, Gauducheau E, Lemeshow S, Salomon R. European system for cardiac operative risk evaluation (EuroScore). Eur J Cardiothorac Surg. 1999;16(1):9-13.

14. Zakeri R, Freemantle N, Barnett V, Lipkin GW, Bonser RS, Graham TR, et al. Relation between mild renal dysfunction and outcomes after coronary artery bypass grafting. Circulation. 2005;112(9 Suppl):I270-5. 
15. Foley RN, Murray AM, Li S, Herzog CA, McBean AM, Eggers PW, et al. Chronic kidney disease and the risk for cardiovascular disease, renal replacement and death in the United States Medicare population, 1998 to 1999. J Am Soc Nephrol 2005:16:489-95.

16. Go AS, Chertow GM, Fan D, McCullogh CE, Hsu CY. Chronic kidney disease and the risk of death, cardiovascular events and hospitalization. New Engl J Med 2004;351(13):1296-305.

17. Shlipak MG, Fried LF, Crump C, Bleyer AJ, Manolio TA, Tracy RP, et al. Elevations of inflammatory and procoagulant biomarkers in elderly persons with renal insufficiency. Circulation. 2003;107(1):87-92.

18. Blacher J, Safar ME, Guerin AP, Pannier B, Marchais SJ, London GM. Aortic pulse wave velocity index and mortality in end-stage renal disease. Kidney Int. 2003;63(5):1852-60.

19. Raggi P, Boulay A, Chasan-Taber S, Amin N, Dillon M, Burke SK, et al. Cardiac calcification in adult hemodialysis patients. A link between end-stage renal disease and cardiovascular disease? J Am Coll Cardiol. 2002;39(4):695-701.

20. Levin A, Thompson CR, Ethier J, Carlisle EJ, Tobe S, Mendelssohn D, et al. Left ventricular mass index increase in early renal disease: impact of decline in hemoglobin. Am J Kidney Dis. 1999;34(1):125-34.

21. Holzmann MJ, Hammar N, Ahnve S, Nordqvist T, Pehrsson K, Ivert T. Renal insufficiency and long-term mortality and incidence of myocardial infarction in patients undergoing coronary artery bypass grafting. Eur Heart J. 2007;28(7):865-71.

22. Sarnak MJ, Levey AS, Schoolwerth AC, Coresh J, Culleton B, Hamm LL, et al. Kidney disease as a risk factor for development of cardiovascular disease: a statement from the American Heart Association Councils on Kidney in Cardiovascular Disease, High Blood Pressure Research, Clinical Cardiology, and Epidemiology and Prevention. Circulation. 2003;108(17):2154-69.

23. Rinehart AL, Herzog CA, Collins AJ, Flack JM, Ma JZ, Opsahl JA. A comparison of coronary angioplasty and coronary artery bypass grafting outcomes in chronic dialysis patients. Am J Kidney Dis. 1995;25(2):281-90.

24. Reusser LM, Osborn LA, White HJ, Sexson R, Crawford MH. Increased morbidity after coronary angioplasty in patients on chronic hemodialysis. Am J Cardiol. 1994;73(13):965-7.

25. Hemmelgarn BR, Southern D, Culleton BF, Mitchell LB, Knudtson ML, Ghali WA. Provincial Project for Outcomes Assessment in Coronary Heart Disease (APPROACH) Investigators. Survival after coronary revascularization among patients with kidney disease. Circulation. 2004;110(14):1890-5. 


\section{Chapter 4}

\section{Risk factors for deterioration of renal}

function after coronary artery bypass grafting

Eur J Cardiothorac Surg. 2010;37:106-111

\section{Authors}

Albert H. M. van Straten ${ }^{1}$ Mohamed A. Soliman Hamad ${ }^{1}$ André J. van Zundert ${ }^{2}$ Elisabeth J. Martens ${ }^{3}$ Jacques P. A. M. Schönberger ${ }^{1}$ Andre M. de Wolf ${ }^{4}$

2 Department of Anesthesiology, Catharina Hospital - Brabant Medical School, Eindhoven, The Netherlands \& University Hospital Ghent, Ghent, Belgium.

3 Department of Education and Research, Catharina Hospital, Eindhoven, The Netherlands \& Center of Research on Psychology in Somatic diseases, Department of Medical Psychology, Tilburg University, The Netherlands.

4 Department of Anesthesiology, The Feinberg School of Medicine, Northwestern University, Chicago, Illinois, USA 


\begin{abstract}

\section{Objectives}

Various definitions of impairment of renal function after coronary artery bypass grafting are used in the literature. Depending on the definition several risk factors are identified. We analysed our data to determine risk factors for deterioration of the creatinine clearance of $10 \%$ or more postoperatively.
\end{abstract}

\title{
Methods
}

All patients undergoing isolated coronary surgery in a single centre between January 1998 and December 2007 are included. Clinical data, including demographics and renal risk factors, were prospectively collected in our database. The most recent preoperative serum creatinine level and the maximum serum creatinine level within the first week postoperatively were used to calculate the creatinine clearance. A deterioration of $10 \%$ or more was considered to be an endpoint for this study.

\section{Results}

In 10,098 out of a total of 10,626 patients, the preoperative as well as the postoperative creatinine clearance could be calculated. In 1053 patients the deterioration of the creatinine clearance was $10 \%$ or more. We could identify the following risk factors: advanced age, diabetes, chronic obstructive pulmonary disease, peripheral vascular disease, emergency operation, previous cardiac surgery, low preoperative hemoglobin level, high preoperative C-reactive protein level, perioperative myocardial infarction, re-exploration and the number of blood transfusions.

\section{Conclusions}

Risk factors for deterioration of renal function after revascularization have been confirmed in this study. In addition, we found peripheral vascular disease, previous cardiac surgery, low preoperative hemoglobin, increased preoperative C-reactive protein level, perioperative myocardial infarction and the number of blood transfusions to be risk factor, that have not been earlier described. 


\section{Introduction}

Several risk factors for impairment of renal function after coronary artery bypass grafting (CABG) have been identified, of which female gender, age, diabetes mellitus, hypertension, preoperative creatinine clearance $<50 \mathrm{ml} / \mathrm{min}$, impaired left ventricular function, need for intra aortic balloon pump (IABP) and re-exploration are most often mentioned (1-4). Several studies state that deterioration of renal function occurs more often after conventional coronary artery bypass operation with the use of extracorporeal circulation (ECC) than after off-pump coronary artery bypass (OPCAB) (5- 9) although others could not confirm this statement $(3,4,10)$. In addition, the use of aprotinin during CABG has been identified as another important risk factor for impairment of renal function (11-12). Others could not support this finding $(13,14)$. Various definitions of impairment of renal function after CABG are used in the literature. Some authors use postoperative serum creatinine levels $(5,6,10)$, some with a cut-off value of $1.5 \mathrm{mg} / \mathrm{dl}$ as an endpoint (6), while others use creatinine clearance as the postoperative marker for renal function, with a cut-off point of $50 \mathrm{ml} / \mathrm{min}$ as an endpoint (4). Sometimes the postoperative creatinine clearance is compared with the preoperative value to indicate change in renal function $(4,15)$. The Cockroft-Gault formula for creatinine clearance ( $\mathrm{CrCl}$ ) (16) and the Modification of Diet in Renal Disease (MDRD) formula for estimated glomerular filtration rate (e-GFR) (17) have been used to determine renal function. Recently, deterioration of renal function has been described as a predictor of poor long-term survival (18). We analysed our data to determine risk factors for deterioration of creatinine clearance after CABG adding some variables which, to our knowledge have not yet been described as such.

\section{Materials and Methods}

\section{Patients}

In this retrospective study, we analyzed the data of all patients undergoing isolated CABG with or without use of extra-corporeal circulation (ECC) in a single center (Catharina Hospital, Eindhoven, the Netherlands) between January 1998 and December 2007. Clinical data, including demographics and renal risk factors, were prospectively collected in a database. The study was approved by the local Medical Ethics Review Committee.

\section{Operative techniques}

In CABG surgery, all patients received short-acting anaesthetic drugs to facilitate early extubation. Normothermic extracorporeal circulation (ECC) was performed using nonpulsatile flow. Cold crystalloid cardioplegia (St Thomas' solution) or warm blood car- 
dioplegia was used to induce and maintain cardioplegic cardiac arrest, according to the surgeon's preference. All patients undergoing CABG received a low dose aprotinin (2 million kallikrein inhibiting units) during extracorporeal circulation, administered to the prime solution. The anaesthetic management in OPCAB surgery was the same as in CABG surgery, but aprotinin was omitted.

\section{Estimation of renal function}

Creatinine clearance $(\mathrm{CrCl})$ was determined using the Cockroft-Gault formula (15), which is different for men [(140-age) $x$ weight/(serum $\mathrm{Cr} \times 72)$ ] and women: [(140-age) $x$ weight/(serum $\mathrm{Cr}$ x 72)) x 0.85]. The most recent preoperative serum creatinine level and the maximum serum creatinine within the first week postoperatively or if sooner before discharge were used to calculate the $\mathrm{CrCl}$ and the percentage change from the preoperative value. Patients with preoperative $\mathrm{CrCl}$ below $15 \mathrm{ml} . \mathrm{min}^{-1}$ and those treated with dialysis were excluded from this study. A deterioration of $10 \%$ or more was considered to be an endpoint for this study.

\section{Statistical analyses}

Discrete variables were compared with the Chi-square test and are presented as percentages. Continuous variables were compared with the Student unpaired t-test and univariate logistic regression analyses were performed to investigate the impact of biomedical variables on renal function. If significant at $p<0.05$, the variables were included into the multivariable logistic regression analyses for renal function. A $p$-value $<0.05$ was used for all tests to indicate statistical significance. Odds ratios (OR) with a confidence interval $(\mathrm{Cl})$ of $95 \%$ with p-values are reported. All statistical analyses were performed using SPPS version 15.0 (SPSS Inc, Chicago, IL).

\section{Results}

Between January 1998 and December 2007, a total of 10626 patients underwent isolated CABG surgery with or without ECC. Preoperative $\mathrm{CrCl}$ was not calculated in 432 patients due to emergency situation or missing patient's weight. Postoperative $\mathrm{CrCl}$ was not calculated in $\mathbf{2 7 7}$ patients due to mortality before renal function could be determined. Complete data were obtained in 10098 patients. Mean preoperative $\mathrm{CrCl}$ was $74.5 \pm 24.4$ (7-308) $\mathrm{ml} \mathrm{min}^{-1}$ (figure 1) and the mean postoperative $\mathrm{CrCl}$ was $79.2 \pm 28.4$ (figure 2). 

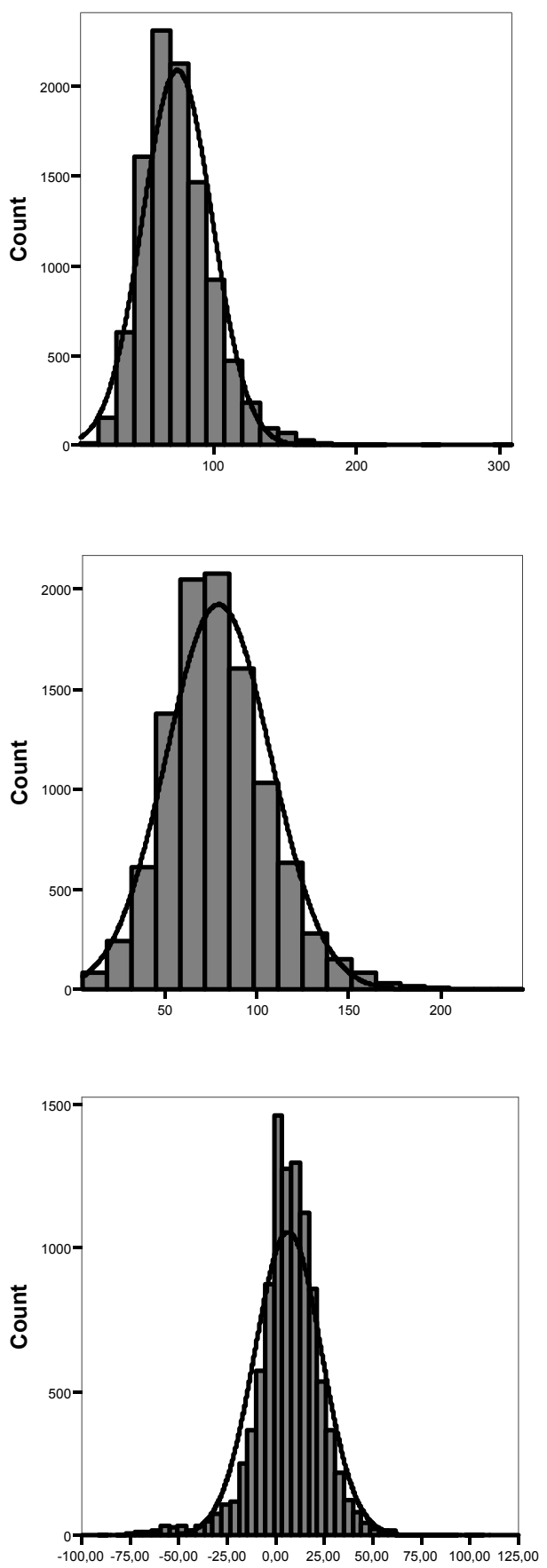

Figure 1. Preoperative creatinine clearance

Figure 2. Postoperative creatine clearance

Figure 3 Percentage change in creatinine clearance 
Distribution of changes in $\mathrm{CrCl}$ is shown in figure 3. Eighty patients required any form of renal replacement therapy (continuous hemofiltration or dialysis). Deterioration of the $\mathrm{CrCl}$ of ten percent or more was found in 1053 patients.

Patients' preoperative and perioperative demographic and clinical characteristics stratified by the degree of deterioration of $\mathrm{CrCl}$ are presented in Table 1 .

Patients with a deterioration of $\mathrm{CrCl}$ of more than 10 percent were older, had more often diabetes, a body mass index (BMI) of more than $35 \mathrm{~kg} . \mathrm{m}^{-2}$, chronic obstructive pulmonary disease (COPD), hypertension, peripheral vascular disease (PVD), a left ventricular ejection fraction (EF) of less than 35\%, an emergency operation, previous cardiac surgery and more preoperative myocardial infarctions. The preoperative hemoglobin $(\mathrm{Hb})$ level as well the preoperative $\mathrm{CrCl}$ was lower whereas the preoperative C-reactive protein (CRP) level was higher. Off- pump CABG was performed less often, whereas the duration of ECC was longer. Complications such as the need for intra-aortic balloon pump support (IABP), perioperative infarction and re-exploration for any cause were more frequent. The number of red blood cell (RBC) units transfused was higher.

\section{Univariate analyses}

Results of univariate logistic regression analyses to identify risk factors for deterioration in $\mathrm{CrCl}$ of $10 \%$ or more are shown in Table 2.

Preoperative significant risk factors were: advanced age, diabetes, $\mathrm{BMI}>35 \mathrm{~kg} \cdot \mathrm{m}^{-2}$, COPD, hypertension, PVD, number of preoperative myocardial infarctions, EF $<35 \%$, emergency operation, previous cardiac surgery, lower preoperative $\mathrm{Hb}$ level, higher $\mathrm{CRP}$, and lower preoperative $\mathrm{CrCl}$. On the other hand, gender, $\mathrm{BMI}$ of $<20 \mathrm{~kg} \cdot \mathrm{m}^{-2}$ and functional angina class (CCS) were not identified as risk factors. Significant peri- and postoperative risk factors were CABG versus OPCAB, duration of ECC, the need for $I A B P$, perioperative myocardial infarction, re-exploration for any cause as well as the number of perioperative RBC unit transfusions. The type of cardioplegia and the number of grafts were not identified as risk factors. 
Table 1. Demographic characteristics stratified by deterioration of creatinine clearance.

\begin{tabular}{|c|c|c|c|}
\hline & \multicolumn{3}{|c|}{ Deterioration of creatinine clearance } \\
\hline & $<10 \%$ & $\geq 10 \%$ & $p$-value \\
\hline & $\mathrm{n}=9045$ & $n=1053$ & \\
\hline Male gender & $6998(77.4)$ & 799(75.9) & 0.146 \\
\hline Age & $64.2 \pm 9.5$ & $67.8 \pm 9.4)$ & $<0.0001$ \\
\hline Diabetes & $1839(20.3)$ & $288(27.4)$ & $<0.0001$ \\
\hline $\mathrm{BMI}>35 \mathrm{~kg} \cdot \mathrm{m}^{-2}$ & $192(2.1)$ & $44(4.3)$ & $<0.0001$ \\
\hline BMl<20kg. $\mathrm{m}^{-2}$ & $44(0.5)$ & $5(0.5)$ & 0.599 \\
\hline COPD & $1088(12.0)$ & $172(16.3)$ & $<0.0001$ \\
\hline Hypertension & $3711(41.0)$ & 494(46.9) & $<0.0001$ \\
\hline PVD & $1004(11.1)$ & $151(14.3)$ & 0.001 \\
\hline CCS class & $2.6 \pm 1.2$ & $2.5 \pm 1.3$ & 0.397 \\
\hline$E F<35 \%$ & $265(3.0)$ & $71(7.2)$ & $<0.0001$ \\
\hline Emergency & $227(2.5)$ & 139(13.2) & $<0.0001$ \\
\hline Number of preop MI & $0.48 \pm 0.60$ & $0.53 \pm 0.63$ & 0.005 \\
\hline Redo & $468(5.2)$ & $134(12.7)$ & $<0.0001$ \\
\hline Preop Hb (g.dl ${ }^{-1}$ ) & $13.9 \pm 1.3$ & $13.3 \pm 1.6$ & $<0.0001$ \\
\hline Preop CRP (mg. ${ }^{-1}$ ) & $10.4 \pm 15.9$ & $16.4 \pm 28.9$ & $<0.0001$ \\
\hline 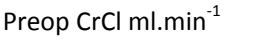 & $75.1 \pm 23.9$ & $69.6 \pm 27.9$ & $<0.0001$ \\
\hline OРСАВ & $825(9.1)$ & $70(6.6)$ & 0.004 \\
\hline Cristaloid cardioplegia & $3772(41.7)$ & $455(43.2)$ & 0.346 \\
\hline Blood cardioplegia & $4090(45.2)$ & $478(45.4)$ & 0.346 \\
\hline ECC-time & $57.0 \pm 33.2$ & $63.7 \pm 38.9$ & $<0.0001$ \\
\hline Number of grafts & $3.4 \pm 1.1$ & $3.4 \pm 1.2$ & 0.894 \\
\hline IABP & $111(1.2)$ & $91(8.6)$ & $<0.0001$ \\
\hline Periop MI & $196(2.2)$ & $90(8.5)$ & $<0.0001$ \\
\hline
\end{tabular}

Results in numbers (percentage) of mean \pm standard deviation

$\mathrm{BMI}=$ body mass index, $\mathrm{COPD}=$ chronic obstructive pulmonary disease, $\mathrm{PVD}=$ peripheral vascular disease, CCS class = Canadian Cardiovascular Society Functional Classification of Anginga, EF = left ventricular ejection fraction, preop $\mathrm{MI}=$ preoperative myocardial infarction, Redo = previous cardiac surgery, preop $\mathrm{Hb}=\mathrm{preop}-$ erative hemoglobin level, preop $\mathrm{CRP}=$ preoperative $\mathrm{C}$-reactive protein level, preop $\mathrm{CrCl}=$ preoperative creatinine clearance , OPCAB = off-pump coronary artery bypass grafting, ECC-time = duration of extracorporeal circulation, IABP = intra-aortic balloon pump support, periop $\mathrm{MI}$ = perioperative myocardial infarction, $\mathrm{RBC}=$ red blood cell 
Table 2.

\begin{tabular}{|c|c|c|}
\hline Risk factor & Odds ratio $(95 \% \mathrm{Cl})$ & p-value \\
\hline \multicolumn{3}{|l|}{ Preoperative risk factors } \\
\hline Male gender & $0.92(0.79-1.06)$ & 0.275 \\
\hline Age* & $1.044(1.036-1.051)$ & $<0.0001$ \\
\hline Diabetes & $1.47(1.27-1.70)$ & $<0.0001$ \\
\hline $\mathrm{BMl}>35 \mathrm{~kg} \cdot \mathrm{m}^{-2}$ & $2.02(1.44-2.82)$ & $<0.0001$ \\
\hline $\mathrm{BMI}<20 \mathrm{~kg} \cdot \mathrm{m}^{-2}$ & $0.98(0.38-2.47)$ & 0.965 \\
\hline COPD & $1.42(1.19-1.70)$ & $<0.0001$ \\
\hline Hypertension & $1.27(1.11-1.41)$ & $<0.0001$ \\
\hline PVD & $1.34(1.11-1.61)$ & 0.002 \\
\hline CCS class* & $0.978(0.929-1.030)$ & 0.397 \\
\hline Number of preop MI* & $1.157(1.046-1.280)$ & 0.005 \\
\hline$E F<35 \%$ & $2.48(1.89-3.26)$ & $<0.0001$ \\
\hline Emergency & $5.90(4.73-7.37)$ & $<0.0001$ \\
\hline Redo & $2.67(2.18-3.27)$ & $<0.0001$ \\
\hline Preop Hb $\left(\mathrm{g} \cdot \mathrm{dl}^{-1}\right)^{*}$ & $0.753(0.719-0.788)$ & $<0.0001$ \\
\hline Preop CRP (mg. $\left.I^{-1}\right)^{*}$ & $1.013(1.009-1.016)$ & $<0.0001$ \\
\hline Preop $\mathrm{CrCl} \mathrm{ml.min}{ }^{-1^{*}}$ & $0.990(0.987-0.993)$ & $<0.0001$ \\
\hline \multicolumn{3}{|c|}{ Peri- and postoperative risk factors } \\
\hline OPCAB & $0.71(0.55-0.91)$ & 0.008 \\
\hline Crystaloid cardioplegia & $1.03(0.90-1.18)$ & 0.648 \\
\hline ECC-time* & $1.005(1.003-1.007)$ & $<0.0001$ \\
\hline Number of grafts* & $0.996(0.941-1.054)$ & 0.894 \\
\hline IABP & $7.61(5.72-10.12)$ & $<0.0001$ \\
\hline Periop MI & $4.21(3.25-5.46)$ & $<0.0001$ \\
\hline Re-exploration & $4.21(3.46-5.13)$ & $<0.0001$ \\
\hline No of blood transfusions* & $1.196(1.173-1.220)$ & $<0.0001$ \\
\hline
\end{tabular}

* entered as a continuous variable

$\mathrm{Cl}$ = conficence interval, $\mathrm{BMI}=$ body mass index, $\mathrm{COPD}=$ chronic obstructive pulmonary disease, PVD = peripheral vascular disease, CCS class = Canadian Cardiovascular Society Functional Classification of Anginga, preop $\mathrm{MI}=$ preoperative myocardial infarction, $\mathrm{EF}=$ ejection fraction, Redo = previous cardiac surgery, preop $\mathrm{Hb}=$ preoperative hemoglobin level, preop $\mathrm{CRP}=$ preoperative $\mathrm{C}$-reactive protein level, preop $\mathrm{CrCl}=\mathrm{preop}$ erative creatinine clearance , OPCAB = off-pump coronary artery bypass, $\mathrm{ECC}=$ extra-corporeal circulation, $\mathrm{IABP}=$ intra-aortic balloon pump , periop $\mathrm{MI}=$ perioperative myocardial infarction 


\section{Multivariate analyses}

All statistically significant preoperative risk factors identified with univariate regression analyses were entered into a multivariate logistic regression analysis. Results of these analyses are shown in Table 3.

Independent preoperative risk factors were: advanced age, diabetes, PVD, emergency operation, previous cardiac surgery, lower $\mathrm{Hb}$ level, higher CRP level and lower preoperative $\mathrm{CrCl}$. Peri- and postoperative risk factors were added to the multivariate model when identified to be significant using the univariate logistic regression analyses. The following factors were identified as independent risk factors (table 4): advanced age, diabetes, COPD, PVD, emergency operations, previous cardiac surgery, lower preoperative $\mathrm{Hb}$ level, higher preoperative CRP level, perioperative myocardial infarction, re-exploration for any cause and the number of RBC unit transfusions.

Table 3. Multivariate analysis of preoperative risk factors

\begin{tabular}{|c|c|c|}
\hline & Odds ratio $(95 \% \mathrm{Cl})$ & $p$-value \\
\hline & \multicolumn{2}{|c|}{ Preoperative risk factors } \\
\hline Age* & $1.044(1.029-1.060)$ & $<0.0001$ \\
\hline Diabetes & $1.59(1.28-1.98)$ & $<0.0001$ \\
\hline $\mathrm{BMI}>35 \mathrm{~kg} \cdot \mathrm{m}^{-2}$ & $1.62(0.94-2.79)$ & 0.079 \\
\hline COPD & $1.28(0.99-2.79)$ & 0.056 \\
\hline Hypertension & $1.19(0.97-1.45)$ & 0.083 \\
\hline PVD & $1.33(1.03-1.74)$ & 0.029 \\
\hline Number of preop $\mathrm{MI}^{*}$ & $1.159(0.991-1.356)$ & 0.065 \\
\hline$E F<35 \%$ & $1.53(0.96-2.45)$ & 0.070 \\
\hline Emergency & $4.57(2.44-8.57)$ & $<0.0001$ \\
\hline Redo & $2.51(1.76-3.58)$ & $<0.0001$ \\
\hline Preop Hb $\left(\text { g. } . \mathrm{dl}^{-1}\right)^{*}$ & $0.858(0.799-0.921)$ & $<0.0001$ \\
\hline Preop CRP $\left(\mathrm{mg} . \mathrm{I}^{-1}\right)^{*}$ & $1.007(1.003-1.012)$ & 0.001 \\
\hline Preop $\mathrm{CrCl}$ ml.min $\min ^{-{ }^{*}}$ & $0.999(0.993-1.004)$ & $<0.0001$ \\
\hline
\end{tabular}

* entered as a continuous variable

$\mathrm{Cl}=$ conficence interval $\mathrm{BMI}=$ body mass index, $\mathrm{COPD}=$ chronic obstructive pulmonary disease, $\mathrm{PVD}=$ peripheral vascular disease, $\mathrm{EF}=$ left ventricular ejection fraction, Redo = previous cardiac surgery, $\mathrm{preop} \mathrm{Hb}=$ preoperative hemoglobin level, preop $\mathrm{CRP}=$ preoperative $\mathrm{C}$-reactive protein level, preop $\mathrm{CrCl}=$ preoperative creatinine clearance 
Table 4. Multivariate logistic regression analyses including peri- and postoperative risk factors

\begin{tabular}{lll}
\hline & Odds ratio $(95 \% \mathrm{Cl})$ & p-value \\
\hline Preoperative risk factors & & \\
Age* & $1.048(1.032-1.065)$ & $<0.0001$ \\
Diabetes & $1.70(1.36-2.13)$ & $<0.0001$ \\
BMI>35kg.m ${ }^{-2}$ & $1.60(0.92-2.79)$ & 0.095 \\
COPD & $1.36(1.04-1.78)$ & 0.024 \\
Hypertension & $1.22(0.99-1.50)$ & 0.059 \\
PVD & $1.35(1.03-1.78)$ & 0.028 \\
Number of preop MI* & $1.162(0.989-1.366)$ & 0.067 \\
EF<35\% & $1.53(0.94-2.51)$ & 0.086 \\
Emergency & $2.19(1.061-4.53)$ & 0.034 \\
Redo & $2.05(1.39-3.02)$ & $<0.0001$ \\
Preop Hb (g.dl $\left.{ }^{-1}\right)^{*}$ & $0.887(0.824-0.954)$ & 0.001 \\
Preop CRP (mg.l $^{-1}$ ( $^{*}$ & $1.008(1.003-1.012)$ & 0.001 \\
Preop CrCl ml.min ${ }^{*}$ & $1.002(0.996-1.008)$ & 0.499 \\
Peri- and postoperative risk factors & & \\
OPCAB & $1.04(0.70-1.57)$ & 0.817 \\
ECC-time* & $1.000(0.997-1.003)$ & 0.879 \\
IABP & $1.77(0.88-3.57)$ & 0.105 \\
Periop MI & $2.83(1.82-4.39)$ & $<0.0001$ \\
Re-exploration & $2.49(1.69-3.65)$ & $<0.0001$ \\
No of RBC units* & $1.152(1.107-1.199)$ & $<0.0001$ \\
\hline
\end{tabular}

* entered as a continuous variable

$\mathrm{BMI}=$ body mass index, $\mathrm{Cl}=$ confidence interval, $\mathrm{COPD}=$ chronic obstructive pulmonary disease, $\mathrm{ECC}$-time = duration of extra-corporeal circulation, $E F=$ ejection fraction, IABP = intra-aortic balloon pump support, $\mathrm{OPCAB}=$ off-pump coronary artery bypass grafting, $\mathrm{PVD}=$ peripheral vascular disease, preop $\mathrm{MI}=$ preoperative myocardial infarction, Redo = previous cardiac surgery, preop $\mathrm{Hb}=$ preoperative hemoglobin level, preop $\mathrm{CRP}=$ preoperative $\mathrm{C}$-reactive protein level, preop $\mathrm{CrCl}=$ preoperative creatinine clearance, periop $\mathrm{MI}$ $=$ perioperative myocardial infarction, $\mathrm{RBC}=$ red blood cells.

\section{Discussion}

In this retrospective single centre study of more than 10,000 patients, we found several independent risk factors for deterioration of renal function after CABG. Some of them are in agreement with previously reported findings whereas others are not. This might be explained by different definitions of deterioration of renal function.

\section{Definition of the study endpoint}

The need for dialysis $(14,20)$, a postoperative creatinine level of $>2.1 \mathrm{mg} / \mathrm{dl}$ (19) or a postoperative $\mathrm{CrCl}$ less than $50 \mathrm{ml} \cdot \mathrm{min}^{-1}$ (4) are examples of study endpoints commonly used. However, in patients with preoperative impaired renal function, only a small extra damage is needed to reach the study endpoint. Patients with preoperative normal renal function may experience severe damage of the kidneys before they reach 
the study endpoint. Consequently, in all of these studies the preoperative renal function, whether defined by the creatinine level or the creatinine clearance, has been identified as a risk factor for reaching the study endpoint. In studying renal impact factors, changes in renal function not reaching the previously described endpoints might be important as well.

Creatinine clearance calculated by the Cockroft-Gault formula has been described as a better indicator for renal function than serum creatinine level in patients undergoing CABG (21). Therefore we defined renal impairment as a $10 \%$ or more deterioration of the preoperative creatinine clearance. Thus, we were able to describe risk factors for minor changes in renal function. Even minor deterioration of renal function in patients with already impaired renal function might lead to clinical problems (18). The clinical significance of the $10 \%$ deterioration in renal function is possibly only obvious in patients with preoperative renal impairment. Furthermore, it seems reasonable to assume that the same risk factors may also play a role in more pronounced deterioration of renal function.

\section{Risk factors}

In agreement with others we found several independent preoperative risk factors: age used as a continuous variable $(4,15,19,20)$, diabetes $(15,20)$, COPD $(20)$, emergency operations (20) and re-exploration for any cause (4). Other independent risk factors, which to our knowledge have not been described, were PVD, previous cardiac surgery, the preoperative $\mathrm{Hb}$ and $\mathrm{CRP}$ level, perioperative myocardial infarction and the number of blood transfusions. Risk factors described by others that could not be confirmed in this study were left ventricular ejection fraction $(6,15)$, preoperative creatinine clearance $(4,6,15,19)$, preoperative angina class (19), BMI $<20 \mathrm{~kg} \cdot \mathrm{m}^{-2}(4)$, the need for $\operatorname{IABP}(4)$, duration of ECC (19), the number of grafts (6) and female sex (4). In contrast with other investigators (5-8), OPCAB was not superior to CABG in preserving renal function in our study. This is in agreement with the findings of others $(3,4,10)$. The use of aprotinin could have even exaggerated the negative effect of the ECC on postoperative renal function (11). As stated earlier, discrepancies in identified risk factors might at least partly be explained by different definitions of renal dysfunction. Already impaired renal function is mentioned in most studies $(4,6,15,19)$ as a risk factor for developing renal insufficiency after cardiac surgery. This seems logical when renal insufficiency is defined as the need for dialysis or a creatinine clearance of less than 50 $\mathrm{ml}^{\mathrm{min}} \mathrm{m}^{-1}$. In our study, using a $10 \%$ or more deterioration of the preoperative creatinine clearance as an endpoint, we could not identify the preoperative creatinine clearance as an independent risk factor. We also noticed an improvement in the mean value of creatinine clearance in comparison with the preoperative value. Only $10.4 \%$ of the whole patient population had postoperative deterioration of $\mathrm{CrCl}$. In the rest of the patients, $\mathrm{CrCl}$ either deteriorated with $<10 \%$ or even improved postoperatively. This 
can possibly explained by hemodilution that is usually observed in the perioperative period (9). Some of the risk factors that were identified in this study; e.g, diabetes and peripheral vascular disease, cannot be corrected preoperatively. These risk factors can be used for risk stratification and informing the patients. Others such as preoperative $\mathrm{Hb}$ and CRP level and the number of blood transfusions can be corrected. Further studies are needed to investigate whether measures to correct preoperative $\mathrm{Hb}$ and $\mathrm{CRP}$ level and avoidance of blood transfusions will lead to better preservation of renal function.

\section{Conclusions}

In this retrospective single centre study of more than 10,000 patients we could identify the following risk factors for a deterioration of $10 \%$ or more of the preoperative creatinine clearance: advanced age, diabetes, chronic obstructive pulmonary disease, peripheral vascular disease, emergency operation, previous cardiac surgery, low preoperative $\mathrm{Hb}$, high preoperative $\mathrm{CRP}$, perioperative myocardial infarction, re-exploration and the number of blood transfusions.

\section{Limitations of the study}

This study had a retrospective design. Some patients were lost to follow up and some data were unobtainable, making results less accurate. The use of introperative and postoperative medications that can affect the renal function such as diuretics and inotropic support was not registered.

\section{References}

1. Ascione R, Nason G, Al-Ruzzeh S, Ko C, Ciulli F, Angelini GD. Coronary revascularisation with or without cardiopulmonary bypass in patients with preoperative nondialysis-dependent renal insufficiency. Ann Thorac Surg. 2001; 72:2020-5.

2. Gerritsen WB, van Boven WJ, Driessen AH, Haas FJ, Aarts LP. Off-pump versus on-pump coronary artery bypass grafting: oxidative stress and renal function. Eur J Cardiothorac Surg. 2001; 20:923-9.

3. Gamoso MG, Phillips-Bute B, Landolfo KP, Newman MF, Stafford-Smith M. Off-pump versus on-pump coronary artery bypass surgery and postoperative renal dysfunction. Anesth Analg. 2000; 91:1080.

4. Asimakopoulos G, Karagounis AP, Valencia O, Alexander N, Howlader M, Sarsam MA, Chandrasekaran $V$. Renal function after cardiac surgery off- versus on-pump coronary artery bypass: analysis using the Cockroft-Gault formula for estimating creatinine clearance. Ann Thorac Surg. 2005; 79:2024-31.

5. Ascione R, Lloyd CT, Underwood MJ, Gomes WJ, Angelini GD. On-pump versus off-pump coronary revascularization: evaluation of renal function. Ann Thorac Surg 1999; 68:493-8.

6. Ogawa M, Yaku H, Doi K, Okano T, Yamada Y, Hayashida K, Fukumoto A. Does off-pump coronary artery bypass beneficially affect renal function? ANZ J Surg. 2005; 75:675-9. 
7. Sellke FW, DiMaio JM, Caplan LR, Ferguson TB, Gardner TJ, Hiratzka LF, Isselbacher EM, Lytle BW, Mack MJ, Murkin JM, Robbins RC; American Heart Association. Comparing on-pump and off-pump coronary artery bypass grafting: numerous studies but few conclusions: a scientific statement from the American Heart Association council on cardiovascular surgery and anesthesia in collaboration with the interdisciplinary working group on quality of care and outcomes research. Circulation. 2005; 111:2858-64.

8. Celik JB, Gormus N, Topal A, Okesli S, Solak H. Effect of off-pump and on-pump coronary artery bypass grafting on renal function. Ren Fail. 2005; 27:183-8.

9. Ascione R, Lloyd CT, Underwood MJ, Gomes WJ, Angelini GD. On-pump versus off-pump coronary revascularization: evaluation of renal function. Ann Thorac Surg. 1999;68(2):493-8.

10. Tang AT, Knott J, Nanson J, Hsu J, Haw MP, Ohri SK. A prospective randomized study to evaluate the renoprotective action of beating heart coronary surgery in low risk patients. Eur J Cardiothorac Surg. 2002; 22:118-23.

11. Mangano DT, Tudor IC, Dietzel C, for the Multicenter Study of perioperative Ischemia (McSPI) Research Froup and the Ischemia Research and Education Foundation. The risk associated with aprotinin in cardiac surgery. N Eng J Med. 2006; 354:353-65.

12. Shaw AD, Stafford-Smith M, White WD, Phillips-Bute B, Swaminathan M, Milano C, Welsby IJ, Aronson $S$, Mathew JP, Peterson ED, Newman MF. The effect of aprotinin on outcome after coronary-artery bypasses grafting. N Engl J Med. 2008; 358:784-93.

13. Lindvall G, Sartipy U, Ivert T, van der Linden J. Aprotinin is not associated with postoperative renal impairment after primary coronary surgery. Ann Thorac Surg. 2008; 86:13-9.

14. Raaykumar A, Ho KM, Cokis C, Slade N. The effect of aprotinin on risk of acute renal failure requiring dialysis after on-pump cardiac surgery. Anaesth Intensive Care 2008;36:374-8.

15. Weerasinghe A, Athanasiou T, Al-Ruzzeh S, Casula R, Tekkis PP, Amrani M, Punjabi P, Taylor K, Stanbridge $\mathrm{R}$, Glenville $\mathrm{B}$. Functional renal outcome in on-pump and off-pump coronary revascularization: a propensity-based analysis. Ann Thorac Surg 2005; 79:1577-83.

16. Cockroft DW, Gault MH. Prediction of creatinine clearance from serum creatinine. Nephron 1976; 16:31-41.

17. Levey AS, Bosch, JP, Lewis JB, Greene T, Rogers N, Roth DA. More accurate method to estimate glomerular filtration rate from serum creatinine: A new prediction equation. Ann Intern Med 1999; 130: 46170.

18. Brown JR, Cochran RP, MacKenzie TA, Furnary AO, Kunzelman KS, Ross CS, Langner CW, Charlesworth DC, Leavitt BJ, Dacey LJ, Helm RE, Braxton JH, Clough RA, Dunton RF, O'Connor GT. Long-term survival after cardiac surgery is predicted by estimated glomerular filtration rate. Ann Thorac Surg 2008;86:412.

19. Antunes PE, Prieto D, Ferrao de Oliviera J, Antunes MJ. Renal dysfunction after myocardial revascularization. Eur J Cardiothorac Surg. 2004 Apr;25(4):597-604.

20. Doddakula K, Al-Sarraf N, Gately K, Hughes A, Tolan M, Young V, McGovern E. Predictors of acute renal failure requiring renal replacement therapy post cardiac surgery in patients with preoperatively normal renal function. Interact Cardiovasc Thorac Surg. 2007;6(3):314-8.

21. Wang F, Dupuis JY, Nathan H, Williams K. An analysis of the association between preoperative renal dysfunction and outcome in cardiac surgery: estimated creatinine clearance or plasma creatinine level as measures of renal function. Chest. 2003;124(5):1852-62. 



\section{Chapter 5}

\section{Which method of estimating renal function is the best predictor of early and late mortality after coronary artery bypass surgery?}

Submitted

Authors

Albert H. M. van Straten ${ }^{1}$

Bart M. J. A. Koene ${ }^{1}$

Mohamed A. Soliman Hamad ${ }^{1}$

Elisabeth. J. Martens ${ }^{2}$

M. Erwin S.H. $\operatorname{Tan}^{1}$

Eric Berreklouw ${ }^{1}$

André A. J. van Zundert ${ }^{3}$

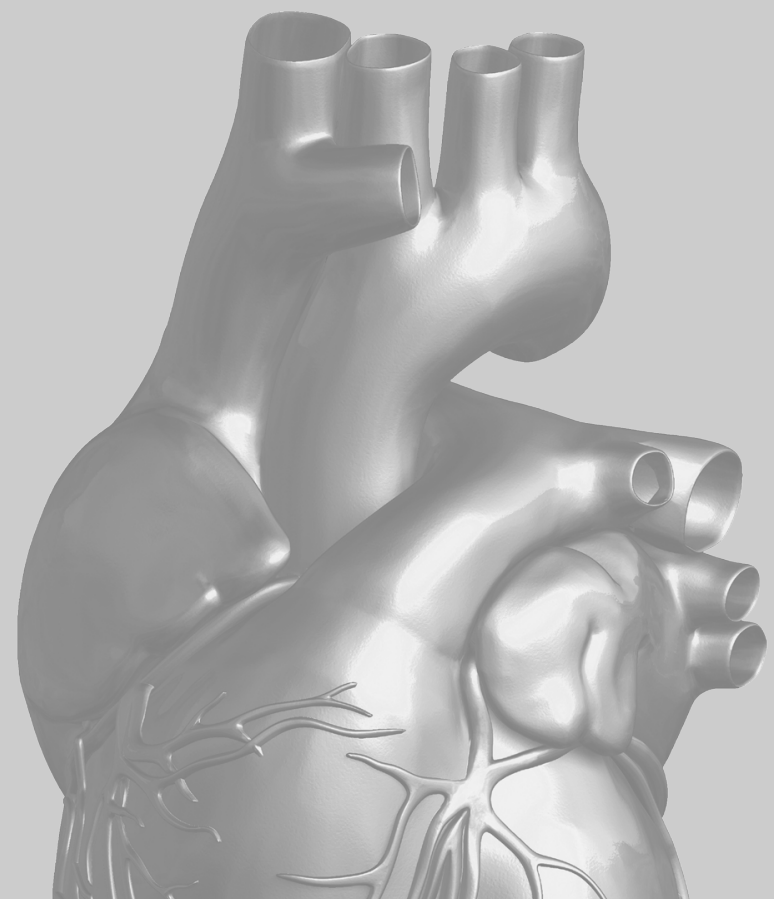

1 Department of Cardio-Thoracic Surgery, Catharina Hospital, Eindhoven, The Netherlands.

2 Department of Education and Research, Catharina Hospital, Eindhoven, The Netherlands \& Center of Research on Psychology in Somatic diseases, Department of Medical Psychology, Tilburg University, The Netherlands.

3 Department of Anesthesiology, Catharina Hospital - Brabant Medical School, Eindhoven, The Netherlands \& University Hospital Ghent, Ghent, Belgium. 


\begin{abstract}
Objectives

Renal insufficiency is associated with an increased risk of complications and mortality after coronary artery bypass graft surgery (CABG). Definitions of renal function in CABG patients vary in the literature.

\section{Methods}

We analyzed preoperative and postoperative renal function data from all patients undergoing isolated CABG from January 1998 until December 2007. Preoperative and postoperative renal function was estimated using serum creatinine ( $\mathrm{SeCr}$ ) levels, creatinine clearance $(\mathrm{CrCl})$ determined by the Cockroft-Gault formula and the glomerular filtration rate (e-GFR) estimated by the Modification of Diet in Renal Disease (MDRD) formula. Receivers Operator Characteristics (ROC) curves and area under the ROC curves were calculated. The relationship between the renal function parameters and mortality was determined.
\end{abstract}

\title{
Results
}

In 9,987 patients, $\mathrm{CrCl}$ had the best discriminatory power to predict early as well as late mortality, followed by e-GFR and finally SeCr. Parameters for early mortality are closer to 1 than those of the postoperative parameters. The relationship between renal function and mortality is non-linear.

\section{Conclusion}

Renal function determined by the Cockroft-Gault formula is the best predictor of early and late mortality after CABG. The relationship between renal function and mortality is non-linear. Any cut-off point used in a risk scoring system will be inaccurate. Renal function as a variable in risk scoring system such as the EuroSCORE needs to be reconsidered. 


\section{Introduction}

Renal insufficiency is associated with an increased risk of complications and mortality after coronary artery bypass grafting (CABG) (1-3). Most studies assessed the relationship between renal insufficiency and early mortality $(2,3)$; only a few studies described the association between renal insufficiency and late mortality after CABG $(1,4)$. The gold standard to determine renal function is the measurement of the glomerular filtration rate, represented by the clearance of an exogenous inert substance such as inulin. This is a cumbersome and time-consuming way to determine GFR and hence some more practical formulas have been developed to estimate the GFR. The CockcroftGault formula is used to estimate the creatinine clearance $(\mathrm{CrCl})$ and more recently the Modification of Diet in Renal Disease (MDRD) has been introduced to estimate the glomular filtration rate (e-GFR). Definitions of impairment of renal function after CABG vary in the literature. Serum creatinine levels $(\mathrm{SeCr})(4,8), \mathrm{CrCl}(6,8,9)$ and e-GFR $(6-8)$ were used, describing renal function as a risk factor for mortality after CABG. We analyzed preoperative and postoperative renal function data from all patients undergoing isolated CABG in our hospital from 1998 until 2007, using three different definitions of renal function ( $\mathrm{SeCr}, \mathrm{CrCl}$ and $\mathrm{e}-\mathrm{GFR}$ ) in order to investigate the relationship between these parameters and early and late mortality and to evaluate their predictive value.

\section{Patients and Methods}

\section{Patients}

This study retrospectively analyzed the data of all patients undergoing isolated CABG or off pump CABG (OPCAB) surgery in a single center (Catharina Hospital in Eindhoven the Netherlands) between January 1998 and December 2007. Clinical data, including demographics and renal function parameters, were prospectively collected in a database. The study was approved by the local Medical-Ethical Review Committee.

\section{Operative technique}

In CABG surgery, all patients received short-acting anesthetic drugs to facilitate early extubation. Normothermic extracorporeal circulation was performed using nonpulsatile flow. Cold crystalloid cardioplegia (St Thomas solution) or warm blood cardioplegia was used to induce and maintain cardioplegic cardiac arrest, according to the surgeon's preference. All patients undergoing CABG received low dose aprotinin (2 million Kallikrein Inactivating Unit) during extracorporeal circulation, administered in the prime solution according to the hospital protocol. The anesthetic management in OPCAB surgery was the same as in CABG surgery, but aprotinin was omitted. 


\section{Estimation of renal function}

Renal function was determined by $\mathrm{SeCr}, \mathrm{CrCl}$ (using the Cockroft-Gault formula (10), which is different for men [(140-age) $x$ weight/(serum $\mathrm{Cr} \times 72)]$ and women: [(140-age) $x$ weight/(serum $\mathrm{Cr} \times$ 72)) $\times$ 0.85], and estimated glomerular filtration rate (using the MDRD formula (16): e-GFR $=186 \times[\text { serum creatinine }]^{-1.154} \times[\text { age }]^{-0.203} \times[0.742$ for women] x [1.212 for black people]).

Calculations were based on the most recent preoperative $\mathrm{SeCr}$ and the largest value of $\mathrm{SeCr}$ within the first week postoperatively or if sooner before discharge.

\section{Follow-Up}

Follow-up data concerning mortality was obtained from the databases of health insurance companies. The data of $9 \%$ of the total patient group could initially not be retrieved from these databases. We therefore contacted the general practitioners to get information about mortality data of these patients or if necessary, the city-authorities of the cities in which the patients lived at the time of the operation. Early mortality was defined as any cause mortality $\leq 30$ days postoperatively, while late mortality was defined as any cause mortality beyond 30 days.

\section{Statistical analyses}

Univariate logistic regression analyses were performed to investigate the impact of biomedical variables on early mortality. If significant at $p<0.05$, the variables were included into the multivariable logistic regression analyses together with the renal function parameters. For each renal function parameter a separate multivariate regression analysis was performed. For late mortality univariate and multivariate Cox regression analyses were performed. Hazard ratios (HR) with 95 percent confidence interval $(\mathrm{Cl})$ with $\mathrm{p}$-values are reported. A $\mathrm{p}$-value $<0.05$ was used for all tests to indicate statistical significance. To compare the discriminatory power of all renal function parameters Receiver Operating Characteristics Curves (ROC) and the area under the curve (AUC) were calculated. Logistic regression analyses were used to calculate the predicted probabilities (Hazard Ratio) of $\mathrm{SeCr}$, eGFR and $\mathrm{CrCl}$ levels. All statistical analyses were performed using SPPS version 15.0 (SPSS Inc, Chicago, IL).

\section{Results}

Between January 1998 and December 2007, a total of 10626 patients underwent isolated CABG or OPCAB surgery. Preoperative SeCr was missing in 267 patients (due to emergency operation) and postoperative SeCr was missing in 102 patients due to mortality before renal function could be determined. In 433 patients, we were not able to calculate the $\mathrm{CrCl}$ or e-GFR due to missing data. We excluded 122 patients were lost to follow-up and 24 patients who were on hemodialysis leaving 9987 patients with com- 
plete data included in this study. Patients' preoperative and perioperative demographic and clinical characteristics are presented in Table 1.

Table 1. Preoperative and perioperative demographic and clinical characteristics

\begin{tabular}{ll}
\hline Variables & incidence \\
\hline Male gender & $7698(77.1)$ \\
Age & $64.6 \pm 9.6$ \\
Angina class & $2.7 \pm 0.9$ \\
Hypertension & $4161(41.7)$ \\
Diabetes & $2098(21.0)$ \\
BMI>35 kg.m ${ }^{-2}$ & $233(2.3)$ \\
COPD & $1242(12.4)$ \\
PVD & $1148(11.5)$ \\
EF <35\% & $326(3.3)$ \\
Emergency & $363(3.6)$ \\
Preop Hb & $13.9 \pm 1.3$ \\
No of grafts & $3.4 \pm 1.1$ \\
Use of IMA & $8858(88.7)$ \\
No RBC transfusions & $1.0 \pm 2.2$ \\
Re-exploration & $531(5.3)$ \\
Periop MI & $282(2.8)$ \\
Early mortality & $198(2.0)$ \\
Late mortality & $1111(11.1)$ \\
\hline
\end{tabular}

Results are expressed as numbers (percentage) or mean \pm standard deviation

$\mathrm{BMI}=$ body mass index; $\mathrm{COPD}=$ chronic obstructive pulmonary disease; $\mathrm{CrCl}<60$ = preoperative creatinine clearance less than $60 \mathrm{ml} / \mathrm{min}$; $\mathrm{EF}=$ estimated left ventricular ejection fraction; IABP = need for perioperative intra aortic balloon pump support; IMA = internam mammary artery; periop $\mathrm{MI}$ = perioperative myocardial infarction; PVD = peripheral vascular disease; $\mathrm{RBC}=$ red blood cell

Renal function parameters are shown in Table 2.

Risk factors for early mortality which were identified using univariate analyses and were entered into the multivariate analysis were: age, diabetes, chronic obstructive pulmonary disease (COPD), left ventricular ejection fraction less than 35 percent (EF $<35 \%$ ), the number of transfused Red Blood Cells (RBCs) and perioperative myocardial infarction (table 3). 
Table 2. Renal function parameters

\begin{tabular}{ll}
\hline Parameter & value \\
\hline Preoperative $\mathrm{SeCr}$ & $101 \pm 27$ \\
Postoperative $\mathrm{SeCr}$ & $99.9 \pm 44.6$ \\
Preoperative $\mathrm{CrCl}$ & $74.5 \pm 24.4$ \\
Postoperative $\mathrm{CrCl}$ & $79.4 \pm 28.3$ \\
Preoperative e-GFR & $67.4 \pm 16.4$ \\
Postoperative e-GFR & $72.6 \pm 21.2$ \\
\hline
\end{tabular}

Values are expressed as mean \pm standard deviation. $\mathrm{SeCr}=$ serum creatinine level; $\mathrm{CrCl}=$ creatinine clearance; e-GFR = estimated glomerular filtration rate

Table 3 Multivariate logistic regression analyses for early mortality and Cox regression analyses for late mortality.

\begin{tabular}{lllll}
\hline & HR early mortality & p-value & HR late mortality & p-value \\
\hline Age & $1.087(1.062-1.113)$ & $<.0001$ & $1.082(1.073-1.091)$ & $<.0001$ \\
Female & $0.85(0.58-1.26)$ & .430 & $0.62(0.53-0.73)$ & $<.0001$ \\
Diabetes & $1.66(1.16-2.37)$ & .005 & $1.44(1.25-1.65)$ & $<.0001$ \\
Hypertension & & & $1.11(0.98-1.26)$ & .098 \\
COPD & $1.88(1.27-2.78)$ & .002 & $1.69(1.45-1.96)$ & $<.0001$ \\
PVD & $0.98(0.62-1.57)$ & .959 & $1.68(1.44-1.97)$ & $<.0001$ \\
EF<35\% & $4.77(2.88-7.88)$ & $<.0001$ & $2.29(1.80-2.92)$ & $<.0001$ \\
Preop Hb & $0.912(0.811-1.026)$ & .125 & $0.829(0.789-0.871)$ & $<.0001$ \\
Emergency & $1.76(0.82-3.73)$ & .141 & & .934 \\
No of grafts & & & $1.00(0.94-1.06)$ & .936 \\
Redo surgery & $1.34(0.78-2.29)$ & .281 & $1.262(1.015-1.570)$ & .036 \\
RBC transfusion & $1.220(1.160-1.284)$ & $<.0001$ & $1.01(0.98-1.04)$ & .369 \\
Re-expl & $1.70(0.99-2.90)$ & .051 & $1.36(1.03-1.79)$ & .027 \\
Periop MI & $4.62(2.81-7.61)$ & $<.0001$ & $1.73(1.26-2.38)$ & .001 \\
\hline
\end{tabular}

* Only significant factors in the univariate analysis were entered into the multivariate analysis $\mathrm{HR}=\mathrm{Hazard}$ Ratio; $\mathrm{COPD}=$ chronic obstructive pulmonary disease; $\mathrm{Hb}=$ hemoglobin level; peripheral vascular disease; $\mathrm{EF}$ = estimated left ventricular ejection fraction; periop $\mathrm{MI}=$ perioperative myocardial infarction

Those independent risk factors were added to the multivariate analyses together with the renal function parameters (table 4). The hazard ratios of the preoperative parameters for early mortality are closer to 1 than those of the postoperative parameters. Age, male gender, diabetes, COPD, peripheral vascular disease (PVD), EF<35\%, preoperative hemoglobin level, previous cardiac surgery, re-exploration and perioperative myocardial infarction were risk factors for late mortality as identified by Cox regression analyses. These factors were entered into the multivariate analyses. The results are shown in table 3. Subsequently the renal function parameters were added to the multivariate analyses together with the independent risk factors. The results of these analyses are shown in table 4. 
The hazard ratios for late mortality of the preoperative parameters are close to the hazard ratios of the postoperative parameters (range 0.984-1.005).

In figure 1 the ROC curves for the different renal function parameters as risk factors for early mortality are shown.

Table 4 Multivariate logistic regression analyses for early mortality and Cox regression analyses for late mortality

\begin{tabular}{lllll}
\hline & HR early mortality & p-value & HR late mortality & p-value \\
\hline Preop $\mathrm{SeCr}$ & $1.003(1.000-1.007)$ & .026 & $1.005(1.004-1.006)$ & $<.0001$ \\
Postop $\mathrm{SeCr}$ & $1.007(1.006-1.009)$ & $<.0001$ & $1.004(1.003-1.005)$ & $<.0001$ \\
Preop $\mathrm{CrCl}$ & $0.988(0.978-0.998)$ & .018 & $0.988(0.983-0.992)$ & $<.0001$ \\
Postop $\mathrm{CrCl}$ & $0.958(0.950-0.966)$ & $<.0001$ & $0.987(0.983-0.990)$ & $<.0001$ \\
Preop e-GFR & $0.989(0.979-0.999)$ & .026 & $0.984(0.979-0.988)$ & $<.0001$ \\
Postop e-GFR & $0.960(0.952-0.968)$ & $<.0001$ & $0.985(0.982-0.989$ & $<.0001$ \\
\hline
\end{tabular}

$\mathrm{SeCr}=$ serum creatinine level; $\mathrm{CrCl}=$ creatinine clearance; e-GFR = estimated glomerular filtration rate

The areas under the curve are presented in table 5. The postoperative level of $\mathrm{CrCl}$ and e-GFR has the best discriminatory power. For both preoperative and postoperative levels, $\mathrm{CrCl}$ showed the highest discriminatory power, followed by e-GFR and finally $\mathrm{SeCr}$. The postoperative level of $\mathrm{CrCl}$ and e-GFR has the best discriminatory power. For both preoperative and postoperative levels, $\mathrm{CrCl}$ showed the highest discriminatory power, followed by e-GFR and finally $\mathrm{SeCr}$.

Table 5 Area under the ROC curve for renal function parameters.

\begin{tabular}{lllll}
\hline & $\begin{array}{l}\text { Area } \\
\text { early mortality }\end{array}$ & Std error & $\begin{array}{l}\text { Area } \\
\text { late mortality }\end{array}$ & Std error \\
\hline Preop SeCr & .632 & .023 & .634 & .009 \\
Postop SeCr & .778 & .020 & .651 & .009 \\
Preop CrCl & .290 & .019 & .303 & .008 \\
Postop CrCl & .179 & .017 & .291 & .008 \\
Preop e-GFR & .336 & .021 & .342 & .009 \\
Postop e-GFR & .197 & .018 & .326 & .009 \\
\hline
\end{tabular}

$\mathrm{SeCr}=$ serum creatinine level; $\mathrm{CrCl}$ = creatinine clearance; e-GFR = estimated glomerular filtration rate

Figure 2 shows the ROC curves for the renal function parameters as risk factors for late mortality. The corresponding areas under the curves are shown in table 5 . For the three renal function parameters, the postoperative levels had a significantly better discriminatory power than the preoperative levels. Both preoperative and postoperative $\mathrm{CrCl}$ had a higher discriminatory power compared to e-GFR, which in turn was better than SeCr. 
Figure 3 shows the non linear relation between the preoperative and postoperative $\mathrm{CrCl}$ and e-GFR and predicted probability (Hazard Ratio).

\section{ROC Curve}

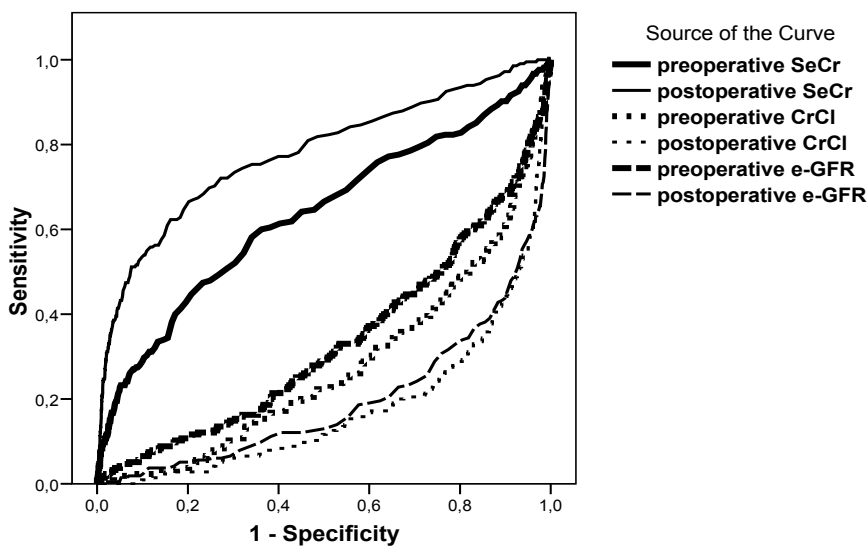

Figure 1 ROC curves of renal function parameters as risk factors for early mortality

ROC Curve

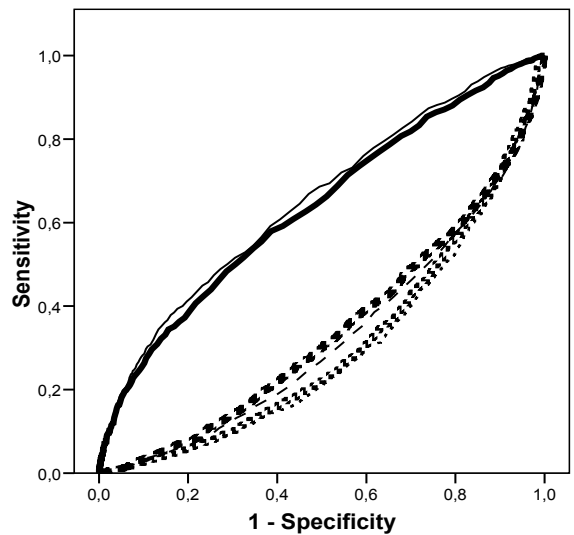

Source of the Curve

preoperative $\mathrm{SeCr}$

- postoperative $\mathrm{SeCr}$

- preoperative $\mathrm{CrCl}$

- postoperative $\mathrm{CrCl}$

- - postoperative e-GFR

Figure $\mathbf{2}$ ROC curves for renal function parameters as risk factors for late mortality. 


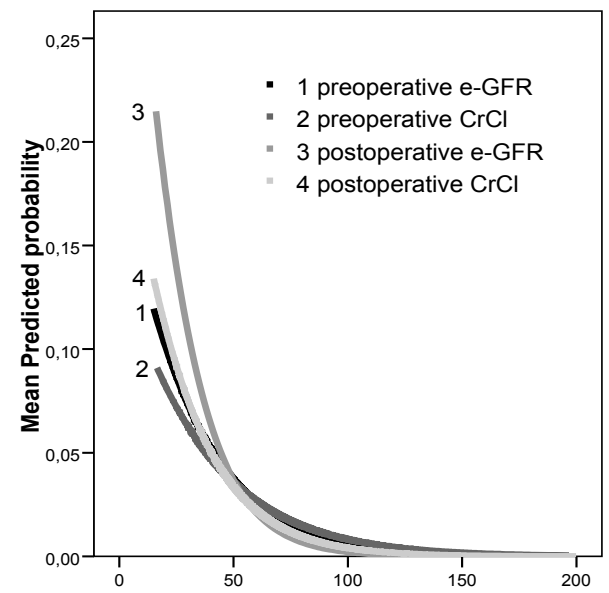

Figure 3. Mean predicted probability of the pre- and postoperative e-GFR and $\mathrm{CrCl}$

\section{Discussion}

In this study of 10,626 patients undergoing CABG in a single institution, renal dysfunction measured by $\mathrm{CrCl}$ showed the highest discriminatory power to predict early and late mortality. The predictive power of $\mathrm{CrCl}$ was greater than that of e-GFR and $\mathrm{SeCr}$. The postoperative levels of all three parameters had a higher discriminatory power than the preoperative ones. All three parameters were revealed as independent risk factors for early as well as late mortality confirming the findings of others $(4,6,9,11)$.

This study confirms superiority of the Cockroft-Gault formula (as expressed by $\mathrm{CrCl}$ ) over the MDRD equation (as expressed in e-GFR) in terms of predictive power for in-hospital mortality, confirming the finding of Lin et al. (6). This may be explained by the fact the Cockcroft- Gault formula includes weight as a variable which indirectly reflects the $\mathrm{BMI}$ which is known to be an independent risk factor for early mortality after CABG (12). Other studies $(13,14)$ revealed that the MDRD equation tends to underestimate the actual GFR in patients with chronic kidney disease but normal serum Creatinine. This may explain why real function estimated by the MDRD equation is a less accurate predictor for early mortality when compared to renal function estimated by the Cockroft-Gault formula. In an earlier study (15) we have shown the value of preoperative creatinine clearance predicting early and late mortality after CABG.

For $\mathrm{SeCr}$, the $\mathrm{CrCl}$ as well as the e-GFR the postoperative renal function has a higher discriminatory power for predicting early mortality compared to the preoperative renal function. This seems logical because the postoperative renal function is the result of the preoperative renal function and the subsequent trauma of the operation $(16,17)$. This operative trauma may lead to deterioration of the renal function with 
subsequent higher early and late mortality. Furthermore, the hazard ratios for the postoperative levels were further away from the value "1" compared to the hazard ratios of the preoperative levels. This means that when the preoperative and postoperative renal function measurements are equally deteriorated, it is the postoperative value which strongly predicts the poor outcome. In other words the preoperative renal function is mostly a stable situation whereas the postoperative renal function is as stated above the result of the surgical trauma on top of the preoperative renal function. Therefore, the postoperative renal function is a better predictor for early mortality. On the other hand, postoperative renal function measurement is strongly dependent on the preoperative value. This association is also stronger with the estimated $\mathrm{Cr} C \mathrm{Cl}$ than with serum creatinine levels (18)

In patients who survive the operation, the postoperative renal function reflects a more or less stable situation. The hazard ratios for late mortality do not differ between preoperative and postoperative renal function parameters. Also the areas under the ROC curves of preoperative and postoperative parameters are almost the same. We also found that the Cockcroft-Gault formula is a better predictor for late mortality after CABG followed by the MDRD equation and than the SeCr.

We found a non-linear relationship between $\mathrm{CrCl}$ and e-GFR and the predicted probability (=hazard ratio), calculated with logistic regression analyses. Any arbitrary cut-off point in a risk scoring system will be inevitably inaccurate. Taking the non-linear predicted probability curves into consideration, classical cut of points for $\mathrm{CrCl}$ and eGFR of $30-59 \mathrm{~mL} / \mathrm{min}$ as moderate renal failure and $<30 \mathrm{~mL} / \mathrm{min}$ as severe renal failure do not seem accurate when used as a dichotomous variable in risk scoring systems. The cut-off point of serum creatinine $>200 \mu \mathrm{mol} / \mathrm{L}$ used in the European System for Cardiac Operative Risk Evaluation (EuroSCORE) $(19,20)$ will be inevitable inaccurate and needs to be reconsidered.

\section{Conclusions}

In patients undergoing isolated coronary artery bypass grafting, renal function estimated by the Cockroft-Gault formula has the best discriminatory power to predict early as well as late mortality followed by the Modification of Diet in Renal Disease (MDRD) formula and finally the serum creatinine level. The postoperative parameters were better predictors compared to the preoperative ones. The relationship between renal function and mortality is non-linear. Any cut-off point used in a risk scoring system will be inaccurate. Renal function as a variable in the EuroSCORE risk scoring system needs to be reconsidered. 


\section{References}

1. Brown JR, Cochran RP, MacKenzie TD, Furnary AP, Kunzelman KS, Ros CS, Dacey LJ, Helm RE, Braxton JH, Clough RA, Dunton RF, O'Connor GT; for the Northern New England Cardiovascular Disease Study Group. Long-term survival after cardiac surgery is predicted by estimated glomerular filtration rate. Ann Thorac Surg 2008;86:4-12.

2. Cooper WA, O'Brien SM, Thourani VH, Guyton RA, Bridges CR, Szczech LA, Petersen R, Peterson ED. Impact of renal dysunction on outcomes of coronary artery bypass surgery. Circulation. 2006; 113:1063-1070

3. Chertow GM, Levy EM, Hammermeister KE, Grover F, Daley J. Independent association between acute renal failure and mortality following cardiac surgery. Am J Med. 1998;104:343-48.

4. Holtzmann MJ, Hammar N, Ahnve S, Nordqvist T, Phersson K, Ivert T. Renal insufficiency and long-term mortality and incidence of myocardial infarction in patients undergoing coronary artery bypass grafting. European Heart Journal 2007; 28:865-71.

5. Brown JR, Cochran RP, Dacey L, Ross CS, Kunzelman KS, Dunton RF, Braxton JH, Charlesworth DC, Clough RA, Helm RE, Leavitt BJ, MacKenzie TA, O'Connor GT and for the Northern New England Cardiovascular Disease Study Group. Perioperative Increases in Serum Creatinine are predictive of increased 90-day mortality after coronary artery bypass graft surgery. Circulation. 2006; 114: I-409-13.

6. Ye Lin, Zhe Zheng, Yan Li, Xin Yuan, Jianfeng Hou, Shiju Zhang, Hongguang Fan, Yang Wang, Wie Li, Shengshou $\mathrm{Hu}$. Impact of renal dysfunction on long-term survival after isolated coronary artery bypass surgery. Ann Thorac Surg. 2009;87:1079-84.

7. Jin R, Grunkemeier GL, Brown JR, Furnary AP. Estimated glomular filtration rate and renal function. Ann Thorac Surg. 2008;86:1-3.

8. Levey AS, Coresh J, Balk E, Kausz AT, Levin A, Steffes MW, Hogg RJ, Perrone RD, Lau J, Eknoyan G; National Kidney Foundation. National Kidney Foundation practice guidelines for chronic kidney disease : evaluation, classification and stratification. Ann Intern Med 2003;139:137-47.

9. Zakeri R, Freemantle N, Barnett V, Lipkin GW, Bonser RS, Graham TR, Rooney SJ, Wilson IC, Cramb R, Keogh BE, Pagano D. Relation between mild renal dysfunction and outcomes after coronary artery bypass grafting. Circulation.2005; 112 [suppl]

10. Cockroft DW, Gault MH. Prediction of creatinine clearance from serum creatinine. Nephron 1976; 16:31-41.

11. Levey AS, Bosch, JP, Lewis JB, Greene T, Rogers N, Roth DA. More accurate method to estimate glomerular filtration rate from serum creatinine: A new prediction equation. Ann Intern Med 1999; 130: 46170.

12. Reeves $\mathrm{BC}$, Ascione R, Chamberlain MH, Angelini GD. Effect of body mass index on early outcomes in patients undergoing coronary artery bypass surgery. J Am Coll Cardiol 2003; 20:668-76.

13. Bostom AG, Kronenberg R, Ritz E. Predictive performance of renal function equations for patients with chronic kidney disease and normal serum creatinine levels. J Am Soc Nephrol. 2002;13:2140-4

14. Rule AD, Larson TS, Bergstrahl EJ, Slezak JM, Jacobsen SJ, Cosio FG. Using serum creatinine to estimate glomerular filtration rate: accuracy in good health and in chronic kidney disease. Ann Intern Med 2004;141:929-37.

15. van Straten AH, Soliman Hamad MA, van Zundert AA, Martens EJ, Schönberger JP, de Wolf AM. Preoperative renal function as a predictor of survival after coronary artery bypass grafting: Comparison with a matched general population. doi:10.1016/j.jtcvs.2009.05.026 . [Epub ahead of print]

16. Provenchere S, Plantefeve G, Hufnagel G, Vicaut E, de Vaumas C, Lecharny JB, Depoix JP, , Vrtovsnik F, Desmonts JM, Philip I. Renal dysfunction after cardiac surgery with normothermic cardiopulmonary bypass: Incidence, risk factors and effect on clinical outcome. Anesth Analg. 2003;96:1258-1264. 
17. Brown JR, Cochran RP, Leavitt BJ, Dacey LJ, Ross CS, MacKenzie TA, Kunzelman KS, Kramer RS, Hernandez F Jr, Helm RE, Westbrook BM, Dunton RF, Malenka DJ, O'Connor GT; Northern New England Cardiovascular Disease Study Group. Multivariable prediction of renal insufficiency developing after cardiac surgery. Circulation. 2007; 116(11 Suppl):I139-43.

18. Noyez L, Plesiewicz I, Verheugt FW. Estimated creatinine clearance instead of plasma creatinine level as prognostic test for postoperative renal function in patients undergoing coronary artery bypass surgery. Eur J Cardiothorac Surg. 2006;29(4):461-5.

19. Dourado R, Queiroz e Melo J, Abecasis J, Ferreira A, Barata JD, Rebocho MJ, Abecasis M, Ferreira M, Neves JP. Serum creatinine values underestimate surgical risk. Rev Port Cardiol. 2009;28(3):269-78.

20. Roques F, Nashef SA, Michel P, Gauducheau E, de Vincentiis C, Baudet E, Cortina J, David M, Faichney A, Gabrielle F, Gams E, Harjula A, Jones MT, Pintor PP, Salamon R, Thulin L. . Risk factors and outcome in European cardiac surgery: analysis of the EuroSCORE multinational database of 19030 patients. Eur J Cardiothorac Surg. 1999 Jun;15(6):816-22; discussion 822-3. 


\section{Chapter 6}

\section{Transfusion of Red Blood Cells: The impact on short-term and long-term survival after coronary artery bypass grafting, a ten year follow-up.}

Interact Cardiovasc Thorac Surg.2010;10:37-42

Authors

Albert H. M. van Straten ${ }^{1}$

Margreet W. A. Bekker ${ }^{1}$

Mohamed A. Soliman Hamad ${ }^{1}$

André A. J. van Zundert ${ }^{2}$

Elisabeth J. Martens ${ }^{3}$

Jacques P. A. M. Schönberger ${ }^{1}$

Andre M. de Wolf ${ }^{4}$.

1 Department of Cardio-Thoracic Surgery, Catharina Hospital, Eindhoven, The Netherlands.

2 Department of Anesthesiology, Catharina Hospital - Brabant Medical School, Eindhoven, The Netherlands \& University Hospital Ghent, Ghent, Belgium.

3 Department of Education and Research, Catharina Hospital, Eindhoven, The Netherlands \& Center of Research on Psychology in Somatic diseases, Department of Medical Psychology, Tilburg University, The Netherlands.

4 Department of Anesthesiology, The Feinberg School of Medicine, Northwestern University, Chicago, Illinois, USA 


\begin{abstract}
Background

Transfusion of red blood cells and other blood products in patients undergoing coronary artery bypass grafting is associated with increased mortality and morbidity.

\section{Methods}

We retrospectively analyzed data of patients who underwent an isolated coronary bypass graft operation between January 1998 and December 2007.
\end{abstract}

\title{
Results
}

Mean follow-up was $1,696 \pm 1,026$ days, with exclusion of 122 patients lost to followup and 80 patients who received more than 10 units of red blood cells (RBC). Of the remaining patients, 8,001 (76.7\%) received no RBC, 1621 (15.2\%) received 1 to 2 units of RBC, $593(5.7 \%)$ received 3 to 5 units and $220(2.1 \%)$ received 6 to10 units. The number of transfused red blood cells was a predictor for early but not for late mortality. When compared to expected survival, survival of patients not receiving any blood product was better, while survival of patients receiving more than 3 units of red blood cells was worse.

\section{Conclusions}

Transfusion of red blood cells is an independent, dose-dependent risk factor for early mortality after revascularization. Compared to expected survival, receiving no red blood cells improves patient long-term survival, whereas receiving three or more units of red blood cells significantly decreases patient survival. 


\section{Introduction}

Transfusion of red blood cells (RBC) in patients undergoing coronary artery bypass grafting (CABG) is associated with increased mortality and morbidity (1-4). Transfusion of RBC as a risk factor for early mortality has been well established whereas the effect of RBC transfusion on late mortality has been less well described.

This study analyzes the effect of peri-operative transfusion of RBCs on short- and long-term mortality after CABG in our centre and to compare survival rates with expected survival based on the general Dutch population.

\section{Methods}

The study was performed after permission of the local Medical Ethics Committee. We studied the data of all patients undergoing isolated CABG in our center between January 1998 and December 2007. Clinical data, were prospectively collected in our database. Patients were classified into 4 groups stratified by number of units of transfused RBC: Group 1 did not receive any unit of RBC; $n=6,828(65.5 \%)$, Group 2 received 1 to 2 units; $n=2,371(22.7 \%)$, Group 3 received 3 to 5 units; $n=900$ (8.6\%) and Group 4 received 6 to10 units; $n=326$ (3.1\%). Patients with more than ten units of transfused RBC were excluded from further analyses $(n=69)$.

Normothermic extra-corporeal circulation (ECC) was performed using nonpulsatile flow. Cold crystalloid cardioplegia ("St Thomas" solution) or warm blood cardioplegia was used to induce and maintain cardioplegic arrest, according to the surgeon's preference. All patients undergoing CABG with the use of extra-corporeal circulation, received a low dose aprotinin ( 2 million kallikrein inactivating units) during extra-corporeal circulation.

Follow-up data concerning mortality of patients were gathered using databases of health insurance companies, general practitioners and local authorities. Early mortality was defined as any cause mortality $\leq 30$ days postoperatively, while late mortality was defined as any cause mortality $>30$ days.

To calculate the survival rate of general population cohorts that were matched for age, gender with patient groups, data were used from the database of the Dutch Central Bureau for Statistics (CBS). We consider the survival of the matched population cohort the expected survival of the patient group.

\section{Statistical analyses}

Discrete variables were compared with the Chi-square test and are presented as numbers and percentages. Continuous variables were compared with the Student t-test and analysis of variance (ANOVA). Univariate and multivariate logistic and Cox propor- 
tional hazard regression analyses were performed to investigate the impact of perioperative transfusion of blood products on early and late mortality at follow-up. Univariate analyses were used to test for the potentially confounding effect of biomedical and demographic factors on outcome. The cumulative long-term survival was estimated according to the Kaplan-Meier method, comparing differences between groups with the log-rank test. One, five and ten-year survival were compared using the time table method and the Wilcoxon test. A p-value $<0.05$ was used for all tests to indicate statistical significance. All statistical analyses were performed using SPPS version 15.0 (SPSS Inc, Chicago, IL).

\section{Results}

During a ten-year period (January 1998 till December 2007) 10626 patients underwent CABG. After excluding patients who were lost to follow-up $(n=122)$ and patients who received more than 10 units of $\mathrm{RBC}(\mathrm{n}=80), 10425$ patients were analyzed. The total number of transfused units of RBC was 10 006; the total number of transfused units of FFP was 2 095; and the total number of transfused units of platelets was 375 . The minimum follow-up period for surviving patients was 60 days. Mean follow-up was $1691 \pm 1058$ days (range: 0 (operative death)-3708 days). Median was 1,629 days.

Baseline characteristics stratified by the number of received units of RBC are shown in table 1.

Patients in group 1 were more often younger males, had less often chronic obstructive pulmonary disease (COPD) and peripheral vascular disease (PVD), had a better left ventricular function (ejection fraction (EF) $>35 \%$ ), renal function and a higher preoperative hemoglobin level and a shorter duration of extra-corporeal circulation (ECC-time). Emergency operations and previous cardiac surgery were seen more frequently in groups 3 and 4 . Patients receiving more RBC received also more fresh frozen plasma (FFP) and platelets.

The incidence of postoperative complications stratified by the number of received units of RBC is shown in table 2. 
Table 1: Baseline characteristics stratified by received units of red blood cells

\begin{tabular}{llllll}
\hline & O RBC & $1-2 \mathrm{RBC}$ & $3-5 \mathrm{RBC}$ & $6-10 \mathrm{RBC}$ & p-value \\
& $\mathrm{N}=6828$ & $\mathrm{~N}=2371$ & $\mathrm{~N}=900$ & $\mathrm{~N}=326$ & \\
\hline Age & $63.2 \pm 9.4$ & $67.1 \pm 9.2$ & $67.7 \pm 9.5$ & $67.4 \pm 9.3$ & $<.0001$ \\
Male & $5934(86.9)$ & $1387(58.5)$ & $485(53.9)$ & $219(67.2)$ & $<.0001$ \\
Diabetes & $1370(20.1)$ & $554(23.4)$ & $207(23.0)$ & $65(19.9$ & .003 \\
Hypertension & $2799(41.0)$ & $1016(42.9)$ & $394(43.8)$ & $142(43.6)$ & .191 \\
COPD & $830(12.2)$ & $291(12.3)$ & $137(15.2)$ & $51(15.6)$ & .020 \\
PVD & $723(10.6)$ & $324(13.7)$ & $111(12.3)$ & $51(15.6)$ & $<.0001$ \\
EF <35\% & $188(2.8)$ & $97(4.2)$ & $43(5.0)$ & $20(6.8)$ & $<.0001$ \\
CrCl ml.min ${ }^{-1}$ & $79.2 \pm 25.5$ & $63.4 \pm 22.4$ & $60.2 \pm 24.1$ & $59.5 \pm 25.4$ & $<.0001$ \\
Preoperative Hb g.dl ${ }^{-1}$ & $14.3 \pm 1.1$ & $13.2 \pm 1.3$ & $12.8 \pm 1.5$ & $13.0 \pm 1.7$ & $<.0001$ \\
Emergency & $136(2.0)$ & $104(4.4)$ & $100(11.1)$ & $77(23.6)$ & $<.0001$ \\
Off-pump & $774(11.3)$ & $110(4.6)$ & $33(3.7)$ & $11(3.4)$ & $<.0001$ \\
Duration of ECC & $54.1 \pm 33.8$ & $61.9 \pm 30.1$ & $66.2 \pm 33.9$ & $74.0 \pm 43.1$ & $<.0001$ \\
Redo & $279(4.1)$ & $150(6.3)$ & $126(14.0)$ & $64(19.6)$ & $<.0001$ \\
Number of grafts & $3.4 \pm 1.1$ & $3.5 \pm 1.0$ & $3.3 \pm 1.1$ & $3.4 \pm 1.1$ & .002 \\
Number of FFP & $0.03 \pm 0.26$ & $0.19 \pm 0.68$ & $0.58 \pm 1.14$ & $2.47 \pm 2.32$ & $<.0001$ \\
Number of Platelets & $0.01 \pm 0.01$ & $0.02 \pm 0.02$ & $0.09 \pm 0.36$ & $0.45 \pm 0.82$ & $<.0001$ \\
\hline
\end{tabular}

Results as number(percentage) or mean \pm standard deviation. COPD = chronic obstructive pulmonary disease, $\mathrm{PVD}=$ peripheral vascular disease, $\mathrm{EF}=$ left ventricular ejection fraction, Preop $\mathrm{CrCl}=$ preoperative creatinine clearance, $\mathrm{Hb}=$ hemoglobin level, Redo = previous cardiac surgery, $\mathrm{ECC}=$ extra-corporeal circulation

Table 2: Postoperative complications stratified by received units of red blood cells

\begin{tabular}{llllll}
\hline Complication & $\begin{array}{l}\text { O RBC } \\
\mathrm{N}=6828\end{array}$ & $\begin{array}{l}1-2 \mathrm{RBC} \\
\mathrm{N}=2371\end{array}$ & $\begin{array}{l}3-5 \mathrm{RBC} \\
\mathrm{N}=900\end{array}$ & $\begin{array}{l}6-10 \mathrm{RBC} \\
\mathrm{N}=326\end{array}$ & $\mathrm{p}$-value \\
\hline $\begin{array}{l}\text { Renal failure } \\
\text { (need for dialysis) }\end{array}$ & $5(0.1)$ & $18(0.7)$ & $16(1.8)$ & $15(4.5)$ & $<.0001$ \\
CVA & & & & \\
Mediastinitis & $37(0.5)$ & $24(1.0)$ & $15(1.7)$ & $8(2.4)$ & $<.0001$ \\
IABP & $41(0.6)$ & $30(1.2)$ & $10(1.1)$ & $7(2.1)$ & $<.0001$ \\
Re-exploration & $43(0.6)$ & $46(1.9)$ & $70(7.8)$ & $55(16.9)$ & $<.0001$ \\
Periop MI & $97(1.4)$ & $105(4.4)$ & $159(17.7)$ & $166(50.9)$ & $<.0001$ \\
\hline
\end{tabular}

Data are expressed as number (percentage).

CVA = cerebrovascular accident, IABP = intra-aortic balloon pump support, Periop $\mathrm{MI}$ = perioperative myocardial infarction

Univariate logistic regression analyses revealed the numbers of units of RBC, FFP and platelets as continuous variables as risk factors for early mortality (table 3 ).

All risk factors that were identified with univariate logistic regression analyses were entered into a multivariate logistic regression model. The number of units of RBC as a continuous variable was an independent risk factor for early mortality. 
Table 3: Predictors of early mortality ( $\leq 30$ days post $C A B G$ ); Univariate and multivariate logistic regression analyses.

\begin{tabular}{|c|c|c|c|c|}
\hline & Univariate analyses & & Multivariate analysis & \\
\hline & Early mortality & & Early mortality & \\
\hline Risk factor & $\mathrm{HR}(95 \% \mathrm{Cl})$ & $p$-value & $\mathrm{HR}$ & p-value \\
\hline RBC & $1.308(1.267-1.351)$ & $<.0001$ & $1.214(1.126-1.308)$ & $<.0001$ \\
\hline FFP & $1.397(1.326-1.471)$ & $<.0001$ & $0.904(0.783-1.043)$ & .165 \\
\hline Platelets & $2.806(2.368-3.326)$ & $<.0001$ & $1.136(0.764-1.688)$ & .529 \\
\hline Age* & $1.082(1.065-1.099)$ & $<.0001$ & $1.060(1.036-1.085)$ & $<.0001$ \\
\hline Male gender & $0.77(0.58-1.02)$ & .068 & & \\
\hline COPD & $1.91(1.41-2.60)$ & $<.0001$ & $1.84(1.27-2.65)$ & .001 \\
\hline Diabetes & $1.48(1.12-1.96)$ & .005 & $1.59(1.14-2.23)$ & .006 \\
\hline $\mathrm{CrCl} \mathrm{ml.min}{ }^{-1^{*}}$ & $0.971(0.966-0.976)$ & $<.0001$ & $0.987(0.979-0.995)$ & .002 \\
\hline$E F<35 \%$ & $6.02(4.17-8.68)$ & $<.0001$ & $4.56(2.86-7.26)$ & $<.0001$ \\
\hline Preop $\mathrm{Hb}^{*}$ & $0.696(0.640-0.758)$ & $<.0001$ & $0.997(0.894-1.113)$ & .962 \\
\hline PVD & $1.60(1.16-2.23)$ & .005 & $1.02(0.67-1.55)$ & .906 \\
\hline Redo & $4.26(3.12-5.84)$ & $<.0001$ & $1.32(0.81-2.14)$ & .259 \\
\hline Emergency & $6.78(4.94-9.31)$ & $<.0001$ & $1.20(0.61-2.38)$ & .590 \\
\hline Yr of operation & $0.947(0.906-0.989)$ & .014 & $1.006(0.951-1.063)$ & .840 \\
\hline ECC-time* & $1.011(1.007-1.014$ & $<.0001$ & $1.003(0.999-1.006)$ & .098 \\
\hline Periop MI & $5.78(3.97-8.43)$ & $<.0001$ & $3.87(2.43-6.18)$ & $<.0001$ \\
\hline Re-exploration & $5.78(4.27-7.83)$ & $<.0001$ & $2.55(1.63-3.98)$ & .001 \\
\hline IABP & $14.68(10.51-20.50)$ & $<.0001$ & $4.76(2.81-8.05)$ & $<.0001$ \\
\hline Hypertension & $0.94(0.73-1.21)$ & .656 & & \\
\hline Off pump & $0.68(0.41-1.17)$ & .144 & & \\
\hline No grafts* & $0.912(0.817-1.018)$ & 0.302 & & \\
\hline
\end{tabular}

*entered as a continuous variable. HR = Hazard ratio; COPD = chronic obstructive pulmonary disease, Preop $\mathrm{CrCl}=$ preoperative creatinine clearance, $\mathrm{EF}=$ left ventricular ejection fraction, $\mathrm{Hb}=$ hemoglobin level, $\mathrm{PVD}=$ peripheral vascular disease, Redo = previous cardiac surgery, ECC = extra-corporeal circulation, Periop $\mathrm{MI}=$ perioperative myocardial infarction, IABP = intra-aortic balloon pump support

Results of Cox regression analyses regarding risk factors of late mortality are shown in table 4. Univariate analyses revealed the numbers of units of transfused RBC, FFP and platelets as risk factors for late mortality.

All risk factors that were identified with univariate analyses were entered into the multivariate Cox regression model. The number of units of transfused RBC, FFP and platelets were not identified as predictors of late mortality. 
Table 4: Predictors of late mortality ( $>30$ days post $C A B G$ ); Univariate and multivariate Cox regression analyses

\begin{tabular}{|c|c|c|c|c|}
\hline & $\begin{array}{l}\text { Univariate analyses } \\
\text { Late mortality }\end{array}$ & & $\begin{array}{l}\text { Multivariate analysis } \\
\text { Late mortality }\end{array}$ & \\
\hline Risk factor & $\mathrm{HR}(95 \% \mathrm{Cl})$ & $p$-value & $\mathrm{HR}$ & p-value \\
\hline RBC & $1.162(1.128-1.196)$ & $<0.0001$ & $1.035(0.994-1.007)$ & .091 \\
\hline FFP & $1.149(1.076-1.227)$ & $<0.0001$ & $1.008(0.928-1.093)$ & .856 \\
\hline Platelets & $1.333(1.125-1.732)$ & 0.032 & $1.197(0.932-1.537)$ & .159 \\
\hline Age* & $1.094(1.085-1.103)$ & $<0.0001$ & $1.064(1.055-1.073)$ & $<.0001$ \\
\hline Male gender & $0.83(0.72-0.96)$ & 0.013 & $1.54(1.33-1.77)$ & $<.0001$ \\
\hline COPD & $1.80(1.54-2.10)$ & $<0.0001$ & $1.70(1.49-1.95)$ & $<.0001$ \\
\hline Diabetes & $1.74(1.52-2.00)$ & $<0.0001$ & $1.50(1.32-1.71)$ & $<.0001$ \\
\hline $\mathrm{CrCl} \mathrm{ml.min}{ }^{-1^{*}}$ & $0.975(0.972-0.977)$ & $<0.0001$ & $0.989(0.986-0.993)$ & $<.0001$ \\
\hline$E F<35 \%$ & $2.59(2.03-3.31)$ & $<0.0001$ & $2.51(2.03-3.09)$ & $<.0001$ \\
\hline Preop $\mathrm{Hb}^{*}$ & $0.612(0.573-0.655)$ & $<0.0001$ & $0.864(0.825-0.904)$ & $<.0001$ \\
\hline PVD & $2.30(1.97-2.69)$ & $<0.0001$ & $1.54(1.34-1.78)$ & .0001 \\
\hline Redo & $1.54(1.25-1.90)$ & $<0.0001$ & $1.16(0.94-1.42)$ & .148 \\
\hline Hypertension & $1.22(1.07-1.38)$ & 0.002 & $1.07(0.95-1.20)$ & .256 \\
\hline Yr of operation & $0.961(0.938-0.985)$ & .002 & $0.966(0.940-0.993)$ & .012 \\
\hline No of grafts* & $1.084(1.027-1.144)$ & 0.003 & $0.991(0.940-1.043)$ & .721 \\
\hline Periop MI & $1.81(1.33-2.47)$ & $<0.0001$ & $1.99(1.54-2.58)$ & $<.0001$ \\
\hline Re-exploration & $1.62(1.29-2.04)$ & $<0.0001$ & $1.52(1.19-1.93)$ & .001 \\
\hline IABP & $1.95(1.38-2.76)$ & $<0.0001$ & $1.94(1.46-2.59)$ & $<.0001$ \\
\hline Emergency & $1.25(0.93-1.67)$ & 0.128 & & \\
\hline Off pump & $0.76(0.58-1.00)$ & 0.053 & & \\
\hline
\end{tabular}

*entered as a continuous variable. $\mathrm{HR}=\mathrm{Hazard}$ ratio Preop $\mathrm{CrCl}=$ preoperative creatinine clearance, $\mathrm{COPD}=$ chronic obstructive pulmonary disease, $\mathrm{EF}<35$ = left ventricular ejection fraction less than $35 \%, \mathrm{Hb}=$ hemoglobin level, PVD = peripheral vascular disease, Redo = previous cardiac surgery, Periop $\mathrm{MI}=$ perioperative myocardial infarction. IABP = intra-aortic balloon pump support

In figure 1 and 2 the long-term and expected survival of the patients receiving 0 or 1-2 RBC and patients receiving 3-5 or 6-10 RBC are shown. Log Rank test showed significant differences between all patient groups. One- five and nine year survival rates are shown in table 5. Patients receiving 0 RBC had a better than expected five and nine year survival. No difference was found between the one, five and nine years survival rates of patients receiving 1-2 RBC and their expected survival rates, whereas one, five and nine years survival rates of patients receiving more than 2 RBC were worse than expected. 


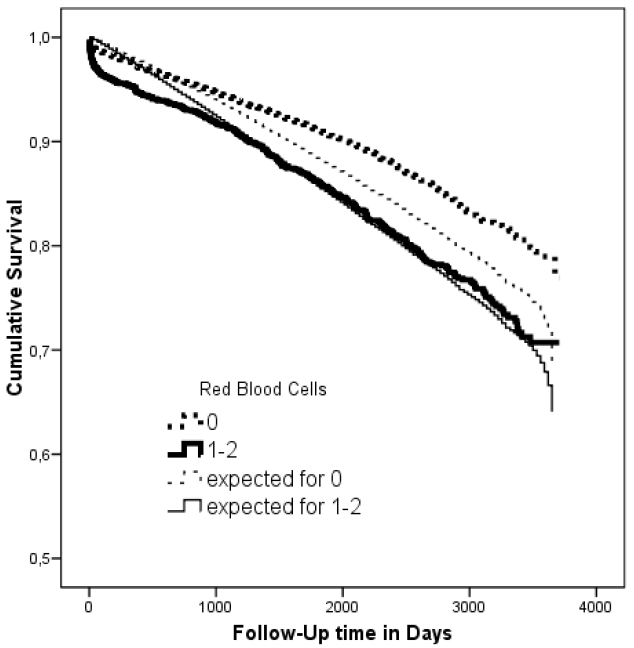

Figure 1: Kaplan -Meier survival curve stratified by units of transfused Red Blood Cells and the expected survival for patients receiving less than 3 RBC.

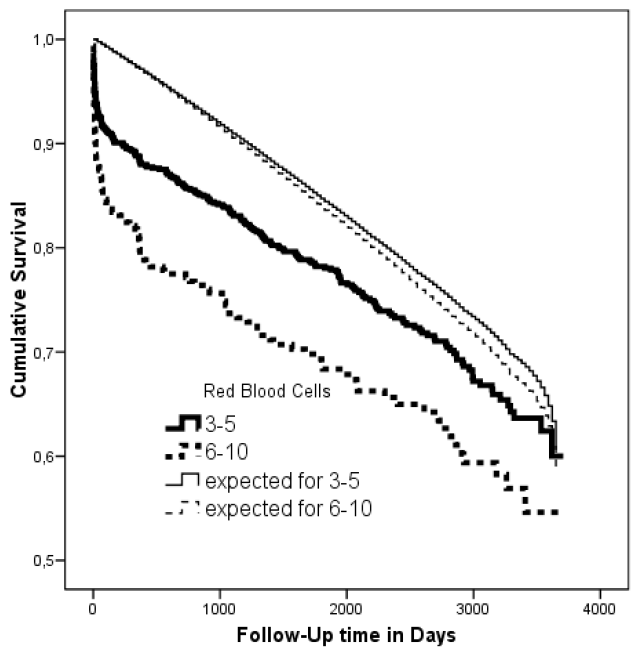

Figure 2: Kaplan -Meier survival curve stratified by units of transfused Red Blood Cells and the expected survival for patients receiving more than $2 \mathrm{RBC}$. 
Table 5: One- five and ten-years observed and expected survival

\begin{tabular}{llllll}
\hline & & 1-year & 5 -years & 9 -years & p-value \\
\hline 0 RBC & Observed & $95.9 \pm 0.3$ & $89.3 \pm 0.5$ & $79.0 \pm 1.2$ & $<.0001$ \\
& Expected & $95.8 \pm 0.1$ & $85.7 \pm 0.2$ & $72.7 \pm 0.7$ & \\
\multirow{3}{*}{$1-2$ RBC } & Patients at risk & 5659 & 2565 & 274 & \\
& Observed & $93.4 \pm 0.5$ & $83.3 \pm 0.9$ & $70.8 \pm 1.8$ & .363 \\
& Expected & $94.7 \pm 0.1$ & $82.5 \pm 0.2$ & $67.6 \pm 0.5$ & \\
\multirow{3}{*}{ 3-5 RBC } & Patients at risk & 2045 & 1125 & 157 & \\
& Observed & $85.8 \pm 1.2$ & $75.1 \pm 1.8$ & $61.2 \pm 2.8$ & \\
& Expected & $94.4 \pm 0.1$ & $81.3 \pm 0.2$ & $64.5 \pm 0.4$ & $<.0001$ \\
& Patients at risk & 741 & 435 & 63 & \\
& Ob-10 RBC & $77.2 \pm 2.4$ & $66.6 \pm 2.9$ & $54.7 \pm 4.3$ & $<.0001$ \\
& Observed & $94.2 \pm 0.1$ & $80.3 \pm 0.2$ & $62.5 \pm 0.4$ & \\
\hline
\end{tabular}

9 years because of small numbers at 10 years

Results as percentage cumulative survival \pm standard error at the time of the interval

Figure 3 shows the correlation between the number of transfused RBC units and the predicted mortality.

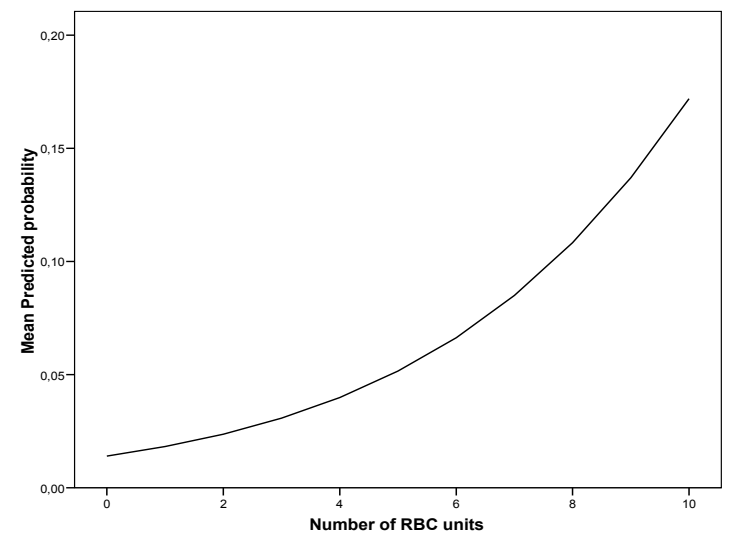

Figure 3. Correlation between the number of transfused RBC units and the predicted mortality

\section{Discussion}

This study revealed the number of transfused Red Blood Cells to be an independent predictor of early but not for late mortality after CABG. Compared to expected survival, we noted that in patients receiving three or more units of RBC survival was decreased significantly, whereas receiving no RBC improved patient survival. 
Blood products are transfused to increase hemoglobin and thereby improving tissue oxygenation and finally outcome $(1,3,5-8)$. However, several studies suggest that transfusion of blood products may be harmful by increasing the risk of post-operative infection, myocardial or cerebrovascular ischemia, renal failure, poorer functional recovery and death $(1-5,7,8)$. Transfusion of blood products may initiate a second inflammatory response by modification of the patient's systemic response and by directly introducing bioactive substances into the circulation, apart from the primary inflammatory response initiated by cardiopulmonary bypass $(2-4,6,8,9)$. Our study has shown that patients who received $\geq 3$ RBC units had a higher incidence of postoperative complications. This can explain the higher early mortality in these patients.

According to Koch and colleagues (2), patients who received blood products had a significantly reduced postoperative functional recovery at 6 months. Kuduvalli et al. as well as Murphy et al. described a higher mortality rate in the first 30 days after operation as well as through the first postoperative year in patients who received perioperative blood transfusions $(3,6)$. Engoren et al. found transfusion to be a risk factor for long-term (up to five years) mortality (7). Koch et al. showed a significantly reduced survival of transfused patients at six months, five and ten years (4). Our findings of reduced long-term survival in patients receiving perioperative $\mathrm{RBC}$ transfusions are in agreement with these investigations, though in our study the number of RBC transfusions was not identified as an independent predictor of late mortality. Therefore, reduced long-term survival in patients receiving more than two units of RBC might be explained by higher early mortality.

The incidence of re-exploration (in most cases for excessive bleeding) is much higher in patients receiving more RBCs. We tried to compensate for this possible confounding effect by entering re-exploration into the multivariate model together with the number of RBC. The threshold of the hemoglobin level for transfusion of RBC in our centre is $9 \mathrm{gr} / \mathrm{dL}$ unless postoperative ischemia is present. The threshold increases to $11 \mathrm{gr} / \mathrm{dL}$ in case of ischemia. This explains why the incidence of perioperative myocardial infarction is higher in patients receiving more RBC. In the present study, perioperative myocardial infarction was an independent predictor of early as well as late mortality. After adjustment for excessive bleeding and postoperative ischemia the number of transfused RBC is still an independent predictor of early mortality.

With regard to other baseline characteristics, the patient groups also appeared to be widely different. Well known risk factors for early as well as late mortality such as older age, COPD, diabetes, low $\mathrm{CrCl}, \mathrm{EF}<35 \%$, and others were more frequently found in patients receiving more $\mathrm{RBC}$ transfusions. These findings are in agreement with the findings of previous reports $(2,4,5,7,8,10)$. When adjusted for these risk factors by multivariate analyses, transfusion of RBCs was an independent risk factor for early mortality after CABG. In order to eliminate the confounding effect of exceptional surgical problems we excluded patients who received more than ten units of RBC. Such a 
massive transfusion was mostly caused by massive blood loss or other special circumstances which certainly affect the prognosis.

In our study, the number off-pump coronary artery bypass (OPCAB) operations is relatively small (8.9\%). Although OPCAB was not identified as a significant factor for early or late mortality, the number of patients having OPCAB was significantly higher in patients receiving no transfusion than in the other groups. This means that OPCAB can decrease the need for RBC transfusions, which confirms the conclusions of other investigators (11).

We used the Dutch Central Bureau for Statistics (CBS) database to calculate the survival of the general population cohorts. This organisation keeps track of mortality rates of the overall Dutch population.

Late survival is highly dependent on age. Because age is significantly different between the patient groups we found it necessary to match for age when comparing long term survival after CABG to the long term survival of a matched general population cohort.

Female gender is considered an independent risk factor for early mortality after CABG (12-14). In this study we could not confirm this finding. Multivariate analysis however designates male gender as risk factor for late mortality. Abramov et al concluded the same after adjustment for other risk factors (12). Therefore, we decided to match the general population cohorts for sex.

In patients who did not receive any blood products we observed a better than expected survival. However, these results must be interpreted with care. Before undergoing $C A B G$, patients are screened for severe underlying diseases. If severe underlying disease is present, it is aggressively treated or alternative treatment to CABG is considered, thus biasing the CABG group. Survival of patients who received 1 to 2 units of blood products was not significantly different from the expected survival rate. In patients who received more than 2 units of blood products a worse than expected survival was noted. When studying the survival curves and life table, it is obvious that after the early postoperative period the curves run parallel. This finding confirms our observation that the number of transfused RBC was not a predictor of late mortality. It might be reassuring for patients to know that if they survive the first postoperative period, their prognosis is not influenced anymore by the blood transfusions they received.

\section{Limitations}

This is an observational retrospective investigation, in which unknown variables could influence final results. Furthermore we did not study the effect of duration of RBC storage. This issue has been recently addressed (15). The strengths of this investigation are the large prospectively collected data set and the follow-up period of ten years. 


\section{Conclusion}

Perioperative transfusion of $\mathrm{RBC}$ is an independent, dose-dependent risk factor for early but not for late mortality after CABG. Compared to expected survival, receiving no red blood cells improves patient's long-term survival, whereas receiving three or more units of RBC decreases patient survival significantly. This is mainly caused by a higher mortality within the first 30 postoperative days in these patients.

\section{References}

1. Rawn JD. Blood transfusion in cardiac surgery. A silent epidemic revisited. Circulation 2007;116:25232524

2. Koch CG, Khandwala F, Li L, Estafanous FG, Loop FD, Blackstone EH. Persistent effect of red cell transfusion on health-related quality of life after cardiac surgery. Ann Thorac Surg 2006;82:13-20

3. Kuduvalli M, Oo AY, Newall N, Grayson AD, Jackson M, Desmond MJ, Fabri BM, Rashid A. Effect of perioperative red blood cell transfusion on 30-day and 1-year mortality following coronary artery bypass surgery. Eur J Cardio-Thorac Surg 2005;27(4):592-598

4. Koch CG, Li L, Duncan Al, Mihaljevic T, Loop FD, Starr NJ, Blackstone EH. Transfusion in coronary artery bypass grafting is associated with reduced long-term survival. Ann Thorac Surg 2006;81:1650-1657

5. Scott BH. Blood transfusion in cardiac surgery: Is it appropriate? Ann Cardiac Anaest 2007;10:108-112

6. Murphy GJ, Reeves BC, Rogers CA, Rizvi SIA, Culliford L, Angelini GD. Increased mortality, postoperative morbidity, and costs after red blood cell transfusion in patients having cardiac surgery. Circulation 2007;116:2544-2552

7. Engoren MC, Habib RH, Zacharias AZ, Schwann TA, Riordan CJ, Durham SJ. Effect of blood transfusion on long-term survival after cardiac operation. Ann Thorac Surg 2002;74:1180-1186

8. Leal-Novel SR, Rincon-Ferrari MD, Garcia-Curiel A, Herruzo-Aviles A, Camacho-Larana P, GarnachoMontero J, Amaya-Villar R. Transfusion of blood components and postoperative infection in patients undergoing cardiac surgery. Chest 2001;119(5):1461-1468

9. Fransen E, Maessen J, Detener M, Senden N, Buurman W. Impact of blood transfusions on inflammatory mediator release in patients undergoing cardiac surgery. Chest 1999;116(5):1233-1239

10. Ranucci M. Allogeneic blood transfusions and infections after cardiac surgery. Am Heart J 2007;153:e21

11. Mack MJ, Pfister A, Bachand D, Emery R, Magee MJ, Connolly M, Subramanian V. Comparison of coronary bypass surgery with and without cardiopulmonary bypass in patients with multivessel disease. J Thorac Cardiovasc Surg. 2004;127(1):167-73.

12. Abramov D, Tamariz MG, Sever JY, Christakis GT, Bhatnagar G, Heenan AL, Goldman BS, Fremes SE. The influence of gender on the outcome of coronary artery bypass surgery. Ann Thorac Surg 2000;70(3):800-5.

13. Brandrup-Wognsen G, Berggren $\mathrm{H}$, Hartford M, Hjalmarson A, Karlsson T, Herlitz J. Female sex is associated with increased mortality and morbidity early, but not late, after coronary artery bypass grafting. Eur Heart J 1996;17(9):1426-31.

14. Guru V, Fremes SE, Austin PC, Blackstone EH, Tu JV. Gender differences in outcomes after hospital discharge from coronary artery bypass grafting. Circulation 2006;113(4):507-16.

15. Koch CG, Li Liang, Sessler DI, Figueroa P, Hoeltge GA, Mihaljevic T, Blackstone EH. Duration of red-cell storage and complications after cardiac surgery. N Engl J Med 2008;358:1229-1239 


\section{Chapter 7}

\section{Risk factors for red blood cell transfusion after coronary artery bypass grafting}

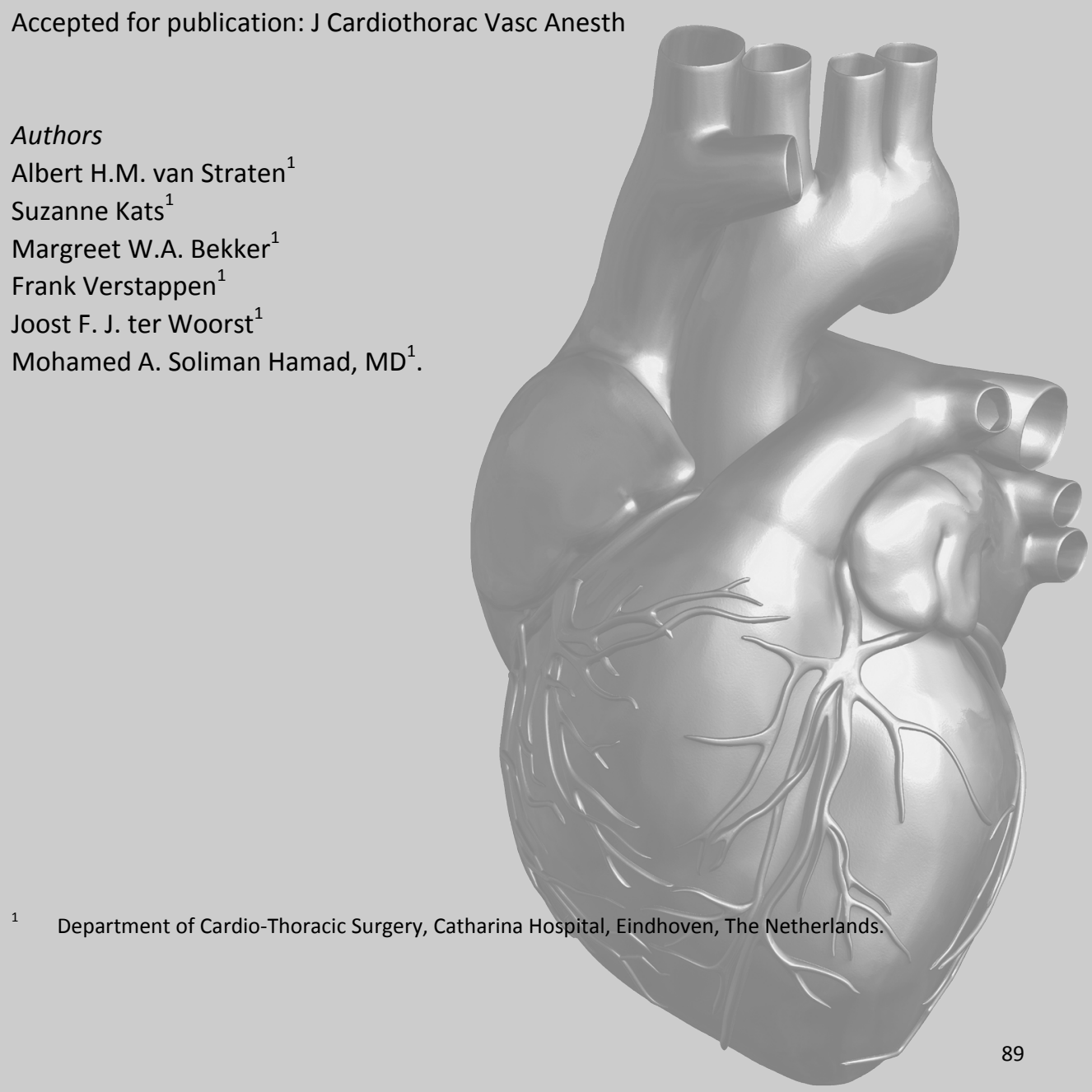




\begin{abstract}
Objectives

Perioperative transfusion of red blood cells is associated with increased morbidity and mortality. We investigated the correlation between preoperative risk factors and the number of red blood cell units received in patients undergoing coronary artery bypass grafting.
\end{abstract}

\title{
Methods
}

A retrospective analysis of prospectively collected data.

Setting: A single centre study performed in an educational hospital.

Participants: All patients who underwent isolated coronary artery bypass grafting between 1998 and 2007 ( $n=10,626)$ were included.

Interventions: Isolated coronary artery bypass grafting.

\section{Measurements and Main Results}

Univariate and multivariate logistic regression analyses were performed to investigate the impact of preoperative and perioperative factors on transfusion of one or more units of red blood cells. The following independent risk factors for receiving red blood cell units were identified: age, female gender, low body surface area, low left ventricular ejection fraction $(<35 \%)$, emergency operation, previous cardiac surgery, low preoperative hemoglobin and low preoperative creatinine clearance. Perioperative risk factors were: use of extra-corporeal circulation, longer bypass time, use of crystalloid cardioplegia, the need for intra-aortic balloon pump, perioperative myocardial infarction and re-exploration for any cause.

\section{Conclusions}

In this study, we identified risk factors for receiving red blood cells in patients undergoing coronary artery bypass grafting. We were able to implement these factors in our daily practice by sharpening our criteria for the direct availability of red blood cells in the operating theatre. 


\section{Introduction}

It is well known that transfusion of red blood cells (RBC) in cardiac surgery, either perioperatively or postoperatively, is associated with increased morbidity and mortality (1). It is considered to be a risk factor for postoperative infection, increased early mortality and increased hospital length of stay (1-4). Moreover, RBC transfusion increases hospital costs (1). Despite all transfusion protocols, the indication for RBC transfusion varies widely between different institutions. Consequently, the amount of patients receiving one or more units of RBC varies between $25 \%$ and $95 \%$ (5).

In this study we analyzed the patient characteristics and sought for a relation between these characteristics and the number of RBC's received after coronary artery bypass grafting (CABG).

\section{Patients and Methods}

\section{Patients}

We studied the data of all patients undergoing isolated CABG in a single center between January 1998 and December 2007. Starting in January 1998 clinical data, including demographic data, risk factors and complications were prospectively collected in a database. Patients were classified into 2 groups stratified by transfusion of RBC: Group 1 did not receive any unit of RBC; Group 2 received one or more RBC's. The study has been performed after permission of the local Medical Ethics Committee.

\section{Operative technique}

All patients received short-acting anesthetic drugs to facilitate early extubation. After median sternotomy, all patients received $3 \mathrm{mg} / \mathrm{kg}$ heparin (Leo Pharma, the Netherlands) intravenously. Because we used low dose $(200 \mathrm{ml}, 10000$ Kallikrein Inhibiting Units $/ \mathrm{mL}$ ) aprotinin (Bayer Health Care Pharmaceuticals) added to the prime in all patients, we repeated heparin administration $1 \mathrm{mg} / \mathrm{kg}$ every hour during cardiopulmonary bypass (CPB). This was guided by by measuring the activated cloting time (ACT) which was kept above the level of 480 seconds. Normothermic extracorporeal circulation (ECC) was performed using non-pulsatile flow. The lowest temperature was kept above 36 C, and patients was actively rewarmed in needed. Intermittent cold crystalloid cardioplegia ("St Thomas" solution) or intermittent warm blood cardioplegia was used to induce and maintain cardioplegic arrest, according to the surgeon's preference. Patients undergoing off-pump coronary artery bypass (OPCAB) surgery did not receive aprotinin. Since 2002 , we started to use the cell saver routinely in all CABG patients. At the end of cardiopulmonary bypass, or at the end of the procedure in case 
of OPCAB, heparin was neutralized by protamin chloride (Valeant Pharmaceuticals, the Netherlands). The dose of protamin was $1 \mathrm{mg}$ per $1 \mathrm{mg}$ heparine given.

\section{Indications of RBC transfusion:}

In our hospital, transfusion of one or more RBC units is indicated in the postoperative period in case of hemoglobin level $<8 \mathrm{~g} / \mathrm{dl}$ or hematocrite value of $<0.25$. A hemoglobin level of $<9.5 \mathrm{~g} / \mathrm{d}$ is adopted in case of hemodynamically unstable patients or patients with postoperative ischemia or excessive bleeding.

\section{Statistical Analyses}

Discrete variables were compared with the Chi-square test and are presented as numbers and percentages. Continuous variables were compared with the Student t-test and analysis of variance (ANOVA) and are presented as means \pm standard deviations. Univariate and multivariate logistic regression analyses were performed to investigate the impact of several preoperative and perioperative factors on receiving one or more transfusions of red blood cells. Univariate analyses were used to test for the potentially confounding effect of biomedical and demographic factors on outcome. If significant at $p<0.05$, confounders were included into the multivariable logistic regression model. A p-value $<0.05$ was used for all tests to indicate statistical significance. Odds ration (OR) with $95 \%$ confidence intervals $(\mathrm{Cl})$ are reported. All statistical analyses were performed using SPPS version 15.0 (SPSS Inc, Chicago, IL).

\section{Results}

During a ten year period (January 1998 till December 2007) 10626 patients underwent isolated CABG. In 6,828 (65.5\%) patients, no blood transfusion was needed and in $3,798(34.5 \%)$ patients, at least one RBC unit was transfused. Of these, 2,371 $(22.7 \%)$ patients received 1 to 2 units of RBC, 900 (8.6\%) patients received 3 to 5 units of RBC, $326(3.1 \%)$ patients received 6 to10 units of RBC and $79(0.7 \%)$ patients received more than 10 units of RBC. The mean number of transfused RBC units per patient was $0.75 \pm$ 2.0 (0 - 48) units. The total number of transfused units of RBC was 10,006 . Baseline patients' characteristics stratified by the number of received units of RBC are shown in table 1.

Patients receiving no $\mathrm{RBC}$ were more often younger males, had a higher body surface area (BSA), less often a body mass index (BMI) $<20 \mathrm{~kg} \cdot \mathrm{m}-2$ and hypertension, a better left ventricular ejection fraction (EF), less often an emergency operation and previous cardiac surgery, a higher preoperative hemoglobin $(\mathrm{Hb})$ and lower $\mathrm{C}$-reactive protein (CRP) level and a better preoperative creatinin clearance $(\mathrm{CrCl})$. Operative and postoperative characteristics were also different between the 2 groups: patients receiving RBC underwent less often OPCAB received less often blood cardioplegia, the 
duration of extra-corporeal circulation (ECC) was longer, the mammary artery was less often used, intra-aortic balloon pump support (IABP) was more often needed and the patients had more often a perioperative myocardial infarction and re-exploration for any cause.

Table 1. Demographic characteristics stratified by blood transfusion

\begin{tabular}{|c|c|c|c|}
\hline & \multicolumn{3}{|c|}{ Blood transfusion } \\
\hline & No $(n=6902)$ & Yes $(n=3724)$ & $p$ value \\
\hline \multicolumn{4}{|c|}{ Preoperative characteristics } \\
\hline Male gender & 6005 (87.0) & $2183(58.6)$ & $<0.0001$ \\
\hline Age & $63.2 \pm 9.4$ & $67.2 \pm 9.3$ & $<0.0001$ \\
\hline Diabetes & $1391(20.2)$ & $859(23.1)$ & $<0.0001$ \\
\hline BSA & $1.96 \pm 0.32$ & $1.81 \pm 0.36$ & $<0.0001$ \\
\hline $\mathrm{BMI}<20 \mathrm{~kg} \cdot \mathrm{m}^{-2}$ & $15(0.2)$ & $35(1.0)$ & $<0.0001$ \\
\hline COPD & $840(12.2)$ & $493(13.2)$ & 0.117 \\
\hline Hypertension & $2827(41.0)$ & $1605(43.1)$ & 0.034 \\
\hline PVD & 729 (10.6) & $502(13.5)$ & $<0.0001$ \\
\hline CCS class & $2.7 \pm 0.9$ & $2.8 \pm 0.9$ & 0.008 \\
\hline$E F<35 \%$ & $192(2.9)$ & $172(4.8)$ & $<0.0001$ \\
\hline Emergency & $137(2.0)$ & $312(8.4)$ & $<0.0001$ \\
\hline Number of preop MI & $0.49 \pm 0.61$ & $0.49 \pm 0.61$ & 0.850 \\
\hline Redo & $280(4.1)$ & $373(10.0)$ & $<0.0001$ \\
\hline Preop Hb (g.dl ${ }^{-1}$ ) & $14.3 \pm 1.1$ & $13.0 \pm 1.4$ & $<0.0001$ \\
\hline Preop CRP (mg.l ${ }^{-1}$ ) & $10.0 \pm 15.7$ & $14.4 \pm 23.8$ & $<0.0001$ \\
\hline Preop $\mathrm{CrCl}\left(\mathrm{ml} . \mathrm{min}^{-1)}\right.$ & $79.2 \pm 25.5$ & $62.1 \pm 23.2$ & $<0.0001$ \\
\hline \multicolumn{4}{|c|}{ Peri-operative characteristics } \\
\hline OPCAB & 784(11.4) & $157(4.2)$ & $<0.0001$ \\
\hline Blood cardioplegia & $3184(54.5)$ & $1624(47.6)$ & $<0.0001$ \\
\hline ECC time & $54.1 \pm 33.8$ & $64.5 \pm 33.4$ & $<0.0001$ \\
\hline Number of grafts & $3.4 \pm 1.1$ & $3.4 \pm 1.1$ & 0.151 \\
\hline IMA & $6297(91.2)$ & $3074(82.5)$ & $<0.0001$ \\
\hline IABP & $45(0.7)$ & $197(5.3)$ & $<0.0001$ \\
\hline Periop MI & $106(1.5)$ & $208(5.6)$ & $<0.0001$ \\
\hline Re-exploration & $99(1.4)$ & 484(13.0) & $<0.0001$ \\
\hline
\end{tabular}

Results in numbers (percentage) or mean \pm standard deviation

$\mathrm{BMI}=$ body mass index, $\mathrm{COPD}=$ chronic obstructive pulmonary disease, $\mathrm{PVD}=$ peripheral vascular disease, CCS class = Canadian Cardiovascular Society Functional Classification of Anginga, EF = left ventricular ejection fraction, preop $\mathrm{MI}=$ preoperative myocardial infarction, Redo = previous cardiac surgery, preop $\mathrm{Hb}=\mathrm{preop}-$ erative hemoglobin level, preop $\mathrm{CRP}=$ preoperative $\mathrm{C}$-reactive protein level, preop $\mathrm{CrCl}=$ preoperative creatinin clearance , OPCAB = off-pump coronary artery bypass grafting, ECC-time = duration of extracorporeal circulation, IMA = use of at least one internal mammaria artery, IABP = intra-aortic balloon pump counterpulsation, periop $\mathrm{MI}=$ perioperative myocardial infarction 


\section{Univariate predictors}

Univariate logistic regression analyses revealed the following preoperative risk factors for receiving any RBC (table 2): female gender, advanced age, diabetes, lower BSA, BMI $<20$ kg.m-2, hypertension, peripheral vascular disease (PVD), EF < 35\%, emergency operation, previous cardiac surgery, low $\mathrm{Hb}$, higher $\mathrm{CRP}$ and low $\mathrm{CrCl}$. Operative and postoperative risk factors that were revealed were: use of extra-corporeal circulation, use of crystalloid cardioplegia, longer ECC-time, not using a mammary artery as a bypass, the need for IABP, a perioperative infarction and re-exploration for any cause.

Table 2. Univariate logistic regression analyses for receiving blood transfusions

\begin{tabular}{|c|c|c|}
\hline & Hazard ratio $(95 \% \mathrm{Cl})$ & $p$ value \\
\hline \multicolumn{3}{|l|}{ Preoperative risk factors } \\
\hline Male gender & $0.21(0.19-0.23)$ & $<0.0001$ \\
\hline Age* & $1.049(1.044-1.053)$ & $<0.0001$ \\
\hline Diabetes & $1.18(1.07-1.30)$ & $<0.0001$ \\
\hline $\mathrm{BSA}^{*}$ & $0.211(0.179-0.249)$ & $<0.0001$ \\
\hline $\mathrm{BMI}<20 \mathrm{~kg} \cdot \mathrm{m}^{-2}$ & $4.45(2.43-8.17)$ & $<0.0001$ \\
\hline COPD & $1.10(0.97-1.24)$ & 0.113 \\
\hline Hypertension & $1.09(1.00-1.18)$ & 0.033 \\
\hline PVD & 1.31(1.16-1.49) & $<0.0001$ \\
\hline CCS class* & $1.058(1.015-1.103)$ & 0.008 \\
\hline Number of preop MI* & $1.006(0.943-1.074)$ & 0.850 \\
\hline$E F<35 \%$ & $1.72(1.40-2.13)$ & $<0.0001$ \\
\hline Emergency & $4.51(3.67-5.54)$ & $<0.0001$ \\
\hline Redo & $2.63(2.24-3.09)$ & $<0.0001$ \\
\hline Preop Hb (g.dl $\left.{ }^{-1}\right)^{*}$ & $0.473(0.455-0.491)$ & $<0.0001$ \\
\hline Preop CRP (mg. $\left.{ }^{-1}\right)^{*}$ & $1.012(1.009-1.015)$ & $<0.0001$ \\
\hline 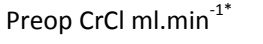 & $0.970(0.968-0.972)$ & $<0.0001$ \\
\hline \multicolumn{3}{|c|}{ Peri- and postoperative risk factors } \\
\hline OPCAB & $0.34(0.28-0.41)$ & $<0.0001$ \\
\hline Blood cardioplegia & $0.76(0.69-0.82)$ & $<0.0001$ \\
\hline ECC-time* & $1.010(1.009-1.011)$ & $<0.0001$ \\
\hline Number of grafts* & $1.026(0.991-1.063)$ & 0.151 \\
\hline IMA & $0.45(0.40-0.51)$ & $<0.0001$ \\
\hline IABP & $8.51(6.14-11.79)$ & $<0.0001$ \\
\hline Periop MI & $3.79(2.99-4.80)$ & $<0.0001$ \\
\hline Re-exploration & $10.26(8.23-12.79)$ & $<0.0001$ \\
\hline
\end{tabular}

$\mathrm{Cl}=$ conficence interval, * entered as a continuous variable, $\mathrm{BMI}=$ body mass index, COPD = chronic obstructive pulmonary disease, $\mathrm{PVD}=$ peripheral vascular disease, CCS class = Canadian Cardiovascular Society Functional Classification of Anginga, preop $\mathrm{MI}=$ preoperative myocardial infarction, $\mathrm{EF}=$ left ventricular ejection fraction, Redo = previous cardiac surgery, preop $\mathrm{Hb}=$ preoperative hemoglobin level, preop $\mathrm{CRP}=$ preoperative $\mathrm{C}$-reactive protein level, preop $\mathrm{CrCl}=$ preoperative creatinin clearance, $\mathrm{OPCAB}=$ off-pump coronary artery bypass grafting, ECC-time = duration of extra-corporeal circulation, IABP = intra-aortic balloon pump counterpulsation, periop $\mathrm{MI}=$ perioperative myocardial infarction 


\section{Multivariate analyses}

All preoperative risk factors that were identified with univariate logistic regression analyses were entered into a multivariate logistic regression model (table 3). Independent risk factors for receiving any number of RBC units were: female gender, lower $\mathrm{BSA}$, emergency operation, previous cardiac surgery, low preoperative $\mathrm{Hb}$ and low preoperative $\mathrm{CrCl}$.

Table 3. Multivariate analyses of preoperative risk factors

\begin{tabular}{lll}
\hline & Hazard ratio $(95 \% \mathrm{Cl})$ & p value \\
Preoperative riskfactors & & .002 \\
Age* & $0.989(0.981-0.996)$ & $<.0001$ \\
Male gender & $0.56(0.49-0.64)$ & .517 \\
Diabetes & $0.96(0.84-1.08)$ & $<.0001$ \\
BSA $^{*}$ & $0.190(0.129-0.280)$ & .546 \\
BMI<20kg.m ${ }^{-2}$ & $1.25(0.59-2.65)$ & .783 \\
Hypertension & $0.98(0.88-1.09)$ & .253 \\
PVD & $1.09(0.93-1.27)$ & .372 \\
CCS class* & $1.02(0.97-1.080)$ & .006 \\
EF<35\% & $1.47(1.11-1.93)$ & $<0.0001$ \\
Emergency & $6.70(4.44-10-12)$ & $<0.0001$ \\
Redo CABG & $2.40(1.95-2.96)$ & $<0.0001$ \\
Preop Hb $\left(\mathrm{g} . \mathrm{dl}^{-1}\right)^{*}$ & $0.555(0.531-0.581)$ & 0.719 \\
Preop CRP $\left({\left.\mathrm{mg} . I^{-1}\right)^{*}}_{\text {Preop CrCl ml.min }}^{-1 *}\right.$ & $1.001(0.997-1.004)$ & $<0.0001$ \\
\hline
\end{tabular}

$\mathrm{Cl}=$ conficence interval, * entered as a continuous variable, $\mathrm{BSA}=$ body surface area, $\mathrm{BMI}=$ body mass index, $\mathrm{PVD}=$ peripheral vascular disease, $\mathrm{EF}=$ left ventricular ejection fraction, Redo = previous cardiac surgery, preop $\mathrm{Hb}=$ preoperative hemoglobin level, preop CRP = preoperative C-reactive protein level, preop $\mathrm{CrCl}=$ preoperative creatinin clearance , OPCAB = off-pump coronary artery bypass grafting, IMA = use of at least one internal mammaria artery, ECC-time = duration of extra-corporeal circulation, IABP = intra-aortic balloon pump counterpulsation, periop $\mathrm{MI}=$ perioperative myocardial infarction

When operative and postoperative risk factors were also entered in the multivariate model the following independent risk factors were identified (table 4): age, female gender, low BSA, emergency operation, previous cardiac surgery, low preoperative $\mathrm{Hb}$, low preoperative $\mathrm{CrCl}$, use of extra-corporeal circulation, longer ECC-time, the need for IABP, perioperative myocardial infarction and re-exploration for any cause. 
Table 4. Multivariate logistic regression analyses including peri- and postoperative risk factors

\begin{tabular}{|c|c|c|}
\hline & Hazard ratio $(95 \% \mathrm{Cl})$ & $P$ value \\
\hline \multicolumn{3}{|c|}{ Preoperative risk factors } \\
\hline Age * & $0.984(0.976-0.992)$ & $<0.0001$ \\
\hline Male gender & $0.48(0.38-0.52)$ & $<0.0001$ \\
\hline Diabetes & $0.88(0.76-1.01)$ & 0.083 \\
\hline $\mathrm{BSA} *$ & $0.170(0.112-0.257)$ & $<0.0001$ \\
\hline $\mathrm{BMI}<20 \mathrm{~kg} \cdot \mathrm{m}^{-2}$ & $1.34(0.58-3.12)$ & 0.488 \\
\hline Hypertension & $0.99(0.89-1.11)$ & 0.917 \\
\hline PVD & $1.04(0.88-1.22)$ & 0.597 \\
\hline CCS class & $1.054(0.997-1.116)$ & 0.065 \\
\hline$E F<35 \%$ & $1.59(1.19-2.11)$ & 0.001 \\
\hline Emergency & $5.74(3.67-8.97)$ & $<0.0001$ \\
\hline Redo & $2.39(1.89-3.02)$ & $<0.0001$ \\
\hline Preop Hb $\left(\right.$ g. $\left.\mathrm{dl}^{-1}\right) *$ & $0.512(0.488-0.537)$ & $<0.0001$ \\
\hline Preop CRP (mg. $\left.I^{-1}\right)$ & $1.000(0.996-1.004)$ & 0.999 \\
\hline Preop $\mathrm{CrCl}\left(\mathrm{ml} \cdot \mathrm{min}^{-1)}\right.$ & $0.981(0.977-0.984)$ & $<0.0001$ \\
\hline \multicolumn{3}{|c|}{ Peri-and postoperative risk factors } \\
\hline OPCAB & $0.24(0.19-0.30)$ & $<0.0001$ \\
\hline IMA & $1.02(0.85-1.23)$ & 0.765 \\
\hline ECC time * & $1.010(1.008-1.012)$ & $<0.0001$ \\
\hline Blood cardioplegia & $0.83(0.74-0.94)$ & 0.03 \\
\hline IABP & $3.90(3.37-6.42)$ & $<0.0001$ \\
\hline Periop MI & $3.23(2.32-4.50)$ & $<0.0001$ \\
\hline Re-exploration & $24.96(18.83-33.08)$ & $<0.0001$ \\
\hline
\end{tabular}

$\mathrm{Cl}=$ conficence interval, * entered as a continuous variable, $\mathrm{BSA}=$ body surface area, $\mathrm{BMI}=$ body mass index, $P V D=$ peripheral vascular disease, $E F=$ left ventricular ejection fraction, Redo = previous cardiac surgery, preop $\mathrm{Hb}=$ preoperative hemoglobin level, preop $\mathrm{CRP}=$ preoperative C-reactive protein level, $\operatorname{preop} \mathrm{CrCl}=$ preoperative creatinin clearance, $\mathrm{OPCAB}=$ off-pump coronary artery bypass grafting, IMA = use of at least one internal mammaria artery, ECC-time = duration of extra-corporeal circulation, IABP = intra-aortic balloon pump counterpulsation, periop $\mathrm{MI}=$ perioperative myocardial infarction

\section{Discussion}

This study identifies the independent risk factors for prediction of RBC transfusion after CABG surgery in 10,626 patients.

In our patient population there was an overall transfusion rate of $34.5 \%$, of which the majority of patients received 1 or 2 units of RBC $(22.7 \%)$. In the literature percentages of 25 to $95 \%$ of patients receiving RBC after CABG have been described by Stover and colleagues (5). They suggested that this variability could not be explained by difference in patient preoperative characteristics or length of CPB or solely by calculated perioperative blood loss. This difference appeared to be institution-dependent; in some institutions the use of RBC transfusion appeared excessive relative to the perioperative blood loss (5). In our hospital, the policy of RBC transfusion is guided by the 
$\mathrm{Hb}$ level postoperatively $(<8.0 \mathrm{~g} / \mathrm{dL}$ ). However, in hemodynamically unstable patients or in patients with excessive bleeding, transfusion of RBC might not be precisely follow that policy. According to Scott (6), Patients with cardiovascular disease should be transfused at higher hematocrite levels when compared to their healthy counterparts. Because of lack of randomized trials to define the optimum transfusion trigger in cardiac surgery, this issue remains controversial.

In agreement with other studies we found that female gender is a predictive factor for transfusion of RBC (7-11). Most female patients have lower BSA due to smaller body size and have lower preoperative $\mathrm{Hb}$. Both lower BSA and lower $\mathrm{Hb}$ preoperatively have also shown to be significant predictors of transfusion in our study. The reason why female patients receive more RBC has been extensively studied by Shevde et al. (9). Their conclusion was that it remains unclear why female patients receive more RBC, but that it may interact with other factors determining the probability of transfusion like age, weight, preoperative $\mathrm{Hb}$ and duration of surgery.

Low creatinin clearance has been identified as a risk factor for RBC transfusion in several studies $(8,10,11)$. Renal dysfunction is often associated with low hemoglobin level which is also a risk factor for transfusion. Another explanation may be that renal dysfunction, as comorbidity prolongs hospital stay and increases the incidence of complication, which might increase the amount of RBC transfusions.

In an emergency setting, most patients are anticoagulated with heparin, thrombolysis or treated with anti-platelets like clodiprogel. This may explain why emergency operation is a predictive factor for transfusion of RBC.

Significant peri- or postoperative predictors of transfusion were: the use of cardiopulmonary bypass (CPB), longer perfusion time, the use of crystalloid cardioplegia, the need for an IABP, perioperative infarction and re-exploration for any cause, i.e. bleeding and ischemia.

Hemodilution due to the use of CPB is proportionally greater for women than for men, owing to their smaller weight and therefore smaller circulating volume. On the other hand, however, hemodilution seems to derange the efficacy of anticoagulation, as was demonstrated by Srivastava and collegues (12). The mechanism of this hemodilution-enhanced coagulation has not yet been resolved.

It has been well-established that during the use of CPB the platelet count is decreased to about $60 \%$ of the preoperative value. Furthermore, platelets are irreversibly activated by adherence to the CPB circuit (13). Nuttall et al. demonstrated that OPCAB surgery reduces perioperative bleeding and is associated with an overall reduction in allogenic transfusion requirement (14). Our results show that OPCAB surgery has a protective effect against postoperative blood transfusion (Odds ratio $=0.24$ ). During OPCAB, our patients received $1 \mathrm{mg} / \mathrm{kg}$ heparin intravenously or as much as needed to get an activated clotting time (ACT) of above 300 seconds. 
Reoperation has also been identified as an independent risk factor for blood transfusion. Christenson et al. showed that redo CABG is associated with significantly increased risk of hemorrhage (15). Preparation in scarred tissue by itself creates more bleeding and also increases the risk of graft damage with subsequent more bleeding. They suggested that blood conservation techniques such as the use of cell saver and plasma sequestration may reduce the risk of transfusion during redo CABG.

Whether blood cardioplegia is superior to crystalloid cardioplegia has been the subject of some large meta-analyses $(16,17)$. Jacob et al. (17) studied 22 trials comparing blood cardioplegia to crystalloid cardioplegia including the meta-analysis of Guru et al (16). In none of these trials transfusion of RBC was a primary or secondary endpoint. In 2006, Kacila et al. stated that the use of blood cardioplegia leads to a significant reduction in the amount of $\mathrm{RBC}$ transfusion as compared to crystalloid cardioplegia in a study group of 100 patients (18). Our results, in this large number of patients, are in agreement with their results. Blood cardioplegia might reduce the degree of hemodilution with consequent higher $\mathrm{Hb}$ level.

Re-exploration is usually performed for extensive postoperative bleeding which increases the transfusion rate. However re-exploration for any cause was an independent predictor of transfusion in our study group. Thus, re-exploration preformed for ischemia also increases the risk of transfusion. These patients might need CPB with consequent heparinization and longer perfusion time. This complication leads to longer intensive care and hospital stay, which also increases the risk of transfusion. Moreover, the trigger $\mathrm{Hb}$ value of transfusion is higher in these patients. The same applies also for patients with perioperative infarction and those in need for IABP.

The independent, patient related risk factors of blood transfusion have led us to follow a new strategy concerning the direct availability of packed red blood cells in the operating theatre. Normally, for every elective CABG patient 2 units of RBC are directly available in the operating theatre. If these 2 units are not used they are returned back to the laboratory to be used for another patient. However, the quality of these RBC is sometimes decreased and cannot be used anymore. This lack of quality can be caused by the method of storage in the operating theatre. Moreover, RBC can lose their quality only during transport. With the new protocol, in a selected group of patients, no units of RBC are directly available in the operating theatre. In this group of patients a cross match test is performed and blood samples are screened for irregular antibodies, but no units of RBC are ordered.

This new procedure is followed only in male patients aged $<70$ years, with a BSA $>$ $1.7 \mathrm{~m}^{2}$ and a preoperative $\mathrm{Hb}>7.5 \mathrm{mmol} / \mathrm{L}$ and in which the test for irregular antibodies is negative. The main goal of this new strategy is maintenance of quality and cost reduction.

In the first 150 patients managed according to this new strategy, $11 \%$ needed one or more units of RBC perioperatively. No adverse events were reported. Our new pro- 
tocol was even extended after the promising results of the first 150 patients to include both male and female patients, and patients with preoperative $\mathrm{Hb}$ level $>7 \mathrm{mmol} / \mathrm{L}$.

\section{Limitations}

This is study is an observational investigation in which unknown variables could have influenced final results. The retrospective design of this study is vulnerable to a lot of bias. Some data were lacking making the results less accurate. However, it concerns a large prospectively collected data set. The use of cell saver was routinely adopted in CABG patients since 2002. However, information about retransfusion of cell saver blood is lacking in our database.

\section{Conclusions}

In this study we identified both preoperative and perioperative risk factors influencing postoperative RBC transfusion. We were able to implement these factors in our daily practice by sharpening of our criteria for the direct availability of RBC in the operating theatre.

\section{References}

1. Murphy GJ, Reeves BC, Rogers CA, Rizvi SIA, Culliford L, Angelini GD. Increased mortality, postoperative morbidity, and costs after red blood cell transfusion in patients having cardiac surgery. Circulation 2007;116:2544-2552

2. Engoren MC, Habib RH, Zacharias AZ, Schwann TA, Riordan CJ, Durham SJ. Effect of blood transfusion on long-term survival after cardiac operation. Ann Thorac Surg 2002;74:1180-1186

3. Speiss BD. Transfusion and outcome in heart surgery. Ann Thorac Surg 2002;74:986-987

4. Leal-Novel SR, Rincon-Ferrari MD, Garcia-Curiel A, Herruzo-Aviles A, Camacho-Larana P, GarnachoMontero J, Amaya-Villar R. Transfusion of blood components and postoperative infection in patients undergoing cardiac surgery. Chest 2001;119(5):1461-1468

5. Stover EP, Siegel LC, Parks RMPH,Levin J, Body SC, Maddi R, D’Ambra MN, Mangano DT, Spiess BD. Variability in transfusion practice for coronary artery bypass surgery persists despite national consensus guidelines: a 24-institution study. Anesthesiology 1998;88(2):327-333.

6. Scott BH. Blood transfusion in cardiac surgery: is it appropriate? Ann Card Anaesth. 2007 Jul;10(2):10812.

7. Scott BH, Seifert FC, Glass PSA, Grimson R. Blood use in patients undergoing coronary artery bypass surgery: Impact of cardiopulmonary bypass pump, hematocrit, gender, age, and body weight. Anesth Analg 2003;97:958-63

8. Karkouti K, Cohen MM, McCluskey SA, Sher GD. A multivariable model for predicting the need for blood transfusion in patients undergoing first-time elective coronary bypass graft surgery. Transfusion 2001;41:1193-1203 


\section{CHAPTER 7}

9. Shevde K, Pagala M, Kashikar A, Tagaraj C, Shabaz N, Iqbal M, Idupuganti R. Gender is an essential determinat of blood transfusion in patients undergoing coronary artery bypass graft procedure. J Clin Anesth 2000;12:109-116

10. Magovern JA, Sakert T, Benckart DH, Burkholder JA, Liebler GA, Magovern GJ Sr, Magovern GJ Jr. A model for predicting transfusion after coronary artery bypass grafting. Ann Thor Surg 1996;61:27-32

11. Arora RC, Légaré JF, Buth KJ, Sullivan JA, Hirsch GM. Identifying patients at risk of intraoperative and postoperative transfusion in isolated CABG: Toward selective conservation strategies. Ann Thor Surg 2004;78:1547-55

12. Srivastava AR, Banerjee A, Misra BB, Minhas HM, Virmani S. Does hemodilution by the crystalloid priming solution derange the efficacy of anticoagulation during cardiopulmonary bypass? J Card Surg 2008;23:239-245

13. Kirklin/Barratt-Boyes. Cardiac Surgery. $3^{\text {rd }}$ edition, 2003;66-131

14. Nuttall GA, Erchul DT, Haight TJ, Ringhofer SN, Miller TL, Oliver WC, Zehr KJ, Schroeder DR. A comparison of bleeding and transfusion in patients who undergo coronary artery bypass grafting via sternotomy with and without cardiopulmonary bypass. J Cardiothor Vasc Anesth 2003;17(4):447-451

15. Christenson JT, Schmuziger M, Simonet F. Reoperative coronary artery bypass procedures: risk factors for early mortality and late survival. Eur J Cardio-Thor Surg 1997;11:129-133

16. Guru V, Omura J, Alghamdi AA, Weisel R, Fremes SE. Is blood superior to crystalloid cardioplegia? A meta-analysis of randomized clinical trials. Circulation 2006;114(suppl I):I-331-I-338)

17. Jacob S, Kallikourdis A, Sellke F, Dunning J. Is blood cardioplegia superior to crystalloid cardioplegia? Int Cardiovasc Thorac Surg 2008;7:491-499

18. Kacila M, Schäfer K, Subasić E, Granov N, Omerbasić E, Kucukalić F, Selimović-Mujicić E. Influence of two different types of cardioplegia on hemodilution during and after cardiopulmonary bypass, postoperative chest-drainage bleeding and consumption of donor blood products. Bosn J Basic Med Sci 2006;6(3):48-53 


\section{Chapter 8}

\section{Effect of duration of red blood cell storage on early and late mortality after coronary artery bypass grafting}

Submitted

Authors

Albert H. M. van Straten ${ }^{1}$

Mohamed A. Soliman Hamad ${ }^{1}$

André A. J. van Zundert ${ }^{2}$

Elisabeth J. Martens, PhD $^{3}$

F. J. ter Woorst ${ }^{1}$

Andre M. de Wolf ${ }^{4}$

Volkher Scharnhorst ${ }^{5}$

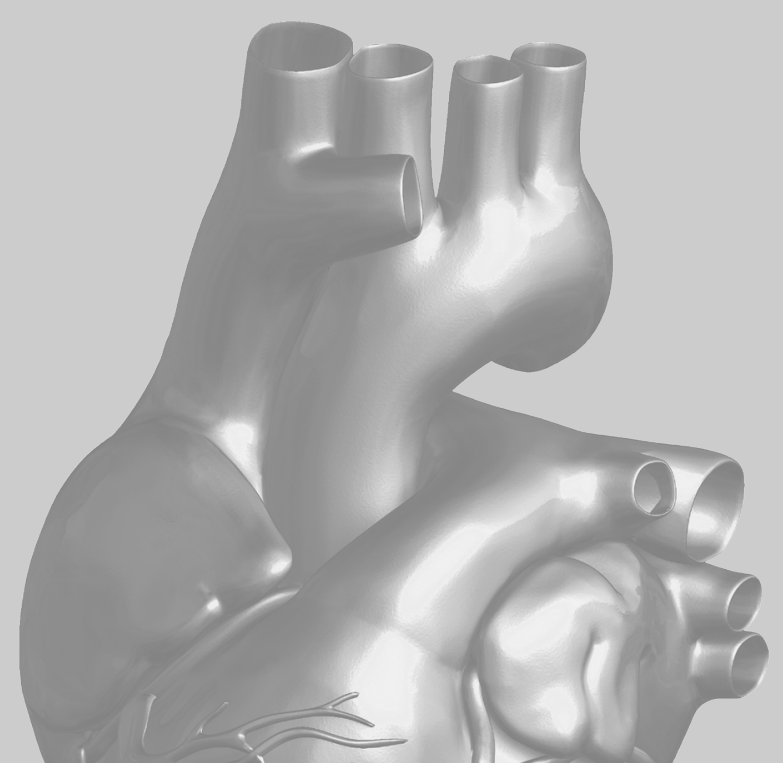

1 Department of Cardio-Thoracic Surgery, Catharina Hospital, Eindhoven, The Netherlands

2 Department of Anesthesiology, Catharina Hospital - Brabant Medical School, Eindhoven, The Netherlands \& University Hospital Ghent, Ghent, Belgium

3 Department of Education and Research, Catharina Hospital, Eindhoven, The Netherlands \& Center of Research on Psychology in Somatic Diseases, Department of Medical Psychology, Tilburg University, The Netherlands.

4 Department of Anesthesiology, Feinberg School of Medicine, Northwestern University, Chicago, Illinois, USA

5 Clinical Laboratory, Catharina Hospital, Eindhoven, The Netherlands 


\begin{abstract}
Objectives

Recently, concern has been expressed about the transfusion of older red blood cells (RBCs) after cardiac surgery. We tested the hypothesis that longer storage of transfused RBCs increases the risk of early and late mortality in patients who undergo coronary artery bypass grafting.
\end{abstract}

\title{
Methods
}

We retrospectively analyzed data of patients who underwent isolated coronary artery bypass grafting between January 1998 and December 2007 in Catharina Hospital, Eindhoven, the Netherlands, and received up to $10 \mathrm{U}$ of RBCs intraoperatively or during the first 5 postoperative days. The patients were divided into 3 groups according to the storage time of the RBCs with a cutoff point of 14 days as follows: "only younger blood" ( $n=1422)$, "only older blood" ( $n=1719)$, and at least $1 \mathrm{U}$ of older RBCs ("any older blood") (n=2175).

\section{Results}

The mean follow-up time was $1693 \pm 1058$ days (range, 0-3708 days). The median follow-up time was 1629 days. Univariate and multivariate logistic regression analyses revealed that the number of transfused units but not the storage time of blood entered either as a continuous variable or as a dichotomous variable with a cutoff point of 14 days was a risk factor for early mortality. Neither the number of transfused units nor the storage time was an independent risk factor for late mortality. Log-rank testing revealed no statistical difference in survival among the patient groups.

\section{Conclusions}

The storage time of RBCs is not a risk factor for early or late mortality in patients who undergo coronary artery bypass grafting. 


\section{Introduction}

Critically ill patients, including those who undergo cardiac surgery, experience more severe complications if they receive blood transfusions (1-3). The storage time of red blood cells (RBCs) may affect the risk of experiencing those complications (4-12), because RBCs undergo structural and functional changes that reduce function and viability after transfusion $(12-16)$. Recently, some $(17,18)$ but not all $(19-21)$ investigators have expressed their concern about using older RBCs for transfusion during or after cardiac surgery. In those reports, several endpoints in heterogeneous patient populations were mentioned. We therefore investigated whether longer storage of transfused RBCs increased the risk of early or late mortality in a large group of patients who underwent coronary artery bypass grafting at a single medical center.

\section{Patients and Methods}

\section{Patients}

This study included the data of all adult patients (age range, $\geq 18$ years) who underwent isolated coronary artery bypass grafting (CABG) in a single medical center in Catharina Hospital, Eindhoven, The Netherlands, between January 1998 and December 2007. Clinical data (including demographic information, risk factors, and complications) from January 1998 through December 2007 were collected in a database. All patients who received between 1 and $10 \mathrm{U}$ of RBCs intraoperatively or during the first 5 postoperative days were included in this study. Patients who received more than $10 \mathrm{U}$ of RBCs during that period were excluded.

\section{Methods}

Approval was obtained from the institution's research review board before the initiation of the study. Data concerning blood transfusions and the storage time of RBCs were collected from the database of the hospital transfusion service. For every patient, the maximum storage time of the transfused RBCs was used for the analysis. The patients were divided into 3 groups according to the storage time of the RBCs they received: the "only younger blood" group ( $n=1422)$, the "only older blood" group $(n=1719)$, and those who received at least $1 \mathrm{U}$ of older RBCs; ie, the "any older blood" group ( $n=2175$ ). The cutoff point for duration of storage of RBCs was 14 days. In this study, "younger blood" refers to RBCs younger than 14 days, and "older blood" refers to RBCs older than 14 days. Patients in the only older RBCs group were also included in the any older RBCs group. Leucocyte reduction was performed for all RBC units before storage and within 24 hours after donation. RBCs were reconstituted with SAG- 
mannitol to a hematocrit value of $60 \%( \pm 5 \%)$, which enabled a maximum storage time of 35 days.

\section{Operative techniques}

All patients received short-acting anesthetic drugs to facilitate early extubation. Normothermic extracorporeal circulation (ECC) was performed with nonpulsatile flow. According to the surgeon's preference, either cold intermittent crystalloid cardioplegia (St. Thomas' solution) or intermittent warm blood cardioplegia was used to induce and maintain cardioplegic arrest. All patients who underwent CABG with the use of ECC received low-dose aprotinin ( 2 million KIU) during ECC that was administered in the prime solution of the ECC (this was the regular practice in the hospital in which the procedure was performed). Patients who underwent off-pump surgery did not receive aprotinin.

\section{Follow-up data}

Follow-up data on the mortality of the patients studied were gathered from the databases of Dutch health insurance companies. Initially, the data of $9 \%$ of the total patient group could not be retrieved from those databases. To obtain mortality data on those patients, we contacted the appropriate general practitioners (or, if necessary, the authorities) of the cities in which the patients lived at the time of their operation. Postoperative mortality was defined as early ( $\leq 30$ days) or late ( $>30$ days).

\section{Statistical analyses}

Discrete variables were compared with the chi-square test and are presented as numbers and percentages. Continuous variables were compared with the $t$ test and analysis of variance and are presented as the mean \pm SD. Univariate and multivariate logistic regression analyses were performed to investigate the impact of biomedical variables on early mortality. Multivariate analyses were used to test for the potentially confounding effects of biomedical and demographic factors on outcome. Cox proportional hazard regression analyses were performed for the same analyses of late mortality. If they were statistically significant at a $P$ value of $<0.05$, confounders were included in the multivariable logistic and Cox regression analyses. Factors that were statistically significant in the multivariate analyses were entered in a multivariate model together with items of interest (the number of transfused blood components and the maximum storage time per blood component as a continuous variable and as a dichotomous variable). Long-term survival was described with the Kaplan-Meier method. The comparison of long-term survival in the study groups was performed with log-rank statistics. The zero time point indicates the time of CABG. A $P$ value of $<0.05$ was used for all tests to indicate statistical significance. Hazard ratios with $95 \%$ confidence intervals are reported. All statistical analyses were performed with SPSS software (Statistical Product and Service Solutions, version 15.0, SSPS Inc, Chicago, Illinois). 


\section{Results}

During a 10-year period (January 1998 through December 2007) 10,626 adult patients underwent CABG in Catharina Hospital, Eindhoven, The Netherlands. A total of 3597 patients received at least $1 \mathrm{U}$ of RBCs perioperatively and were included in this study. After 122 patients who were lost to follow-up were excluded, we found that 1422 of the remaining patients received younger RBCs (the "only younger blood" group), 2175 patients received at least $1 \mathrm{U}$ of older RBCs (the "any older blood" group), and 1719 patients received older RBCs (the "only older blood" group). The mean follow-up time was $1693 \pm 1058$ days (range, 0-3708 days), with 0 days for operative deaths. The median follow-up time was 1629 days. The baseline characteristics stratified by the storage time of the transfused blood are shown in Table 1.

The baseline characteristics of the patients who received only younger blood, any older blood, and only older blood are shown in Table 1. Patients who received only younger blood were relatively younger (66.7 vs 67.6 years), more often had chronic obstructive pulmonary disease (COPD) (14.7\% vs $12 \%$ ), and had a higher preoperative hemoglobin level (13.2 vs $12.9{\mathrm{gr} . \mathrm{dL}^{-1}}^{\text {) }}$ than did patients of the any older blood or only older blood groups. In the only older blood group of patients, the number of grafts was higher (3.4 vs 3.5 ), but the percentage of re-exploration was less ( $11.7 \%$ vs $9.0 \%)$. The number of transfused RBC units was higher in the any older blood group than in the only younger blood group and lower in the only older blood group than in the only younger blood group. The number of transfused units of fresh frozen plasma (FFP) and platelets were highest in the any older blood group.

Late mortality occurred more often in patients who received younger blood, but no difference was found in the incidence of early mortality among the three groups (Table 2). 
Table 1. Baseline characteristics stratified by the duration of storage of red blood cells

\begin{tabular}{llllll}
\hline & $\begin{array}{l}\text { Only younger RBCs } \\
(\mathrm{n}=1422)\end{array}$ & $\begin{array}{l}\text { Any older RBCs } \\
(\mathrm{n}=2175)\end{array}$ & $P$ Value & $\begin{array}{l}\text { Only older RBCs } \\
(\mathrm{n}=1719)\end{array}$ & $\begin{array}{l}\text { P Value } \\
\text { Preoperative factors }\end{array}$ \\
Age (y) & $66.7 \pm 9.4$ & $67.6 \pm 9.2$ & 0.06 & $67.6 \pm 9.2$ & 0.011 \\
Male sex & $847(59.6)$ & $1244(57.2)$ & 0.167 & $977(56.8)$ & 0.127 \\
Diabetes & $327(23.0)$ & $499(22.9)$ & 0.968 & $401(23.3)$ & 0.832 \\
Hypertension & $601(42.3)$ & $951(43.7)$ & 0.390 & $772(44.9)$ & 0.139 \\
COPD & $209(14.7)$ & $270(12.4)$ & 0.050 & $207(12.0)$ & 0.030 \\
PVD & $179(12.6)$ & $307(14.1)$ & 0.195 & $244(14.2)$ & 0.208 \\
EF <35\% & $73(5.3)$ & $87(4.2)$ & 0.137 & $65(4.0)$ & 0.080 \\
CrCl & $64.0 \pm 21.1$ & $63.1 \pm 21.6$ & 0.233 & $63.6 \pm 21.6$ & 0.669 \\
Emergency & $105(7.4)$ & $176(8.1)$ & 0.447 & $119(6.9)$ & 0.626 \\
Hb (g.dL $\left.{ }^{-1}\right)$ & $13.2 \pm 1.3$ & $12.9 \pm 1.4$ & $<0.0001$ & $13.0 \pm 1.4$ & $<0.0001$ \\
Redo & $142(10.0)$ & $198(9.1)$ & 0.382 & $137(8.0)$ & 0.051 \\
Perioperative factors & & & & & 0.019 \\
No. of grafts & $3.4 \pm 1.1$ & $3.4 \pm 1.1$ & 0.054 & $3.5 \pm 1.1$ & 0.019 \\
Off-pump & $60(4.2)$ & $94(4.3)$ & 0.933 & $78(4.5)$ & 0.727 \\
ECC time & $64.2 \pm 33.5$ & $64.0 \pm 32.1$ & 0.864 & $63.0 \pm 30.8$ & 0.314 \\
Reexploration & $167(11.7)$ & $263(12.1)$ & 0.793 & $154(9.0)$ & 0.011 \\
Periop MI & $71(5.0)$ & $123(5.7)$ & 0.407 & $83(4.8)$ & 0.868 \\
No. of RBC & $2.6 \pm 1.5$ & $2.8 \pm 1.7$ & $<0.0001$ & $2.4 \pm 1.4$ & 0.004 \\
No. of FFP & $0.42 \pm 1.15$ & $0.54 \pm 1.30$ & 0.005 & $0.40 \pm 1.08$ & 0.579 \\
No. of platelets & $0.06 \pm 0.30$ & $0.10 \pm 0.39$ & $<0.0001$ & $0.08 \pm 0.35$ & 0.075 \\
\hline Results are expressed & & & & \\
\hline
\end{tabular}

*Results are expressed as the mean \pm SD or as number (percentage).

$\mathrm{RBC}=$ red blood cells, $\mathrm{COPD}=$ chronic obstructive pulmonary disease, $\mathrm{PVD}=$ peripheral vascular disease, $\mathrm{EF}$ = ejection fraction, $\mathrm{CrCl}=$ creatinine clearance, $\mathrm{Hb}$ hemoglobin level, $\mathrm{ECC}$ time $=$ duration of extracorporeal circulation, $\mathrm{MI}=$ myocardial infarction, $\mathrm{FFP}=$ fresh frozen plasma.

Table 2. Early and late mortality stratified by the duration of storage of red blood cells

\begin{tabular}{llllll}
\hline End point & $\begin{array}{l}\text { Younger RBCs } \\
\mathrm{n}=1422\end{array}$ & $\begin{array}{l}\text { Any older RBCs* } \\
\mathrm{n}=2175\end{array}$ & P Value & $\begin{array}{l}\text { Only older RBCs* } \\
\mathrm{n}=1719\end{array}$ & P Value \\
\hline Early mortality & $52(3.7)$ & $16(4.9)$ & 0.096 & $67(3.9)$ & 0.778 \\
Late mortality & $258(18.1)$ & $327(15.0)$ & 0.014 & $235(13.7)$ & 0.001 \\
\hline
\end{tabular}

*Compared with younger RBCs group. RBCs = red blood cells.

Risk factors for early mortality identified by univariate logistic regression analysis and for late mortality identified by Cox regression analyses are shown in Table 3. When the maximum storage time was used as a continuous variable, having received at least $1 \mathrm{U}$ of older RBCs or only older blood was not identified as a risk for either early or late mortality. However, the number of transfused unit of RBCs, FFP, and platelets were significant for both early and late mortality. 
Table 3. Univariate logistic regression analyses of risk factors for early mortality and Cox regression analyses for late mortality

\begin{tabular}{|c|c|c|c|c|}
\hline \multirow[b]{2}{*}{ Risk factors } & \multicolumn{2}{|l|}{ Early mortality } & \multicolumn{2}{|l|}{ Late mortality } \\
\hline & Hazard ratio $(95 \% \mathrm{Cl})$ & $P$ Value & Hazard ratio $(95 \% \mathrm{Cl})$ & Value \\
\hline \multicolumn{5}{|l|}{ Preoperative factors } \\
\hline Age $(y)^{*}$ & $1.086(1.067-1.105)$ & $<0.0001$ & 1.091 (1.083-1.099) & $<0.0001$ \\
\hline Male sex & $0.70(0.52-0.94)$ & 0.019 & $0.85(0.75-0.97)$ & 0.021 \\
\hline COPD & $2.05(1.49-2.82)$ & $<0.0001$ & $1.94(1.68-2.23)$ & $<0.0001$ \\
\hline Diabetes & $1.42(1.05-1.91)$ & 0.023 & $1.73(1.52-1.96)$ & $<.0001$ \\
\hline Preop $\mathrm{CrCl}^{*}$ & 0.965 (0.959-0.972) & $<0.0001$ & 0.967 (0.964-0.970) & $<0.0001$ \\
\hline$E F<35 \%$ & $5.90(4.00-8.71)$ & $<0.0001$ & $2.64(2.10-3.31)$ & $<0.0001$ \\
\hline Preop $\mathrm{Hb}^{*}$ & $0.725(0.662-0.795)$ & $<0.0001$ & $0.731(0.702-0.761)$ & $<.0001$ \\
\hline Redo & $3.40(2.37-4.87)$ & $<.0001$ & $1.60(1.32-1.94)$ & $<0.0001$ \\
\hline PVD & $1.58(1.11-2.25)$ & 0.012 & $2.29(1.98-2.64)$ & $<0.0001$ \\
\hline Emergency & $5.69(3.98-8.14)$ & $<0.0001$ & $1.27(0.98-1.66)$ & 0.071 \\
\hline Hypertension & $0.97(0.70-1.21)$ & 0.630 & $1.22(1.08-1.37)$ & 0.001 \\
\hline \multicolumn{5}{|c|}{ Perioperative and postoperative factors } \\
\hline No. of grafts* & $0.956(0.850-1.076)$ & 0.457 & $1.084(1.031-1.140)$ & 0.002 \\
\hline Periop MI & $6.00(4.03-8.94)$ & $<0.0001$ & $1.82(1.37-2.42)$ & $<0.0001$ \\
\hline Reexploration & $4.50(3.17-6.39)$ & $<0.0001$ & $1.39(1.11-1.75)$ & 0.004 \\
\hline Off-pump & $0.73(0.43-1.24)$ & 0.251 & $0.68(0.52-0.89)$ & 0.005 \\
\hline Yr of operation* & $0.959(0.915-1.005)$ & 0.077 & $0.961(0.934-0.989$ & 0.006 \\
\hline Max storage of RBCs per patient* & $1.017(0.991-1.045)$ & 0.206 & $1.013(0.999-1.027)$ & 0.071 \\
\hline Any older RBC & $1.35(0.96-1.89)$ & 0.083 & $1.03(0.87-1.21)$ & 0.714 \\
\hline Only older RBC & $1.06(0.73-1.54)$ & 0.725 & $0.96(0.80-1.14)$ & 0.665 \\
\hline No. of FFP * & $1.378(1.262-1.505$ & $<0.0001$ & $1.143(1.075-1.215)$ & $<0.0001$ \\
\hline No. of platelets* & $2.360(1.812-3.075)$ & $<0.0001$ & 1.295 (1.005-1.668) & 0.046 \\
\hline No. of RBC* & $1.441(1.374-1.511)$ & $<0.0001$ & $1.162(1.131-1.193)$ & $<0.0001$ \\
\hline
\end{tabular}

*Entered as a continuous variable. $\mathrm{COPD}=$ chronic obstructive pulmonary disease, $\mathrm{CrCl}=$ creatinine clearance, $\mathrm{EF}=$ left ventricular ejection fraction, $\mathrm{Hb}=$ hemoglobin level, $\mathrm{PVD}=$ peripheral vascular disease, $\mathrm{MI}=$ myocardial infarction, RBCs = red blood cells, FFP = fresh frozen plasma.

Other risk factors for early mortality were age, female sex, COPD, diabetes, low creatinine clearance $(\mathrm{CrCl})$, a left ventricular ejection fraction $(\mathrm{EF})$ of $<35 \%$, a low preoperative hemoglobin $(\mathrm{Hb})$ level, previous cardiac surgery, peripheral vascular disease (PVD), emergency operation, perioperative myocardial infarction, or reexploration for any cause. For late mortality, the risk factors were age, female sex, COPD, diabetes, low $\mathrm{CrCl}$, a left ventricular $\mathrm{EF}$ of $<35 \%$, a lower preoperative $\mathrm{Hb}$ level, previous cardiac surgery, PVD, hypertension, the number of grafts, perioperative myocardial infarction, reexploration, the use of ECC, and the year of operation. All risk factors identified via univariate analyses were entered into the multivariate logistic regression and the multivariate Cox regression model. The results are shown in Table 4. 
Table 4. Results of multivariate logistic regression analyses for early mortality and Cox regression analyses for late mortality

\begin{tabular}{|c|c|c|c|c|}
\hline & Early mortality & & Late mortality & \\
\hline Risk Factors & $\mathrm{HR}(95 \% \mathrm{Cl})$ & $P$ Value & $\mathrm{HR}(95 \% \mathrm{Cl})$ & $P$ Value \\
\hline Any older RBCs & $1.13(0.76-1.66)$ & 0.529 & $1.02(0.85-1.22)$ & 0.763 \\
\hline Only older RBCs & $1.02(0.67-1.56)$ & 0.894 & $1.01(0.83-1.23)$ & 0.872 \\
\hline No. of RBC units * & $1.262(1.125-1.416)$ & $<0.0001$ & $1.010(0.947-1.077)$ & 0.764 \\
\hline No. of FFP units* & $0.863(0.721-1.033)$ & 0.109 & $1.056(0.956-1.165)$ & 0.282 \\
\hline No. of platelet * & $1.321(0.832-2.097)$ & 0.238 & $1.027(0.725-1.454)$ & 0.882 \\
\hline Age $(y)^{*}$ & 1.065 (1.035-1.097) & $<0.0001$ & $1.051(1.036-1.066)$ & $<0.0001$ \\
\hline Male sex & $1.40(0.93-2.12)$ & 0.102 & $1.68(1.28-2.03)$ & $<0.0001$ \\
\hline COPD & $2.20(1.43-3.37)$ & $<0.0001$ & $1.91(1.55-2.37)$ & $<0.0001$ \\
\hline Diabetes & $1.60(1.06-2.41)$ & 0.023 & 1.39 (1.14-1.69) & 0.001 \\
\hline $\mathrm{CrCl}^{*}$ & 0.991 (0.979-1.003) & 0.124 & $0.980(0.974-0.986)$ & $<0.0001$ \\
\hline$E F<35 \%$ & $4.74(2.71-8.27)$ & $<0.0001$ & $1.95(1.37-2.77)$ & $<0.0001$ \\
\hline Preoperative $\mathrm{Hb}^{*}$ & $1.024(0.896-1.171)$ & 0.726 & $0.813(0.759-0.870)$ & $<0.0001$ \\
\hline Redo & $1.11(0.61-2.00)$ & 0.726 & $1.17(0.87-1.56)$ & 0.290 \\
\hline PVD & $1.22(0.76-1.98)$ & 0.400 & 1.54 (1.24-1.92) & $<0.0001$ \\
\hline Hypertension & & & $1.20(1.00-1.43)$ & 0.044 \\
\hline No. of grafts & & & $0.974(0.894-1.062)$ & 0.553 \\
\hline Perioperative MI & $4.33(2.56-7.35)$ & $<0.0001$ & $1.90(1.31-2.75)$ & 0.001 \\
\hline Reexploration & $1.62(0.90-2.89)$ & 0.101 & $1.29(0.91-1.81)$ & 0.141 \\
\hline Off-pump surgery & & & $0.78(0.43-1.41)$ & 0.418 \\
\hline
\end{tabular}

*Entered as a continuous variable Max ST RBCs = maximum storage time of RBCs per patient, RBCs = red blood cells, FFP $=$ fresh frozen plasma, $C O P D=$ chronic obstructive pulmonary disease, $\mathrm{CrCl}=\mathrm{creatinine}$ clearance, $\mathrm{EF}=$ ejection fraction, $\mathrm{Hb}=$ hemoglobin, $\mathrm{PVD}=$ peripheral vascular disease, $\mathrm{MI}=$ myocardial infarction.

When the maximum storage time was used as a continuous variable, having received least $1 \mathrm{U}$ of older RBCs or only older blood was not a risk factor for early or late mortality. The only predictors of early mortality were the number of RBC units, advanced age, COPD, diabetes, a left ventricular EF of $<35 \%$, and perioperative myocardial infarction. The numbers of units of FFP and platelets were not significant predictors of late mortality. Predictors of late mortality were advanced age, male sex, COPD, diabetes, low $\mathrm{CrCl}$ clearance, a left ventricular EF of $<35 \%$, a lower preoperative $\mathrm{Hb}$ level, PVD, hypertension, and perioperative myocardial infarction.

The survival curves of patients who received a transfusion of younger blood or least $1 \mathrm{U}$ of older RBCs (Figure 1 ) and those who received younger blood or only older blood (Figure 2 ) were similar, with $P$ values of 0.269 and 0.806 , respectively. 


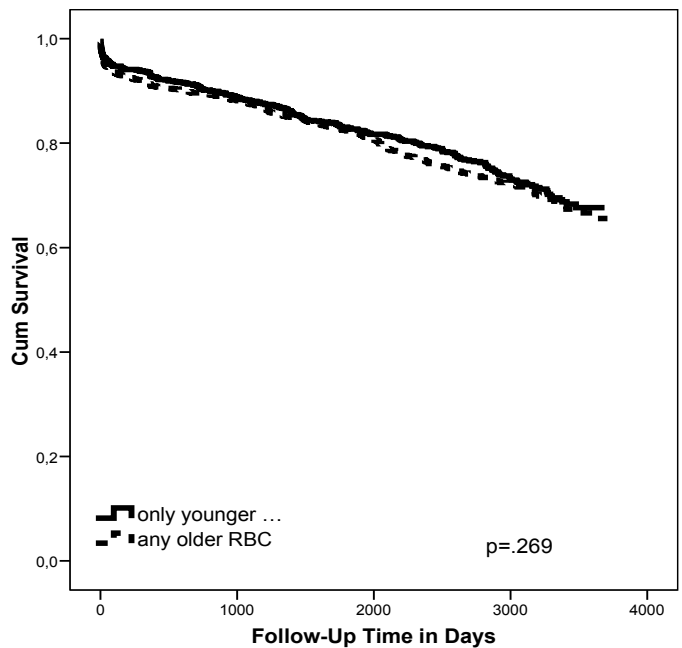

Figure 1: Kaplan-Meier survival curves for "only younger blood" and "any older blood" patient groups

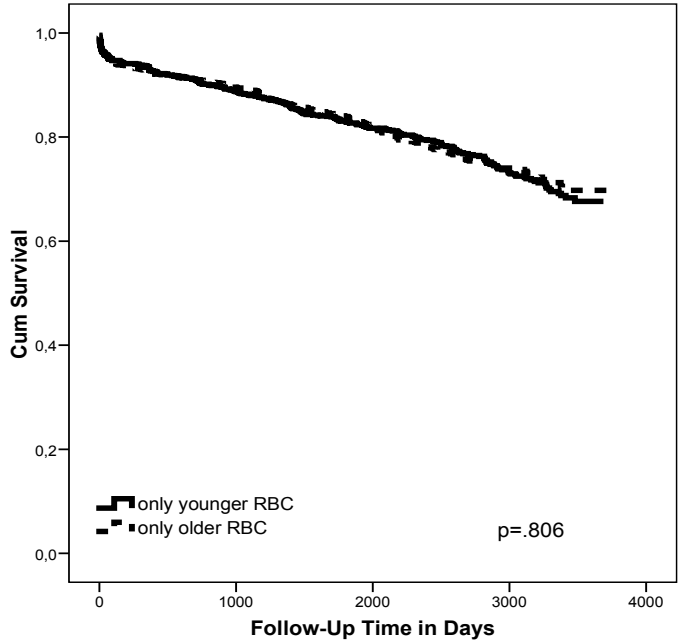

Figure 2: Kaplan-Meier survival curves for "only younger blood" and " only older blood" patient groups 


\section{Discussion}

In this retrospective analysis of 3597 patients who received a transfusion of RBCs during or after $C A B G$, the storage time of the transfused RBCs was not a significant predictor of early or late mortality. The effect of the transfusion of stored blood on the outcome of patients who undergo cardiac surgery remains controversial (17-21). That controversy might be due to the various patient populations studied, differences in study design or analysis, or different methods of blood storage. Vamvakas and Carven (19) studied the effect of the length of blood storage on postoperative morbidity in 268 consecutive patients who received a blood transfusion after CABG. Those authors found no association between the age of the transfused blood and the incidence of postoperative morbidity according to the length of intensive care treatment or hospital stay. Similar results were demonstrated by van de Watering and colleagues (20), who could not show an effect of the storage time of RBCs on mortality and morbidity in their analysis of 2732 patients who had undergone CABG. However, those authors did not exclude the negative effect of older blood on postoperative infection (20). Koch and colleagues (17) and Basran and colleagues (18) found that the transfusion of older RBCs was a risk factor for various complications and increased early mortality after cardiac surgery. In the study by Koch and colleagues, more patients who received older blood exhibited preoperative mitral regurgitation, left ventricular dysfunction, and peripheral vascular disease (17). In our study, the baseline characteristics of the groups studied were similar; this rendered confounding effects unlikely. By using multivariate analysis, we excluded the possible negative effects of those risk factors.

Our retrospective analysis was designed to minimize the effects of other complex procedures on early and late outcome. First, we only studied patients who underwent CABG, because the complexity of the surgical procedure can affect early as well as late outcome. Other studies included patients who underwent valve surgery (17) or redo surgery (18). Second, we excluded patients who received more than $10 \mathrm{U}$ of RBCs ( $0.5 \%$ of the total CABG population). The need for such a large number of transfused blood units reflects a major complication or a possible surgical catastrophic event. Those patients usually have a higher incidence of morbidity and/or mortality. The poor outcomes in such cases cannot be attributed only to the storage time of transfused RBCs. Furthermore, in addition to the 2 groups who received only younger blood or only older blood, we also examined a third group of patients: those who received at least $1 \mathrm{U}$ of old RBCs (the any older blood group). In that way, we tested the hypothesis that having received any number of units of older RBCs can affect outcome. The absence of a significant difference in early and late mortality disproves that hypothesis. We arbitrarily dichotomized our study population into groups with a cutoff point of 14 days. Koch and colleagues (17) used the same storage time (14 days), to define their "newer blood" and "older blood" groups. van de Watering and colleagues (20) used a 
storage time of 18 days. Other authors have used storage time as a continuous variable in their study analyses $(18,21)$. These factors can also explain the controversy that exists concerning the effect of storage time on the prognosis.

It has been assumed that preserved RBCs undergo functional and structural changes that begin after 2 weeks of storage $(13-16,22)$. The deformability of RBCs reduces with longer storage time; this leads to reduced microvascular flow (13-14). Oxygen delivery capacity of the stored RBCs is also reduced due to the depletion of 2,3-diphosphoglycerate (2,3-DPG) (23). The transfusion of stored rigid RBCs with low oxygen transport capacity could thus impede blood flow and predispose the patient to the development of ischemia. Our study does not support that hypothesis, because we found that the effect of a transfusion of older blood on mortality was not significant. It is possible that the effect of storage of RBCs on oxygen delivery is only physiologically significant, reversible, or insufficient to affect mortality. After transfusion, 2,3-DPG levels usually normalize within a few days (24). Tinmouth and Chin-Yee (25) indicated that the transfusion of 2,3-DPG-depleted blood in human and animal subjects produced no impairment in work performance, mortality, or tolerance of hypoxemic conditions. In addition, various storage conditions can retard the deterioration of RBCs. van de Watering and colleagues (20) did not find an association between the storage time of RBCs and adverse outcome after CABG, and their results confirm those of our study. Differences in blood withdrawal techniques, processing, and storage protocols for blood components among countries might explain the varying results. The protocol for the preservation of RBCs in The Netherlands seems to be safe for patients who need a transfusion of RBCs after CABG.

We suggest that the possible harm caused by the transfusion of stored RBCs must be weighed against the clinical benefits of transfusion. Prospective randomized studies are needed to determine the significance of storage effects of transfused RBCs after CABG. However, this is unlikely to occur because of the general shortage of blood for transfusion, logistical difficulties, and ethical issues worldwide.

\section{Limitations of this study}

In this retrospective study, other factors that are unaccounted for in the described demographic characteristics may have caused the differences cited. A prospective randomized trial could eliminate that shortcoming. Unfortunately, we were not able to report the causes of death in the study subjects. Our study is to our knowledge the second single-center study on the effect of storage time of RBCs after CABG that has been performed in The Netherlands. Whether the results of Dutch studies apply to CABG patients in countries in which other types of blood withdrawal, processing, and storage protocols of RBCs are implemented remains to be investigated. 


\section{Conclusions}

In a group of 3597 (of a total of 10 626) patients who received between 1 and $10 \mathrm{U}$ of RBCs within the first 5 postoperative days after CABG, we found a clear relationship between the number of transfused RBCs and early mortality. The storage time of RBCs was not a predictor of early or late mortality.

\section{Acknowledgements}

The authors thank the Sanquin Blood Supply Foundation in The Netherlands for help in collecting the data for this study. We also thank Prof. A. Brand and Dr. L. van de Watering for their support and advice in preparing the manuscript.

\section{References}

1. Robinson WP 3rd, Ahn J, Stiffler A, Rutherford EJ, Hurd H, Zarzaur BL, Baker CC, Meyer AA, Rich PB. Blood transfusion is an independent predictor of increased mortality in nonoperatively managed blunt hepatic and splenic injuries. J Trauma. 2005; 58:437-444; discussion 444-445.

2. Taylor RW, Manganaro L, O'Brien J, Trottier SJ, Parkar N, Veremakis C. Impact of allogenic packed red blood cell transfusion on nosocomial infection rates in the critically ill patient. Crit Care Med. 2002; 30:2249-2254.

3. Malone DL, Dunne J, Tracy JK, Putnam AT, Scalea TM, Napolitano LM. Blood transfusion, independent of shock severity, is associated with worse outcome in trauma. J Trauma. 2003; 54:898-905; discussion 905-907.

4. Koch CG, Li L, Duncan Al, Mihaljevic T, Cosgrove DM, Loop FD, Starr NJ, Blackstone EH. Morbidity and mortality risk associated with red blood cell and blood-component transfusion in isolated coronary artery bypass grafting. Crit Care Med. 2006; 34:1608-1616.

5. Kuduvalli M, Oo AY, Newall N, Grayson AD, Jackson M, Desmond MJ, Fabri BM, Rashid A. Effect of perioperative red blood cell transfusion on 30-day and 1-year mortality following coronary artery bypass surgery. Eur J Cardiothorac Surg. 2005; 27:592-598.

6. Leal-Noval SR, Rincón-Ferrari MD, García-Curiel A, Herruzo-Avilés A, Camacho-Laraña P, GarnachoMontero J, Amaya-Villar R. Transfusion of blood components and postoperative infection in patients undergoing cardiac surgery. Chest. 2001; 119:1461-1468.

7. Engoren MC, Habib RH, Zacharias A, Schwann TA, Riordan CJ, Durham SJ. Effect of blood transfusion on long-term survival after cardiac operation. Ann Thorac Surg. 2002; 74:1180-1186.

8. Zallen G, Offner PJ, Moore EE, Blackwell J, Ciesla DJ, Gabriel J, Denny C, Silliman CC. Age of transfused blood is an independent risk factor for postinjury multiple organ failure. Am J Surg. 1999; 178:570-572.

9. Mynster T, Nielsen HJ; Danish RANX05 Colorectal Cancer Study Group. Storage time of transfused blood and disease recurrence after colorectal cancer surgery. Dis Colon Rectum. 2001; 44:955-964.

10. Offner PJ, Moore EE, Biffl WL, Johnson JL, Silliman CC. Increased rate of infection associated with transfusion of old blood after severe injury. Arch Surg. 2002; 137:711-716; discussion 716-717.

11. Purdy FR, Tweeddale MG, Merrick PM. Association of mortality with age of blood transfused in septic ICU patients. Can J Anaesth. 1997; 44:1256-1261.

12. Tinmouth A, Fergusson D, Yee IC, Hébert PC; ABLE Investigators; Canadian Critical Care Trials Group. Clinical consequences of red cell storage in the critically ill. Transfusion. 2006; 46:2014-2027. 
13. Wolfe LC. Oxidative injuries to the red cell membrane during conventional blood preservation. Semin Hematol. 1989; 26:307-312.

14. Berezina TL, Zaets SB, Morgan C, Spillert CR, Kamiyama M, Spolarics Z, Deitch EA, Machiedo GW. Influence of storage on red blood cell rheological properties. J Surg Res. 2002; 102:6-12.

15. d'Almeida MS, Jagger J, Duggan M, White M, Ellis C, Chin-Yee IH. A comparison of biochemical and functional alterations of rat and human erythrocytes stored in CPDA-1 for 29 days: implications for animal models of transfusion. Transfus Med. 2000; 10:291-303.

16. Kirkpatrick UJ, Adams RA, Lardi A, McCollum CN. Rheological properties and function of blood cells in stored bank blood and salvaged blood. Br J Haematol. 1998; 101:364-368.

17. Koch CG, Li L, Sessler DI, Figueroa P, Hoeltge GA, Mihaljevic T, Blackstone EH. Duration of red-cell storage and complications after cardiac surgery. N Engl J Med. 2008; 358:1229-1239.

18. Basran S, Frumento RJ, Cohen A, Lee S, Du Y, Nishanian E, Kaplan HS, Stafford-Smith M, BennettGuerrero $\mathrm{E}$. The association between duration of storage of transfused red blood cells and morbidity and mortality after reoperative cardiac surgery. Anesth Analg. 2006 Jul;103(1):15-20, table of contents. Retraction in: Shafer SL. Anesth Analg. 2009; 108:1953.

19. Vamvakas EC, Carven JH. Length of storage of transfused red cells and postoperative morbidity in patients undergoing coronary artery bypass graft surgery. Transfusion. 2000; 40:101-109.

20. van de Watering L, Lorinser J, Versteegh M, Westendord R, Brand A. Effects of storage time of red blood cell transfusions on the prognosis of coronary artery bypass graft patients. Transfusion. 2006; 46:1712-1718.

21. Yap CH, Lau L, Krishnaswamy M, Gaskell M, Yii M. Age of transfused red cells and early outcomes after cardiac surgery. Ann Thorac Surg. 2008; 86:554-559.

22. Ho J, Sibbald WJ, Chin-Yee IH. Effects of storage on efficacy of red cell transfusion: when is it not safe? Crit Care Med. 2003; 31:S687-S697.

23. Valeri CR, Collins FB. The physiologic effect of transfusing preserved red cells with low 2,3diphosphoglycerate and high affinity for oxygen. Vox Sang. 1971; 20:397-403.

24. Högman CF, Meryman HT. Storage parameters affecting red blood cell survival and function after transfusion. Transfus Med Rev. 1999; 13:275-296.

25. Tinmouth A, Chin-Yee I. The clinical consequences of the red cell storage lesion. Transfus Med Rev. 2001; 15:91-107. 



\section{Chapter 9}

\section{Effect of storage time of transfused plasma on early and late mortality after coronary artery bypass grafting}

Submitted

Authors

Albert H. M. van Straten ${ }^{1}$

Mohamed A. Soliman Hamad ${ }^{1}$

Elisabeth J. Martens ${ }^{2}$

Volkher Scharnhorst ${ }^{3}$

M.Erwin S. H. $\operatorname{Tan}^{1}$

Andre M. de Wolf, MD ${ }^{4}$

André A. J. van Zundert ${ }^{5}$

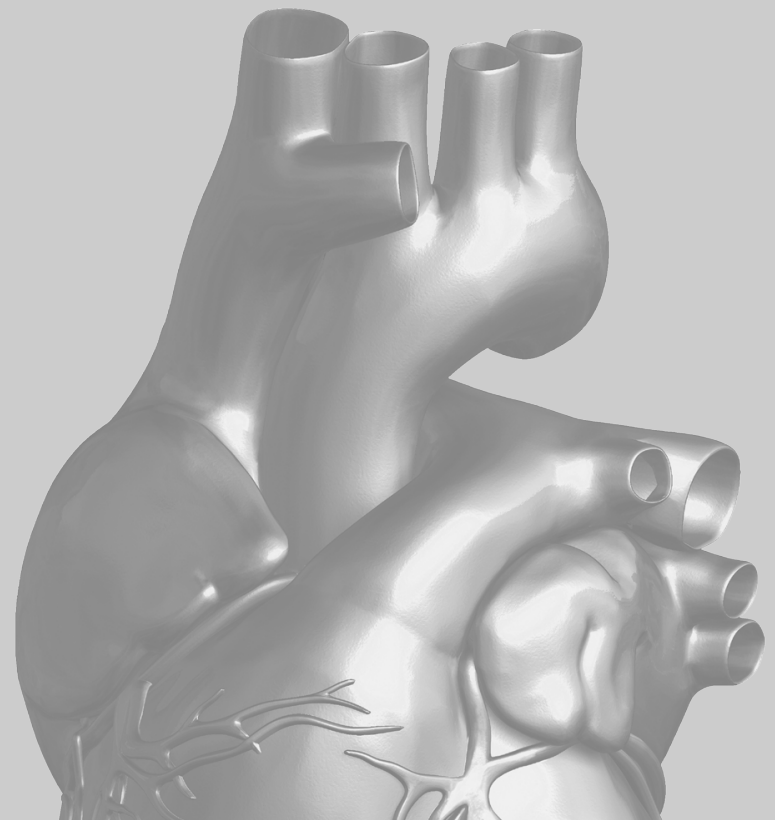

1 Department of Cardiothoracic Surgery, Catharina Hospital, Eindhoven, The Netherlands;

2 Department of Education and Research, Catharina Hospital, Eindhoven, The Netherlands;

3 Department of Education and Research, Catharina Hospital, Eindhoven, The Netherlands and

4 Department of Anesthesiology, The Feinberg School of Medicine, Northwestern University, Chicago, Illinois, USA

5 Department of Anesthesiology, Catharina Hospital - Brabant Medical School, Eindhoven, The Netherlands and the University Hospital Ghent, Ghent, Belgium 


\begin{abstract}
Background

Since some concern has been raised about the storage time of Red Blood Cells and outcome after cardiac surgery we investigated whether longer storage time of transfused plasma increases the risk for early or late mortality in patients who have undergone coronary artery bypass grafting.
\end{abstract}

\title{
Methods
}

We retrospectively analyzed the data of all 10,626 patients who underwent isolated coronary artery bypass grafting in Catharina Hospital, Eindhoven, The Netherlands, between January 1998 and December 2007. All patients who received at least $1 \mathrm{U}$ of plasma intraoperatively or during the first 5 postoperative days were studied. They were divided into 3 groups (the "only younger plasma" group, the "only older plasma" group, and the "any older plasma" group) according to the storage time of the plasma (cutoff point, 323 days).

\section{Results}

After we had excluded 122 patients who were lost to follow-up, we found that 375 of the remaining patients received only younger plasma, 370 patients received any older plasma, and 200 patients received only older plasma (mean follow-up, $1565 \pm 1137$ days; median follow-up, 1629 days). The storage time of plasma, when entered as either a continuous variable or as a dichotomous variable, was a risk factor for early but not late mortality. Log-rank testing revealed no statistical difference in long-term survival among the groups.

\section{Conclusions}

Longer storage time of plasma is a risk factor for early but not late mortality in patients who have undergone coronary artery bypass grafting. 


\section{Background}

Critically ill patients, including those who have undergone cardiac surgery, often experience more severe complications if they have received a blood transfusion in the perioperative period $(1,2)$. The storage time of red blood cells may influence the risk of such complications (3-8) because those cells may undergo structural and functional changes that can reduce their function and viability after transfusion (8-10). Recently, some $(11)$ but not all $(12,13)$ authors have expressed concern about a higher perioperative mortality when using older red blood cells for transfusion after cardiac surgery. In their reports, several endpoints regarding heterogeneous patient populations were mentioned.

The transfusion of fresh-frozen plasma from female donors can lead to transfusion-related acute lung injury (14-19). To our knowledge, no data regarding the effect of the storage time of transfused fresh-frozen plasma on early and late outcomes after coronary artery bypass grafting are available. We therefore studied whether the storage time of transfused fresh-frozen plasma increases the risk for early and late mortality in a large group of patients who underwent coronary artery bypass grafting in a single centre.

\section{Patients and Methods}

\section{Patients}

This study included the data of all adult patients who underwent isolated coronary artery bypass grafting in Catharina Hospital, Eindhoven, The Netherlands, between January 1998 and December 2007. Data collection was initiated in January 1998, when clinical information (demographic data, risk factors, and complications) on the study subjects was prospectively collected in a database.

\section{Methods}

Approval was obtained from the institution's research review board. Data on blood transfusions and the storage time of fresh-frozen plasma were collected from the database of the hospital transfusion service. All patients who had received at least $1 \mathrm{U}$ of fresh-frozen plasma between the day of operation and the fifth postoperative day were included in this study. Patients who had received more than $10 \mathrm{U}$ of red blood cells were excluded from the analysis. The maximum time of storage of the transfused fresh-frozen plasma per patient was referred to as the "maximum storage time." The patients were divided into 3 groups according to the storage time of fresh-frozen plasma: those who received only fresh-frozen plasma that had been stored for $<323$ days (the younger fresh-frozen plasma group), patients who received only fresh-frozen 
plasma that had been stored for $\geq 323$ days (the only older fresh-frozen plasma group), and patients who received a least 1 older fresh-frozen plasma unit (the any older freshfrozen plasma group). We used the cut-off point of 323 days because that was the median maximum storage time of all fresh-frozen plasma transfused in this study. Patients in the only older fresh-frozen plasma group were included in the any older fresh-frozen plasma group.

\section{Operative technique}

All patients received short-acting anesthetic drugs to facilitate early extubation. Normothermic extracorporeal circulation was performed using nonpulsatile flow. Either cold crystalloid cardioplegia (St. Thomas' solution) or warm blood cardioplegia, according to the surgeon's preference, was used to induce and maintain cardioplegic arrest. All patients who underwent coronary artery bypass grafting with the use of extracorporeal circulation received low-dose aprotinin (2 million KIU) during extracorporeal circulation that was administered in the prime solution of the heart-lung machine, as was the usual practice in our hospital. Patients who underwent off-pump surgery did not receive aprotinin.

\section{Storage of fresh-frozen plasma}

After withdrawal of the donor blood, the plasma was frozen and stored for at least 6 months at $-30^{\circ} \mathrm{C}$ before it was released for transfusion. During those 6 months, the donor was tested for viral diseases. The maximum allowed storage time is two years.

\section{Follow-up}

Follow-up data on the mortality of the patients studied were gathered from the databases of Dutch health insurance companies. Initially, the data of $9 \%$ of the total patient group could not be retrieved from those databases. We then contacted the general practitioners of those subjects to obtain the required mortality data. If necessary, we also contacted the authorities of the city in which those patients lived at the time of surgery. Postoperative mortality was defined as early (<31 days) or late ( $>30$ days).

\section{Indication for transfusion of fresh-frozen plasma}

If coagulation disorders measured by activated partial plastin time (APTT), prothrombin time (PTT), international normalized ratio (INR) and fibrinogen level are present in case of excessive bleeding, fresh-frozen plasma is transfused.

\section{Statistical analyses}

Discrete variables were compared with the chi-square test and are presented as numbers and percentages. Continuous variables were compared with the $t$ test and analysis of variance and are presented as the mean \pm Standard Deviation. Univariate and multivariate logistic regression analyses were performed to investigate the impact of 
several risk factors on early mortality. Multivariate analyses were used to test for the potentially confounding effects of biomedical and demographic factors on outcome. Cox proportional hazard regression analyses were performed for the same analyses of late mortality. If they were significant at a $P$ value of $<0.05$, confounders were included in multivariate logistic and Cox regression analyses.

Factors that were significant in the univariate analyses were entered into a multivariate model together with the items of interest (the number of transfused freshfrozen plasma units and the maximum storage time per fresh-frozen plasma unit as a continuous variable and as a dichotomous variable). Long-term survival was described with the Kaplan-Meier method. A comparison of long-term survival was performed with log-rank statistics. The zero time point indicated the time of coronary artery bypass grafting. A $\mathrm{P}$ value of $<0.05$ was used for all tests to indicate statistical significance. Hazard ratios with $95 \%$ confidence intervals are reported. Predicted probability for early mortality was calculated for the per patient maximum storage time using logistic regression analyses. All statistical analyses were performed with SPSS software (Statistical Product and Service Solutions, version 15.0, SSPS Inc, Chicago, Illinois).

\section{Results}

During a 10-year period (January 1998 through December 2007) 10626 patients underwent coronary artery bypass grafting in our hospital. Excluded from the analysis were patients who were lost to follow-up $(n=122)$ and those who received more than $10 U$ of red blood cells $(n=80)$. Of the remaining patients, 375 received only younger fresh-frozen plasma, 370 received any older fresh-frozen plasma, and 200 patients received only older fresh-frozen plasma. The mean follow-up was $1565 \pm 1137$ days (range, 0-3704 days). The median follow-up time was 1506 days. The mean storage time for fresh-frozen plasma was 341 $\$ 94$ days (range, 196-730 days), and the median storage time was 323 days. The distribution of fresh-frozen plasma storage time is shown in Figure 1.

Baseline characteristics stratified by storage time are shown in Table 1. 


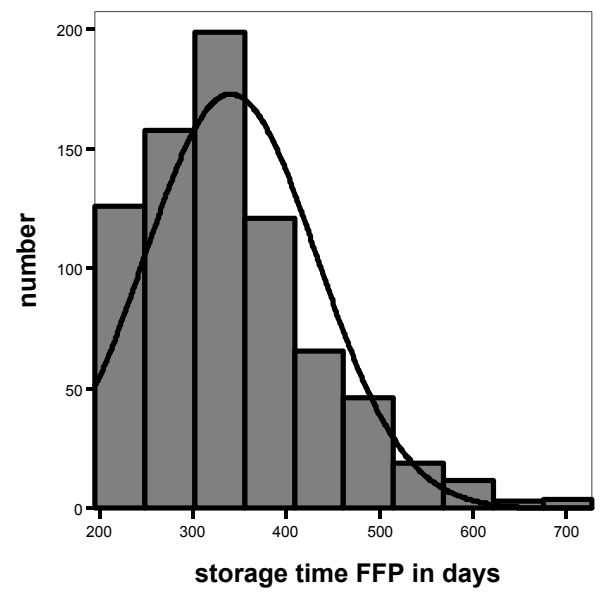

Figure 1 Distribution of maximum (per patient) storage time of fresh frozen plasma

None of the differences in baseline characteristics among the patient groups was significant except for re-exploration, which occurred more often in patients who had received only younger fresh-frozen plasma, and the number of transfused units of fresh-frozen plasma and platelets, which were higher in patients who had received any older fresh-frozen plasma. Only the number of units of transfused platelets was higher in the group of patients who had received only older fresh-frozen plasma.

Early mortality occurred more often in patients who received older fresh-frozen plasma (ie, in $7.0 \%$ of those who received any older fresh-frozen plasma and in $9.0 \%$ of those who received only older fresh-frozen plasma) than in patients who received younger fresh-frozen plasma (3.2\%), as shown in Table 2. 
Table 1 Baseline characteristics stratified by storage age of blood components

\begin{tabular}{|c|c|c|c|c|c|}
\hline & $\begin{array}{l}\text { Younger FFP } \\
N=375\end{array}$ & $\begin{array}{l}\text { Any older FFP } \\
N=370\end{array}$ & $p$-value & $\begin{array}{l}\text { Only older FFP } \\
N=200\end{array}$ & $\mathrm{p}$-value \\
\hline \multicolumn{6}{|c|}{ Preoperative factors } \\
\hline Age & $65.0 \pm 9.4$ & $65.7 \pm 9.9$ & .288 & $66.4 \pm 9.3$ & .088 \\
\hline Male & $305(81.3)$ & $307(83.0)$ & .313 & $164(82.0)$ & .470 \\
\hline Diabetes & $76(20.3)$ & $69(18.6)$ & .321 & $37(18.5)$ & .348 \\
\hline Hypertension & $146(38.9)$ & $134(36.2)$ & .245 & $83(41.5)$ & .305 \\
\hline COPD & $45(12.0)$ & $50(13.5)$ & .305 & $29(14.4)$ & .234 \\
\hline PVD & $48(12.8)$ & $44(11.9)$ & .396 & $28(14.0)$ & .388 \\
\hline$E F<35 \%$ & $12(3.4)$ & $18(5.3)$ & .163 & $6(3.2)$ & .560 \\
\hline $\mathrm{CrCl}$ & $71.2 \pm 23.9$ & $70.5 \pm 23.9$ & .690 & $70.1 \pm 24.3$ & .606 \\
\hline Emergency & $46(12.3)$ & $49(13.2)$ & $.386)$ & $29(14.5)$ & .263 \\
\hline $\mathrm{Hb}\left(\mathrm{g} \cdot \mathrm{dl}^{-1}\right)$ & $13.7 \pm 1.5$ & $13.8 \pm 1.4$ & .414 & $13.6 \pm 1.1$ & .494 \\
\hline Redo & $55(14.7)$ & $52(14.1)$ & .447 & $28(14.0)$ & .467 \\
\hline \multicolumn{6}{|c|}{ Peri- and postoperative factors } \\
\hline No of grafts & $3.3 \pm 1.2$ & $3.4 \pm 1.1$ & .471 & $3.3 \pm 1.1$ & .708 \\
\hline Off-pump & $26(6.9)$ & $26(7.0)$ & .537 & $18(9.0)$ & .233 \\
\hline ECC time & $66.2 \pm 44.0$ & $65.4 \pm 42.9$ & .798 & $65.2 \pm 45.6$ & .786 \\
\hline IABP & $32(8.5)$ & $30(8.1)$ & .469 & $15(7.5)$ & .398 \\
\hline Re-exploration & $134(35.7)$ & $120(32.4)$ & .191 & $50(25.0)$ & .005 \\
\hline Periop MI & $32(8.5)$ & $28(7.6)$ & .364 & $14(7.0)$ & .318 \\
\hline No of RBC & $3.7 \pm 2.7$ & $3.8 \pm 2.8$ & .740 & $3.3 \pm 2.5$ & .066 \\
\hline No of FFP & $2.5 \pm 1.1$ & $2.8 \pm 1.5$ & .001 & $2.4 \pm 1.1$ & .409 \\
\hline No of platelets & $0.29 \pm 0.56$ & $0.46 \pm 0.81$ & .001 & $0.42 \pm 0.75$ & .016 \\
\hline
\end{tabular}

Results are expressed as mean \pm standard deviation or as number(percentage) COPD = chronic obstructive pulmonary disease, $\mathrm{PVD}=$ peripheral vascular disease, $\mathrm{EF}=$ left ventricular ejection fraction, $\mathrm{CrCl}=\mathrm{creatinine}$ clearance, $\mathrm{ECC}$-time = duration of extra-corporeal circulation, Redo = history of previous cardiac surgery, $\mathrm{Hb}$ = preoperative hemoglobin level, IABP = intra-aortic balloon pump support, Periop $\mathrm{MI}$ = perioperative myocardial infarction, no of RBC = number of transfused Red Blood Cells, No of FFP, number of transfused fresh frozen plasma.

Table 2. Early and late mortality in patients receiving younger and older FFP

\begin{tabular}{llllll}
\hline & Younger FFP & Any older FFP & p-value* & Only older FFP & p-value* \\
\hline Early mortality & $12(3.2)$ & $29(7.8)$ & .004 & $18(9.0)$ & .003 \\
Late mortality & $58(15.5)$ & $43(11.6)$ & 0.077 & $17(8.5)$ & .011 \\
\hline
\end{tabular}

*compared to younger FFP

Univariate logistic regression analyses (Table 3) revealed that the maximum storage time of fresh-frozen plasma, as both a continuous variable and a dichotomous variable with a cut-off point of 323 days (only older fresh-frozen plasma and any older freshfrozen plasma versus younger fresh-frozen plasma), was a significant risk factor for early mortality. 
Table 3 Univariate logistic regression analyses of risk factors for early mortality and Cox regression analyses for late mortality.

\begin{tabular}{lllll}
\hline & Early mortality & \multicolumn{3}{c}{ Late mortalty } \\
\hline Preoperative factors & & & & \\
Risk factor & HR $(95 \% \mathrm{Cl})$ & p-value & HR(95\%Cl) & -value \\
Age* & $1.043(1.005-1.082)$ & .027 & $1.077(1.051-1.104)$ & $<.0001$ \\
Male gender & $0.65(0.31-1.37)$ & .264 & $0.72(0.45-1.14)$ & .169 \\
COPD & $2.34(1.11-4.96)$ & .026 & $2.43(1.53-3.84)$ & $<.0001$ \\
Diabetes & $2.54(1.31-4.94)$ & .006 & $1.97(1.28-3.04)$ & .002 \\
CrCl* & $0.977(0.961-0.992)$ & .003 & $0.969(0.958-9.979)$ & $<.0001$ \\
EF<35\% & $4.20(1.50-11.73)$ & .014 & $2.03(0.88-4.65)$ & .093 \\
Preop Hb* & $0.702(0.577-0.855)$ & $<.0001$ & $0.767(0.671-0.877)$ & $<.0001$ \\
Redo & $3.40(1.72-6.73)$ & .001 & $1.78(1.11-2.86)$ & .017 \\
PVD & $1.78(0.80 / 4.00)$ & .120 & $2.21(1.35-3.61)$ & .001 \\
Emergency & $3.52(1.75-7.07)$ & .001 & $1.54(0.89-2.66)$ & .122 \\
Hypertension & $1.18(0.62-2.25)$ & .355 & $1.50(1,01-2.23)$ & .045 \\
Peri and postoperative factors & & & \\
No of grafts* & $0.825(0.634-1.074)$ & .152 & $1.003(0.857-1.175)$ & .970 \\
Periop MI & $3.04(1.33-6.91)$ & .013 & $3.03(1.80-5.12)$ & $<.0001$ \\
Re-exploration & $0.79(0.39-1.57)$ & .313 & $0.93(0.62-1.40)$ & .745 \\
Off pump & $1.47(0.50-4.31)$ & .476 & $0.77(0.28-2.10)$ & .616 \\
Year of operation & $0.972(0.975-1.080)$ & .596 & $0.961(0.879-1.052)$ & .390 \\
Max ST FFP* & $1 / 004(1.001-1.007)$ & .005 & $1.001(0.999-1.003)$ & .294 \\
Any Older FFP & $2.57(1.29-5.12)$ & .007 & $0.98(0.66-1.47)$ & .943 \\
Only Older FFP & $2.99(1.41-6.34)$ & .004 & $0.80(0.46-1.39)$ & .439 \\
No of FFP & $1.264(1.074-1.487)$ & .005 & $1.239(1.096-1.400)$ & .001 \\
No of platelets & $1.698(1.228-2.347)$ & .001 & $1.183(0.893-1.566)$ & .242 \\
No of RBC & $1.220(1.091-1.364)$ & $<.0001$ & $1.089(1.016-1.168)$ & .016 \\
\hline
\end{tabular}

*entered as a continuous variable. $\mathrm{HR}=$ Hazard ratio, $\mathrm{Cl}=$ confidence interval, $\mathrm{COPD}=$ chronic obstructive pulmonary disease, $\mathrm{Preop} \mathrm{CrCl}=$ preoperative creatinine clearance, $\mathrm{EF}=$ left ventricular ejection fraction, $\mathrm{Hb}$ $=$ hemoglobin level, Redo = previous cardiac surgery, PVD = peripheral vascular disease, Periop $\mathrm{MI}=$ perioperative myocardial infarction, $\max \mathrm{ST}=$ maximum storage time per patient, $\mathrm{RBC}=$ red blood cells, $\mathrm{FFP}=$ fresh frozen plasma

All risk factors that were identified via univariate analyses were entered into the multivariate logistic regression and multivariate Cox regression models (Table 4). 
Table 4 Multivariate logistic regression analyses for early mortality and Cox regression analyses for late mortality

\begin{tabular}{lllll}
\hline & Early mortality & & Late mortality & \\
\hline Risk factor & HR $(95 \% \mathrm{Cl})$ & $\mathrm{p}$-value & $\mathrm{HR}(95 \% \mathrm{Cl})$ & $\mathrm{p}$-value \\
Max ST FFP* & $1.004(1.001-1.008)$ & .023 & $1.001(0.998-1.003)$ & .622 \\
Any Older FFP & $2.29(1.00-5.22)$ & .048 & $0.93(0.62-1.51)$ & .104 \\
Only Older FFP & $3.43(1.32-8.92)$ & .011 & $0.78(0.42-1.43)$ & .159 \\
& & & & .110 \\
No of RBC * & $1.067(0.902-1.261)$ & .451 & $0.931(0.852-1.016)$ & $<.0001$ \\
No of FFP* & $1.025(0.785-1.338)$ & .856 & $1.347(1.165-1.558)$ & .003 \\
No of platelets* & $1.406(0.847(2.332)$ & .188 & & $<.0001$ \\
Age* & $1.022(0.972-1.075)$ & .401 & $1.048(1.016-1.081)$ & .018 \\
COPD & $1.83(0.72-1.07)$ & .201 & $2.68(1.67-4.31)$ & .064 \\
Diabetes & $3.34(1.46-7.62)$ & .004 & $1.75(1.10-2.79)$ & .043 \\
CrCl* & $0.995(0.974-1.016)$ & .640 & $0.986(0.972-1.001)$ & .078 \\
EF<35\% & $3.65(1.08-12.29)$ & .036 & & .216 \\
Preop Hb* & $0.837(0.649-1.079)$ & .170 & $0.860(0.744-0.995)$ & \\
Redo & $1.74(0.68-4.47)$ & .244 & $1.57(0.95-2.61)$ & \\
PVD & & & $1.40(0.81-2.42)$ & \\
Emergency & $2.22(0.68-7.18)$ & .183 & & \\
Periop MI & $4.11(1.54-10.95)$ & .005 & $3.62(2.00-6.56)$ & $<.0001$ \\
\hline
\end{tabular}

*entered as a continuous variable. $\mathrm{HR}=$ Hazard ratio, $\mathrm{Cl}=$ confidence interval, $\mathrm{COPD}=$ chronic obstructive pulmonary disease, Preop $\mathrm{CrCl}=$ preoperative creatinine clearance, $\mathrm{EF}=$ left ventricular ejection fraction, $\mathrm{Hb}$ $=$ hemoglobin level, Redo = previous cardiac surgery, PVD = peripheral vascular disease, Periop $\mathrm{MI}=$ perioperative myocardial infarction, $\max \mathrm{ST}=$ maximum storage time per patient, $\mathrm{RBC}=$ red blood cells, FFP = fresh frozen plasma

Other risk factors for early mortality were age, chronic obstructive pulmonary disease, diabetes, low creatinine clearance, a left ventricular ejection fraction of $<35 \%$, a low preoperative hemoglobin level, previous cardiac surgery, emergency operation, perioperative myocardial infarction, and the number of units of transfused red blood cells, fresh-frozen plasma, and platelets. Univariate Cox regression analyses did not reveal the maximum storage time of fresh-frozen plasma as a risk factor for late mortality. Factors that were significant for late mortality were age, chronic obstructive pulmonary disease, diabetes, low creatinine clearance, a low preoperative hemoglobin level, previous cardiac surgery, peripheral vascular disease, hypertension, perioperative myocardial infarction, and the number of units of transfused red blood cells and fresh-frozen plasma.

\section{Early mortality}

The maximum storage time of fresh-frozen plasma, when entered as a continuous and as a dichotomous variable with a cutoff point of 323 days (only older fresh-frozen 
plasma and any older fresh-frozen plasma versus younger fresh-frozen plasma), was identified as an independent risk factor for early mortality. Since the number of RBC, FFP and platelets are entered into the multivariate model this effect is independent of the number of transfusion of blood products. Other independent risk factors for early mortality were: diabetes, a left ventricular ejection fraction of $<35 \%$, and perioperative myocardial infarction

The predicted probability for early mortality increases with storage time for all patients as well as for patients who received 1 or 2 units of FFP as is shown in figure 2 and 3.

\section{Late mortality}

The maximum storage time of fresh-frozen plasma, when entered as continuous variable as well as a dichotomous variable with a cutoff point of 323 days (older versus younger fresh-frozen plasma), was not identified as an independent risk factor for late mortality.

Independent risk factors for late mortality were the number of transfused freshfrozen plasma units, age, chronic obstructive pulmonary disease, diabetes, a low preoperative haemoglobin level, and perioperative myocardial infarction.

The survival curves of patients who received a transfusion of younger and those who received any older fresh-frozen plasma are shown in Figure 4. The survival curves of those patients who received a transfusion of younger and of those who received only older fresh-frozen plasma are shown in Figure 5. The difference between the curves did not reach statistical significance. However it is clear that there is a distinct difference in the early postoperative period.

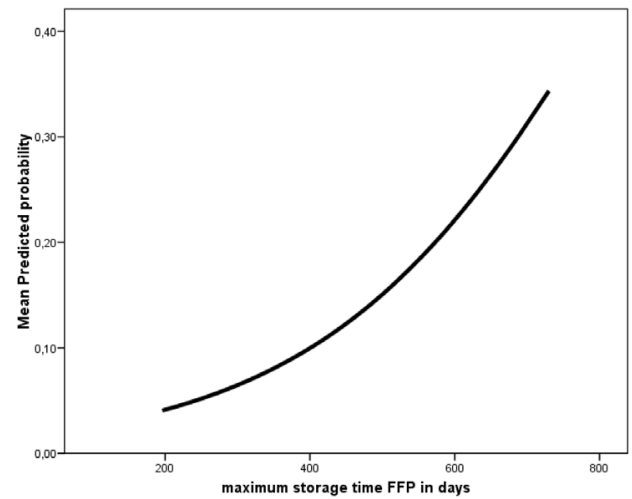

Figure 2 Predicted probability for early mortality for all patients 

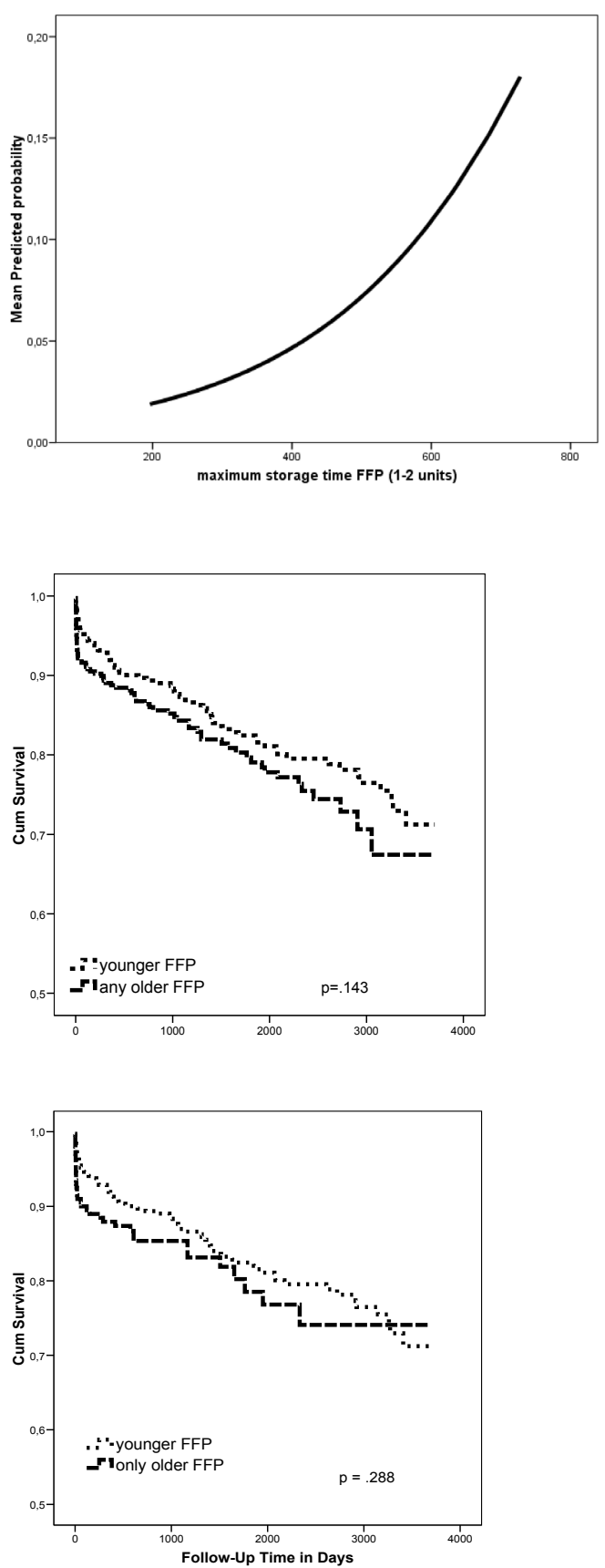

Figure 3 Predicted probability for early mortality for patients with 1-2 FFP

Figure 4 Kaplan-Meier curves for patients receiving only younger or any older FFP.
Figure 5 Kaplan-Meier curves for patients receiving younger or only older FFP. 


\section{Discussion}

This retrospective study shows that the transfusion of older frozen plasma is an independent risk factor for early but not late mortality. The study population consisted of patients who received at least $1 \mathrm{U}$ of fresh-frozen plasma and up to $10 \mathrm{U}$ of red blood cells intraoperatively or within the first 5 postoperative days after coronary artery bypass grafting. Patients who received more than $10 \mathrm{U}$ of red blood cells were excluded from this study. The reason is that most of these patients experienced massive blood loss due to surgical calamities that caused various complications, including death. Thus, the outcome in these cases is mainly influenced by the major surgical insult. The decision to transfuse younger or older FFP was random based on the availability of the FFP. The cut-off point for younger and older FFP of 323 days (the median of the storage times) is arbitrary. In the multivariate logistic regression analyses both the maximum storage time used as a continuous variable as well as used as a dichotomous variable are revealed as independent risk factors. The year of operation did not prove to be an independent risk factor for early mortality and the storage protocol did not change over time. This indicates a real effect of storage age on early mortality. The predicted probability for early mortality increased with longer per patient maximum storage times. The same was found in patient who received 1 or 2 units of FFP. This confirms the results of the multivariate regression analyses that showed that the storage time was an independent risk factor.

Despite the fact that the incidence of late mortality was less in the "any older" group and the "only older" group multivariate analyses revealed that late mortality was not influenced by the storage time of fresh-frozen plasma. Surprisingly, the number of units of transfused red blood cells, fresh-frozen plasma, and platelets did not prove to be a risk factor for early mortality. This can be probably explained by the fact that in this subgroup of patients who received fresh-frozen plasma, the mean number of transfused red blood cell units was already high (mean, $3.6 \pm 2.6 \mathrm{U}$ ). The transfusion of additional red blood cells in those patients did not increase the risk for mortality or morbidity any further.

In earlier reports, transfusion-related acute lung injury was described (14-19). The authors of those reports suggested that leucocyte antibodies and fresh-frozen plasma from female donors might be important risk factors for the development of transfusion-related acute lung injury in critically ill patients.

Using the plasma of multiparous women would increase that risk even further (20).

To our knowledge, no data on the effect of the storage time of fresh-frozen plasma on short-term and long-term outcomes after coronary artery bypass grafting are available. We found a clear relationship between the storage time of fresh-frozen plasma and early mortality. Baseline characteristics between patients who received younger fresh- 
frozen plasma and those who received older fresh-frozen plasma were similar. To further eliminate the effect of confounders, multivariate analyses were performed. The results of those analyses led to the conclusion that the transfusion of older freshfrozen plasma resulted in a poorer early outcome and that there was no relationship between the storage time of fresh-frozen plasma and late outcome.

It has been demonstrated that prothrombin time and activated partial thromboplastin time are influenced by freezing and storage. That effect is more pronounced at $-20^{\circ} \mathrm{C}$ than at $-70^{\circ} \mathrm{C}(21)$. Factor VIII levels are influenced by the storage temperature after thawing $(22,23)$ or after storage without freezing $(24)$. It has also been shown that slow freezing causes a more pronounced decrease in the level of factor VIII than does more rapid freezing (25). In The Netherlands, blood products are stored at $-30^{\circ} \mathrm{C}$. At that temperature, the degeneration of clotting factors and other proteins cannot be excluded. Degeneration may lead to less effective clotting factors, and the degenerated proteins produce unknown adverse effects. This possible progressive degeneration of proteins might be the reason for which our subjects who received older fresh-frozen plasma had a relatively worse outcome. Further studies are needed to investigate the possible progressive degeneration of proteins. Because most transfused fresh-frozen plasma is older than 300 days, it might be advantageous to use, whenever possible, younger fresh-frozen plasma for transfusion until that issue has been further clarified.

\section{Limitations of this study}

In this retrospective study, factors not included in the list of demographic characteristics may explain the differences between the patients' groups. A prospective randomized trial should solve that shortcoming. Unfortunately, we were not able to report the cause of death in our study subjects. This investigation was a single-center study performed in The Netherlands. Whether our results can be applied to coronary artery bypass grafting performed in other countries in which different protocols for blood withdrawal, processing, and storage are practiced remains to be determined.

\section{Conclusions}

In 745 of 10626 patients who underwent coronary artery bypass grafting and who received fresh-frozen plasma intraoperatively or within the first 5 postoperative days after coronary artery bypass grafting, we found that the longer storage time of freshfrozen plasma was an independent risk factor for early but not late mortality. 


\section{Acknowledgements}

The authors thank the Sanquin Blood Supply Foundation in The Netherlands for help in collecting the data for this study. We also thank Prof. A. Brand and Dr. L. van de Watering for their support and advice in preparing the manuscript.

\section{References}

1. Robinson WP 3rd, Ahn J, et al. Blood transfusion is an independent predictor of increased mortality in nonoperatively managed blunt hepatic and splenic injuries. J Trauma2005;58:437-44; discussion 444-5.

2. Malone DL, Dunne J, Tracy JK, Putnam AT, Scalea TM, Napolitano LM. Blood transfusion, independent of shock severity, is associated with worse outcome in trauma. J Trauma 2003;54:898-905; discussion 905-7.

3. Koch CG, Li L, Duncan Al, et al. Morbidity and mortality risk associated with red blood cell and bloodcomponent transfusion in isolated coronary artery bypass grafting. Crit Care Med 2006;34:1608-16.

4. Kuduvalli M, Oo AY, Newall Net al. Effect of peri-operative red blood cell transfusion on 30-day and 1year mortality following coronary artery bypass surgery. Eur J Cardiothorac Surg 2005;27:592-8.

5. Engoren MC, Habib RH, Zacharias A, Schwann TA, Riordan CJ, Durham SJ. Effect of blood transfusion on long-term survival after cardiac operation. Ann Thorac Surg 2002;74:1180-6.

6. Zallen G, Offner PJ, Moore EE, et al. Age of transfused blood is an independent risk factor for postinjury multiple organ failure. Am J Surg 1999;178:570-2.

7. Purdy FR, Tweeddale MG, Merrick PM. Association of mortality with age of blood transfused in septic ICU patients. Can J Anaesth 1997;44:1256-61.

8. Tinmouth A, Fergusson D, Yee IC, Hébert PC; ABLE Investigators; Canadian Critical Care Trials Group. Clinical consequences of red cell storage in the critically ill. Transfusion 2006;46:2014-27.

9. Wolfe LC. Oxidative injuries to the red cell membrane during conventional blood preservation. Semin Hematol 1989;26:307-12.

10. Berezina TL, Zaets SB, Morgan C, et al. Influence of storage on red blood cell rheological properties. J Surg Res 2002;102:6-12.

11. Koch CG, Li L, Sessler DI,et al. Duration of red-cell storage and complications after cardiac surgery. N Engl J Med 2008;358:1229-39.

12. Vamvakas EC, Carven JH. Length of storage of transfused red cells and postoperative morbidity in patients undergoing coronary artery bypass graft surgery. Transfusion 2000;40:101-9.

13. van de Watering L, Lorinser J, Versteegh $M$, Westendord R, Brand A. Effects of storage time of red blood cell transfusions on the prognosis of coronary artery bypass graft patients. Transfusion 2006;46:1712-8.

14. Chapman $\mathrm{CE}$, Stainsby $\mathrm{D}$, Jones $\mathrm{H}$, et al. Ten years of hemovigilance reports of transfusion-related acute lung injury in the United Kingdom and the impact of preferential use of male donor plasma. Transfusion 2009;49:440-52.

15. Wiersum-Osselton JC, Porcelijn L, van Stein D, Vlaar AP, Beckers EA, Schipperus MR. Transfusionrelated acute lung injury (TRALI) in the Netherlands in 2002-2005 [in Dutch].Ned Tijdschr Geneeskd 2008;152:1784-8.

16. Middelburg RA, van Stein D, Briët E, van der Bom JG. The role of donor antibodies in the pathogenesis of transfusion-related acute lung injury: a systematic review. Transfusion2008;48:2167-76.

17. Wright SE, Snowden CP, Athey SC, et al. Acute lung injury after ruptured abdominal aortic aneurysm repair: the effect of excluding donations from females from the production of fresh frozen plasma. Crit Care Med 2008;36:1796-802. 
18. Win N, Massey E, Lucas G, et al. Ninety-six suspected transfusion related acute lung injury cases: investigation findings and clinical outcome. Hematology 2007;12:461-9.

19. Eder AF, Herron R, Strupp A, et al. Transfusion-related acute lung injury surveillance (2003-2005) and the potential impact of the selective use of plasma from male donors in the American Red Cross. Transfusion 2007;47:599-607.

20. Sachs UJ, Link E, Hofmann C, Wasel W, Bein G. Screening of multiparous women to avoid transfusionrelated acute lung injury: a single centre experience. Transfus Med 2008;18:348-54.

21. Alesci S, Borggrefe M, Dempfle CE. Effect of freezing method and storage at -20 degrees $C$ and -70 degrees C on prothrombin time, aPTT and plasma fibrinogen levels. Thromb Res 2009;124:121-6.

22. Buchta $C$, Felfernig $M$, Höcker $P$, et al. Stability of coagulation factors in thawed, solvent/detergenttreated plasma during storage at 4 degrees $C$ for 6 days. Vox Sang 2004;87:182-6.

23. Lamboo M, Poland DC, Eikenboom JC, et al. Coagulation parameters of thawed freshfrozen plasma during storage at different temperatures. Transfus Med 2007;17:182-6.

24. Smith JF, Ness PM, Moroff G, Luban NL. Retention of coagulation factors in plasma frozen after extended holding at 1-6 degrees C. Vox Sang 2000;78:28-30.

25. Swärd-Nilsson AM, Persson PO, Johnson U, Lethagen S. Factors influencing factor VIII activity in frozen plasma. Vox Sang 2006;90:33-9. 



\section{Chapter 10}

\section{Preoperative C-Reactive Protein Levels to Predict Early and Late Mortality After Coronary Artery Bypass Surgery: 8 Years' Follow-up}

J Thorac Cardiovasc Surg. 2009 ;138(4):954-8.

Authors

AHM van Straten ${ }^{1}$

André A. J. van Zundert ${ }^{2}$

Mohamed A. Soliman Hamad ${ }^{1}$

Elisabeth J. Martens ${ }^{3}$

Jacques P. A. M. Schönberger ${ }^{1}$

Andre M. de Wolf ${ }^{4}$.

1 Department of Cardio-Thoracic Surgery, Catharina Hospital, Eindhoven, The Netherlands.

2 Department of Anesthesiology, Catharina Hospital - Brabant Medical School, Eindhoven, The Netherlands \& University Hospital Ghent, Ghent, Belgium.

3 Department of Education and Research, Catharina Hospital, Eindhoven, The Netherlands \& Center of Research on Psychology in Somatic diseases, Department of Medical Psychology, Tilburg University, The Netherlands.

4 Department of Anesthesiology, The Feinberg School of Medicine, Northwestern University, Chicago, Illinois, USA 


\begin{abstract}

\section{Objectives}

There is limited evidence that increased preoperative levels of C-reactive protein are associated with increased mortality after coronary artery bypass grafting. We retrospectively investigated the predictive value of preoperative C-reactive protein levels on early and late mortality after coronary artery bypass grafting in 5669 patients.
\end{abstract}

\title{
Methods
}

Patients undergoing isolated coronary artery bypass grafting between January 2000 and December 2007 ( $n=8500$ ) were studied. Preoperative demographic data and risk factors, and outcome data (mortality) were prospectively collected in a database. Preoperative C-reactive protein levels were retrieved from the laboratory data.

\section{Results}

In 5669 of 8500 patients, the preoperative C-reactive protein level could be retrieved. Seventy-five patients were lost to follow-up. Preoperative C-reactive protein levels of > $10 \mathrm{mg} / \mathrm{L}$ were an independent risk factor for early mortality, while preoperative Creactive protein levels of $>5 \mathrm{mg} / \mathrm{L}$ were risk factors for late mortality. Other risk factors were age, sex, chronic obstructive pulmonary disorder, diabetes, left ventricular ejection fraction $<35 \%$, peripheral vascular disease, and previous cardiac surgery. We found a higher mean C-reactive protein value in patients with an ejection fraction < $35 \%(18.5 \pm 33 \mathrm{mg} / \mathrm{L})$, compared to those with an ejection fraction of $>35 \%(P<$ $.0001)$.

\section{Conclusions}

Preoperative C-reactive protein levels can be used in risk stratification in coronary artery bypass grafting surgery. C-reactive protein level of $>10 \mathrm{mg} / \mathrm{L}$ is a risk factor for early mortality, while a level of $>5 \mathrm{mg} / \mathrm{L}$ is a risk factor for late mortality. 


\section{Introduction}

Increased levels of C-reactive protein (CRP) are associated with an increased incidence of coronary and cardiac events after percutaneous coronary intervention (1). In patients with chronic heart failure, CRP levels form a major prognostic factor (2).

A few reports address the correlation between elevated levels of preoperative CRP and early (3) and late mortality (4) after coronary artery bypass graft (CABG) surgery. In one study, a correlation was found between elevated levels of CRP and early graft occlusion (5). We investigated whether elevated preoperative CRP levels are associated with higher early and late mortality in a large patient population undergoing isolated CABG.

\section{Patients and Methods}

\section{Patients}

Since 2000, we have been able to measure preoperative CRP levels at our hospital. This study analyzed the data of patients who had undergone an isolated CABG between January 2000 and December 2007 at a single center. Clinical data including demographics and risk factors were prospectively collected and placed in a database. Preoperative CRP levels were retrieved from the laboratory databank. This study was performed after permission from the local ethics medical committee.

\section{Operative techniques}

All patients received short-acting anesthetic drugs to facilitate early extubation. Extracorporeal circulation (ECC) was performed using normothermic non-pulsatile flow. Cold crystalloid cardioplegia ("St Thomas" solution) or warm blood cardioplegia was used to induce and maintain cardioplegic arrest, according to the surgeon's preference. All patients undergoing CABG with the use of extra-corporeal circulation (ECC), received a low dose of aprotinin (2 million Kallikrein Inactivating Unit "KIU") during ECC, administered in the prime solution of the ECC. Patients undergoing off-pump surgery did not receive any aprotinin.

\section{Preoperative CRP levels}

Preoperative CRP levels were retrieved from the laboratory databank. Values below 6 $\mathrm{mg} / \mathrm{L}$ were reported as "CRP $<6$," making analysis of CRP as a continuous variable difficult. We therefore converted a "CRP $<6$ " into a value of 5 in all analyses looking at continuous CRP levels. For most analyses, CRP levels were grouped into 4 groups: "group < 6" (which included those with CRP levels < $6 \mathrm{mg} / \mathrm{L}$ ); "group 6 to 10" (which included those with CRP levels between 6 and $10 \mathrm{mg} / \mathrm{L}$ ); "group 11 to 30" (which in- 
cluded those with CRP levels between 11 and $30 \mathrm{mg} / \mathrm{L}$ ); and finally, "group > 30" (which included those with CRP levels greater than $\mathrm{mg} / \mathrm{L}$ ). Lastly, "group unknown" included patients with an unknown preoperative CRP level. Because in our laboratory a CRP value less than $6 \mathrm{mg} / \mathrm{L}$, reported as $5 \mathrm{mg} / \mathrm{L}$, is considered abnormal, this value was used as a cut-off in several analyses studying preoperative CRP levels as a dichotomous variable. We have chosen for 3 arbitrary values to divide patients with abnormal CRP levels into different groups and to examine if the degree of elevation of CRP is correlated with the prognosis. The value of $10 \mathrm{mg} / \mathrm{L}$ was used as a cut-off point in the study of Biancari et al (3) and the value of $30 \mathrm{mg} / \mathrm{L}$ was used by Milazzo et al (6).

\section{Follow-Up}

Follow-up data concerning mortality were gathered using databases of health insurance companies. The data of $9 \%$ of the total patient group could initially not be retrieved from these databases. We therefore contacted the general practitioners by telephone in order to get information about mortality data of those patients. For the remaining patients we contacted the city-authorities of the cities in which the patients lived at the time of the operation. Early mortality was defined as any cause mortality within 30 days postoperatively, whereas late mortality was defined as any cause mortality $>30$ days.

\section{Statistical Analyses}

Discrete variables were compared with the Chi-square test and are presented as numbers and percentages. Continuous variables were compared with analysis of variance and $t$ test and are presented as means \pm standard deviations. Univariate and multivariate logistic regression analyses and Cox proportional hazard regression analyses (enter procedure) were performed to investigate the impact of biomedical variables on early mortality and late mortality, respectively. Comparison of the long term survival between the different groups is performed with the use of (Wilcoxon "Gehan") statistic test. Univariate analyses were used to test for the potentially confounding effect of biomedical and demographic factors on outcome. If significant at $P<.05$, confounders were included into the multivariable regression analyses. The cumulative incidence of death in CRP groups was estimated according to the Kaplan-Meier method, comparing differences between groups with the log-rank test. The zero time point indicates the time of CABG. A P value <.05 was used for all tests to indicate statistical significance. Hazard ratios (HR) with 95\% confidence intervals (Cl) are reported. All statistical analyses were performed using SPPS software (Statistical Product and Services Solutions, version 15.0, SPSS Inc, Chicago, IL, USA). 


\section{Results}

Between January 2000 and December 2007, 8500 patients underwent isolated CABG in our centre. In 5669 patients, a preoperative CRP level could be retrieved from the laboratory databank. Out of the 8500 patients, follow-up data was incomplete for 75 patients, resulting ultimately in 5625 patients with a measured preoperative CRP level and a complete follow-up. Mean follow-up period was $1394 \pm 858$ days) with a median of 1373 days. Demographic and clinical data stratified by preoperative CRP groups are listed in table 1.

Table 1. Demographic and clinical data stratified by preoperative CRP

\begin{tabular}{lllllll}
\hline Demographics Group 1 & Group 2 & Group 3 & Group 4 & Group 5 & P \\
& $\begin{array}{l}\text { CRP }<6 \mathrm{mg} / \mathrm{L} \\
(\mathrm{n}=3698)\end{array}$ & $\begin{array}{l}\text { CRP 6-10 mg/L CRP 11-30 mg/L CRP }>30 \mathrm{mg} / \mathrm{L} \\
(\mathrm{n}=778)\end{array}$ & $\begin{array}{l}\text { CRP unknown } \\
(\mathrm{n}=823)\end{array}$ & $\begin{array}{l}\mathrm{n}=370) \\
(\mathrm{n}=2831)\end{array}$ \\
\hline Age & $64.2 \pm 9.5$ & $64.6 \pm 9.6$ & $65.8 \pm 9.2$ & $66.9 \pm 8.7$ & $65.1 \pm 9.6$ & $<.0001$ \\
Male sex & $2960(80.0 \%)$ & $586(75.3 \%)$ & $605(73.5 \%)$ & $278(75.1 \%)$ & $2130(75.2 \%)$ & $<.0001$ \\
Hypertension & $1613(43.6 \%)$ & $361(46.4 \%)$ & $400(48.6 \%)$ & $172(46.5 \%)$ & $1189(42.0 \%)$ & .006 \\
COPD & $402(10.9 \%)$ & $104(13.4 \%)$ & $140(17.0 \%)$ & $62(16.8 \%)$ & $365(12.9 \%)$ & $<.0001$ \\
Diabetes & $785(21.2 \%)$ & $180(23.1 \%)$ & $199(24.2 \%)$ & $84(22.7 \%)$ & $615(21.7 \%)$ & .359 \\
EF <35\% & $81(2.3 \%)$ & $29(3.8 \%)$ & $34(4.3 \%)$ & $24(6.7 \%)$ & $113(4.2 \%)$ & $<.0001$ \\
PVD & $382(10.3 \%)$ & $98(12.6 \%)$ & $133(16.2 \%)$ & $64(17.3 \%)$ & $320(11.3 \%)$ & $<.0001$ \\
CrCL & $75.5 \pm 25.4$ & $75.3 \pm 27.6$ & $73.6 \pm 29.7$ & $70.9 \pm 30.3$ & $72.3 \pm 26.8$ & $<.0001$ \\
Preop MI & $1402(38.3 \%)$ & $328(42.9 \%)$ & $369(45.4 \%)$ & $186(51.4 \%)$ & $1247(44.8 \%)$ & $<.0001$ \\
Prior CABG & $174(4.7 \%)$ & $38(4.9 \%)$ & $32(3.9 \%)$ & $24(6.5 \%)$ & $166(5.9 \%)$ & .071 \\
Off pump & $425(11.5 \%)$ & $95(12.2 \%)$ & $80(9.7 \%)$ & $39(10.5 \%)$ & $302(10.7 \%)$ & .435 \\
No grafts & $3.4 \pm 1.1$ & $3.4 \pm 1.1$ & $3.5 \pm 1.0$ & $3.5 \pm 1.0$ & $3.3 \pm 1.1$ & $<.0001$ \\
Emergency & $37(1.0 \%)$ & $10(1.3 \%)$ & $16(1.9 \%)$ & $16(4.3 \%)$ & $249(8.8 \%)$ & $<.0001$ \\
Periop MI & $87(2.4 \%)$ & $25(3.2 \%)$ & $22(2.7 \%)$ & $11(3.0 \%)$ & $91(3.2 \%)$ & .276 \\
Re-exploration $)$ & $161(4.4 \%)$ & $44(5.7 \%)$ & $43(5.2 \%)$ & $19(5.1 \%)$ & $156(5.5 \%)$ & .229 \\
IABP & $36(1.0 \%)$ & $10(1.3 \%)$ & $18(2.2 \%)$ & $14(3.8 \%)$ & $91(3.2 \%)$ & $<.0001$ \\
\hline
\end{tabular}

Results are expressed as $\mathrm{n}(\%)$ of patient or mean \pm standard deviation, $\mathrm{CABG}=$ coronary artery bypass grafting, $\mathrm{COPD}=$ chronic obstructive pulmonary disease, $\mathrm{CrCL}=$ preoperative creatinine clearance $(\mathrm{mL} / \mathrm{min}), \mathrm{EF}=$ left ventricular ejection fraction, IABP = intra-aortic balloon pump support, Periop $\mathrm{MI}=$ perioperative myocardial infarction, Preop $\mathrm{MI}=$ preoperative myocardial infarction, $\mathrm{PVD}=$ peripheral vascular disease.

Patients with elevated CRP levels were more often older females and had more often chronic obstructive pulmonary disease (COPD), poorer left ventricular ejection fraction $(\mathrm{EF})$, peripheral vascular disease (PVD), lower creatinine clearance $(\mathrm{CrCl})$ and a history of preoperative myocardial infarction.

Early and late mortality rates stratified by preoperative CRP groups are shown in table 2 
Table 2. Early and late mortality stratified by preoperative CRP groups

\begin{tabular}{lllllll}
\hline & Group 1 & Group 2 & Group 3 & Group 4 & Group 5 & P \\
& $\begin{array}{l}\text { CRP }<6 \mathrm{mg} / \mathrm{L} \\
(\mathrm{n}=3698)\end{array}$ & $\begin{array}{l}\text { CRP 6-10 mg/L CRP 11-30 mg/L } \\
(\mathrm{n}=778)\end{array}$ & $\begin{array}{l}\text { CRP }>30 \mathrm{mg} / \mathrm{L} \\
(\mathrm{n}=823)\end{array}$ & $\begin{array}{l}\text { CRP unknown } \\
(\mathrm{n}=370)\end{array}$ & $(\mathrm{n}=2831)$ & \\
\hline Early mortality & $52(1.4 \%)$ & $15(1.9 \%)$ & $33(4.3 \%)$ & $27(7.2 \%)$ & $128(2.6 \%)$ & $<.0001$ \\
Late mortality & $217(5.8 \%)$ & $80(10.1 \%)$ & $88(11.5 \%)$ & $38(10.2 \%)$ & $747(15.5 \%)$ & $<.0001$ \\
\hline
\end{tabular}

Early mortality rates increase with increasing preoperative CRP levels. For early mortality, the difference between group 1 and 2 was not significant $(P=.408)$, all other group comparisons were significant (all $P$ values $<.05$ ). For late mortality, only the differences between group 1 and groups 2, 3 and 4 were statistically significant. In group 5 the incidence of late mortality was high. Most of the missing preoperative CRP values were those of patients included in the early phase of the study.

In table 3 we have shown the survival rate of each group after one and five years. With regard to 5-year survival, the difference was statistically significant between all groups except for between "group 6 to 10" and "group unknown" and between "group 11 to 30 " and "group unknown".

Table3: One and 5-year survival in the different groups (stratified by preoperative CRP)

\begin{tabular}{lllllll}
\hline Survival & Group $<6$ & Group 6-10 & Group 11-30 & Group $>30$ & \multicolumn{2}{c}{ Group unknown P value } \\
\hline 1-year & $96.1 \pm 0.3 \%$ & $93.7 \pm 0.9 \%$ & $89.1 \pm 1.2 \%$ & $84.8 \pm 2.1 \%$ & $92.5 \pm 0.4 \%$ & $<.0001$ \\
5-year & $89.3 \pm 0.7 \%$ & $84.5 \pm 1.7 \%$ & $77.8 \pm 2.2 \%$ & $73.3 \pm 3.5 \%$ & $84.0 \pm 0.6 \%$ & $<.0001$ \\
\hline
\end{tabular}

Univariate logistic regression analyses revealed preoperative CRP level both as a continuous variable and as a dichotomous variable with a cut-off value of $6 \mathrm{mg} / \mathrm{L}$ as a risk factor for early mortality (table 4). Other patient-related risk factors that were identified include: age, COPD, diabetes, $\mathrm{EF}<35 \%$, peripheral vascular disease (PVD), low creatinine clearance, previous cardiac surgery and emergency operations. Gender, hypertension and the use of extra-corporeal circulation were not identified as risk factors for early mortality. Complications, such as perioperative myocardial infarction, perioperative use of IABP and re-exploration were also identified as risk factors for early mortality. 
Table 4. Predictors of early mortality; Univariate and multivariate logistic regression analyses.

\begin{tabular}{|c|c|c|c|c|}
\hline & Univariate analyses & & Multivariate analysis & \\
\hline Risk factor & $\mathrm{HR}(95 \% \mathrm{Cl})$ & $P$ value & $\mathrm{HR}$ & $P$ value \\
\hline Preop CRP* & $1.017(1.013-1.022)$ & $<.0001$ & $1.013(1.007-1.019)$ & $<.0001$ \\
\hline Age* & $1.082(1.065-1.099)$ & $<.0001$ & $1.056(1.026-1.087)$ & .001 \\
\hline COPD & $1.91(1.41-2.60)$ & $<.0001$ & $1.67(1.05-2.64)$ & .029 \\
\hline Diabetes & $1.48(1.12-1.96)$ & .005 & $1.63(1.08-2.47)$ & .020 \\
\hline$E F<35 \%$ & $6.02(4.18-8.68)$ & $<.0001$ & $3.52(1.88-6.61)$ & $<.0001$ \\
\hline PVD & $1.60(1.15-2.23)$ & .005 & $1.49(0.92-2.42)$ & .102 \\
\hline $\mathrm{CrCl}$ & $0.971(0.966-0.976)$ & $<.0001$ & $0.980(0.971-0.990)$ & $<.0001$ \\
\hline Prior CABG & $4.26(3.11-5.83)$ & $<.0001$ & $2.98(1.64-5.41)$ &.$<.0001$ \\
\hline Emergency & $6.94(4.94-9.32)$ & $<.0001$ & $2.32(0.89-5.99)$ & .082 \\
\hline Periop MI & $5.79(3.97-8.43)$ & $<.0001$ & & \\
\hline Re-exploration & $5.78(4.27-7.82)$ & $<.0001$ & & \\
\hline IABP & $14.96(10.52-20.52)$ & $<.0001$ & & \\
\hline PreopCRP>5 mg/L** & $2.86(2.00-4.10)$ & $<.0001$ & $2.36(1.58-3.53)$ & $<.0001$ \\
\hline Male sex & $0.77(0.58-1.02)$ & .069 & & \\
\hline Hypertension & $0.94(0.73-1.21)$ & .659 & & \\
\hline$N$ of grafts* & $0.912(0.817-1.017)$ & .099 & & \\
\hline Preop MI & $1.12(0.92-1.37)$ & .227 & & \\
\hline Off pump & $0.68(0.41-1.13)$ & .145 & & \\
\hline Off pump & $0.69(0.41-1.17)$ & .174 & & \\
\hline
\end{tabular}

${ }^{*}=$ entered as a continuous variable. ${ }^{* *}=$ entered as a dichotomous variable with a cut-off point of $5 \mathrm{mg} / \mathrm{L}$ in a separate multivariate model as used for CRP as a continuous variable. $\mathrm{HR}=$ hazard ration, $\mathrm{CABG}=$ coronary artery bypass grafting, $\mathrm{COPD}=$ chronic obstructive pulmonary disease, $\mathrm{CrCL}=$ creatinine clearance, $\mathrm{EF}=$ ejection fraction, IABP = intra-aortic balloon pump support, $\mathrm{PVD}=$ peripheral vascular disease, Periop $\mathrm{MI}=$ perioperative myocardial infarction.

All preoperative risk factors that were identified with univariate logistic regression analyses were entered into the multivariate logistic regression model. Preoperative CRP as a continuous variable did prove to be an independent risk factor for early mortality. Other independent risk factors were: age, COPD, Diabetes, EF<35\%, PVD, low creatinine clearance and previous cardiac surgery. Emergency operation did not prove to be an independent risk factor. When the preoperative CRP level as a dichotomous parameter with a cut-off point of $6 \mathrm{mg} / \mathrm{L}$ was entered in a multivariate model using the same variables, it was also an independent risk factor.

Results of Cox regression analyses for risk factors of late mortality are shown in table 5 .

Univariate analyses revealed preoperative CRP level both as a continuous variable and as a dichotomous variable with a cut-off value of $6 \mathrm{mg} / \mathrm{L}$ as a risk factor for late mortality. Furthermore, patient related risk factors that were identified included: age, gender, COPD, diabetes, EF<35\%, PVD, low creatinine clearance, history of preoperative myocardial infarction, previous cardiac surgery, number of grafts, use of extra- 
corporeal circulation, emergency situations and hypertension. Complications such as perioperative myocardial infarction, perioperative use of IABP and re-exploration were also identified as risk factors for late mortality

Table 5. Predictors of late mortality (>30 days post CABG); Univariate and multivariate Cox regression analyses.

\begin{tabular}{lllll}
\hline & Univariate analyses & & Multivariate analysis & \\
\hline Risk factor & HR $(95 \% \mathrm{Cl})$ & $P$ value & $\mathrm{HR}$ & $P$ value \\
Preop CRP* & $1.010(1.008-1.013)$ & $<.0001$ & $1.007(1.004-1.010)$ & $<.0001$ \\
Age* & $1.090(1.082-1.097)$ & $<.0001$ & $1.063(1.049-1.078)$ & $<.0001$ \\
COPD & $1.91(1.68-2.18)$ & $<.0001$ & $1.70(1.42-2.07)$ & $<.0001$ \\
Diabetes & $1.68(1.49-1.88)$ & $<.0001$ & $1.71(1.42-2.07)$ & $<.0001$ \\
EF<35\% & $3.16(2.61-3.81)$ & $<.0001$ & $2.30(1.64-3.22)$ & $<.0001$ \\
PVD & $2.14(1.88-2.45)$ & $<.0001$ & $1.71(1.38-2.14)$ & $<.0001$ \\
CrCI* & $0.975(0.973-0.977)$ & $<.0001$ & $0.986(0.982-0.992)$ & $<.0001$ \\
Preoperative MI & $1.29(1.19-1.40)$ & $<.0001$ & $1.18(1.03-1.35)$ & .016 \\
Prior CABG & $1.97(1.68-2.31)$ & $<.0001$ & $1.92(1.42-2.61)$ & $<.0001$ \\
Off-pump & $0.67(0.53-0.86)$ & .001 & $1.19(0.83-1.72)$ & .330 \\
No of grafts* & $1.055(1.009-1.104)$ & .019 & $1.199(0.832-1.729)$ & .677 \\
Emergency & $2.09(1.73-2.53)$ & $<.0001$ & $2.07(1.20-3.55)$ & .008 \\
Hypertension & $1.16(1.04-1.29)$ & .004 & $1.07(0.90-1.29)$ & .414 \\
Periop MI & $2.51(2.02-3.12)$ & $<.0001$ & & \\
Re-exploration & $2.07(1.74-2.45)$ & $<.0001$ & & \\
IABP & $3.77(3.07-4.63)$ & $<.0001$ & & .021 \\
CRP $>5$ mg/L $* *$ & $2.20(1.86-2.60)$ & $<.0001$ & $1.79(1.50-2.14)$ & \\
Male sex & $0.84(0.75-0.951)$ & .005 & $1.28(1.03-1.58)$ & \\
\hline
\end{tabular}

*=entered as a continuous variable. ${ }^{* *}=$ entered as a dichotomous variable with a cut-off point of $6 \mathrm{mg} / \mathrm{L}$ in a separate multivariate model as used for CRP as a continuous variable. HR = hazard ration, CABG = coronary artery bypass grafting, $\mathrm{COPD}=$ chronic obstructive pulmonary disease, $\mathrm{CrCL}=$ creatinine clearance, $\mathrm{EF}=$ ejection fraction, IABP = intra-aortic balloon pump support, $\mathrm{PVD}=$ peripheral vascular disease, Periop $\mathrm{MI}=$ perioperative myocardial infarction.

All preoperative risk factors that were identified with univariate analyses were entered into the multivariate Cox regression model. Preoperative CRP level as a continuous variable was independent risk factors for late mortality. Age, gender, COPD, diabetes, $\mathrm{EF}<35 \%$, PVD, low creatinine clearance, history of preoperative myocardial infarction, previous cardiac surgery, and emergency operation were also independent predictors of late mortality. Use of extra-corporeal circulation and hypertension were not identified as independent risk factors. Preoperative CRP level proved also to be a risk factor when entered as a dichotomous parameter with a cut-off point of $6 \mathrm{mg} / \mathrm{L}$ in a multivariate model using the same variables.

Survival according to the Kaplan Meyer method stratified by preoperative CRP groups is plotted in figure 1. Log-rank test showed that the differences were statistically significant with an overall $P$ value of $<0.0001$. Differences observed between 
groups 1-4 were all significant (all $P$ values $<0.05$ ) with the exception of the difference between group 3 and $4(p=0.151)$.

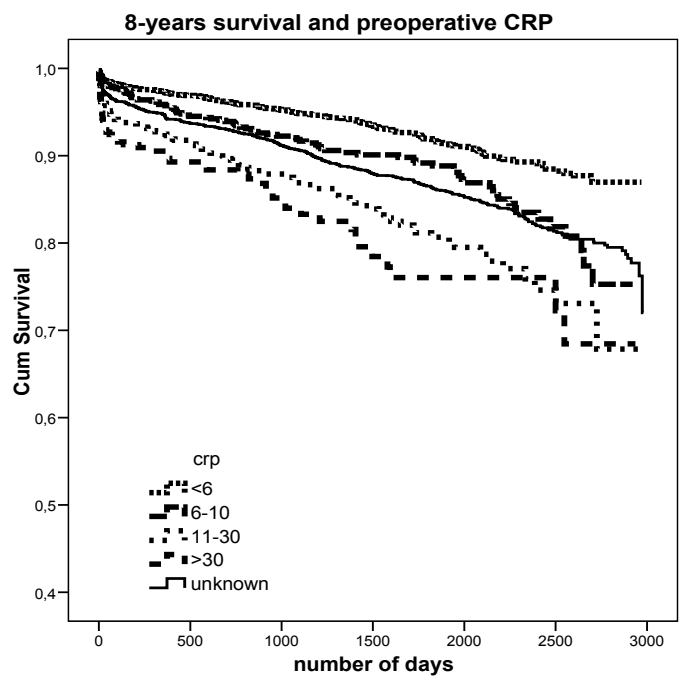

Figure 1 Survival stratified by preoperative CRP groups (Kaplan Meier)

The relationship between left ventricular ejection fraction and preoperative CRP is shown in table 6. Patients with an impaired preoperative left ventricular function $(E F<35 \%)$ have higher preoperative CRP levels $(p<0.0001)$.

Table 6. Left ventricular ejection fraction and preoperative CRP

\begin{tabular}{lll}
\hline LVEF & $\begin{array}{l}\text { CRP* } \mathrm{mg} / \mathrm{L} \\
\text { (mean } \pm \text { SD) }\end{array}$ & Number of patients \\
& $10.1 \pm 17$ & 6219 \\
\hline $35 \%$ & $18.5 \pm 33$ & 181 \\
\hline $35 \%$ & & \\
\hline
\end{tabular}

LVEF = left ventricular ejection fraction $P$ value $<0.001$

\section{Comment}

In this study it is confirmed that preoperative CRP level is an independent risk factor for early and late mortality after CABG as shown by others $(3,4)$. C-reactive protein is an acute phase protein and elevated levels might be an indication of an underlying infectious disease or other inflammatory process. Every patient was investigated for underlying disease before surgery. If any sign of infection was found, the operation was postponed unless the cardiac condition did not allow this. This is the reason that in 
the group of patients, with a CRP level of more than $30 \mathrm{mg} / \mathrm{L}$, emergency operations are more frequent than in groups with lower CRP level as shown in table 1. So, we can assume that in elective cases no evident signs of infectious disease were present. However, elevated levels of CRP were still found in some patients. Only since 2004 we routinely measure preoperative CRP in every patient. Therefore we do miss CRP values in patients who were operated upon in the early years of the study. This explains why the group of patients with missing values had a higher risk for late mortality compared to the groups with low CRP levels. Since these patients are operated upon in the beginning of the study the follow-up period is longer and thus the chance for late mortality is higher. We considered it still worthwhile to include patients from the early years in the study to clarify the impact of preoperative CRP levels on late mortality.

There was no difference in early mortality between "group $<6$ " and "group 6 to 10 ". Further increase of preoperative CRP did increase the risk of early mortality. This suggests that a cut-off value of $10 \mathrm{mg} / \mathrm{L}$ is probably a good indicator for increased risk of early mortality. For late mortality, preoperative CRP level was an independent risk factor when it was used as a continuous variable indication increasing risk with increasing CRP levels. Importantly, log-rank test showed no difference between group "11 to 30 " and "group > 30" indicating that a further increase in preoperative CRP over 30 $\mathrm{mg} / \mathrm{L}$ does not further increase the risk of late mortality. It seems remarkable that even a small increase in preoperative CRP level $(6-10 \mathrm{mg} / \mathrm{L})$ showed to be a risk factor for late mortality. The predictive value of $\mathrm{C}$-reactive protein for recurrent cardiovascular events and death has been established previously among patients with documented coronary artery disease (7). A recent study (8) has shown that patients with increased C-reactive protein undergoing coronary artery bypass grafting, have an increased long term risk of cardiovascular events. This could explain the poorer long term survival in these patients. Interestingly, elevated CRP levels were found in patients with a low ejection fraction, a finding confirmed by others $(4,5)$.

\section{Limitations of this study}

This is not a prospective randomized study, which warrants cautiousness in our conclusions. The second limitation is that in our institution a CRP level of less than $6 \mathrm{mg} / \mathrm{L}$ is reported as " $<6 \mathrm{mg} / \mathrm{L}$ " thus limiting the result as a continuous variable as discussed before. One of the most important limitations of this study is the number of missing CRP values in the early years. We tried to overcome this problem by using proper statistical tools. 


\section{Conclusions}

In conclusion, preoperative CRP levels can be used in risk stratification in coronary bypass surgery (CABG), with levels $>10 \mathrm{mg} / \mathrm{L}$ as a risk factor for early mortality and levels $>5 \mathrm{mg} / \mathrm{L}$ as a risk factor for late mortality. A prospective study might show if postponing the operation could influence the prognosis in this group of patients.

\section{References}

1. Bassuk SS, Rifai N, Ridker PM. High-sensitivity C-reactive protein: clinical importance. Curr Probl Cardiol 2004;29s:439-93.

2. Yin WH, Chen JW, Jen HL, Chiang MC, Huang WP, Feng AN, et al. Independent prognostic value of elevated high-sensitivity C-reactive protein in chronic heart failure. Am Heart J 2004;147:931-8.

3. Biancari F, Lahtinen J, Lepojärvi S, Rainio P, Salmela E, Pokela R, et al. Preoperative C-reactive protein and outcome after coronary artery bypass surgery. Ann Thorac Surg 2003;76:2007-12.

4. Kangasniemi OP, Biancari F, Luukkonen J, Vuorisalo S, Satta J, Pokela R, et al. Preoperative C-reactive protein is predictive of long-term outcome after coronary artery bypass surgery. Eur J Cardiothorac Surg 2006;29:983-5.

5. Hedman A, Larsson PT, Alam M, Wallen NH, Nordlander R, Samad BA. CRP, IL-6 and endothelin-1 levels in patients undergoing coronary artery bypass grafting. Do preoperative inflammatory parameters predict early graft occlusion and late cardiovascular events? Int J Cardiol. 2007;120:108-14.

6. Milazzo D, Biasucci LM, Luciani N, Martinelli L, Canosa C, Schiavello R, et al. Elevated levels of Creactive protein before coronary artery bypass grafting predict recurrence of ischemic events. Am J Cardiol. 1999;84(4):459-61, A9.

7. Zebrack JS, Muhlestein JB, Horne BD, Anderson JL; Intermountain Heart Collaboration Study Group. Creactive protein and angiographic coronary artery disease: independent and additive predictors of risk in subjects with angina. J Am Coll Cardiol. 2002;39(4):632-7.

8. van der Harst $P$, Voors $A A$, Volbeda $M$, Buikema $H$, van Veldhuisen DJ, van Gilst WH. Usefulness of preoperative C-reactive protein and soluble intercellular adhesion molecule-1 level for predicting future cardiovascular events after coronary artery bypass grafting. Am J Cardiol. 2006;97(12):1697-701. 



\section{Chapter 11}

\section{Preoperative hemoglobin level as a predictor of survival after coronary artery bypass grafting, a comparison with the matched general population}

Circulation. 2009;120(2):118-25.

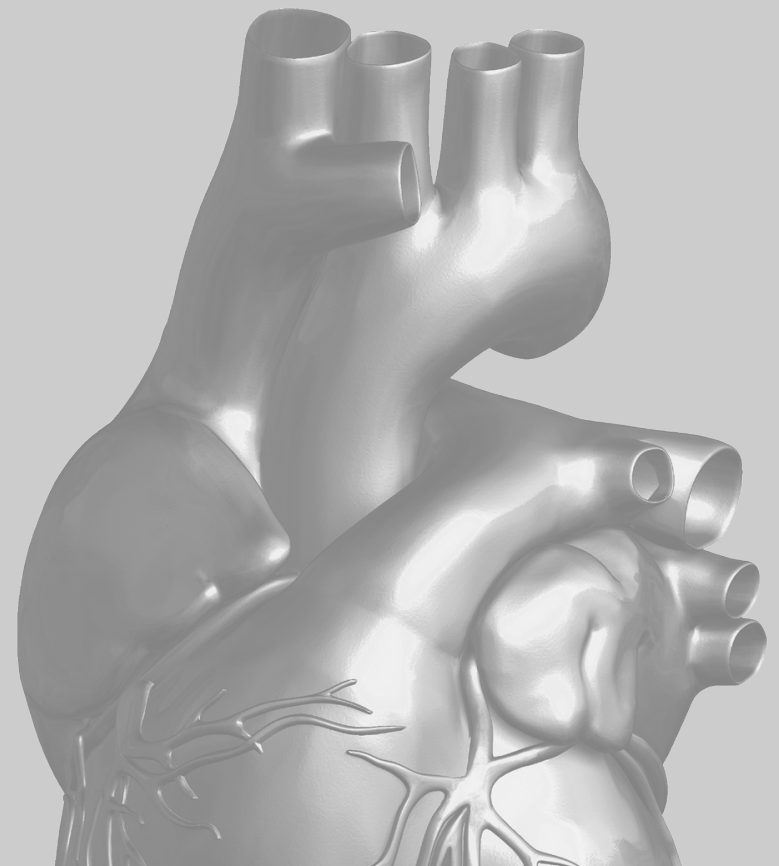

Authors

Albert HM van Straten Mohamed A. Soliman Hamad André J. van Zundert Elisabeth J. Martens, Jacques P. A. M. Schönberger ${ }_{1}$ Andre M. de Wolf

Department of Cardio-Thoracic Surgery, Catharina Hospital, Eindhoven, The Netherlands.

2 Departments of Anesthesiology, Catharina Hospital - Brabant Medical School, Eindhoven, The Netherlands \& University Hospital Ghent, Ghent, Belgium.

3 Department of Education and Research, Catharina Hospital, Eindhoven, The Netherlands

4 Department of Anesthesiology, The Feinberg School of Medicine, Northwestern University, Chicago, Illinois, USA 


\begin{abstract}

\section{Background}

The predictive value of preoperative hemoglobin value after coronary artery bypass grafting has not been well established. We studied how preoperative hemoglobin level affects survival of patients after coronary artery bypass grafting. Late mortality was compared to that of a general population.
\end{abstract}

\title{
Methods
}

Early and late mortality of all consecutive patients undergoing isolated CABG between January 1998 and December 2007 was determined. Patients were classified into 4 groups stratified by preoperative hemoglobin level. The cut-off point for anemia was $13 \mathrm{~g} / \mathrm{dL}$ for men and $12 \mathrm{~g} / \mathrm{dL}$ for women. Expected survival of a matched general Dutch population cohort was obtained from the database of the Dutch Central Bureau for Statistics.

\section{Results}

Excluding 122 patients who were lost to follow-up and 481 patients with missing preoperative hemoglobin levels, complete data were obtained in 10025 patients. Multivariate logistic regression analyses revealed anemia to be an independent risk factor for higher early mortality. Cox regression analyses revealed low hemoglobin level, both as a continuous variable and as a dichotomous variable (anemia), to be a predictor of higher late mortality. Compared to expected survival, patients with the lowest preoperative hemoglobin levels had a worse outcome, whereas patients with the highest hemoglobin levels had a better outcome.

\section{Conclusions}

Lower preoperative hemoglobin level is an independent predictor of late mortality in patients undergoing CABG, whereas anemia is a risk factor for early and late mortality. Compared to the general population, anemic patients had worse survival than expected, whereas non-anemic patients had better survival then expected. 


\section{Background}

The role of preoperative hemoglobin as a predictor of short-term and long-term outcomes after coronary artery bypass grafting (CABG) has not been well established. Using univariate and multivariate logistic models, Zindrou and coworkers found that low hemoglobin level was a predictor of in-hospital death after $\mathrm{CABG},{ }^{1}$ In the risk prediction model of Magovern and associates found that anemia is an independent predictor for mortality or morbidity. ${ }^{2}$ Kulier and colleagues reported that low preoperative hemoglobin level was an independent risk factor for renal and neurological complications, whereas an increase in cardiac events was due to other factors associated with preoperative anemia such as renal duysfunction. ${ }^{3}$ In a study by Cladellas and colleagues, ${ }^{4}$ preoperative hemoglobin level of less than $12 \mathrm{~g} / \mathrm{dL}$ was a risk factor for inhospital mortality and serious adverse outcomes in patients undergoing valve surgery, whereas Karkouti and colleagues ${ }^{5}$ found that preoperative anemia (hemoglobin $<12.5$ $\mathrm{g} / \mathrm{dL}$ ) was independently associated with adverse outcomes in patients after cardiac surgery, including valve surgery. In patients undergoing elective vascular surgery, Dunkelgrun and colleagues found anemia to be an independent predictor of poor perioperative and long-term cardiovascular outcome. ${ }^{6}$

According to the World Health Organization (WHO), anemia is defined as hemoglobin $<13 \mathrm{~g} / \mathrm{dL}$ for men and $<12 \mathrm{~g} / \mathrm{dL}$ for women. Several cut-off points for preoperative hemoglobin as a risk factor for poor early outcomes have been described, including $10 \mathrm{~g} / \mathrm{dL}^{7} 11 \mathrm{~g} / \mathrm{dL}^{3}$ and $12 \mathrm{~g} / \mathrm{dL}^{3}{ }^{4}$ It is not clear whether poor outcomes are caused by the low hemoglobin level itself or by other risk factors that are frequently present in anemic patients. To our knowledge, no data are available on the association between low preoperative hemoglobin levels and long-term outcomes in patients undergoing CABG. We therefore analyzed the data of patients undergoing CABG in a single center to determine the predictive value of low hemoglobin level in combination with comorbidities on early and late mortality.

\section{Patients and Methods}

Data of all patients undergoing isolated CABG in a single center between January 1998 and December 2007 were analyzed. Starting in January 1998, clinical data, including demographic data, risk factors, and complications, were prospectively collected in a database. This study was performed after permission from the local ethics medical committee.

Patients were classified into 4 groups stratified by the preoperative hemoglobin level. In the first group (referred to as very low), the hemoglobin level in men was $<12$ $\mathrm{g} / \mathrm{dL}$, and in women, $<11 \mathrm{~g} / \mathrm{dL}$. In the second group (referred to as low), the hemoglo- 
bin level in men was $\geq 12$ and $<13 \mathrm{~g} / \mathrm{dL}$, and in women, $\geq 11$ and $<12 \mathrm{~g} / \mathrm{dL}$. According to the WHO definition, patients in the very low and low groups had anemia. In the third group (referred to as normal), the hemoglobin level in men was $\geq 13$ and $<14.5$ $\mathrm{g} / \mathrm{dL}$, and in women, $\geq 12$ and $<13.5 \mathrm{~g} / \mathrm{dL}$. In the fourth group (referred to as high normal), the hemoglobin level in men was $\geq 14.5 \mathrm{~g} / \mathrm{dL}$, and in women, $\geq 13.5 \mathrm{~g} / \mathrm{dL}$.

For calculating survival of a general population cohort, data were obtained from the Dutch Central Bureau for Statistics (CBS). This is the database registering information about all citizens living in the Netherlands. Every year, a report from the CBS is available online about mortality within the normal population stratified by age and sex. We have matched each group in our study with the general population according to age and sex. Because the incidence of mortality within the general population varies per year, the matching was also done to compare the survival of each group with the survival of the general population for the same year when the studied patients were operated. We considered the survival of the matched general population cohort to represent the expected survival of the patient group.

All patients received short-acting anesthetic drugs to facilitate early extubation. Normothermic extracorporeal circulation was performed using non-pulsatile flow. Cold crystalloid cardioplegia ("St Thomas" solution) or warm blood cardioplegia was used to induce and maintain cardioplegic arrest, according to the surgeon's preference. Patients undergoing CABG with the use of extra-corporeal circulation received low dose aprotinin ( 2 million kallikrein inactivating units) during extracorporeal circulation, administered in the prime solution of the heart-lung machine. Patients undergoing offpump surgery did not receive aprotinin.

Follow-up data concerning mortality of patients were collected from the databases of health insurance companies. The data of $9 \%$ of the total patient group initially could not be retrieved from these databases. We therefore contacted the patients' general practitioners to obtain information about mortality data for those patients or, if necessary, the city-authorities of the cities in which the patients lived at the time of the operation. Early mortality was defined as any-cause mortality within the first 30 postoperative days, whereas late mortality was defined as any-cause mortality beyond 30 days.

Discrete variables were compared with the chi-square test and are presented as numbers and percentages. Continuous variables were compared with the $t$ test and analysis of variance and are presented as mean \pm standard deviation (SD). Univariate and multivariate logistic and Cox proportional hazard regression analyses were performed to investigate the impact of preoperative hemoglobin on early and late mortality. Univariate analyses were used to test for the potentially confounding effect of biomedical and demographic factors on mortality. If significant at $P<.05$, confounders were included in the multivariable regression models. Cumulative long-term survival was estimated according to the Kaplan-Meier method comparing differences between 
groups with the log-rank test. Time table analyses were performed to compare survival of patient groups with expected survival using the Wilcoxon test to determine statistical significance. The zero time point indicates the time of CABG. A $P$ value $<.05$ was used for all tests to indicate statistical significance. Hazard ratios (HR) with $95 \%$ confidence intervals $(\mathrm{Cl})$ are reported. All statistical analyses were performed using the statistical software, SPSS (Statistical Product and Services Solutions, version 15.0, SPSS Inc, Chicago, IL).

The authors had full access to the data and take responsibility for its integrity. All authors have read and agree to the manuscript as written.

\section{Results}

During a 10-year period (January 1998 through December 2007), 10626 patients underwent CABG. After excluding 122 patients who were lost to follow-up and 481 patients with missing preoperative hemoglobin levels, data from 10025 patients were analyzed (the preoperative hemoglobin level was missing in 2 patients who were lost to follow up). The patients were divided into 4 categories: 635 patients (6.3\%) in the very low group, 973 patients $(9.7 \%)$ in the low group, 4392 patients $(43.8 \%)$ in the normal group, and 4025 patients $(40.2 \%)$ in the high normal group. The distribution of preoperative hemoglobin levels for men and women is shown in Figure 1. The mean preoperative hemoglobin level for men was $14.1 \pm 1.2 \mathrm{~g} / \mathrm{dL}$, and for women, $12.9 \pm 1.2$ $\mathrm{g} / \mathrm{dL}$. The minimum follow-up for surviving patients was 60 days, with a mean followup of $1693 \pm 1052$ days and a median of 1622 days (range, 0-3708 days) (0 days for patients who died on the first postoperative day).

Figure 1. showes the distribution of the preoperative Hemoglobin level in 7723 Men and 2302 Women 

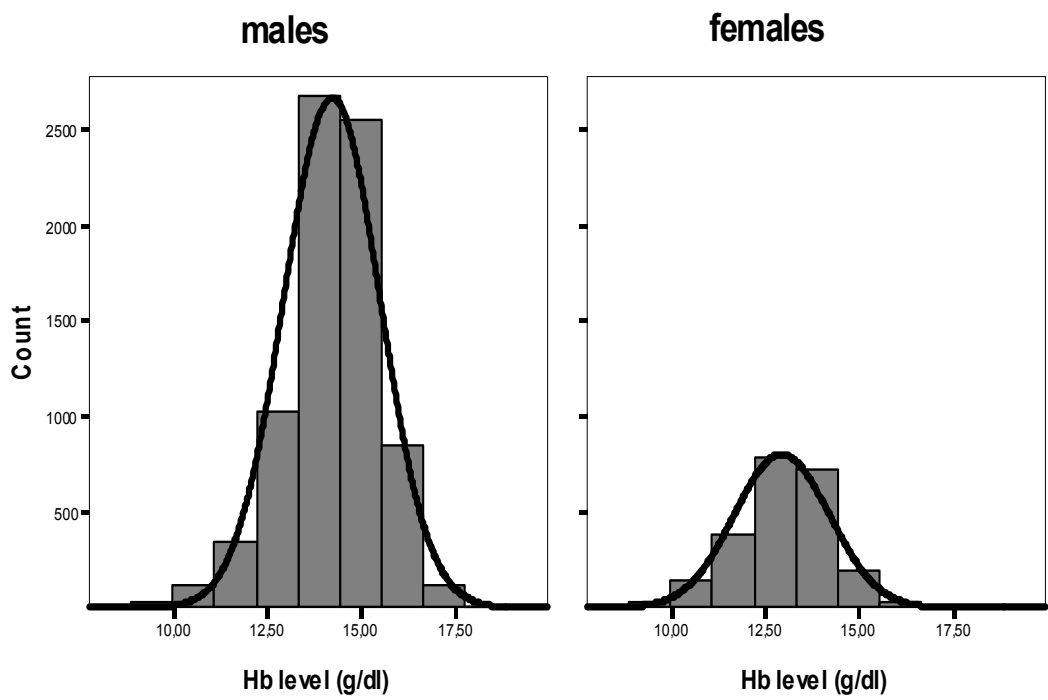

Figure 1

Baseline characteristics stratified by preoperative hemoglobin levels are shown in Table 1.

Patients with higher preoperative hemoglobin were more often younger men. Furthermore, lower preoperative hemoglobin was associated with diabetes, chronic obstructive pulmonary disease (COPD), peripheral vascular disease, low left ventricular ejection fraction, low creatinine clearance, emergency operation, history of previous cardiac surgery, the use of donor blood transfusion(s), and the need for intra-aortic balloon pump support.

Early and late mortality were more frequently seen in the groups with lower preoperative hemoglobin levels, as shown in Table 2.

Late mortality was defined as death more than 30 days after the index surgery The annual incidence of death was 7.8 per 100 patient-years in the very low group, 5.3 in the low group, 2.6 in the normal group and 1.8 in the high normal group. During the study period, the overall early mortality fell from $2.9 \%$ in 1998 to $1 \%$ in 2007. 
Table 1. Baseline Characteristics of 10025 Patients Undergoing Coronary Artery Bypass Grafting, Stratified by Preoperative Hemoglobin Level

\begin{tabular}{llllll}
\hline & Very Low & Low & Normal & High Normal & P value \\
& $\mathrm{n}=635(6.3 \%)$ & $\mathrm{n}=973(9.7 \%)$ & $\mathrm{n}=4392(43.8 \%)$ & $\mathrm{n}=4025(40.2 \%)$ & \\
\hline Age, $\mathrm{y}$ & $70.5 \pm 7.9$ & $68.2 \pm 9.2$ & $65.0 \pm 9.2$ & $62.4 \pm 9.4$ & $<0.001$ \\
Male & $451(71.0)$ & $658(67.6)$ & $3371(76.8)$ & $3243(80.6)$ & $<0.001$ \\
Diabetes & $209(32.9)$ & $275(28.3)$ & $939(21.4)$ & $698(17.3)$ & $<0.001$ \\
Hypertension & $282(44.4)$ & $427(43.9)$ & $1784(40.6)$ & $1708(42.4)$ & 0.084 \\
COPD & $104(16.4)$ & $142(14.6)$ & $532(12.1)$ & $485(12.0)$ & 0.003 \\
PVD & $121(19.1)$ & $132(13.6)$ & $525(12.0)$ & $389(9.7)$ & $<0.001$ \\
EF $<35 \%$ & $33(5.2)$ & $40(4.1)$ & $143(3.3)$ & $114(2.8)$ & 0.006 \\
CrCl<60 mL/min & $345(54.3)$ & $443(45.5)$ & $1367(31.1)$ & $797(19.8)$ & $<.001$ \\
Emergency & $39(6.1)$ & $35(3.6)$ & $107(2.4)$ & $74(1.8)$ & $<0.001$ \\
Off-pump & $41(6.5)$ & $72(7.4)$ & $376(8.6)$ & $415(10.3)$ & 0.001 \\
Duration ECC & $59.9 \pm 31.8$ & $60.4 \pm 34.0$ & $57.6 \pm 36.1$ & $56.7 \pm 31.9$ & 0.006 \\
Redo & $58(9.1)$ & $76(7.8)$ & $286(6.5)$ & $202(5.0)$ & $<0.001$ \\
Number of grafts & $3.4 \pm 1.1$ & $3.4 \pm 1.1$ & $3.4 \pm 1.1$ & $3.4 \pm 1.1$ & 0.553 \\
Units of RBC & $3.0 \pm 8.8$ & $2.1 \pm 8.6$ & $1.1 \pm 4.7$ & $0.9 \pm 5.4$ & $<0.001$ \\
IABP & $30(4.7)$ & $29(3.0)$ & $70(1.6)$ & $58(1.4)$ & $<0.001$ \\
Re-exploration & $36(5.7)$ & $60(6.2)$ & $212(4.8)$ & $227(5.6)$ & 0.216 \\
Periop MI & $15(2.4)$ & $33(3.4)$ & $123(2.8)$ & $107(2.7)$ & 0.575 \\
\hline
\end{tabular}

Data are expressed as number (percentage) or mean \pm SD.

$\mathrm{COPD}=$ chronic obstructive pulmonary disease; $\mathrm{CrCl}=$ creatinine clearance; $\mathrm{EF}=$ left ventricular ejection

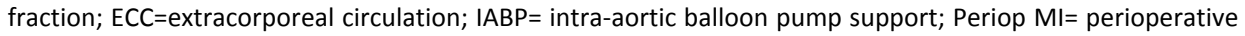
myocardial infarction; PVD= peripheral vascular disease; Redo, previous cardiac surgery.

Table 2. Early and Late Mortality in 10025 Patients After CABG, Stratified by Preoperative Hemoglobin Level

\begin{tabular}{llllll}
\hline Mortality & $\begin{array}{l}\text { Very Low } \\
(n=635)\end{array}$ & $\begin{array}{l}\text { Low } \\
(n=973)\end{array}$ & $\begin{array}{l}\text { Normal } \\
(n=4392)\end{array}$ & $\begin{array}{l}\text { High Normal } \\
(n=4025)\end{array}$ & P value \\
\hline Early & $39(6.1)$ & $41(4.2)$ & $86(2.0)$ & $61(1.5)$ & $<0.0001$ \\
Late & $156(24.6)$ & $186(19.2)$ & $481(11.0)$ & $285(7.1)$ & $<0.001$ \\
\hline
\end{tabular}

Data are expressed as numbers(percentage). Early mortality was defined as death within 30 days of the index surgery.

Risk factors for early mortality identified by univariate and multivariate logistic regression analyses are shown in Table 3. Univariate logistic regression analysis revealed low preoperative hemoglobin level, as a continuous variable as well as a dichotomous variable (anemia), as a risk factor for early mortality. Other risk factors for early mortality by univariate analysis were age, COPD, diabetes, low creatinine clearance, left ventricular ejection fraction $<35 \%$, number of units of donor blood, previous cardiac surgery, peripheral vascular disease, emergency situations, and the year of operation. Complications such as perioperative myocardial infarction, perioperative use of intraaortic balloon pump support, and re-exploration for any cause were also identified as 
risk factors for early mortality. Sex, hypertension, and the use of extra-corporeal circulation were not risk factors for early mortality.

Table 3. Predictors of Early Mortality by Univariate and Multivariate Logistic Regression Analyses

\begin{tabular}{|c|c|c|c|c|}
\hline & Univariate Analysis & & Multivariate Analysis & \\
\hline Risk factor & $\mathrm{HR}(95 \% \mathrm{Cl})$ & $P$ value & $\mathrm{HR}(95 \% \mathrm{Cl})$ & $P$ value \\
\hline \multicolumn{5}{|l|}{ Preoperative factors } \\
\hline Preoperative $\mathrm{Hb}^{*}$ & $0.696(0.640-0.758)$ & $<0.001$ & 0.907 (0.821-1.002) & 0.056 \\
\hline Anemia & $2.94(2.23-3.89)$ & $<0.001$ & & \\
\hline Age* $^{*}$ & 1.077 (1.059-1.095) & $<0.001$ & $1.053(1.030-1.075)$ & $<0.0001$ \\
\hline Male sex & $0.75(0.56-1.01)$ & 0.059 & & \\
\hline COPD & $1.89(1.36-2.61)$ & $<0.001$ & $1.70(1.20-2.41)$ & 0.003 \\
\hline Hypertension & $0.96(0.73-1.25)$ & 0.774 & & \\
\hline Diabetes & $1.61(1.20-2.15)$ & 0.001 & 1.49 (1.09-2.04) & 0.012 \\
\hline $\mathrm{CrCl}^{*}$ & $0.97(0.96-0.98)$ & 0.001 & $0.982(0.975-0.989$ & $<0.0001$ \\
\hline$E F<35 \%$ & $5.43(3.64-8.09)$ & $<0.001$ & $4.00(2.60-6.17)$ & $<0.001$ \\
\hline Redo & $4.55(3.29-6.30)$ & $<0.001$ & $2.42(1.60-3.67)$ & $<.0001$ \\
\hline PVD & 1.69 (1.20-2.39) & 0.003 & $1.28(0.87-1.87)$ & 0.195 \\
\hline Emergency & 8.55 (5.86-12.47) & $<0.001$ & 4.05 (2.35-6.97) & 0.139 \\
\hline Year of operation & $0.943(0.901-0.988)$ & 0.014 & $0.963(0.915-1.014)$ & 0.156 \\
\hline \multicolumn{5}{|c|}{ Peri- and postoperative factors } \\
\hline Number of grafts* & $0.89(0.79-1.00)$ & 0.070 & & \\
\hline No. of RBC units* & $1.32(127-1.37)$ & $<0.001$ & & \\
\hline Periop MI & $6.63(4.48-9.79)$ & $<0.001$ & & \\
\hline Re-exploration & $5.72(4.14-7.91)$ & $<0.001$ & & \\
\hline IABP & $16.22(11.23-23.45)$ & $<0.001$ & & \\
\hline Off-pump & $0.65(0.38-1.13)$ & 0.132 & & \\
\hline
\end{tabular}

*entered as a continuous variable.

Abbreviations: $\mathrm{COPD}=$ chronic obstructive pulmonary disease; $\mathrm{Cl}=$ confidence interval; $\mathrm{CrCl}=$ preoperative creatinine clearance; $\mathrm{EF}=$ left ventricular ejection fraction; $\mathrm{HR}=$ hazard ratio; $\mathrm{Hb}=$ preoperative hemoglobin level; $\mid \mathrm{ABP}=$ intra-aortic balloon pump support; Periop $\mathrm{MI}=$ perioperative myocardial infarction; $\mathrm{PVD}=$ peripheral vascular disease; Redo= previous cardiac surgery; $\mathrm{RBC}=$ red blood cell.

Preoperative risk factors for early mortality identified with univariate logistic regression analysis were entered into the multivariate logistic regression model. Separate analyses were performed for hemoglobin as a continuous variable and as a dichotomous variable (anemia). Anemia was a predictor of early mortality (HR 1.48 (1.082.02); $p=.013$ ) whereas the preoperative hemoglobin level as a continuous variable was not. When peri- and postoperative factors (number of received red blood cell (RBC) units, perioperative myocardial infarction, re-exploration, and use of IABP) were entered into the multivariate model, neither anemia nor preoperative hemoglobin level was a significant risk factor for early mortality. Other independent preoperative risk factors for early mortality by multivariate analysis were age, COPD, diabetes, low 
creatinine clearance, ejection fraction $<35 \%$, and previous cardiac surgery. Emergency operation and peripheral vascular disease were not risk factors for early mortality.

Results of Cox regression analyses for risk factors of late mortality are shown in Table 4.

Table 4. Predictors of Late Mortality by Univariate and Multivariate Cox Regression Analyses

\begin{tabular}{|c|c|c|c|c|}
\hline & $\begin{array}{l}\text { Univariate Analysis } \\
\text { Late mortality }\end{array}$ & & $\begin{array}{l}\text { Multivariate Analysis } \\
\text { Late mortality }\end{array}$ & \\
\hline Risk factor & $\mathrm{HR}(95 \% \mathrm{Cl})$ & $P$ value & $\mathrm{HR}(95 \% \mathrm{Cl})$ & $P$ value \\
\hline \multicolumn{5}{|c|}{ Preoperative factors } \\
\hline Preop Hb* & $0.73(0.70-0.76)$ & $<0.001$ & $0.840(0.801-0.880)$ & $<0.001$ \\
\hline Anemia & $2.70(2.38-3.07)$ & $<0.001$ & & \\
\hline Age* & 1.09 (1.08-1.99) & $<0.001$ & $1.066(1.055-1.076)$ & $<0.001$ \\
\hline Male sex & $0.86(0.76-1.00)$ & 0.056 & $1.65(1.43-1.91)$ & $<0.001$ \\
\hline COPD & 1.95 (1.69-2.26) & $<0.001$ & 1.45 (1.26-1.66) & $<0.001$ \\
\hline Hypertension & $1.22(1.09-1.38)$ & 0.001 & $1.11(0.98-1.25)$ & 0.100 \\
\hline Diabetes & $1.72(1.51-1.96)$ & $<0.001$ & $1.45(1.26-1.66)$ & $<0.001$ \\
\hline $\mathrm{CrCl}^{*}$ & $0.97(0.97-0.97)$ & $<0.001$ & $0.990(0.986-0.993)$ & $<0.001$ \\
\hline$E F<35 \%$ & $2.52(2.00-3.19)$ & $<0.001$ & $2.19(1.73-2.77)$ & $<0.001$ \\
\hline PVD & $2.32(2.00-2.68)$ & $<0.001$ & $1.69(1.45-1.96)$ & $<0.001$ \\
\hline Redo & $1.58(1.30-1.92)$ & $<0.001$ & $1.31(1.07-1.61)$ & 0.009 \\
\hline Emergency & $1.33(0.95-1.86)$ & 0.093 & & \\
\hline Year of operation & $0.967(0.940-996)$ & 0.026 & $0.964(0.935-0.993$ & 0.017 \\
\hline \multicolumn{5}{|c|}{ Peri- and postoperative factors } \\
\hline $\mathrm{N}$ of grafts* & $1.08(1.02-1.13)$ & 0.003 & & \\
\hline Off pump & $0.70(0.53-0.91)$ & 0.009 & & \\
\hline No RBC units* & $1.09(1.07-1.11)$ & $<0.001$ & & \\
\hline Periop MI & $1.87(1.39-2.51)$ & $<0.001$ & & \\
\hline Re-exploration & $1.48(1.18-1.85)$ & 0.001 & & \\
\hline IABP & $2.13(1.53-2.97)$ & $<0.001$ & & \\
\hline
\end{tabular}

*entered as a continuous variable.

Abbreviations: $\mathrm{COPD}=$ chronic obstructive pulmonary disease; $\mathrm{Cl}=$ confidence interval; $\mathrm{CrCl}=$ preoperative creatinine clearance; $\mathrm{EF}=$ left ventricular ejection fraction; $\mathrm{HR}=$ hazard ratio; $\mathrm{Hb}=$ preoperative hemoglobin level; $\mathrm{IABP}=$ intra-aortic balloon pump support; Periop $\mathrm{MI}=$ perioperative myocardial infarction; $\mathrm{PVD}=$ peripheral vascular disease; Redo= previous cardiac surgery; $\mathrm{RBC}=$ red blood cell.

Univariate analyses revealed preoperative hemoglobin level, both as a continuous variable and as a dichotomous variable (anemia), as a risk factor for late mortality. Other risk factors for late mortality by univariate analysis were age, COPD, hypertension, diabetes, low creatinine clearance, ejection fraction $<35 \%$, peripheral vascular disease, previous cardiac surgery, the year of operation, the number of grafts, use of extra-corporeal circulation and the number of units of RBC. Complications such as perioperative myocardial infarction, perioperative use of intra-aortic balloon pump, and re-exploration were also risk factors for late mortality. 
Preoperative risk factors for late mortality identified with univariate analyses were entered into the multivariate Cox regression model. The preoperative hemoglobin level, entered as a continuous variable as well as a dichotomous variable (anemia), was an independent risk factor for late mortality. Calculation of the hazard ratio for preoperative hemoglobin as a continuous variable and as a dichotomous variable was performed with separate analyses. Other preoperative risk factors for late mortality by multivariate analysis were age, male gender, COPD, diabetes, low creatinine clearance, ejection fraction $<35 \%$, peripheral vascular disease, the year of operation, and previous cardiac surgery. However, hypertension was not independent risk factors for late mortality. When peri- and postoperative factors (number of grafts, use of extracorporeal circulation, number of received RBC units, perioperative myocardial infarction, re-exploration and use if IABP) were entered into the multivariate model, hemoglobin level $(H R=0.843(0.803-0.884) ; p$-value $<0.0001)$ as well as anemia $(H R=1.61$ (1.40-1.85); $p$-value $<0.0001)$ were still significant as independent risk factors.

In Figure 2, the long-term survival rates of the 4 groups and the expected survival rates are shown.

Log-rank test of the survival curves (Figure 2 ) showed a $P$ value of $<.001$ for differences between the 4 patient groups.

In figure 3 and 4, the survival curves of the patient groups were compared to the survival curves of the matched cohorts of the normal citizens of the general Dutch population which we considered the expected survival.

Figure 3 shows that the survival of groups 1 and 2 patients is worse than that their matched cohorts of the general population (expected for 1 and 2), $P<0.001$.

Figure 4 shows that the survival of group 3 and 4 patients is better than that their matched cohorts of the general population (expected for 3 and 4), $P<0.005$.

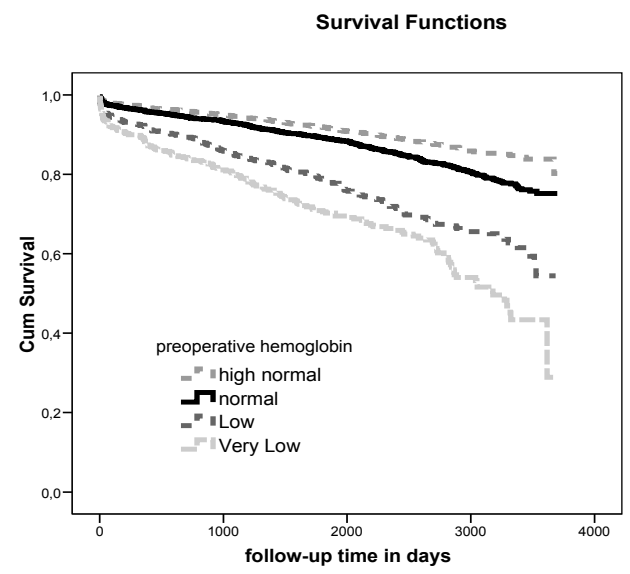

Figure 2. Kaplan-Meier Curves and Preoperative Hemoglobin Level Groups 
Survival Functions

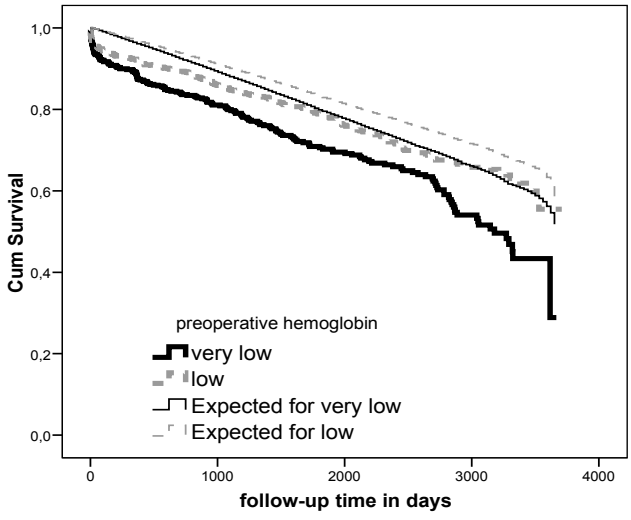

Survival Functions

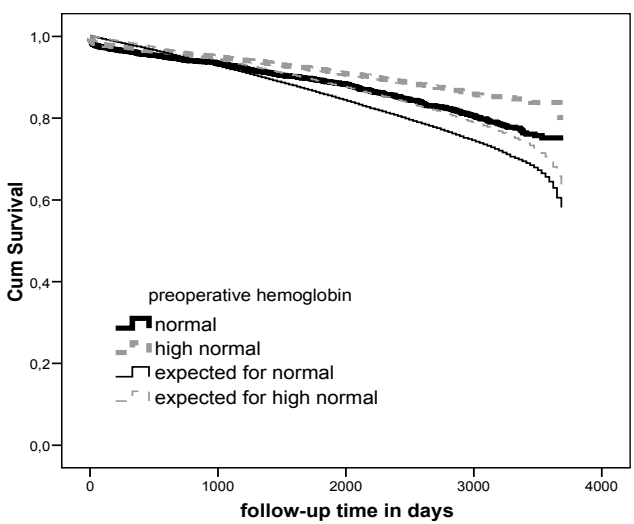

Figure 3 and 4. Kaplan-Meier Curves with Actual Versus Expected Survival

The very low group, in which the hemoglobin level in men was $<12 \mathrm{~g} / \mathrm{dL}$, and in women, $<11 \mathrm{~g} / \mathrm{dL}$. The low group, in which the hemoglobin level in men was $\geq 12$ and < $13 \mathrm{~g} / \mathrm{dL}$, and in women, $\geq 11$ and $<12 \mathrm{~g} / \mathrm{dL}$. The normal group, in which the hemoglobin level in men was $\geq 13$ and $<14.5 \mathrm{~g} / \mathrm{dL}$, and in women, $\geq 12$ and $<13.5 \mathrm{~g} / \mathrm{dL}$. The high normal group, in which the hemoglobin level in men was $\geq 14.5 \mathrm{~g} / \mathrm{dL}$, and in women, $\geq 13.5 \mathrm{~g} / \mathrm{dL}$.

Survival at 1, 5, and 9 years, corresponding with Figures 3 and 4, is shown in Table 5.

Table 5. Survival at 1, 5, and 9 Years Stratified by Preoperative Hemoglobin Level Groups and Expected Survival

\begin{tabular}{|c|c|c|c|c|c|}
\hline & & 1 Year & 5 Years & 9 Years & $P$ value \\
\hline \multirow[t]{2}{*}{ Very Low Group } & Observed & $83.1 \pm 1.6 \%$ & $66.8 \pm 2.3 \%$ & $37.6 \pm 5.2 \%$ & \\
\hline & Expected & $92.5 \pm 0.1 \%$ & $75.6 \pm 0.3 \%$ & $56.1 \pm 0.7 \%$ & $<.001$ \\
\hline \multirow[t]{2}{*}{ Low Group } & Observed & $89.0 \pm 1.0 \%$ & $73.8 \pm 1.7 \%$ & $56.2 \pm 3.6 \%$ & \\
\hline & Expected & $93.8 \pm 0.1 \%$ & $79.7 \pm 0.2 \%$ & $63.0 \pm 0.5 \%$ & $<.001$ \\
\hline \multirow[t]{2}{*}{ Normal Group } & Observed & $94.2 \pm 0.4 \%$ & $86.6 \pm 0.6 \%$ & $74.7 \pm 1.4 \%$ & \\
\hline & Expected & $95.3 \pm 0.1 \%$ & $84.2 \pm 0.2 \%$ & $69.3 \pm 0.5 \%$ & 0.005 \\
\hline \multirow[t]{2}{*}{ High Normal Group } & Observed & $95.8 \pm 0.3 \%$ & $89.9 \pm 0.6 \%$ & $83.4 \pm 1.3 \%$ & \\
\hline & Expected & $96.0 \pm 0.1 \%$ & $86.0 \pm 0.1 \%$ & $72.5 \pm 0.3 \%$ & .001 \\
\hline
\end{tabular}

Data are expressed as cumulative proportion \pm SD.

* 9 years because of small numbers at 10 years 


\section{Discussion}

In this retrospective analysis of prospectively collected data from more than 10000 consecutive patients who underwent CABG in a single center, we found both anemia, defined as hemoglobin level $<13 \mathrm{~g} / \mathrm{dL}$ for men and $<12 \mathrm{~g} / \mathrm{dL}$ for women, and the preoperative hemoglobin level as a continuous variable to be independent risk factors for late mortality. Anemia was a predictor for early mortality, whereas the hemoglobin level as a continuous variable was not. When compared to a matched general population cohort, survival of anemic patients was worse, whereas non-anemic patients had better than expected long-term survival.

Anemia has been identified as a predictor of poor short-term and long-term outcomes in a non-operative setting in the general and elderly population, ${ }^{8,9}$ in patients with coronary artery disease, ${ }^{10,11}$ and in patients with congestive heart failure. ${ }^{12}$ Recently, several studies addressed preoperative anemia as a predictor of poor shortterm outcome after cardiac surgery. ${ }^{1-5}$ Most of these studies used cut-off points for preoperative hemoglobin varying from $10 \mathrm{~g} / \mathrm{dL}$ to $12.5 \mathrm{~g} / \mathrm{dL}$. Only 2 studies found the preoperative hemoglobin level to be a predictor of poor short-term outcome specifically in patients after CABG. ${ }^{3,7}$ Multivariate analyses performed by Bell and colleagues revealed that preoperative hemoglobin level $<10 \mathrm{~g} / \mathrm{dL}$ was not significant as an independent risk factor for early mortality and only mildly significant for morbidity. ${ }^{7}$ Multivariate analyses described by Kulier and colleagues ${ }^{3}$ showed that preoperative anemia and red blood cell transfusion were both independent but additive risk factors for adverse early outcomes. At the same hemoglobin level, the risk for adverse events increased significantly with transfusion of red blood cells. In our study, we also found increased use of transfusion in patients with low hemoglobin levels, but multivariate analysis showed that the preoperative hemoglobin level used as a dichotomous variable with a cut-off point of $13 \mathrm{~g} / \mathrm{dL}$ for men and $12 \mathrm{~g} / \mathrm{dL}$ for women was an independent predictor of early mortality. However, preoperative hemoglobin level used as a continuous variable was not an independent risk factor of early mortality. It is difficult to establish whether or not the correlation between hemoglobin level and early mortality is linear, because of confounders that occur more frequently in patients with low hemoglobin levels such as advanced age, diabetes, peripheral vascular disease, renal function impairment, and low left ventricular ejection fraction. This can also explain the discrepancy in findings between different studies. Each study included different variables for statistical adjustment, and some studies differ in their availability or treatment of preoperative transfusion information ${ }^{7}$. Discrepancy may be partially due to methodological differences. Zindrou and coworkers ${ }^{1}$ defined low hemoglobin as $10 \mathrm{~g} / \mathrm{dL}$ or less; Magovern and associates ${ }^{2}$ defined anemia as $12.5 \mathrm{~g} / \mathrm{dL}$ or less for males, $11.0 \mathrm{~g} / \mathrm{dL}$ or less for females, or need for preoperative transfusion. 
To our knowledge, no data are available on preoperative hemoglobin level as a predictor of long-term outcome of patients undergoing CABG. Recently, Dunkelgrun and colleagues ${ }^{6}$ identified anemia as a predictor of major adverse cardiac events in patients undergoing elective vascular surgery. In our study, preoperative hemoglobin level as a continuous variable was a predictor of late mortality. Also, when used as a dichotomous variable using the WHO criteria for anemia, anemia was a predictor of late mortality. To describe a cut-off point of a variable that is also significant as a continuous variable is debatable. As stated earlier, the cut-off points used in literature vary. The risk of late mortality increases with lower preoperative hemoglobin levels. However, the quantitative nature of this correlation is difficult to establish because, as stated earlier, of confounders that occur more frequently in patients with low hemoglobin such as advanced age, diabetes, peripheral vascular disease, renal function impairment, and low left ventricular ejection fraction.

It is not clear why patients with low preoperative hemoglobin have lower longterm survival after CABG. These patients may be particularly sensitive to anemia, having limited ability to compensate through increased heart rate and stroke volume ${ }^{13}$. Failure of CABG patients to compensate adequately the effects of anemia may result in tissue hypoxia, cellular failure, and eventual organ dysfunction and failure ${ }^{7}$. Such death would occur over the postoperative course.

Clearly, advanced age is associated with worse late survival. Although appropriate statistical tests can be used to distinguish between the effects caused by age and by hemoglobin level, the interpretation of survival curves remains difficult. Life expectancy also varies with sex and race. Over the years, variation in life expectancy and mortality rates of the Dutch population has been well documented by the Dutch Central Bureau for Statistics. We used data from the Central Bureau for Statistics to compare survival of our patients with the survival of general population cohorts matched for age and sex (expected survival). Cumulative survival of patients in the high-normal group as well as the expected survival were better than cumulative survival in the normal group of patients, whereas survival of patients in the very low group was worse than in the low group. In the general population, a certain percentage of people have anemia and coronary artery disease. In non-anemic patients undergoing CABG, the coronary problem is treated. Most patients after CABG are receiving aspirin and hypocholesterolemic drugs and are treated for underlying diseases such as hypertension. This treatment, as well as the protection provided by revascularization, may contribute to improved survival and explain why non-anemic patients have improved survival compared to a matched general population cohort. Furthermore, before undergoing CABG, patients are screened for other severe underlying disease. If severe underlying disease is present, alternative treatment instead of CABG is considered, thus enriching the CABG group with patients of above-average health (except for the coronary artery disease). 
A low hemoglobin level should be considered not only as a marker for comorbidities but also as an independent predictor of higher short-term and long-term mortality. Whether treatment of anemia before surgery can improve clinical outcomes remains to be established, despite the promising results of some studies. ${ }^{14,15}$

\section{Limitations of This Study}

This is a retrospective study with some missing data. Our study was based on the retrospective evaluation of patient charts. We couldn't retrieve the cause of death on long-term follow up. Exact values of EF were not available in some patients. That is why we used $\mathrm{EF}$ as a dichotomous variable $(\mathrm{EF}<35 \%)$. We recommend caution in interpreting the results of the comparison with the general population. The Central Bureau for Statistics database includes the total Dutch population. Therefore, the data of the patients described in this study and of those treated at other Dutch cardiac surgery centers are included. Because of this, the magnitude of differences between groups tends to be lessened. The annual number of patients undergoing CABG in the Netherlands is small, (10 000 patients), compared to the total number of the general population, limiting the effect of this inaccuracy. While studying long-term follow-up data, it is inevitable that operative results from the past are included. Since early mortality dropped from $2.9 \%$ in 1998 to $1 \%$ in 2007 , we must be cautious in using these results to predict the outcome of future patients.

\section{Conclusions}

In this study, preoperative hemoglobin level, used as a continuous variable as well as a dichotomous variable (anemia) with a cut-off point of $13 \mathrm{~g} / \mathrm{dL}$ for men and $12 \mathrm{~g} / \mathrm{dL}$ for women, was an independent risk factor for late mortality of patients undergoing CABG, whereas anemia was a predictor of early mortality. When compared to expected survival of a general population cohort, patients with the lowest hemoglobin level had a worse outcome, whereas patients with the high hemoglobin level had a better outcome.

\section{Disclosures}

The authors state that they have no conflicts to disclose. 


\section{Clinical Perspective}

This single-centre, observational study investigated the association between preoperative hemoglobin level and both early and late mortality in more than 10000 coronary surgery patients. To our knowledge, no data are available on preoperative hemoglobin level as a predictor of long-term outcome of patients undergoing coronary artery bypass grafting. The predictive value of preoperative hemoglobin level indicates the importance of better investigating and managing preoperative anemia in coronary surgery patients. An important finding of this study is that patients with normal preoperative hemoglobin level have a better long term survival than age- and sex-matched groups of the general Dutch population. Although this information has no significance in preoperative assessment and decision making, it gives the patient a rough idea about their long-term prognosis.

\section{References}

1. Zindrou D, Taylor KM, Bagger JP. Preoperative haemoglobin concentration and mortality rate after coronary artery bypass surgery. Lancet. 2002; 359:1747-1748.

2. Magovern JA, Sakert T, Magovern GJ, Benckart DH, Burkholder JA, Liebler GA, Magovern GJ Sr. A model that predicts morbidity and mortality after coronary artery bypass graft surgery. J Am Coll Cardiol. 1996; 28:1147-1153.

3. Kulier A, Levin J, Moser R, Rumpold-Seitlinger G, Tudor IC, Snyder-Ramos SA, Moehnle P, Mangano DT; Investigators of the Multicenter Study of Perioperative Ischemia Research Group. Impact of preoperative anemia on outcome in patients undergoing coronary artery bypass graft surgery. Circulation. 2007; 116:471-479.

4. Cladellas M, Bruguera J, Comín J, Vila J, de Jaime E, Martí J, Gomez M. Is pre-operative anaemia a risk marker for in-hospital mortality and morbidity after valve replacement? Eur Heart J. 2006; 27:10931099.

5. Karkouti K, Wijeysundera DN, Beattie WS; Reducing Bleeding in Cardiac Surgery (RBC) Investigators. Risk associated with preoperative anemia in cardiac surgery: a multicenter cohort study. Circulation. 2008; 117:478-484.

6. Dunkelgrun M, Hoeks SE, Welten GM, Vidakovic R, Winkel TA, Schouten O, van Domburg RT, Bax JJ, Kuijper R, Chonchol M, Verhagen HJ, Poldermans D. Anemia as an independent predictor of perioperative and long-term cardiovascular outcome in patients scheduled for elective vascular surgery. Am J Cardiol. 2008; 101:1196-1200.

7. Bell ML, Grunwald GK, Baltz JH, McDonald GO, Bell MR, Grover FL, Shroyer LW. Does preoperative hemoglobin independently predict short-term outcomes after coronary artery bypass graft surgery? Ann Thorac Surg. 2008; 86:1415-1423.

8. Sarnak MJ, Tighiouart H, Manjunath G, MacLeod B, Griffith J, Salem D, Levey AS. Anemia as a risk factor for cardiovascular disease in The Atherosclerosis Risk in Communities (ARIC) study. J Am Coll Cardiol. 2002; 40:27-33.

9. Izaks GJ, Westendorp RG, Knook DL. The definition of anemia in the older person. JAMA. 1999; 281:1714-1717. 
10. Sabatine MS, Morrow DA, Giugliano RP, Burton PB, Murphy SA, McCabe CH, Gibson CM, Braunwald E. Association of hemoglobin levels with clinical outcomes in acute coronary syndromes. Circulation. 2005; 111:2042-2049.

11. Reinecke H, Trey T, Wellmann J, Heidrich J, Fobker M, Wichter T, Walter M, Breithardt G, Schaefer RM. Haemoglobin-related mortality in patients undergoing percutaneous coronary interventions. Eur Heart J. 2003; 24:2142-2150.

12. Tang YD, Katz SD. Anemia in chronic heart failure: prevalence, etiology, clinical correlates, and treatment options. Circulation. 2006; 113:2454-2461.

13. Armas-Loughran B, Kalra R, Carson JL. Evaluation and management of anemia and bleeding disorders in surgical patients. Med Clin North Am. 2003;87(1):229-42.

14. Mancini DM, Katz SD, Lang CC, LaManca J, Hudaihed A, Androne AS. Effect of erythropoietin on exercise capacity in patients with moderate to severe chronic heart failure. Circulation. 2003; 107:294-299.

15. Silverberg DS, Wexler D, Blum M, Keren G, Sheps D, Leibovitch E, Brosh D, Laniado S, Schwartz D, Yachnin T, Shapira I, Gavish D, Baruch R, Koifman B, Kaplan C, Steinbruch S, laina A. The use of subcutaneous erythropoietin and intravenous iron for the treatment of the anemia of severe, resistant congestive heart failure improves cardiac and renal function and functional cardiac class, and markedly reduces hospitalizations. J Am Coll Cardiol. 2000; 35:1737-1744. 


\section{Chapter 12}

\section{Effect of body mass index on early and late mortality after coronary artery bypass grafting}

Ann Thorac Surg 2010:89:30-37

Authors

Albert HM van Straten ${ }^{1}$

Sander Bramer ${ }^{1}$

Mohamed A. Soliman Hamad ${ }^{1}$

André A.J. van Zundert ${ }^{2}$

Elisabeth J. Martens ${ }^{3}$

Jacques P. A. M. Schönberger ${ }^{1}$

Andre M. de Wolf ${ }^{4}$

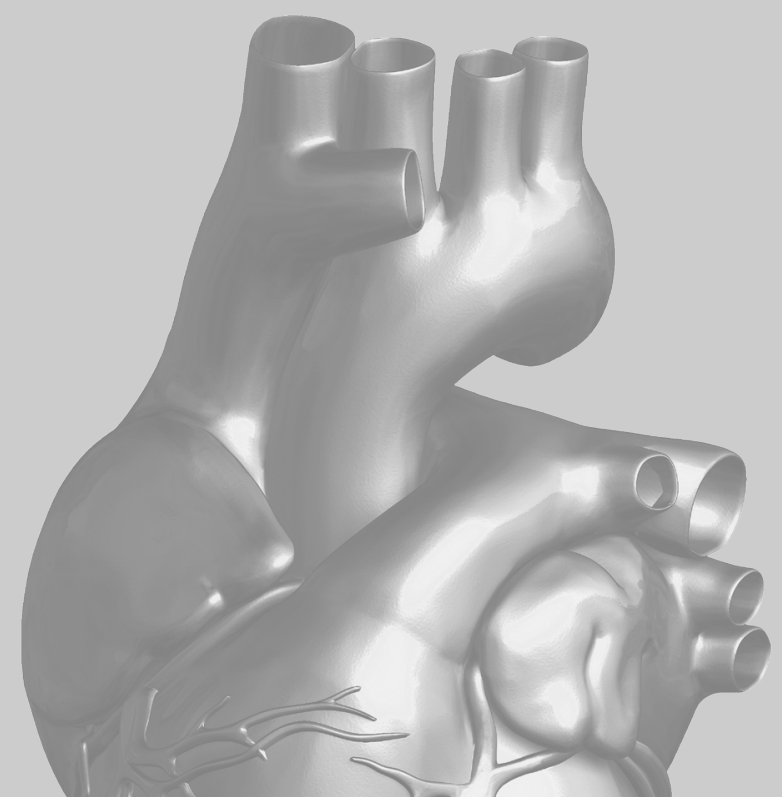

1 Department of Cardio-Thoracic Surgery, Catharina Hospital, Eindhoven, The Netherlands.

2 Department of Anesthesiology, Catharina Hospital - Brabant Medical School, Eindhoven, The Netherlands \& University Hospital Ghent, Ghent, Belgium.

3 Department of Education and Research, Catharina Hospital, Eindhoven, The Netherlands, \& Center of Research on Psychology in Somatic Diseases, Department of Medical Psychology, Tilburg University, The Netherlands.

4 Department of Anesthesiology, The Feinberg School of Medicine, Northwestern University, Chicago, Illinois, USA 


\section{Abstract}

\section{Background}

The effect of obesity on the long-term outcome after coronary artery bypass grafting (CABG) remains controversial. We analyzed data of patients undergoing coronary artery bypass grafting (CABG) in a single center, to determine the predictive value of body mass index (BMI) in combination with comorbidities on both 30-day and late mortality.

\section{Methods}

Thirty-day and late mortality (>30 days) of consecutive patients undergoing isolated CABG from January 1998 until December 2007 was determined. Patients were classified into 5 groups according to preoperative BMI (underweight, normal weight, overweight, obesity, and morbid obesity).

\section{Results}

After excluding 122 patients who were lost to follow-up and 236 patients with missing preoperative BMI, 10268 patients were studied. Multivariate logistic regression analyses showed that underweight was associated with higher 30-day mortality (hazard ratio $[\mathrm{HR}], 2.63$; 95\% confidence interval $[\mathrm{Cl}], 1.13-6.11, \mathrm{P}=.025)$. Multivariate Cox regression analyses did reveal morbid obesity as an independent predictor of late mortality. (HR 1.67 95\% Cl 1.15-2.43, P = .007).

\section{Conclusions}

In patients undergoing isolated coronary artery bypass grafting, underweight is an independent predictor for 30-day mortality and morbid obesity is an independent predictor for late mortality. 


\section{Introduction}

Obesity in the Western world has achieved alarming proportions and is related to morbidity such as diabetes, hypertension and coronary artery disease, reduced life expectancy, impaired quality of life, and increased health-care costs. (1-4) However, it remains controversial whether obesity is related to increased long-term mortality after coronary artery bypass grafting (CABG) (5-10). In a recent meta-analysis, Oreopoulos and colleagues (11) showed that overweight and obesity are associated with a neutral or even beneficial effect on all-cause mortality after coronary revascularization. This controversial finding is described as the "obesity paradox." Because obesity is a potentially treatable condition, the identification of obesity as a risk factor for reduced life expectancy after CABG is an important issue.

The objective of this study was to determine the effect of body mass index (BMI) on 30-day and late mortality after CABG.

\section{Methods}

\section{Patients}

This study was performed after permission from the local medical ethics committee. We analyzed data from patients undergoing isolated CABG in a single center in the Netherlands between January 1998 and December 2007. Clinical data, including demographics, risk factors, and complications, were prospectively collected in our database. We were not able to determine ethnicity in our patient groups, but the Dutch population is mostly Caucasian. Patients were divided into 5 groups based on BMI $(9$, $12,13,14,15)$ : underweight (BMI $\left.<20 \mathrm{~kg} / \mathrm{m}^{2}\right)$, normal weight (BMI, 20.0-24.9 kg/m²), overweight (BMI, $25.0-29.9 \mathrm{~kg} / \mathrm{m}^{2}$ ), obesity $\left(\mathrm{BMI}, 30.0-34.9 \mathrm{~kg} / \mathrm{m}^{2}\right)$, and morbid obesity $\left(B M I>34.9 \mathrm{~kg} / \mathrm{m}^{2}\right)$. Because most studies comparing $\mathrm{BMI}$ to early and late death after CABG used a limit of $20 \mathrm{~kg} / \mathrm{m}^{2}$ in defining underweight we decided not to use the cut off point of 18.5 defined by the National Institution of Health (16).

\section{Operative techniques}

All patients received short-acting anesthetic drugs to facilitate early extubation. Normothermic extracorporeal circulation used nonpulsatile flow. Cold crystalloid cardioplegia ("St Thomas" solution) or warm blood cardioplegia was used to induce and maintain cardioplegic arrest, according to the surgeon's preference. Patients undergoing $C A B G$ with extracorporeal circulation received low-dose aprotinin ( 2 million kallikrein inactivating units) during extracorporeal circulation, administered in the prime solution. 


\section{Follow-up}

Follow-up data concerning mortality were gathered using databases of health insurance companies. The data of $9 \%$ of the patient group could not initially be retrieved from these databases. We therefore contacted the patients' general practitioners or, if necessary, the authorities of the cities in which the patients lived at the time of the operation. In this way, we retrieved information about mortality in $99 \%$ of patients. Late mortality was defined as any-cause mortality $>30$ days postoperatively.

\section{Statistical analysis}

Discrete variables were compared with the chi-square test and presented as numbers and percentages. Continuous variables were compared with the $t$ test and analysis of variance and presented as mean \pm standard deviation (SD). Univariate and multivariate logistic regression analyses were performed to investigate the impact of potential risk factors on early mortality. Cox proportional hazard regression analyses were performed to investigate the impact of potential risk factors on late mortality. Univariate analyses tested the potentially confounding effects of risk factors on mortality. If significant at $P<.05$, confounders were included in the multivariable logistic and Cox regression analyses, besides the BMI groups (reference group: normal weight). Given the pronounced difference in sex distribution between the BMI groups, sex was included in the multivariate models as well. The cumulative long-term survival was estimated according to the Kaplan-Meier method, comparing differences between groups with the log-rank test. Survival was also estimated using the same method adjusted for other risk factors. The zero time point indicates the time of CABG. Odds ratios (OR) and hazard ratios (HR) with $95 \%$ confidence intervals $(\mathrm{Cl})$ are reported. A $P$ value $<.05$ was used for all tests to indicate statistical significance. All statistical analyses were performed using the statistical software, SPSS (Statistical Product and Services Solutions, version 15.0, SPSS Inc, Chicago, IL).

\section{Results}

During a 10-year period (January 1998 - December 2007), 10626 patients underwent isolated CABG at our institution. After excluding 122 patients who were lost to followup and 236 patients with missing preoperative BMI, 10268 patients were studied. Almost all patients who were lost to follow-up were foreigners or living abroad. Zero days were recorded for intraoperative deaths; minimum follow-up for surviving patients was 2 months. Mean follow-up was $65.5 \pm 34.2$ months (maximum follow-up = 123.6 months). Mean BMI of the study group was $27.1 \pm 3.7 \mathrm{~kg} / \mathrm{m}^{2}$ (range, $15.4-58.8$ $\left.\mathrm{kg} / \mathrm{m}^{2}\right)$. Distribution of $\mathrm{BMI}$ is shown in Figure 1. 


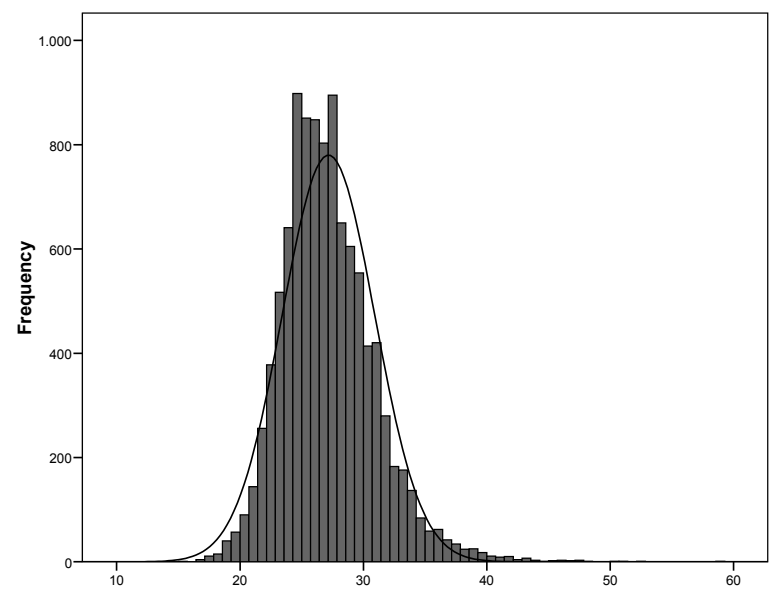

Figure 1. Distribution of BMI in 10,268 Patients Before CABG

Baseline characteristics stratified by BMI groups are shown in Table 1.

Morbidly obese patients were younger, and patients with underweight or morbid obesity were more often women than normal weight, overweight and obese patients. Diabetes and hypertension were associated with overweight, obesity, and morbid obesity. Patients who were underweight were more likely to have estimated left ventricular ejection fraction $(\mathrm{EF})<35 \%$ and creatinine clearance $(\mathrm{CrCl})<60 \mathrm{~mL} / \mathrm{min}$. Reexploration for any cause was more frequent in patients with underweight.

Thirty-day and late mortality were higher in patients with underweight compared to patients with normal weight, overweight, obesity, or morbid obesity, as shown in Table 2 
Table1. Baseline Characteristics of 10268 Patients Stratified by BMI Groups

\begin{tabular}{|c|c|c|c|c|c|c|}
\hline & Underweight & Normal weight & Overweight & Obesity & Morbid obesity & $P$ value \\
\hline Sample size & $128(1.2)$ & $2896(28.2)$ & $5234(51.0)$ & $1686(16.4)$ & $324(3.2)$ & \\
\hline \multicolumn{7}{|c|}{ Preoperative characteristics } \\
\hline Age, y & $63.8 \pm 10.5$ & $65.7 \pm 9.7$ & $64.6 \pm 9.4$ & $63.4 \pm 9.4$ & $61.3 \pm 9.9$ & $<.001$ \\
\hline Men & $61(47.7)$ & $2203(76.1)$ & $4241(81.0)$ & $1228(72.8)$ & $192(59.3)$ & $<.001$ \\
\hline Diabetes & $13(10.2)$ & $410(14.2)$ & $1071(20.5)$ & $530(31.4)$ & $142(43.8)$ & $<.001$ \\
\hline Hypertension & $50(39.1)$ & $1047(36.2)$ & $2170(41.5)$ & $834(49.5)$ & $200(61.7)$ & $<.001$ \\
\hline COPD & $21(16.4)$ & $360(12.4)$ & $618(11.8)$ & $229(13.6)$ & $55(17.0)$ & .02 \\
\hline PVD & $24(18.8)$ & 345 (11.9) & $601(11.5)$ & $191(11.3)$ & $37(11.4)$ & .14 \\
\hline$E F<35 \%$ & $12(9.4)$ & $133(4.6)$ & $131(2.5)$ & $53(3.1)$ & $14(4.3)$ & $<.001$ \\
\hline $\mathrm{CrCl}<60 \mathrm{~mL} / \mathrm{min}$ & $94(73.4)$ & $1286(44.4)$ & 1251 (23.9) & $256(15.2)$ & $33(10.2)$ & $<.001$ \\
\hline Emergency & $5(3.9)$ & $141(4.9)$ & $194(3.7)$ & $48(2.8)$ & $8(2.5)$ & .005 \\
\hline Redo & $6(4.7)$ & $180(6.2)$ & $323(6.2)$ & $89(5.3)$ & $18(5.6)$ & .61 \\
\hline \multicolumn{7}{|c|}{ Peri and postoperative characterisitics } \\
\hline Off-pump & $16(12.5)$ & $255(8.8)$ & $446(8.5)$ & $155(9.2)$ & $37(11.4)$ & .23 \\
\hline IMA & $109(85.2)$ & 2546 (87.9) & $4643(88.7)$ & $1490(88.4)$ & $294(90.7)$ & .34 \\
\hline No. of grafts & $3.2 \pm 1.2$ & $3.4 \pm 1.1$ & $3.4 \pm 1.1$ & $3.3 \pm 1.1$ & $3.4 \pm 1.1$ & .02 \\
\hline $\mathrm{IABP}$ & $5(3.9)$ & $83(2.9)$ & 97 (1.9) & $27(1.6)$ & $5(1.5)$ & .006 \\
\hline Re-exploration & $13(10.2)$ & $187(6.5)$ & $266(5.1)$ & $77(4.6)$ & $17(5.2)$ & .004 \\
\hline Periop MI & $5(3.9)$ & $97(3.3)$ & $144(2.8)$ & $46(2.7)$ & $7(2.2)$ & .44 \\
\hline
\end{tabular}

Data are expressed as number (\%) or mean \pm SD.

Abbreviations: $\mathrm{BMI}=$ body mass index; $\mathrm{COPD}=$ chronic obstructive pulmonary disease; $\mathrm{CrCl}=\mathrm{creatinine}$ clearance; $E F=l$ eft ventricular ejection fraction; $I A B P=$ need for perioperative intra-aortic balloon pump support; $\mathrm{IMA}=$ internal mammary artery; Periop $\mathrm{MI}=$ perioperative myocardial infarction; $\mathrm{PVD}=$ peripheral vascular disease; Redo= previous cardiac surgery.

Table 2. Early and Late Mortality Stratified by Preoperative BMI Groups

\begin{tabular}{lllllll}
\hline BMI Group & $\begin{array}{l}\text { Underweight } \\
(\mathrm{n}=128)\end{array}$ & $\begin{array}{l}\text { Normal Weight } \\
(\mathrm{n}=2896)\end{array}$ & $\begin{array}{l}\text { Overweight } \\
(\mathrm{n}=5234)\end{array}$ & $\begin{array}{l}\text { Obesity } \\
(\mathrm{n}=1686)\end{array}$ & $\begin{array}{l}\text { Morbid Obesity } \\
(\mathrm{n}=324)\end{array}$ & P value \\
\hline Early mortality & $10(7.8)$ & $73(2.5)$ & $105(2.0)$ & $41(2.4)$ & $8(2.5)$ & $<.0001$ \\
Late mortality & $20(15.6)$ & $364(12.6)$ & $547(10.5)$ & $172(10.2)$ & $34(10.5)$ & .012 \\
\hline
\end{tabular}

Data are expressed as number (\%).

Early mortality was defined as death within 30 days of the index surgery.

Late mortality was defined as death more than 30 days after the index surgery.

Risk factors for 30-day mortality identified by univariate and multivariate logistic regression analyses are shown in Table 3. Univariate logistic regression analyses revealed underweight as a risk factor for 30-day mortality, whereas overweight, obesity, or morbid obesity were not. Other preoperative risk factors for 30-day mortality identified by univariate analysis were: advancing age, chronic obstructive pulmonary disease (COPD), diabetes, $\mathrm{EF}<35 \%$, peripheral vascular disease (PVD), $\mathrm{CrCl}<60 \mathrm{~mL} / \mathrm{min}$, previous cardiac surgery, and emergency operation. Complications, such as perioperative 
myocardial infarction, re-exploration, and perioperative need for intra-aortic balloon pump, were also identified by univariate analysis as risk factors for 30-day mortality. Multivariate analysis revealed underweight as an independent risk factor for 30-day mortality, along with advancing age, COPD, diabetes, $\mathrm{EF}<35 \%, \mathrm{CrCl}<60 \mathrm{~mL} / \mathrm{min}$, previous cardiac surgery and emergency operation.

Table 3. Predictors of Early Mortality by Univariate and Multivariate Logistic Regression Analyses

\begin{tabular}{|c|c|c|c|c|}
\hline & Univariate Analysis & & Multivariate An & \\
\hline Risk factor & OR $(95 \% \mathrm{Cl})$ & $P$ value & OR $(95 \% \mathrm{Cl})$ & $P$ value \\
\hline Underweight & $3.27(1.65-6.50)$ & 0.001 & $2.63(1.13-6.11)$ & 0.025 \\
\hline Overweight & $0.79(0.58-1.07)$ & 0.130 & 0.99 (0.71-1.39) & 0.963 \\
\hline Obesity & $0.95(0.65-1.41)$ & 0.833 & $1.31(0.83-2.06)$ & 0.246 \\
\hline Morbid obesity & $0.97(0.46-2.05)$ & 0.955 & $1.66(0.74-3.69)$ & 0.217 \\
\hline $\operatorname{Age}^{1}$ & $1.08(1.07-1.10)$ & $<0.001$ & $1.07(1.05-1.10)$ & $<0.001$ \\
\hline COPD & $2.06(1.51-2.81)$ & $<0.001$ & $1.84(1.31-2.57)$ & $<0.001$ \\
\hline Diabetes & $1.55(1.17-2.06)$ & 0.002 & 1.45 (1.05-1.99) & 0.023 \\
\hline$E F<35 \%$ & $5.62(3.83-8.24)$ & $<0.001$ & $4.28(2.82-6.50)$ & $<0.001$ \\
\hline PVD & $1.70(1.21-2.38)$ & 0.002 & $1.35(0.93-1.95)$ & 0.113 \\
\hline $\mathrm{CrCl}<60 \mathrm{~mL} / \mathrm{min}$ & $3.24(2.48-4.23)$ & $<0.001$ & $1.65(1.17-2.34)$ & 0.005 \\
\hline Redo & $4.11(2.95-5.72)$ & $<0.001$ & $2.64(1.76-3.94)$ & $<0.001$ \\
\hline Emergency & $5.70(4.00-8.12)$ & $<0.001$ & $3.48(2.13-5.70)$ & $<0.001$ \\
\hline Periop MI & $6.17(4.21-9.06)$ & $<0.001$ & & \\
\hline Re-exploration & $5.70(4.16-7.81)$ & $<0.001$ & & \\
\hline IABP & $14.4(10.1-20.4)$ & $<0.001$ & & \\
\hline Male sex & $0.79(0.58-1.07)$ & 0.127 & $1.18(0.84-1.65)$ & 0.334 \\
\hline Hypertension & $0.97(0.75-1.27)$ & 0.875 & & \\
\hline Off-pump & $0.69(0.40-1.17)$ & 0.170 & & \\
\hline
\end{tabular}

Early mortality was defined as death within 30 days of the index surgery.

${ }^{1}$ entered as a continuous variable by year

$\mathrm{Cl}=$ confidence interval; $\mathrm{COPD}=$ chronic obstructive pulmonary disease; $\mathrm{CrCl}=$ creatinine clearance; $\mathrm{EF}=\mathrm{left}$ ventricular ejection fraction; $\mathrm{OR}=$ Odds ratio; $\mathrm{IABP}=$ need for intra-aortic balloon pump support; Periop $\mathrm{MI}=$ perioperative myocardial infarction; $\mathrm{PVD}=$ peripheral vascular disease; Redo=previous cardiac surgery.

Results of Cox regression analyses for late mortality are shown in Table 4.

By univariate analysis, overweight was associated with lower late mortality. Other risk factors for late mortality by univariate analysis were: advancing age, COPD, diabetes, $\mathrm{EF}<35 \%, \mathrm{CrCl}<60 \mathrm{~mL} / \mathrm{min}, \mathrm{PVD}$, hypertension, previous cardiac surgery, and CABG with the use of extra corporal circulation. Complications such as perioperative myocardial infarction, perioperative need for intra-aortic balloon pump, and re-exploration were also identified as risk factors for late mortality. 
Table 4. Predictors of Late Mortality by Univariate and Multivariate Cox Regression Analyses

\begin{tabular}{|c|c|c|c|c|}
\hline \multirow[b]{2}{*}{ Risk factor } & \multicolumn{2}{|c|}{ Univariate Analysis } & \multicolumn{2}{|c|}{ Multivariate Analysis } \\
\hline & OR $(95 \% \mathrm{Cl})$ & $P$ value & OR $(95 \% \mathrm{Cl})$ & $P$ value \\
\hline Underweight & $1.29(0.82-2.03)$ & 0.258 & $1.38(0.87-2.21)$ & 0.172 \\
\hline Overweight & $0.82(0.71-0.93)$ & 0.003 & $0.98(0.85-1.13)$ & 0.797 \\
\hline Obesity & $0.83(0.69-1.00)$ & 0.050 & $1.12(0.92-1.37)$ & 0.257 \\
\hline Morbid obesity & $0.98(0.69-1.39)$ & 0.928 & $1.67(1.15-2.43)$ & 0.007 \\
\hline Age* & $1.09(1.08-1.10)$ & $<0.001$ & 1.08 (1.07-1.09) & $<0.001$ \\
\hline COPD & $1.95(1.69-2.25)$ & $<0.001$ & $1.68(1.45-1.94)$ & $<0.001$ \\
\hline Diabetes & $1.72(1.51-1.96)$ & $<0.001$ & $1.66(1.43-1.93)$ & $<0.001$ \\
\hline$E F<35 \%$ & $2.64(2.10-3.31)$ & $<0.001$ & $2.30(1.82-2.90)$ & $<0.001$ \\
\hline $\mathrm{CrCl}<60 \mathrm{~mL} / \mathrm{min}$ & $2.92(2.60-3.29)$ & $<0.001$ & $1.52(1.31-1.76)$ & $<0.001$ \\
\hline PVD & $2.24(1.94-2.60)$ & $<0.001$ & $1.70(1.46-1.98)$ & $<0.001$ \\
\hline Male sex & $0.87(0.76-1.00)$ & 0.056 & $1.43(1.24-1.66)$ & $<0.001$ \\
\hline Hypertension & $1.22(1.08-1.37)$ & 0.001 & $1.08(0.96-1.22)$ & 0.260 \\
\hline Redo & $1.60(1.32-1.95)$ & $<0.001$ & 1.39 (1.14-1.71) & 0.001 \\
\hline Emergency & $1.29(0.98-1.69)$ & 0.064 & & \\
\hline Off-pump & $0.68(0.52-0.89)$ & 0.006 & & \\
\hline Periop MI & $1.85(1.36-2.52)$ & $<0.001$ & & \\
\hline Re-exploration & $1.45(1.17-1.81)$ & 0.001 & & \\
\hline IABP & $2.01(1.47-2.79)$ & $<0.001$ & & \\
\hline
\end{tabular}

Late mortality was defined as death more than 30 days after the index surgery.

${ }^{*} 1$ entered as a continuous variable by year

Abbreviations: $\mathrm{Cl}=$ confidence interval; $\mathrm{COPD}=$ chronic obstructive pulmonary disease; $\mathrm{CrCl}=\mathrm{creatinine}$ clearance; $E F=$ left ventricular ejection fraction; $O R=$ Odds ratio; $I A B P=$ need for intra-aortic balloon pump support; Periop $\mathrm{MI}=$ perioperative myocardial infarction; $\mathrm{PVD}=$ peripheral vascular disease; Redo= previous cardiac surgery.

Morbid obesity was significantly associated with late mortality by multivariate analysis entering only preoperative risk factors. Increasing age, COPD, diabetes, $\mathrm{EF}<35 \%, \mathrm{CrCl}$ $<60 \mathrm{~mL} / \mathrm{min}, \mathrm{PVD}$, previous cardiac surgery, and male sex were independent risk factors as well.

In Figure 2, long-term survival stratified by BMI groups is depicted.

Patients who were underweight had significantly lower survival compared to all other BMI groups (log-rank test, $P=.02$ ) Survival was lower for patients who were normal weight versus patients who were overweight $(P=.001)$, whereas no other differences in long-term survival between BMI groups were significant $(P>.05)$. 
Survival Functions

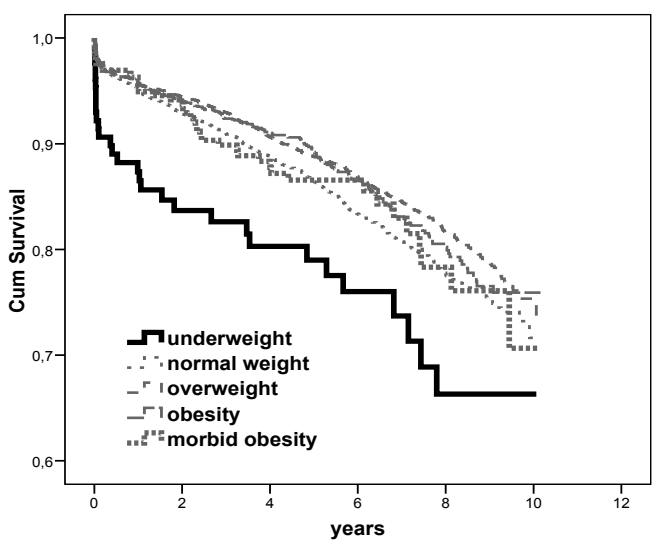

Survival Function at mean of covariates

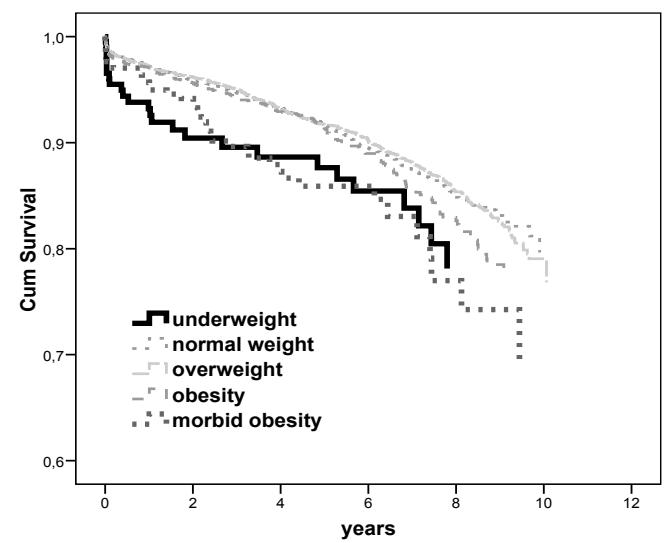

Figure 2

Figure 3

Figure (3) shows the long-term survival of different patients groups adjusted for other significant risk factors that were identified by the multivariate regression analysis. These factors are age, COPD, diabetes, ejection fraction $<35 \%$, Creatinin clearance $<$ $60 \mathrm{~mL} / \mathrm{min}$, peripheral vascular disease and male sex. Patients in both the underweight and the morbid obesity groups have lower long-term survival compared to the other groups (long rank test, $\mathrm{P}=0.03$ ) 


\section{Comment}

This retrospective analysis of prospectively collected data demonstrates the predictive value of body weight extremes on mortality of patients undergoing CABG. Underweight is a predictor of 30-day mortality, while morbid obesity is a predictor of late mortality.

In order to be able to use BMI as a preoperative predictor of early and late mortality after $C A B G$, the study design included only preoperative risk factors into the multivariate logistic regression model and the multivariate Cox regression model.

The predictive value of underweight for early mortality has been emphasized by other investigators. In a study by Engelman and colleagues (5), underweight patients $\left(\mathrm{BMI}<20 \mathrm{~kg} / \mathrm{m}^{2}\right)$ who underwent cardiac surgery had $10 \%$ mortality compared with $4 \%$ in the overall patient population. Reeves and colleagues (9) found operative mortality of $6.8 \%$ in underweight patients undergoing isolated CABG compared with $<1 \%$ in patients with normal BMI. On the other hand, Rahmanian and colleagues (12) and Christakis and colleagues (14) did not find underweight patients at higher risk of hospital mortality compared with patients with $\mathrm{BMI}>20 \mathrm{~kg} / \mathrm{m}^{2}$. These conflicting results could be attributed to different preoperative patient profiles. In our series, underweight patients were more often women and more likely to have renal dysfunction (low creatinine clearance), peripheral vascular disease, impaired left ventricular function (ejection fraction $<35 \%$ ), and COPD. Moreover, operative complications such as the need for intra-aortic balloon pump and re-exploration occurred more often in underweight patients.

Several previous studies have shown increased postoperative morbidity in underweight patients $(2,5,9)$, including low cardiac output syndrome, stroke, bleeding, and need for prolonged ventilation. Engelman and colleagues (5) showed a significant association between low BMI and re-exploration for bleeding, a finding that we have shown as well. This can be explained by the fact that underweight patients experience relatively increased hemodilution caused by the priming volume of the heart-lung machine. This may exacerbate cardiopulmonary bypass-related coagulopathy, leading to increased postoperative bleeding in these patients.

All patients are screened for underlying diseases before undergoing CABG. If severe disease is present that might shorten life expectancy, for example, malignancy, therapies other than CABG, such as percutaneous coronary intervention, are considered. Therefore, severe life-shortening diseases that might cause underweight are unlikely to be present at the time of CABG. However, we cannot exclude the possibility of undetected underlying disease as a cause for both being underweight and early mortality. Further studies are needed to clarify this issue.

In accord with other several authors $(2,11,17,18)$, we observed no association between (non-morbid) obesity and early and late mortality after CABG in our patients. 
In the study by Moulton and colleagues (19), obesity was a risk factor for sternal wound infection and atrial dysrhythmia, but not hospital mortality. Similar conclusions were made by Birkmeyer and colleagues (20), who found that obesity was not associated with increased stroke or in-hospital mortality among patients undergoing CABG and that obesity was even associated with decreased risk of postoperative bleeding. On the other hand, Gurm and colleagues (15) found that, among CABG-treated patients, each unit increase in BMI was associated with an $11 \%$ higher adjusted risk of 5year cardiac mortality. The negative effect of morbid obesity on late morbidity confirms the results of others $(9,15)$.

We believe that proper long-term treatment of associated coronary risk factors is essential in improving the long-term survival of obese patients after CABG. The relatively high frequency of women and the relatively young age of the morbidly obese patients, with a presumably longer life expectancy, could have masked the negative effect of obesity on survival, as seen in some studies $(11,21)$. Whether prevention and correction of body weight extremes may be helpful in preventing mortality after CABG remains to be investigated. Instead of the "obesity paradox," the term overweight paradox seems more applicable in our population.

Female sex has been identified as an independent risk factor for early mortality after CABG surgery (22-25). However, in this study, we did not confirm this finding. Male sex was a risk factor for late mortality.

\section{Limitations of this study}

This study is a retrospective study. Therefore, we must be cautious in interpreting our results. Possible confounders not studied, like chronic illness and smoking could have biased the results. The use of arterial grafts was not entered in the analysis due to relatively small number of patients. Some perioperative complications; e.g. prolonged ventilation, pulmonary complications and wound infections were not included in the analysis. These complications might also be correlated to obesity. The study endpoint was any-cause mortality. We were not able to report specific causes of death, morbidity, or hospital readmission that may have been equally interesting endpoints. The use of BMI as a risk factor does not differentiate between body fat and lean mass.

\section{Conclusions}

In patients undergoing isolated CABG, underweight was an independent predictor for 30-day mortality, whereas morbid obesity was a significant predictor of late mortality. 


\section{References}

1. Poirier P, Giles TD, Bray GA, et al; American Heart Association; Obesity Committee of the Council on nutrition, Physical Activity, and Metabolism. Obesity and cardiovascular disease: pathophysiology, evaluation, and effect of weight loss: an update of the 1997 American Heart Association Scientific Statement on Obesity and Heart Disease from the Obesity Committee of the Council on Nutrition, Physical Activity, and Metabolism. Circulation. 2006; 113:898-918.

2. Potapov EV, Loebe M, Anker S, et al. Impact of body mass index on outcome in patients after coronary artery bypass grafting with and without valve surgery. Eur Heart J. 2003; 24:1933-1941.

3. Flegal KM, Graubard BI, Williamson DF, Gail MH. Cause-specific excess deaths associated with underweight, overweight, and obesity. JAMA. 2007; 298:2028-2037.

4. Adams KF, Schatzkin A, Harris TB, et al. Overweight, obesity, and mortality in a large prospective cohort of persons 50 to 71 years old. N Engl J Med. 2006; 355:763-778.

5. Engelman DT, Adams DH, Byrne JG, et al. Impact of body mass index and albumin on morbidity and mortality after cardiac surgery. J Thorac Cardiovasc Surg. 1999; 118:866-873.

6. Habib RH, Zacharias A, Schwann TA, Riordan CJ, Durham SJ, Shah A. Effects of obesity and small body size on operative and long-term outcomes of coronary artery bypass surgery: a propensity-matched analysis. Ann Thorac Surg. 2005; 79:1976-1986.

7. Jin R, Grunkemeier GL, Furnary AP, Handy JR Jr. Is obesity a risk factor for mortality in coronary artery bypass surgery? Circulation. 2005; 111:3359-3365.

8. Prabhakar G, Haan CK, Peterson ED, Coombs LP, Cruzzavala JL, Murray GF. The risks of moderate and extreme obesity for coronary artery bypass grafting outcomes: a study from the Society of Thoracic Surgeons' database. Ann Thorac Surg. 2002; 74:1125-1130; discussion, 1130-1131.

9. Reeves $\mathrm{BC}$, Ascione R, Chamberlain MH, Angelini GD. Effect of body mass index on early outcomes in patients undergoing coronary artery bypass surgery. J Am Coll Cardiol. 2003; 42:668-676.

10. Schwann TA, Habib RH, Zacharias A, et al. Effects of body size on operative, intermediate, and longterm outcomes after coronary artery bypass operation. Ann Thorac Surg. 2001; 71:521-530; discussion, 530-531.

11. Oreopoulos A, Padwal R, Norris CM, Mullen JC, Pretorius V, Kalantar-Zadeh K. Effect of obesity on short- and long-term mortality postcoronary revascularization: a meta-analysis. Obesity (Silver Spring). 2008; 16:442-450.

12. Rahmanian PB, Adams DH, Castillo JG, Chikwe J, Bodian CA, Filsoufi F. Impact of body mass index on early outcome and late survival in patients undergoing coronary artery bypass grafting or valve surgery or both. Am J Cardiol. 2007; 100:1702-1708.

13. Wagner BD, Grunwald GK, Rumsfeld JS, et al. Relationship of body mass index with outcomes after coronary artery bypass graft surgery. Ann Thorac Surg. 2007;84:10-16.

14. Christakis GT, Weisel RD, Buth KJ, et al. Is body size the cause for poor outcomes of coronary artery bypass operations in women? J Thorac Cardiovasc Surg. 1995; 110:1344-1356; discussion, 1356-1358.

15. Gurm HS, Whitlow PL, Kip KE; BARI Investigators. The impact of body mass index on short- and longterm outcomes in patients undergoing coronary revascularization. Insights from the bypass angioplasty revascularization investigation (BARI). J Am Coll Cardiol. 2002; 39:834-840.

16. Clinical guidelines on the identification, evaluation, and treatment of overweight and obesity in adults: Expert Panel on the Identification, Evaluation, and Treatment of Overweight in Adults. Am J Clin Nutr. 1998;68:899-917.

17. Kim J, Hammar N, Jakobsson K, Luepker RV, McGovern PG, Ivert T. Obesity and the risk of early and late mortality after coronary artery bypass graft surgery. Am Heart J. 2003; 146:555-560. 
18. Syrakas CA, Neumaier-Prauser P, Angelis I, Kiask T, Kemkes BM, Gansera B. Is extreme obesity a risk factor for increased in-hospital mortality and postoperative morbidity after cardiac surgery? Results of 2251 obese patients with BMI of 30 to 50. Thorac Cardiovasc Surg. 2007; 55:491-493.

19. Moulton MJ, Creswell LL, Mackey ME, Cox JL, Rosenbloom M. Obesity is not a risk factor for significant adverse outcomes after cardiac surgery. Circulation. 1996; 94(9 Suppl):II87-92.

20. Birkmeyer NJ, Charlesworth DC, Hernandez F, et al. Obesity and risk of adverse outcomes associated with coronary artery bypass surgery. Northern New England Cardiovascular Disease Study Group. Circulation. 1998; 97:1689-1694.

21. Rubinshtein R, Halon DA, Jaffe R, Shahla J, Lewis BS. Relation between obesity and severity of coronary artery disease in patients undergoing coronary angiography. Am J Cardiol. 2006; 97(9):1277-80.

22. Abramov D, Tamariz MG, Sever JY, et al. The influence of gender on the outcome of coronary artery bypass surgery. Ann Thorac Surg. 2000; 70:800-805; discussion, 806.

23. Brandrup-Wognsen $G$, Berggren $H$, Hartford M, Hjalmarson A, Karlsson T, Herlitz J. Female sex is associated with increased mortality and morbidity early, but not late, after coronary artery bypass grafting. Eur Heart J. 1996; 17:1426-1431.

24. Guru V, Fremes SE, Austin PC, Blackstone EH, Tu JV. Gender differences in outcomes after hospital discharge from coronary artery bypass grafting. Circulation. 2006; 113:507-516.

25. Zitser-Gurevich Y, Simchen E, Galai N, Mandel M; ISCAB Consortium. Effect of perioperative complications on excess mortality among women after coronary artery bypass: the Israeli Coronary Artery Bypass Graft Study (ISCAB). J Thorac Cardiovasc Surg. 2002; 123:517-524 



\section{Chapter 13}

\section{Diabetes and survival after coronary artery bypass grafting: Comparison with an age and sex matched population}

Eur J Cardio Thorac Surg 2009 dec. [epub ehead of print] PMID 20036136

Authors

Albert H.M. van Straten ${ }^{1}$, Mohamed A. Soliman Hamad ${ }^{1}$ André A. J. van Zundert ${ }^{2}$ Elisabeth J. Martens ${ }^{3}$ Jacques P. A. M. Schönberger ${ }^{1}$ Joost F. J. ter Woorst ${ }^{1}$ Andre M. de Wolf ${ }^{4}$

1 Department of Cardio-Thoracic Surgery, Catharina Hospital, Eindhoven, The Netherlands.

2 Department of Anesthesiology, Catharina Hospital - Brabant Medical School, Eindhoven, The Netherlands \& University Hospital Ghent, Ghent, Belgium.

3 Department of Education and Research, Catharina Hospital, Eindhoven, The Netherlands \& Center of Research on Psychology in Somatic diseases, Department of Medical Psychology, Tilburg University, The Netherlands.

4 Department of Anesthesiology, The Feinberg School of Medicine, Northwestern University, Chicago, Illinois, USA 


\begin{abstract}
Objectives

Long-term outcome after coronary artery bypass grafting is worse in diabetic patients than in non-diabetic patients. No data are currently available regarding survival rates of diabetic and non-diabetic patients after coronary revascularization compared to cohorts from the general population in the Netherlands, which were matched for age and sex (normal Dutch survival).

\section{Methods}

We retrospectively analyzed the data from 10,626 patients who underwent coronary artery bypass grafting between January 1998 and December 2007. Of these, 8,287 patients were non-diabetic, 1,587 were non-insulin-dependent and 630 were insulindependent diabetic patients (122 patients were lost to follow-up). Survival of these patient groups was compared to the normal Dutch survival.
\end{abstract}

\title{
Results
}

Multivariate analyses revealed non-insulin-dependent diabetes to be a risk factor for early mortality and both insulin-dependent and non-insulin-dependent diabetes as risk factors for late mortality. One, 5- and 10-year survival rates for non-diabetic patients were $94.1 \% \pm 0.3 \%, 86.8 \% \pm 0.4 \%$, and $75.1 \% \pm 1.7 \%$, respectively which was better than the normal Dutch survival. For insulin-dependent diabetic patients, 1-, 5-, and 10-year survival rates were $90.3 \% \pm 1.2 \%, 78.0 \% \pm 2.0$, and $60.5 \% \pm 4.6 \%$, respectively and for noninsulin-dependent diabetic patients $91.4 \% \pm 0.7 \%, 79.0 \% \pm 1.3 \%$ and $58.9 \% \pm 3.4 \%$ respectively, which was worse than the normal Dutch survival.

\section{Conclusions}

Non-insulin-dependent diabetes was a risk factor for early mortality and both types of diabetes were risk factors for late mortality after revascularization. Compared to age and sex matched cohorts from the general Dutch population, the 10-year survival of non-diabetic patients was better; whereas the survival of both types of diabetic patients was worse. 


\section{Introduction}

Diabetes is a risk factor for poor outcomes after percutaneous [1-3] and surgical myocardial revascularization [6-12]. In patients undergoing coronary artery bypass grafting (CABG), the incidence of diabetes ranges from $12 \%$ to $38 \%$ [13-17]. Reports addressing the long-term mortality of diabetic patients after CABG vary, with an incidence ranging from $1.3 \%$ to $6.5 \%$ per patient-year [14-19]. In diabetic patients, revascularization appears to provide better long-term survival than percutaneous interventions does [17-19]. In some studies, diabetes also has been described as a predictor of early mortality [20-22], but others could not confirm this finding [14,23]. On the other hand, little is known about the long-term post-CABG survival of patients with and without diabetes compared to the survival of the general population. In this study, we evaluated the effect of diabetes on early and late mortality after CABG. We also compared the long-term survival of diabetic and non-diabetic patients to the survival of cohorts of the general population in the Netherlands matched for age and sex (normal Dutch survival).

\section{Patients and Methods}

\section{Patients}

In this study, data of all patients undergoing an isolated CABG at a single center (Catharina Hospital, Eindhoven, the Netherlands) between January 1998 and December 2007 were analyzed. Starting in January 1998, clinical data, including demographic data, risk factors, and complications were prospectively collected in a database. Approval of this study was obtained from the institution's research review board. We defined type 1 diabetes as insulin-dependent diabetes and type 2 diabetes as noninsulin-dependent diabetes, which included patients treated with oral medication or nutritional therapy.

Survival of age- and sex-matched cohorts from the general population

For calculating survival of general population cohorts, data from the database of the Dutch Central Bureau for Statistics (CBS), which can be downloaded online (www.cbs.nl), were used. For each year of the study period, general population cohorts were matched with the patient groups for age and gender. The year of operation of the patients group is the starting point for the general population cohorts.

\section{Operative techniques}

All patients received short-acting anesthetic drugs to facilitate early extubation. Extracorporeal circulation was performed using normothermic nonpulsatile flow. Cold crys- 
talloid cardioplegia ("St Thomas" solution) or warm blood cardioplegia was used to induce and maintain cardioplegic arrest, according to the surgeon's preference. All patients undergoing CABG with the use of extracorporeal circulation, received a low dose of aprotinin ( 2 million Kallikrein Inactivating Unit) administered in the prime solution of the extracorporeal circulation. Patients undergoing off-pump surgery did not receive aprotinin.

\section{Follow-Up}

Follow-up data concerning mortality were gathered using databases from health insurance companies. The data of $9 \%$ of the patients in the total patient group initially could not be retrieved from these databases. We therefore contacted the general practitioners by telephone to obtain information about the mortality data of those patients. For the remaining patients, we contacted the city authorities where the patients lived at the time of the operation. Early mortality was defined as any-cause mortality within 30 days postoperatively, whereas late mortality was defined as any-cause mortality that occurred later than 30 days after CABG.

\section{Statistical Analyses}

Discrete variables were compared with the chi-square test and are presented as numbers and percentages. Continuous variables were compared with a $t$ test and the analysis of variance and are presented as means \pm standard deviations. Univariate and multivariate logistic regression analyses were performed to investigate the effect of biomedical variables on early mortality. Multivariate analyses were used to test for the potentially confounding effect of biomedical and demographic factors on outcomes. Cox proportional hazard regression analyses were performed for the same analyses of late mortality. Values for $P$ less than .05 were considered statistically significant. If significant at $P<.05$, confounders were included into the multivariable logistic and Cox regression analyses. Long-term survival was described using the Kaplan-Meier method. Comparisons of long-term survival were done using log-rank statistics. The zero time point indicates the time of CABG. Hazard ratios (HR) with $95 \%$ confidence intervals (CI) are reported. All statistical analyses were performed using SPSS software (Statistical Product and Services Solutions, version 15.0, SPSS Inc, Chicago, IL, USA).

\section{Results}

During a 10-year period (January 1998 and December 2007) 10,626 patients underwent CABG in our hospital. Excluding 122 patients who were lost to follow-up, 8,287 patients $(78.9 \%)$ had no diabetes, 1587 of the patients (15.1\%) had type 2 diabetes, and 630 patients (6\%) had type 1 diabetes. Almost all patients who were lost to followup were foreigners or were living abroad. The minimum follow-up for surviving pa- 
tients was 60 days. Mean follow-up was $1696 \pm 1026$ days (range, 0-3708 days) (0 days for operative deaths).

Baseline characteristics stratified by diabetes type are shown in Table 1.

Table 1. Baseline characteristics stratified by diabetes type

\begin{tabular}{lllll}
\hline & $\begin{array}{l}\text { No diabetes } \\
\mathrm{n}=8287\end{array}$ & $\begin{array}{l}\text { Diabetes type } 2 \\
\mathrm{n}=1587\end{array}$ & $\begin{array}{l}\text { Diabetes type } 1 \\
\mathrm{n}=630\end{array}$ & P value \\
\hline Age, (mean \pm SD) & $64.2 \pm 9.7$ & $66.6 \pm 8.7$ & $64.6 \pm 9.1$ & $<.0001$ \\
Male, & $6535(78.9)$ & $1134(71.5)$ & $410(65.1)$ & $<.0001$ \\
$\mathrm{CrCl}<60 \mathrm{~mL} \cdot \mathrm{min}^{-1}$ & $2231(28.0)$ & $496(32.7)$ & $199(33.5)$ & $<.0001$ \\
Hypertension & $3196(38.6)$ & $843(53.1)$ & $345(54.8)$ & $<.0001$ \\
COPD & $1010(12.2)$ & $224(14.1)$ & $80(12.7)$ & .103 \\
PVD & $867(1.5)$ & $236(14.9)$ & $118(18.7)$ & $<.0001$ \\
BMI > 35 kg.m ${ }^{-2}$ & $130(1.6)$ & $64(4.2)$ & $45(7.5)$ & $<.0001$ \\
LVEF <35\% & $262(3.3)$ & $60(3.9)$ & $32(5.2)$ & .031 \\
Emergency & $379(4.6)$ & $45(2.8)$ & $20(3.2)$ & .003 \\
Off-pump & $767(9.3)$ & $114(7.2)$ & $49(7.8)$ & .018 \\
Prior CABG & $523(6.3)$ & $89(5.6)$ & $35(5.6)$ & .458 \\
IABP & $193(2.1)$ & $30(1.9)$ & $15(2.4)$ & .550 \\
Re-exploration & $447(5,4)$ & $90(5.7)$ & $41(6.5)$ & .473 \\
Periop MI & $260(3.1)$ & $33(2.1)$ & $16(2.5)$ & .061 \\
\hline
\end{tabular}

Values are expressed as number of patients (percentage) unless otherwise mentioned.

$\mathrm{BMI}$ = body mass index; $\mathrm{CABG}=$ coronary artery bypass grafting;

$\mathrm{COPD}=$ chronic obstructive pulmonary disease; $\mathrm{CrCl}=$ creatinine clearance per $1.73 \mathrm{~m}^{2} ; \mathrm{IABP}=$ intra aortic balloon pump support; LVEF = left ventricular ejection fraction; Periop $\mathrm{MI}$ = perioperative myocardial infarction; PVD = peripheral vascular disease

Patients with type 2 diabetes were older and patients with type 1 diabetes were more often female. Impaired renal function, defined as a creatinine clearance level $(\mathrm{CrCl})$ less than $60 \mathrm{ml} . \mathrm{min}^{-1}$ per $1.73 \mathrm{~m}^{2}$, hypertension, body mass index greater than $35 \mathrm{~kg} . \mathrm{m}^{-}$ ${ }^{2}$, and peripheral vascular disease (PVD) were more common in patients with diabetes (both types) than in non-diabetic patients.

Table 2 shows the incidences of early and late mortality stratified by type of diabetes. Early and late mortality are more frequent in both type 1 and type 2 patients. The annual incidence of death was 2.5 per 100 patient-years among non-diabetic patients, 4.1 per 100 patients-years among type 2 diabetic patients, and 4.5 per 100 patientyears among type 1 diabetic patients. During the study period, the overall early mortality rate in our department fell from 2.9\% in 1998 to $1 \%$ in 2007.

Risk factors for early mortality identified by univariate and multivariate logistic regression analyses are shown in Table 3. 
Table 2. Early and late mortality stratified by diabetes type

\begin{tabular}{llllc}
\hline & $\begin{array}{l}\text { No diabetes } \\
\mathrm{n}=8287\end{array}$ & $\begin{array}{l}\text { Diabetes type 2 } \\
\mathrm{n}=1587\end{array}$ & $\begin{array}{l}\text { Diabetes type1 } \\
\mathrm{n}=630\end{array}$ & P value \\
\hline Early mortality, $\mathrm{n}(\%)$ & $183(2.2)$ & $52(3.3)$ & $20(3.2)$ & .018 \\
Late mortality, $\mathrm{n}(\%)$ & $833(10.1)$ & $231(14.6)$ & $106(16.8)$ & $<.0001$ \\
\hline
\end{tabular}

Table 3. Predictors of early mortality; univariate and multivariate logistic regression analyses.

\begin{tabular}{|c|c|c|c|c|}
\hline & Univariate analyses & & Multivariate analyses & \\
\hline & Early mortality & & Early mortality & \\
\hline Risk factor & $\mathrm{HR}(95 \% \mathrm{Cl})$ & $P$ value & $\mathrm{HR}$ & $P$ value \\
\hline Diabetes type2 & 1.50 (1.09-2.05) & .011 & $1.46(1.04-2.05)$ & .029 \\
\hline Diabetes type 1 & $1.20(.95-1.52)$ & .119 & & \\
\hline Age* & 1.082 (1.065-1.099) & $<.0001$ & $1.057(1.036-1.078)$ & $<.0001$ \\
\hline COPD & $1.91(1.41-2.60)$ & $<.0001$ & $1.78(1.27-2.48)$ & .001 \\
\hline $\mathrm{CrCl}^{*}$ & $0.971(0.966-0.976)$ & $<.0001$ & $0.982(0.975-0.989)$ & $<.0001$ \\
\hline LVEF $<35 \%$ & $6.02(4.18-8.68)$ & $<.0001$ & $4.51(3.03-6.71)$ & $<.0001$ \\
\hline PVD & $1.60(1.15-2.23)$ & .005 & $1.31(0.91-1.89)$ & .141 \\
\hline Prior CABG & $4.26(3.11-5.83)$ & $<.0001$ & $2.33(1.56-3.48)$ & $<.0001$ \\
\hline Emergency & $6.79(4.94-9.32)$ & $<.0001$ & $3.88(2.48-6.06)$ & $<.0001$ \\
\hline Male sex & $.77(.58-1.02)$ & .069 & & \\
\hline Hypertension & $.94(.73-1.21)$ & .662 & & \\
\hline $\mathrm{BMI}>35 \mathrm{~kg} / \mathrm{m}^{-2}$ & $.90(.37-2.22)$ & .831 & & \\
\hline Periop MI & $5.79(3.97-8.43)$ & $<.0001$ & & \\
\hline Re-exploration & $5.78(4.27-7.82)$ & $<.0001$ & & \\
\hline IABP & 14.69 (10.52-20.52) & $<.0001$ & & \\
\hline Off pump & $.68(.41-1.13)$ & .145 & & \\
\hline
\end{tabular}

*entered as a continuous variable. $\mathrm{BMI}=$ body mass index, CABG = coronary artery bypass grafting, $\mathrm{COPD}=$ chronic obstructive pulmonary disease, $\mathrm{Cr} \mathrm{Cl}=$ preoperative creatinine clearance per $1.73 \mathrm{~m}^{2}, \mathrm{HR}=$ Hazard ratio, IABP = intra aortic balloon pump support, LVEF = left ventricular ejection fraction, Periop $\mathrm{MI}=$ perioperative myocardial infarction, PVD = peripheral vascular disease

Univariate logistic regression analysis revealed type 2 diabetes but not type 1 diabetes as a risk factor for early mortality. Other risk factors were age, chronic obstructive pulmonary disease (COPD), low $\mathrm{CrCl}$, EF less than 35\%, PVD, previous cardiac surgery, and emergency operation. Sex, hypertension, body mass index $>35 \mathrm{~kg} \cdot \mathrm{m}^{-2}$, and use of extracorporeal circulation were not identified as risk factors for early mortality. Complications such as perioperative myocardial infarction, perioperative use of intra-aortic balloon pump (IABP), and re-exploration also were identified as risk factors for early mortality.

All preoperative risk factors that were identified with the univariate logistic regression analyses were entered into the multivariate logistic regression model. Type 2 diabetes was an independent risk factor for early mortality. Other risk factors were 
age, COPD, low $\mathrm{CrCl}$, EF less than 35\%, previous cardiac surgery, and emergency operation. PVD did not prove to be a risk factor.

Results of Cox regression analyses for risk factors of late mortality are shown in Table 4.

Table 4. Predictors of late mortality; univariate and multivariate Cox regression analyses

\begin{tabular}{|c|c|c|c|c|}
\hline & Univariate analyses & & Multivariate analysis & \\
\hline & Late mortality & & Late mortality & \\
\hline Risk factor & HR $(95 \% \mathrm{Cl})$ & $P$ value & HR & $P$ value \\
\hline Diabetes Type 2 & $1.68(1.45-1.94)$ & $<.0001$ & $1.41(1.21-1.64)$ & .001 \\
\hline Diabetes Type 1 & $1.35(1.22-1.50)$ & $<.0001$ & $1.36(1.22-1.51)$ & $<.0001$ \\
\hline Age* & $1.092(1.083-1.100)$ & $<.0001$ & $1.075(1.064-1.086)$ & $<.0001$ \\
\hline Male sex & $0.86(0.75-0.98)$ & .026 & $1.44(1.22-1.70)$ & $<.0001$ \\
\hline COPD & $1.92(1.67-2.21)$ & $<.0001$ & $1.58(1.34-1.86)$ & $<.0001$ \\
\hline $\mathrm{Cr} \mathrm{Cl}{ }^{*}$ & $0.976(0.973-0.978)$ & $<.0001$ & $0.988(0.984-0.991)$ & $<.0001$ \\
\hline LVEF $<35 \%$ & $2.61(2.08-3.27)$ & $<.0001$ & $2.32(1.78-3.02)$ & $<.0001$ \\
\hline PVD & $2.29(1.98-2.64)$ & $<.0001$ & $1.82(1.54-2.16)$ & $<.0001$ \\
\hline Hypertension & $1.22(1.08-1.37)$ & .001 & $1.08(.93-1.24)$ & .268 \\
\hline Prior CABG & $1.59(1.32-1.92)$ & $<.0001$ & 1.27 ( $1.01-1.59)$ & .033 \\
\hline Emergency & 1.31 (1.01-1.69) & .038 & $1.31(.93-1.85)$ & .114 \\
\hline $\mathrm{BMI}>35 \mathrm{~kg} \cdot \mathrm{m}^{-2}$ & $1.22(.834-1.79)$ & .303 & & \\
\hline Periop MI & $1.84(1.39-2.43)$ & $<.0001$ & & \\
\hline Re-exploration & $1.45(1.17-1.81)$ & .001 & & \\
\hline IABP & 1.99 (1.47-2.70) & $<.0001$ & & \\
\hline Off pump CABG & $.67(.51-.88)$ & .004 & $.78(.56-1.06)$ & .123 \\
\hline
\end{tabular}

*entered as a continuous variable. $\mathrm{HR}=$ Hazard ratio;

$\mathrm{CABG}=$ coronary artery bypass grafting, $\mathrm{Cr} \mathrm{Cl}=$ preoperative creatinine clearance per $1.73 \mathrm{~m}^{2}, \mathrm{COPD}=$ chronic obstructive pulmonary disease, $\mathrm{LVEF}=$ left ventricular ejection fraction, $\mathrm{PVD}=$ peripheral vascular disease, Periop $\mathrm{MI}=$ perioperative myocardial infarction, IABP = intra-aortic balloon pump support

Univariate analyses revealed both types 1 and 2 diabetes as risk factors for late mortality. Other patient- and operation-related risk factors were age, COPD, low $\mathrm{CrCl}$, EF less than $35 \%$, PVD, previous cardiac surgery, female sex, emergency operation and hypertension. Furthermore, complications such as perioperative myocardial infarction, perioperative use of IABP, and re-exploration also were identified as risk factors for late mortality.

All preoperative risk factors identified with univariate analyses were entered into the multivariate Cox regression model. Both type 1 and type 2 diabetes were identified as independent risk factors for late mortality. Other risk factors were age, COPD, low $\mathrm{Cr}$ $\mathrm{Cl}$, EF less than $35 \%$, PVD, previous cardiac surgery and male sex. However, hyperten- 
sion, emergency operation, and use of extracorporeal circulation were not identified as independent risk factors.

Figures 1-3 shows the long-term survival rates stratified by diabetes type and the corresponding normal Dutch survival. Non-diabetic patients had a better survival than type 1 and 2 diabetic patients (figure 1$)$. ( $p$-value <0.0001) Differences between type 1 and 2 diabetic patients were not significant $(P=.483)$.

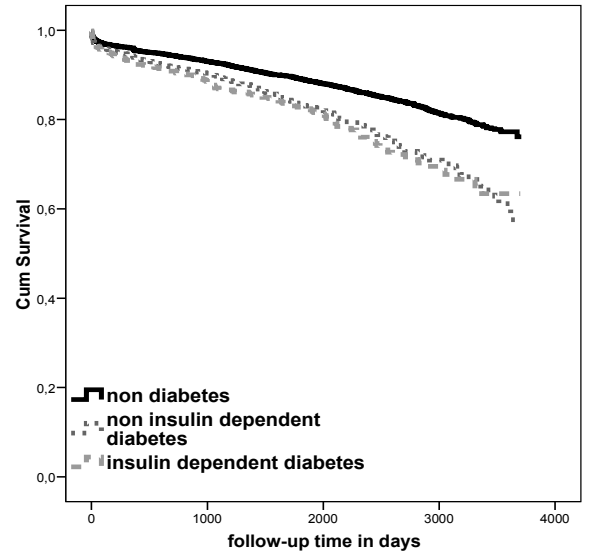

Figure 1 Kaplan-Meier survival curves of nondiabetic, insulin-dependent and non-insulin-dependent diabetic patients.

Log rank diabetic versus non-diabetic: $P$ value $<0.0001$; Log rank type1 versus type 2 diabetes: $P$ value $=.483$

Non-diabetic patients had a better survival compared to the normal Dutch survival (figure 2) (p-value < 0.0001). For non-diabetic patients, 1-, 5-, and 10-year survival rates were $94.1 \% \pm 0.3 \%, 86.8 \% \pm 0.4 \%$, and $75.1 \% \pm 1.7 \%$ respectively. For type 1 and type 2 diabetes patients survival was worse compared to the normal Dutch survival (figure 3) ( $p$-value <0.0001). For type 1 diabetic patients, 1-, 5- and 10-year survival rates were $90.3 \% \pm 1.2 \%, 78.0 \% \pm 2.0 \%$, and $60.5 \% \pm 4.6 \%$ and for type 2 diabetic patients $91.4 \% \pm 0.7 \%, 79.0 \% \pm 1.3 \%$, and $58.9 \% \pm 3.4 \%$, respectively.

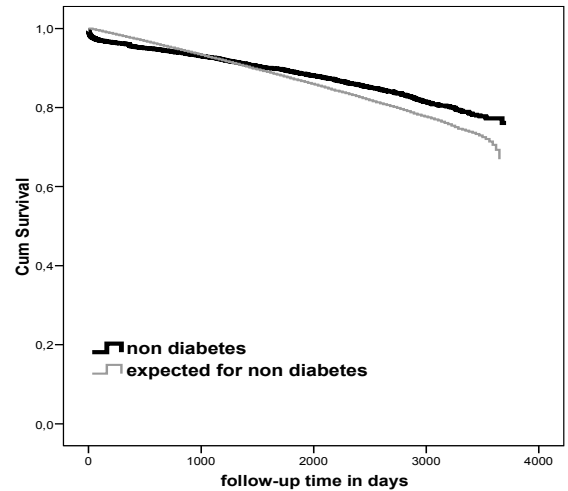

Figure 2 Kaplan-Meier survival curves of nondiabetic patients and the survival of the normal Dutch population.

Log rank non-diabetic versus population: $P$ value $<$ 0.0001 . 


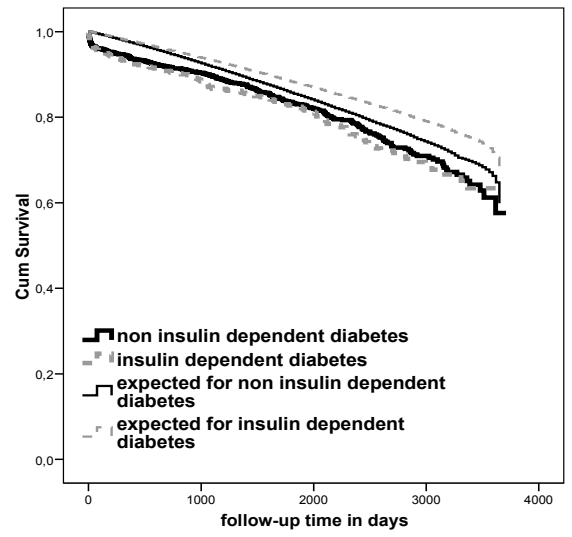

Figure 3 Kaplan-Meier survival curves of insulindependent and non-insulin-dependent diabetic patients and the survival of the normal Dutch population.

Log rank typte-1 diabetes versus population: $P$ value $<0.0001$; Log rank type- 2 diabetes versus population: $P$ value $<0.0001$.

\section{Discussion}

Both insulin-dependent (type 1) and non-insulin-dependent diabetes (type 2) patients had worse long-term survival rates after a CABG than did their non-diabetic counterparts. When compared to age and sex matched cohorts from the general Dutch population, non-diabetic patients had better outcomes; whereas patients with either type 1 or type 2 diabetes had worse outcomes. Differences were larger between the survival rates of type 1 diabetic patients and the normal Dutch survival rates than between the survival rates of type 2 diabetic patients and the normal Dutch survival rates.

Criteria for defining diabetes vary in several studies. Diabetes was defined as the need for diet, oral medication, or insulin in one study [14], while another study defined diabetes as the need for oral medication or insulin whereas nutritional therapy was not included. This might explain the differences in outcomes in several studies. In our study, we defined type 1 diabetes as insulin-dependent diabetes and type 2 diabetes as diabetes requiring oral or nutritional therapy. Twenty-one percent of our patient population were diabetic while other studies reported a prevalence of patients with diabetes ranging from $12 \%$ to $40 \%[12-17,20]$.

\section{Early mortality}

In this study, early mortality was $2.1 \%$ for non-diabetic patients, $3.2 \%$ for type 2 diabetes patients and $3.0 \%$ for type 1 diabetes patients $(P=.013)$. Throughout the entire study, the overall early mortality rate decreased from $2.9 \%$ in 1998 to $1 \%$ in 2007. Several other studies have confirmed the higher incidence of early mortality in diabetic patients [14,19,21-23]. In our study, multivariate regression analysis identified only type 2 diabetes as a risk factor for early mortality. Type 1 diabetes did not prove to be 
an independent risk factor. It is plausible that type-2 diabetes patients were not wellcontrolled preoperatively (and should have been on insuline), leading to a higher early mortality. Other studies provided conflicting information about the effect of diabetes on early mortality $[11,14,25]$. In our series, the Odds ratio for type 2 diabetes was significant but rather low (1.49) compared with the Odds ratios of other risk factors. Type 1 diabetes did not even prove to be a risk factor, indicating that only a small increase in risk for early mortality in diabetic patients can be expected. Although type-1 diabetes patients were relatively younger, the effect of age as a confounder is eliminated by using the logistic regression analysis.

\section{Late mortality}

In this study, the incidence of late mortality was higher in type 1 and type 2 diabetes patients $(P<.0001)$ than it was in non-diabetic patients. The incidence of death was 2.5 per 100 patient-years for non-diabetic patients, 4.1 per 100 patient-years for type 2 diabetes patients, and 4.5 per 100 patient-years for type 1 diabetes patients. These findings are similar to those of several other studies [14,17-20]. The finding that type-1 diabetes affects only late mortality and not early mortality is possibly due to the longterm pathological effect of diabetes on different organic function. Deterioration of renal and neurological function can be enhanced by the pathological effect of diabetes.

Taking into consideration that mortality rates will increase with increasing age, results will depend on the duration of the follow-up. With longer follow-up, higher numbers of deaths per 100 patient-years will be found. Thus, when follow-up is long, 1- and 5-year survival rates will be more meaningful. One and 5-year survival rates of non-diabetic as well as of type 1 and type 2 diabetic patients in this study were comparable to those found by others $[14,21,24]$. On the other hand, Calafiore et al [11] have shown that diabetes is an independent risk factor for early cardiac death only and the long term survival is not statistically significant different for diabetic and non diabetic patients. However, their series consisted of relatively small number of patients $(n=2$ 593) compared to ours ( $n=10$ 514). Lack of statistical significance might simply be a lack of statistical power because of the reduced sample size [11].

Obviously, advanced age is associated with a poorer late survival rate. Type 1 diabetic patients as shown in this study are often younger. Although proper statistical testing can be used to distinguish between effects caused by age and diabetes, interpretation of survival curves remains difficult. Life expectancy may also vary with sex. Also, variation in life expectancy over the years has been well documented in The Netherlands by the Central Bureau for Statistics. This organization keeps track of mortality rates of the overall Dutch population. We used the Central Bureau for Statistics database (www.CBS.nl) to calculate the survival of age and sex matched general population groups. Since the mortality rates of the Dutch population varied during study 
period, we performed the matching of the cohorts for each year of the study period. We consider this the normal Dutch survival. We compared the late survival of the patient groups with this as the "normal Dutch survival". However, caution in interpreting these results is needed, because the Central Bureau for Statistics database contains data of the total Dutch population including patients described in this study as well as patients who were treated in other Dutch cardiac surgery centers. However, the number of patients in The Netherlands who undergo a CABG in 1 year is relatively small compared with the total number of persons in the general population.

We did not only find that survival rates after CABG in non-diabetic patients were better than in diabetic patients, but also better than the survival rates of the normal Dutch population. An explanation for this might be that a certain percentage of the general population has diabetes and coronary disease. One also may assume that our patients were adequately treated for their coronary problem and postoperatively treated with aspirin and anticholesterolemic drugs and were treated for underlying diseases such as hypertension. This treatment, as well as the protection obtained by the revascularization, may contribute to the improved survival and explain why nondiabetic patients have a better survival rate than the general Dutch population. Furthermore, before undergoing CABG, patients are screened for severe underlying disease. If a severe underlying disease is present, an alternative treatment to a CABG must be considered, thus biasing the CABG group.

For both type 1 and type 2 diabetes patients, long-term survival was worse than the normal Dutch survival. Although type 1 diabetes patients were younger, they had survival rates similar to those with type 2 diabetes. The difference in survival between type 1 and the normal Dutch survival is larger than the difference between type 2 and the normal Dutch survival indicating a difference between type 1 and type 2 regarding the impact on late survival. This is confirmed by the higher hazard ratio (1.94 for type 1 versus 1.34 for type 2) found by multivariate Cox regression analyses. To our knowledge, this is the first study to compare survival rates of diabetic and non-diabetic CABG patients to age and sex matched cohorts from the general population. This information may be valuable for informing patients about their prognosis after a CABG. Instead of informing the patient whether he or she will do better or worse than other patients with or without diabetes undergoing CABG we can inform them how their survival will be compared to the normal survival of people of the same age and sex. For nondiabetic patients, this information strengthens the choice for the standard CABG procedure versus other less invasive options such as $\mathrm{PCl}$. It might be reassuring to know that after their CABG operation at least for the next 10 years, their survival will be not worse or even better than the normal Dutch survival, unless they have other risk factors for late mortality. For diabetic patients, however, the prognosis, in terms of longterm survival, is worse. 


\section{Limitations}

This is a retrospective observational study. Therefore, we must be cautious in interpreting our results. The study endpoint is any-cause mortality. We were not able to report causes of death or other morbidities that might be equally interesting. There are no data about perioperative glucose measurement which might affect early outcome.

\section{Conclusions}

Only non-insulin dependent diabetes proved to be a risk factor for early mortality after CABG surgery. Both insulin-dependent and non-insulin-dependent diabetes were predictors of late mortality. Compared to the normal Dutch population, 10-year survival rates were better for non-diabetic patients, while they were worse for noninsulin-dependent diabetic patients and even the worst for insulin-dependent diabetic patients.

\section{References}

1. Ellis SG, Vandormael MG, Cowley MJ, G, Deligonul U, Topol EJ, Bulle TM, the Multivessel Angioplasty Prognosis Study Group. Coronary morphologic and clinical determinants of procedural outcome with angioplasty for multivessel coronary disease. Implications for patient selection. Multivessel Angioplasty Prognosis Study Group. Circulation 1990;82:1193-202.

2. Levine GN, Leya F, Keeler GP, Berdan LG, Jacobs AK, the CAVEAT Investigators. Impact of diabetes mellitus on percutaneous revascularization (CAVEAT-I). CAVEAT-I Investigators. Coronary Angioplasty Versus Excisional Atherectomy Trial. Am J Cardiol 1997;79:748-55.

3. Mueller HS, Lawrence SC, Braunwald E, Forman S, Feit F, Ross A, Schweiger M,Cabin H, Davison R, Miller D, Solomon R, Knatterud GL. Predictors of early morbidity and mortality after thrombolytic therapy of acute myocardial infarction. Analyses of patient subgroups in the Thrombolysis in Myocardial Infarction (TIMI) trial, phase II. Circulation 1992;85:1254-64.

4. Alderman EL, Corley SD, Fisher LD, Chaitman BR, Faxon DP, Foster ED, Killip T,Sosa JA, Bourassa MG. Five-year angiographic follow-up of factors associated with progression of coronary artery disease in the Coronary Artery Surgery Study (CASS). CASS Participating Investigators and Staff. J Am Coll Cardiol 1993;22:1141-54.

5. Gadaleta D, Risucci DA, Nelson RL, Tortolani AJ, Hall M, Parnell V, Chiodo C,Green S. Effects of morbid obesity and diabetes mellitus on risk of coronary artery bypass grafting. Am J Cardiol 1992;70:1613-4.

6. Wells S. Postoperative recovery: how diabetes complicates care. J Cardiovasc Nurs 1993;7:47-58.

7. Yamazaki K, Kato H, Tsujimoto S, Kitamura R. Diabetes mellitus, internal thoracic artery grafting, and risk of an elevated hemidiaphragm after coronary artery bypass surgery. J Cardiothorac Vasc Anesth. 1994;8:437-40.

8. Slaughter MS, Olson MM, Lee JT Jr, Ward HB. A fifteen-year wound surveillance study after coronary artery bypass. Ann Thorac Surg. 1993;56:1063-8. 
9. Stein B, Weintraub WS, Gebhart SP, Cohen-Bernstein CL, Grosswald R, Liberman HA, Douglas JS Jr, Morris DC, King SB 3rd. Influence of diabetes mellitus on early and late outcome after percutaneous transluminal coronary angioplasty. Circulation. 1995;91(4):979-89.

10. Smith LR, Harrell FE Jr, Rankin JS, Califf RM, Pryor DB, Muhlbaier LH, Lee KL, Mark DB, Jones RH, Oldham HN, Glower DD, Reves JG, Sabiston DC Jr. Determinants of early versus late cardiac death in patients undergoing coronary artery bypass graft surgery. Circulation 1991;84(suppl 5):III245-53.

11. Calafiore AM, Di Mauro M, Di Giammarco G, Contini M, Vitolla G, lacò AL, Canosa C, D'Alessandro S. Effect of diabetes on early and late survival after isolated first coronary bypass surgery in multivessel disease. J Thorac Cardiovasc Surg. 2003;125(1):144-54.

12. Leavitt BJ, Sheppard L, Maloney C, Clough RA, Braxton JH, Charlesworth DC, Weintraub RM, Hernandez F, Olmstead EM, Nugent WC, O'Connor GT, Ross CS. Effect of diabetes and associated conditions on long-term survival after coronary artery bypass graft surgery. Circulation 2004;110(11 suppl 1):II41-4.

13. Whang W, Bigger JT Jr. Diabetes and outcomes of coronary artery bypass graft surgery in patients with severe left ventricular dysfunction: results from The CABG Patch Trial database. The CABG Patch Trial Investigators and Coordinators. J Am Coll Cardiol. 2000 Oct;36(4):1166-72. Erratum in: J Am Coll Cardiol 2001;37:2012.

14. Szabó Z, Håkanson E, Svedjeholm R. Early postoperative outcome and medium-term survival in 540 diabetic and 2239 non-diabetic patients undergoing coronary artery bypass grafting. Ann Thorac Surg 2002;74:712-9.

15. Barsness GW, Peterson ED, Ohman EM, Nelson CL, DeLong ER, Reves GJ, Smith PK, Anderson RD, JonesvRH, Mark DB, Califf RM. Relationship between diabetes mellitus and long-term survival after coronary bypass and angioplasty. Circulation 1997;96:2551-6.

16. Clough RA, Leavitt BJ, Morton JR, Plume SK, Hernandez F, Nugent W, Lahey SJ, Ross CS, O'Connor GT. The effect of comorbid illness on mortality outcomes in cardiac surgery. Arch Surg 2002;137:428-32; discussion 432-3.

17. Niles NW, McGrath PD, Malenka D, Quinton H, Wennberg D, Shubrooks SJ, Tryzelaar JF, Clough R, Hearne MJ, Hernandez F Jr, Watkins MW, O'Connor GT; Northern New England Cardiovascular Disease Study Group. Survival of patients with diabetes and multivessel coronary artery disease after surgical or percutaneous coronary revascularization: results of a large regional prospective study. Northern New England Cardiovascular Disease Study Group. J Am Coll Cardiol 2001;37:1008-15.

18. Detre KM, Guo P, Holubkov R, Califf RM, Sopko G, Bach R, Brooks MM, Bourassa MG, Shemin RJ, Rosen $A D$, Krone RJ, Frye RL, Feit F. Coronary revascularization in diabetic patients: a comparison of the randomized and observational components of the Bypass Angioplasty Revascularization Investigation (BARI). Circulation 1999;99:633-40.

19. [No authors listed] Comparison of coronary bypass surgery with angioplasty in patients with multivessel disease. The Bypass Angioplasty Revascularization Investigation (BARI) Investigators. N EngI J Med 1996;335:217-25. Erratum in: N Engl J Med 1997;336:147.

20. Herlitz J, Wognsen GB, Karlson BW, Sjöland H, Karlsson T, Caidahl K, Hartford M, Haglid M. Mortality, mode of death and risk indicators for death during 5 years after coronary artery bypass grafting among patients with and without a history of diabetes mellitus. Coron Artery Dis 2000;11:339-46.

21. Thourani VH, Weintraub WS, Stein B, Gebhart SS, Craver JM, Jones EL, Guyton RA. Influence of diabetes mellitus on early and late outcome after coronary artery bypass grafting. Ann Thorac Surg 1999;67:1045-52.

22. Carson JL, Scholz PM, Chen AY, Peterson ED, Gold J, Schneider SH. Diabetes mellitus increases shortterm mortality and morbidity in patients undergoing coronary artery bypass graft surgery. J Am Coll Cardiol. 2002;40:418-23.

23. Rajakaruna C, Rogers CA, Suranimala C, Angelini GD, Ascione R. The effect of diabetes mellitus on patients undergoing coronary surgery: a risk-adjusted analysis. J Thorac Cardiovasc Surg. 2006;132:802-10. 
24. Filsoufi F, Rahmanian PB, Castillo JG, Mechanick JI, Sharma SK, Adams DH. Diabetes is not a risk factor for hospital mortality following contemporary coronary artery bypass grafting. Interact Cardiovasc Thorac Surg 2007;6:753-8. 


\section{Chapter 14}

\section{Peripheral vascular disease as a predictor of survival after coronary artery bypass grafting: Comparison with an age and sex matched general population}

Ann Thorac Surg 2010;89:414-20

Authors

Albert H. M. van Straten ${ }^{1}$

Cristina Firanescu ${ }^{1}$

M. A. Soliman Hamad ${ }^{1}$

M. Erwin. S. H. $\operatorname{Tan}^{1}$

Joost F. J. ter Woorst ${ }^{1}$

Elisabeth J. Martens ${ }^{2}$

André A. J. van Zundert ${ }^{3}$

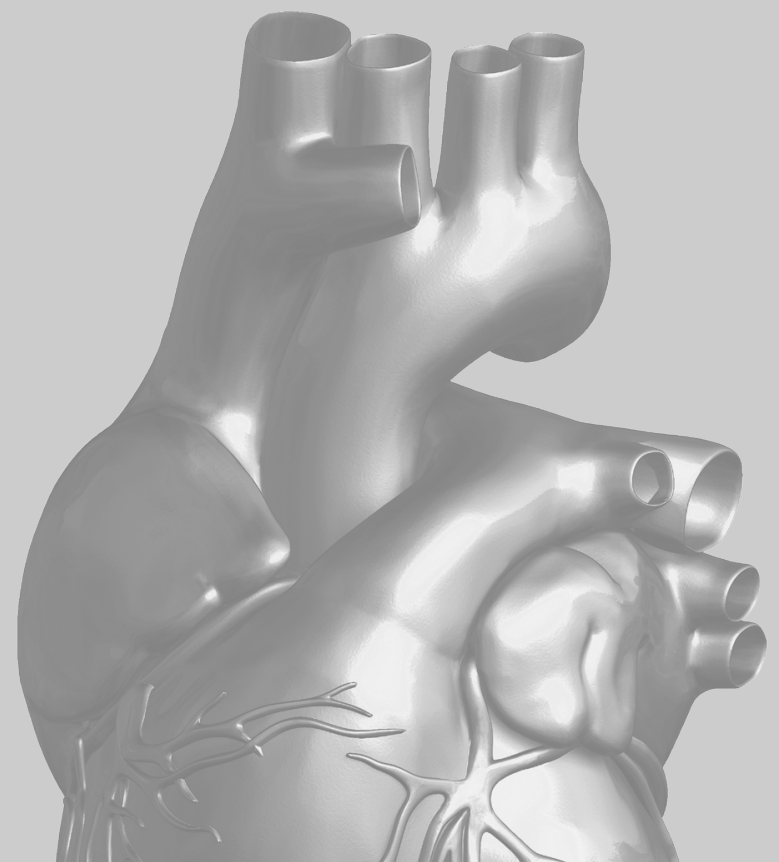

1 Department of Cardio-thoracic surgery, Catharina Hospital, Eindhoven, The Netherlands

2 Department of Education and Research, Catharina Hospital, Eindhoven, The Netherlands, \& Centre of Research on Psychology in Somatic Diseases, Department of Medical Psychology, Tilburg University, The Netherlands.

3 Department of Anesthesiology, Catharina Hospital - Brabant Medical School, Eindhoven, The Netherlands \& University Hospital Ghent, Ghent, Belgium. 


\begin{abstract}
Background

The EuroSCORE, the most popular European scoring system in cardiac surgery, uses the extracardiac arteriopathy as a risk factor for early mortality. We studied the effect of peripheral vascular disease (PVD) on early and late mortality in a large group of patients undergoing isolated CABG surgery.
\end{abstract}

\title{
Methods
}

During a ten-year period (January 1998 through December 2007) 10,626 patients underwent isolated CABG in our hospital. The primary endpoints of this study were early and late all-cause mortality. For each year of the study period, general population cohorts were matched with the patient groups for age and gender (expected survival).

\section{Results}

Out of 10,504 patients included in the analysis, 1,222 (11.63\%) patients had PVD. PVD was identified as an independent risk factor for late mortality [hazard ratio of 1.67(1.43-1.95), $P<.0001$ ], but not for early mortality [hazard ratio of 1.06 (0.70-1.60), $P=.776$ ]. Patients without PVD had a better survival than patients with PVD (log-rank $P$ $<0.0001$ ) and even a better survival compared to the normal Dutch population survival ( $p$-value <.002). PVD patients had a worse than expected survival (log-rank $P<.0001)$.

\section{Conclusions}

Peripheral vascular disease is an independent risk factor only for late mortality but not for early mortality. Compared to age and sex matched cohorts from the general Dutch population, the 10-year survival of patients with peripheral vascular disease was worse; whereas the survival of patients with no peripheral vascular disease was better. 


\section{Introduction}

Patients with peripheral vascular disease (PVD) are known to have a high prevalence of coronary artery disease and they often undergo coronary artery bypass grafting (CABG) [1]. The prevalence of PVD in patients with coronary artery disease varied in several studies between $26 \%$ to $71 \%$ [2-5]. Peripheral vascular disease (PVD) was found to increase twofold to three-fold the risk of cardiovascular mortality [6]. In patients with coronary artery disease (CAD), lower extremity PVD was independently associated with poorer outcomes [7]. The operative mortality with CABG is estimated to be 1.6 to 2.9 - fold higher in patients with PVD $[8,9]$.

In 1999 the EuroSCORE was introduced in Europe [10] and started to be widely used as a scoring system used to predict early mortality in cardiac surgical patients. The standard EuroSCORE underestimated the risk in certain very high-risk patients, therefore in 2003 a more precise logistic regression model was introduced [11]. In both calculating methods, the extracardiac arteriopathy (limb arteries or carotid pathology is identified as a risk factor for early mortality in cardiac surgical patients.

The value of PVD as an independent predictor for early mortality after CABG demonstrated in a non-contemporaneous series [2], can be debated considering the results of more recent cohorts [12]. These results still sustain the fact that PVD is an important predictor for increased late mortality.

To our knowledge there are no large recent studies assessing the impact of PVD on early and late survival after CABG. Therefore we analyzed PVD as a risk factor for early and late mortality in a large group of patients with isolated CABG operated in our department between 1998 and 2008.

\section{Materials and methods}

\section{Patients}

Data of all patients undergoing isolated CABG at a single center (Catharina Hospital, Eindhoven, the Netherlands) between January 1998 and December 2007 were analyzed. Starting in January 1998, clinical data, including demographic data, risk factors, and complications were prospectively collected in our database. The Institutional Research Review Board approved this study and waived the need for patient consent.

\section{Definition}

The presence of peripheral vascular disease was prospectively registered. We defined PVD as disease of the leg arteries below the aortic bifurcation, one of the common carotid arteries, the abdominal aorta or disease of the arm arteries starting with the 
subclavian arteries. The presence of peripheral vascular disease was confirmed by any of the following findings:

- Presentation of the patient eg, intermittent claudications.

- Angiographic or echocardiographic evidence of stenosis in one or more of the above mentioned vessels.

History of a revascularization procedures of one of the above mentioned vessels. e.g; femo-popliteal bypass, carotid stenting.

\section{Study endpoints}

The primary endpoints of this study were early and late all-cause mortality. We calculated the independent predictive value of PVD for early and late mortality, corrected for confounders. The analyzed confounders were pre-, intra-, and postoperative characteristics.

Survival of age- and gender-matched cohorts from the general population

For calculating survival of general population cohorts, data from the database of the Dutch Central Bureau for Statistics (CBS), which can be downloaded online (www.cbs.nl), were used. For each year of the study period, general population cohorts were matched with the patient groups for age and gender. The year of operation of the patients group is the starting point for the general population cohorts.

\section{Operative techniques}

All patients received short-acting anesthetic drugs to facilitate early extubation. Extracorporeal circulation (ECC) was performed using normothermic nonpulsatile flow. Cold crystalloid cardioplegia ("St Thomas" solution) or warm blood cardioplegia was used to induce and maintain cardioplegic arrest, according to the surgeon's preference. All patients undergoing CABG with the use of extracorporeal circulation, received - according to the standard hospital protocol - a low dose of aprotinin (2 million Kallikrein Inactivating Unit) administered in the prime solution of the extracorporeal circulation.

\section{Follow-Up}

Follow-up data concerning mortality were gathered using databases from health insurance companies. The data of $9 \%$ of the patients in the total patient group could initially not be retrieved from these databases. We therefore contacted the general practitioners by telephone to obtain information about the mortality data of those patients. For the remaining patients, we contacted the city authorities where the patients lived at the time of the operation. The closing interval was October-December 2007. However, 122 patients (1.1\%) were lost to follow up. Early mortality was defined as death within 30 days postoperatively or death at anytime if the patient did not leave the hospital or a transfer tertiary hospital alive, whereas late mortality was defined as anycause mortality that occurred at anytime after hospital discharge. 


\section{Statistical Analyses}

Discrete variables were compared with the chi-square test and are presented as numbers and percentages. Continuous variables were compared with a $t$ test and the analysis of variance and are presented as means \pm standard deviations. Univariate and multivariate logistic regression analyses were performed to investigate the effect of biomedical variables on early mortality. Multivariate analyses were used to test for the potentially confounding effect of biomedical and demographic factors on outcomes. Cox proportional hazard regression analyses were performed for the same analyses of late mortality. Values for $P$ less than .05 were considered statistically significant. If significant at $P<.05$, confounders were included into the multivariable logistic and Cox regression analyses. Long-term survival was described using the Kaplan-Meier method. Comparisons of long-term survival were done using log-rank statistics. The zero time point indicates the time of CABG. Hazard ratios (HR) with $95 \%$ confidence intervals $(\mathrm{Cl})$ are reported. All statistical analyses were performed using SPSS software (Statistical Product and Services Solutions, version 15.0, SPSS Inc, Chicago, IL, USA).

\section{Results}

During a ten-year period (January 1998 and December 2007) 10,626 patients underwent isolated CABG in our hospital. 122 patients were lost to follow-up. The minimum follow-up for surviving patients was 60 days. Mean follow-up was 1,625 \pm 1064 days (range, 0-3,708 days) (0 days for operative deaths). In 9282 patients, no preoperative PVD was diagnosed while 1,222 (11.63\%) patients did have preoperative PVD.

Baseline characteristics stratified by PVD are shown in Table 1. Patients with PVD were older, had a worse creatinine clearance $(\mathrm{CrCl})$, and showed more often hypertension, diabetes and a lower preoperative hemoglobin level. Duration of extra-corporeal circulation (ECC) was longer in PVD patients and the number of grafts and transfused Red Blood Cells (RBC) units was higher. Perioperative myocardial infarction occurred more often in PVD patients. 
Table 1. Baseline characteristics stratified by peripheral vascular disease

\begin{tabular}{|c|c|c|c|}
\hline & No PVD & PVD & $P$ value \\
\hline & $n=9282$ & $n=1222$ & \\
\hline \multicolumn{4}{|c|}{ Preoperative characteristics } \\
\hline Age, years & $64.3 \pm 9.7$ & $67.3 \pm 8.2$ & $<.0001$ \\
\hline Male, & 7152 (77.1) & 927 (75.9) & .186 \\
\hline $\mathrm{CrCl}<60 \mathrm{~mL} \cdot \mathrm{min}^{-1}$ & $73.9 \pm 26.1$ & $67.7 \pm 24.9$ & $<.0001$ \\
\hline Hypertension & $3765(40.6)$ & $618(50.6)$ & $<.0001$ \\
\hline COPD & $1118(12.0)$ & 196(16.0) & .103 \\
\hline Diabetes & $1863(20.1)$ & $354(29.0)$ & $<.0001$ \\
\hline $\mathrm{BMI}>35 \mathrm{~kg} \cdot \mathrm{m}^{-2}$ & $213(2.4)$ & $26(2.2)$ & .392 \\
\hline Angina class & $2.7 \pm 0.9$ & $2.7 \pm 0.9$ & .116 \\
\hline LVEF < 35\% & $304(3.4)$ & $50(4.2)$ & .086 \\
\hline No of infarctions & $0.49 \pm 0.61$ & $0.46 \pm 0.61$ & .536 \\
\hline $\mathrm{Hb}(\mathrm{g} / \mathrm{dl})$ & $13.9 \pm 1.3$ & $13.6 \pm 1.4$ & $<.0001$ \\
\hline Emergency & $402(4.3)$ & $42(3.4)$ & .083 \\
\hline Prior CABG & $562(6.1)$ & $85(7.0)$ & .228 \\
\hline \multicolumn{4}{|c|}{ Peri and postoperative characteristics } \\
\hline Off-pump & $839(9.0)$ & $91(7.4)$ & .071 \\
\hline Duration of ECC & $57.2 \pm 34.1$ & $61.8 \pm 32.6$ & $<.0001$ \\
\hline Use of IMA & $8183(88.2)$ & 1076(88.1) & .929 \\
\hline Number of grafts & $3.4 \pm 1.1$ & $3.5 \pm 1.0$ & $<.0001$ \\
\hline Re-exploration & 499(5.4) & $79(6.5)$ & .122 \\
\hline No of RBC units & $1.05 \pm 2.20$ & $1.32 \pm 2.96$ & $<.0001$ \\
\hline Periop MI & $259(2.8)$ & $50(4.1)$ & .013 \\
\hline
\end{tabular}

Values are expressed as number of patients (percentage) unless otherwise mentioned.

$\mathrm{BMI}=$ body mass index; $\mathrm{CABG}=$ coronary artery bypass grafting;

$\mathrm{COPD}=$ chronic obstructive pulmonary disease; $\mathrm{CrCl}=$ creatinine clearance per $1.73 \mathrm{~m}^{2} ; \mathrm{ECC}=$ extracorporeal circulation; $\mathrm{Hb}=$ preoperative hemoglobin level; IABP = intra aortic balloon pump support; IMA = internal mammary artery; LVEF = left ventricular ejection fraction; Periop $\mathrm{MI}=$ perioperative myocardial infarction; PVD = peripheral vascular disease; RBCs = red blood cells

Table 2 shows the incidences of early and late mortality stratified by the presence of preoperative PVD. Early as well as late mortality occurred more frequently in PVD patients. During the study period, the overall early mortality rate in our department decreased from $2.9 \%$ in 1998 to $1 \%$ in 2007.

Table 2. Early and late mortality stratified by the presence of peripheral vascular disease (PVD)

\begin{tabular}{llll}
\hline & No PVD & PVD & P value \\
& $\mathrm{n}=8287$ & $\mathrm{n}=1587$ & \\
\hline Early mortality, $\mathrm{n}(\%)$ & $211(2.3)$ & $44(3.6)$ & .006 \\
Late mortality, $\mathrm{n}(\%)$ & $936(10.1)$ & $235(19.1)$ & $<.0001$ \\
\hline
\end{tabular}


Risk factors for early mortality identified by univariate and multivariate logistic regression analyses are shown in Table 3.

Univariate logistic regression analysis revealed PVD as a risk factor for early mortality.

Table 3 Predictors of early mortality; univariate and multivariate logistic regression analyses.

\begin{tabular}{|c|c|c|c|c|}
\hline & $\begin{array}{l}\text { Univariate analyses } \\
\text { Early mortality }\end{array}$ & & $\begin{array}{l}\text { Multivariate analyses } \\
\text { Early mortality }\end{array}$ & \\
\hline Risk factor & $\mathrm{HR}(95 \% \mathrm{Cl})$ & $P$ value & $\mathrm{HR}$ & $P$ value \\
\hline \multicolumn{5}{|c|}{ Preoperative risk factors } \\
\hline PVD & $1.60(1.15-2.23)$ & .005 & $1.06(0.70-1.60)$ & .776 \\
\hline Age* & 1.082 (1.065-1.099) & $<.0001$ & $1.056(1.033-1.080)$ & $<.0001$ \\
\hline Male sex & $.77(.58-1.02)$ & .069 & & \\
\hline $\mathrm{Cr} \mathrm{Cl} *$ & $0.971(0.966-0.976)$ & $<.0001$ & $0.986(0.978-0.994)$ & .001 \\
\hline Hypertension & $.94(.73-1.21)$ & .662 & & \\
\hline COPD & $1.91(1.41-2.60)$ & $<.0001$ & $1.81(1.25-2.60)$ & .001 \\
\hline Diabetes & $1.46(1.12-1.96)$ & .005 & $1.52(1.09-2.12)$ & .013 \\
\hline $\mathrm{BMI}>35 \mathrm{~kg} / \mathrm{m}^{-2}$ & $.90(.37-2.22)$ & .831 & & \\
\hline Angina class & $1.001(0.880-1.139)$ & .987 & & \\
\hline LVEF $<35 \%$ & $6.02(4.18-8.68)$ & $<.0001$ & $4.55(2.86-7.22)$ & $<.0001$ \\
\hline No of infarctions & $1.128(0.928-1.372)$ & .226 & & \\
\hline Preop Hb & $0.696(0.640-0.758)$ & $<.0001$ & $0.953(0.859-1.058)$ & .370 \\
\hline Emergency & $6.79(4.94-9.32)$ & $<.0001$ & $1.96(1.03-3.74)$ & .039 \\
\hline Prior CABG & $4.26(3.11-5.83)$ & $<.0001$ & $1.60(1.01-2.53)$ & .045 \\
\hline Year of operation & $0.947(0.907-0.989)$ & .015 & $0.998(0.945-1.053)$ & .938 \\
\hline \multicolumn{5}{|c|}{ Peri and postoperative risk factors } \\
\hline Off pump & $.68(.41-1.13)$ & .145 & & \\
\hline Duration of ECC & $1.011(1.007-1.014)$ & $<.0001$ & $1.004(1.001-1.007)$ & .005 \\
\hline No of grafts & $0.912(0.817-1.018)$ & .099 & & \\
\hline Re-exploration & $5.78(4.27-7.82)$ & $<.0001$ & $2.47(1.57-3.88)$ & $<.0001$ \\
\hline No of RBC units & $1.308(1.267-1.350)$ & $<.0001$ & $1.177(1.125-1.232)$ & $<.0001$ \\
\hline Periop Ml & $5.79(3.97-8.43)$ & $<.0001$ & $4.57(2.90-7.20)$ & $<.0001$ \\
\hline
\end{tabular}

*entered as a continuous variable.

$\mathrm{BMI}=$ body mass index; $\mathrm{CABG}=$ coronary artery bypass grafting; $\mathrm{COPD}=$ chronic obstructive pulmonary disease; $\mathrm{CrCl}=$ creatinine clearance per $1.73 \mathrm{~m}^{2} ; \mathrm{ECC}=$ extracorporeal circulation; Preop $\mathrm{Hb}=$ preoperative hemoglobin level; IABP = intra aortic balloon pump support; LVEF = left ventricular ejection fraction; Periop $\mathrm{MI}=$ perioperative myocardial infarction; $\mathrm{PVD}=$ peripheral vascular disease; $\mathrm{RBC}$ = red blood cells

Other preoperative risk factors were age, low $\mathrm{CrCl}$, chronic obstructive pulmonary disease (COPD), Diabetes, left ventricular ejection fraction (EF) less than 35\%, low preoperative hemoglobin level, emergency operation, previous cardiac surgery and the year of operation. Peri- and postoperative risk factors were: duration of ECC, reexploration for any cause, the number of transfused RBC units and perioperative myocardial infarction. All risk factors that were identified with the univariate logistic re- 
gression analyses were entered into the multivariate logistic regression model. The presence of PVD was not an independent risk factor for early mortality. Independent risk factors were age, COPD, low $\mathrm{CrCl}$, Diabetes, EF less than 35\%, previous cardiac surgery, and emergency operation. Even when only preoperative risk factors were entered into the multivariate analysis PVD was not revealed as an independent risk factor (Hazard Ratio 1.29 (0.88-1.89) with a $P$-value of 0.179). Results of Cox regression analyses for risk factors of late mortality are shown in Table 4.

Table 4. Predictors of late mortality; univariate and multivariate Cox regression analyses

\begin{tabular}{|c|c|c|c|c|}
\hline & Univariate analyses & & Multivariate analyses & \\
\hline & Late mortality & & Late mortality & \\
\hline Risk factor & $\mathrm{HR}(95 \% \mathrm{Cl})$ & $P$ value & $\mathrm{HR}$ & $P$ value \\
\hline \multicolumn{5}{|c|}{ Preoperative risk factors } \\
\hline PVD & $2.29(1,98-2.64)$ & $<.0001$ & $1.67(1.43-1.95)$ & $<.0001$ \\
\hline Age* & $1.092(1.083-1.100)$ & $<.0001$ & $1.067(1.057-1.077)$ & $<.0001$ \\
\hline Male sex & $0.86(0.75-0.98)$ & .026 & $1.61(1.37-1.88)$ & $<.0001$ \\
\hline $\mathrm{Cr} \mathrm{Cl} *$ & $0,976(0.973-0.978)$ & $<.0001$ & $0.990(0.986-0.994)$ & $<.0001$ \\
\hline Hypertension & $1.22(1.08-1.37)$ & .001 & $1.14(1.01-1.30)$ & .034 \\
\hline COPD & $1.92(1.67-2.21)$ & $<.0001$ & $1.70(1.47-1.97)$ & $<.0001$ \\
\hline Diabetes & $1.73(1.52-1.96)$ & $<.0001$ & $1.50(1.31-1.72)$ & $<.0001$ \\
\hline $\mathrm{BMI}>35 \mathrm{~kg} / \mathrm{m}^{-2}$ & $1.22(0.83-1.79)$ & .303 & & \\
\hline Angina class & $1.032(0.970-1.098)$ & .313 & & \\
\hline LVEF<35\% & $2.61(2.08-3.27)$ & $<.0001$ & $1.98(1.56-2.52)$ & $<.0001$ \\
\hline No of infarctions & $1.336(1.225-1.456)$ & $<.0001$ & $1.30(1.19-1.43)$ & $<.0001$ \\
\hline Preop Hb & $0.733(0.704-0.764)$ & $<.0001$ & $0.845(0.805-0.886)$ & $<.0001$ \\
\hline Emergency & $1.31(1.01-1.69)$ & .038 & $1.13(0.74-1.75)$ & .555 \\
\hline Prior CABG & $1.59(1.32-1.92)$ & $<.0001$ & $1.11(0.89-1.39)$ & .342 \\
\hline Year of operation & $0.959(0.932-0.987)$ & .004 & $0.958(0.929-0.989)$ & .007 \\
\hline \multicolumn{5}{|c|}{ Peri and postoperative risk factors } \\
\hline Off pump & $0.67(0.51-0.88)$ & .004 & $0.98(0.71-1.35)$ & .928 \\
\hline Duration of ECC & $1.003(1.002-1.004)$ & $<.0001$ & $1.002(0.99-1.004)$ & .148 \\
\hline No of grafts & $1.088(1.035-1.144)$ & .001 & $0.973(0.909-1.040)$ & .417 \\
\hline Re-exploration & $1.45(1.17-1.81)$ & .001 & $1.42(1.08-1.86)$ & .010 \\
\hline No of RBC units & $1.094(1.076-1.113)$ & $<.0001$ & $1.002(0.971-1.035)$ & .885 \\
\hline Periop MI & $1.84(1.39-2.43)$ & $<.0001$ & $1.68(1.23-2.30)$ & .001 \\
\hline
\end{tabular}

*entered as a continuous variable.

$\mathrm{BMI}=$ body mass index; $\mathrm{CABG}=$ coronary artery bypass grafting; $\mathrm{COPD}=$ chronic obstructive pulmonary disease; $\mathrm{CrCl}=$ creatinine clearance per $1.73 \mathrm{~m}^{2} ; \mathrm{ECC}=$ extracorporeal circulation; Preop $\mathrm{Hb}=$ preoperative hemoglobin level; IABP = intra aortic balloon pump support; LVEF = left ventricular ejection fraction; Periop $\mathrm{MI}$ = perioperative myocardial infarction; $\mathrm{PVD}=$ peripheral vascular disease; $\mathrm{RBC}$ = red blood cells

Univariate analyses revealed PVD as a risk factor for late mortality. Other preoperative risk factors were age, female sex, low $\mathrm{CrCl}$, hypertension, COPD, Diabetes, EF less than 
$35 \%$, number of preoperative myocardial infarctions, preoperative hemoglobin level, emergency operation, previous cardiac surgery and the year of operation. Peri- and postoperative risk factors were: use of ECC, duration of ECC, number of grafts, reexploration for any cause, the number of transfused RBC units and perioperative myocardial infarction.

All risk factors identified with univariate analyses were entered into the multivariate Cox regression model. In this case, PVD was identified as independent risk factor for late mortality. Other independent risk factors were age, male sex, low $\mathrm{Cr} \mathrm{Cl}$, hypertension, COPD, Diabetes, EF less than 35\%, number of preoperative myocardial infarctions, low preoperative hemoglobin level, the year of operation, re-exploration for any cause and perioperative myocardial infarction. When only the preoperative risk factors were entered into the multivariate analysis PVD was still an independent risk factor with a Hazard ratio of 1.70 (1.46-1.98) and a p-value of <.0001.

Figure 1 shows the long-term survival rates stratified by PVD and the corresponding normal Dutch survival (expected survival).

Non-PVD patients had a better survival than PVD patients after CABG (log-rank $p$-value $<0.0001)$. Non-PVD patients had a better survival after CABG when compared to the normal Dutch survival $(P$-value $<.002)$. However, PVD patients had a worse than expected survival (log-rank $P$-value $<.0001)$. One, five and nine years survival rates are shown in table 5 . There was no difference between survival of non PVD patients and expected survival ( $P$-value $=0.656,0.422$ and 0.456 respectively). For PVD patients, the actual survival was worse than the expected survival $(P$-values $=0.02,0.01$ and $<.0001$ respectively).

Table 5: Survival at 1, 5, and 9 Years Stratified by PVD Groups

\begin{tabular}{|c|c|c|c|c|c|}
\hline & & 1 Year & 5 Years & 9 Years & $P$ value \\
\hline \multirow[t]{2}{*}{ No PVD } & Observed & $94.1 \pm 0.3 \%$ & $86.5 \pm 0.4$ & $76.1 \pm 1.0 \%$ & \\
\hline & Expected & $95.5 \pm 0.1 \%$ & $84.6 \pm 0.2 \%$ & $70.5 \pm 0.4 \%$ & .456 \\
\hline \multirow[t]{2}{*}{ PVD } & Observed & $87.8 \pm 1.0 \%$ & $74.3 \pm 1.6 \%$ & $51.4 \pm 3.5 \%$ & \\
\hline & Expected & $94.3 \pm 0.1 \%$ & $81.0 \pm 0.2 \%$ & $63.0 \pm 0.5 \%$ & $<.001$ \\
\hline No PVD at risk & & 7737 & 3803 & 463 & \\
\hline PVD at risk & & 883 & 403 & 46 & \\
\hline
\end{tabular}

* 9 years because of small numbers at 10 years, PVD = peripheral vascular diseas 


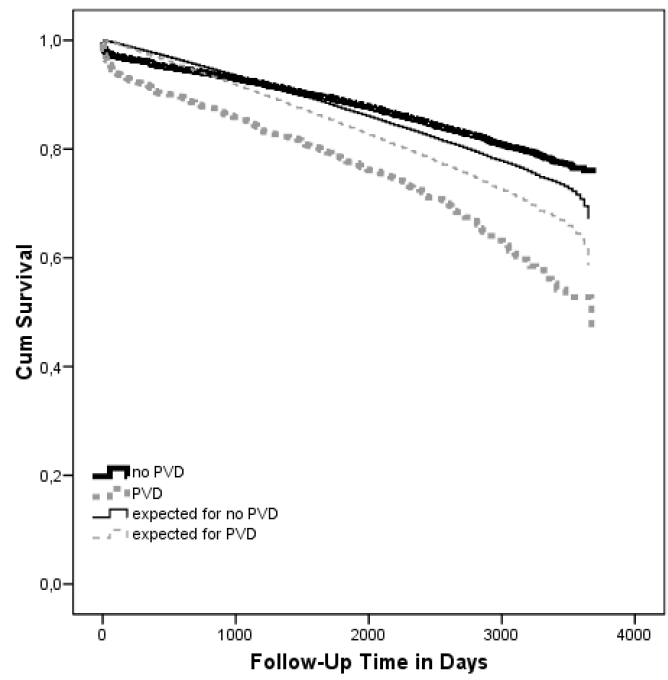

Figure 1 Kaplan-Meier survival curves of patients with and without peripheral vascular disease and the survival of the normal Dutch population.

$\begin{array}{ll}\text { log rank no PVD - expected } & \mathrm{P}=0.002 \\ \text { log rank PVD - expected } & \mathrm{P}=<.0001 \\ \text { No PVD - PVD } & \mathrm{P}=<.0001\end{array}$

\section{Comment}

This retrospective study of a large number of patients undergoing isolated CABG confirms that the presence of PVD is an independent predictor of poorer long term survival after isolated CABG. On the other hand, PVD was not found to significantly affect early mortality in this study.

In our studied group, $11.6 \%$ of the patients undergoing CABG had the preoperative diagnosis of PVD. The presence of PVD was associated with a poorer patient condition due to older age and higher incidence of comorbidities such as hypertension, diabetes, lower preoperative hemoglobin level and renal dysfunction. These patients' characteristics have probably influenced the intraoperative parameters as well. Patients with PVD needed a longer ECC time, more grafts and more RBC transfusions. Perioperative myocardial infarction occurred more often in PVD patients. However, even after adjusting for these confounding factors, the presence of PVD was found to be an independent predictor of poorer long-term survival after CABG.

It is not clear why patients with PVD needed more grafts than the other patients. It is possible that patients with PVD have more extensive coronary artery disease involving more vessels. The need for more grafts might explain the longer ECC time needed 
in these patients. The finding that patients with PVD need more RBC transfusion must be cautiously interpretated because the preoperative $\mathrm{Hb}$ level was lower in these patients than in patients without PVD.

\section{Early mortality}

In our study, early mortality was $2.3 \%$ for non PVD patients and $3.6 \%$ for the patients with PVD $(P=.006)$. The multivariate logistic regression analysis did not find PVD as an independent risk factor for early mortality with a low hazard ratio of 1.06(0.70-1.60), $P=0.776$. The same result was described by Chu et al. [12]. On the other hand, Birkmeyer et al. [2] showed different results, with an in-hospital mortality rate of 2.4-fold higher in patients with PVD (7.7\%) than in patients without evidence of PVD (3.2\%). In their study PVD was an independent predictor for early mortality, but these findings are representing the results of a non-contemporaneous sample [2].

The EuroSCORE risk assessment [10] found extracardiac arteriopathy as an important determinant of the early mortality with an additive weight of 2 points and a $b$ coefficient of 0.655 . The incidence of PVD in their database was similar to ours $15.8 \%$ with intermittent claudication, $4.4 \%$ carotid disease and $1.3 \%$ abdominal aortic disease in the EuroSCORE database vs. a total PVD prevalence of $11.6 \%$ in the present study). Gummert et al.[13] found in a large cohort of patients with isolated CABG a discrepancy between the hospital overall mortality and the predicted mortality $(2.6 \% \mathrm{vs}$ $5.2 \%)$, suggesting an overestimation of the operative risk [13]. Our results are contesting the predictive value of PVD for early mortality raising the question if the extracardiac arteriopathy should be used as one of the predictive risk elements in the EuroSCORE risk stratification model.

\section{Late mortality}

In the current study, PVD was identified as independent risk factor for late mortality with a hazard ratio of 1.67(1.43-1.95). Other studies have also shown poorer prognosis for CABG in patients with PVD [14-16]. Chu et al. found a 9-years survival rate of $82.8 \% \pm 2.4 \%$ for patients without PVD and $72.9 \% \pm 4.1 \%$ for patients with PVD in a smaller group of patients $(n=1164)$ [12]. Gersh et al. [14] found a $10-20 \%$ decrease in survival after CABG in patients with PVD. The effect of PVD on long-term survival after CABG may have several explanations. For example, PVD may be a marker of more severe associated coronary atherosclerotic disease. It is also possible that patients with PVD have more diffuse coronary disease than those without PVD, leading to poorer survival after CABG. Another possibility is that decreased long-term survival among PVD patients after CABG is due to non-cardiac mortality even if revascularization was successful. One of the limitations of our study is that the cause of late death was un- 
known. Knowing the cause of death would have highlighted the causal relationship between PVD and decreased long-term survival after CABG.

\section{Comparison with the general population}

Obviously, advanced age is associated with a poorer late survival rate. Non PVD patients, as shown in this study, are often younger. Although proper statistical testing can be used to distinguish between effects caused by age and gender, interpretation of survival curves remains difficult. Also, variation in life expectancy over the years has been well documented in The Netherlands by the Dutch Central Bureau for Statistics. This organization keeps track of mortality rates of the overall Dutch population. We used the Central Bureau for Statistics database (www.CBS.nl) to calculate the survival of age and sex matched general population groups. Since the mortality rates of the Dutch general population varied during study period, we performed the matching of the cohorts for each year of the study period. We consider this the normal Dutch survival or the expected survival of patients groups. We compared the late survival of the patient groups with this expected survival. However, caution in interpreting these results is needed, because the Central Bureau for Statistics database contains data of the total Dutch population including patients described in this study as well as patients who were treated in other Dutch cardiac surgery centers. However, the number of patients in The Netherlands who undergo a CABG is relatively small compared with the total number of persons in the general population.

We found that survival rate after CABG in non PVD patients was not only better than in PVD patients, but also better than the survival rates of the general Dutch population. An explanation for this might be that a certain percentage of the general population has PVD and coronary disease. The treatment with aspirin, anticholesterolemic drugs and beta- blockers, as well as the protection obtained by the revascularization, may contribute to the improved survival and explain why non PVD patients have a better survival rate than the matched general Dutch population. Furthermore, before undergoing $C A B G$, patients are screened for severe underlying disease. If a severe underlying disease is present, an alternative treatment to a CABG must be considered, thus biasing the CABG group.

When accepting a patient for surgery, a careful assessment of the risk should take place, using a risk stratification model that fits with the current population. This decision making tool should include the factors that identify patients at risk. That is why we consider our results as being valuable when informing the patients about their prognosis after CABG. Instead of informing them whether they will do better or worse than other patients with or without PVD who undergo CABG, we can inform them how their survival will be compared to the normal survival of people of the same age and sex. For non PVD patients, it might be reassuring to know that after their CABG operation at 
least for the next 10 years, their survival will be not worse or even better than the normal Dutch survival, unless they have other risk factors for late mortality.

\section{Limitations}

This is a retrospective observational study. Therefore, we must be cautious in interpreting our results. As mentioned above, the study endpoint is any-cause mortality. We were not able to report causes of death or other morbidities that might be equally interesting.

\section{Conclusions}

Peripheral vascular disease (PVD) is not an independent risk factor for early mortality after CABG. The inclusion of PVD as a risk factor for increased early mortality in the risk stratification models should be re-evaluated considering these recent results. The presence of PVD is identified as independent risk factor for late mortality. Non PVD patients had a better long-term survival than PVD patients and even a better survival when compared to the normal Dutch survival rates. Patients with PVD had a worse than expected survival with an increased risk for late mortality after CABG when compared with non PVD patients.

\section{References}

1. Hertzer NR, Beven EG, Young JR, O'Hara PJ, Ruschhaupt WF 3rd, Graor RA, Dewolfe VG, Maljovec LC. Coronary artery disease in peripheral vascular patients. A classification of 1000 coronary angiograms and results of surgical management. . Ann Surg. 1984;199(2):223-33.

2. Birkmeyer JD, O'Connor GT, Quinton HB, Ricci MA, Morton JR, Leavitt BJ, Charlesworth DC, Hernandez $F$, McDaniel MD. The effect of peripheral vascular disease on in-hospital mortality rates with coronary artery bypass surgery. Northern New England Cardiovascular Disease Study Group. J Vasc Surg. 1995;21(3):445-52

3. Sukhija R, Aronow WS, Yalamanchili K, Sinha N, Babu S. Prevalence of coronary artery disease, lower extremity peripheral arterial disease, and cerebrovascular disease in 110 men with an abdominal aortic aneurysm. Am J Cardiol. 2004;94(10):1358-9

4. Dieter RS, Tomasson J, Gudjonsson T, Brown RL, Vitcenda M, Einerson J, McBride PE. Lower extremity peripheral arterial disease in hospitalized patients with coronary artery disease. Vasc Med. 2003;8(4):233-6.

5. Poredos $\mathrm{P}$, Jug $\mathrm{B}$. The prevalence of peripheral arterial disease in high risk subjects and coronary or cerebrovascular patients. Angiology. 2007;58(3):309-15

6. McDermott MM. The magnitude of the problem of peripheral arterial disease: epidemiology and clinical significance. Cleve Clin J Med. 2006;73 Suppl 4:S2-7 
7. Makowsky MJ, McAlister FA, Galbraith PD, Southern DA, Ghali WA, Knudtson ML, Tsuyuki RT; Alberta Provincial Program for Outcome Assessment in Coronary Heart Disease (APPROACH) Investigators. Lower extremity peripheral arterial disease in individuals with coronary artery disease: prognostic importance, care gaps, and impact of therapy. Am Heart J. 2008 Feb;155(2):348-55.

8. Higgins TL, Estafanous FG, Loop FD, Beck GJ, Blum JM, Paranandi L. Stratification of morbidity and mortality outcome by preoperative risk factors in coronary artery bypass patients. A clinical severity score. JAMA. 1992;267(17):2344-8.

9. O'Connor GT, Plume SK, Olmstead EM, Coffin LH, Morton JR, Maloney CT, Nowicki ER, Levy DG, Tryzelaar JF, Hernandez F. Multivariate prediction of in-hospital mortality associated with coronary artery bypass graft surgery. Northern New England Cardiovascular Disease Study Group. Circulation 1992;85(6):2110-8

10. Nashef SA, Roques F, Michel P, Gauducheau E, Lemeshow S, Salamon R. European system for cardiac operative risk evaluation (EuroSCORE). Eur J Cardiothorac Surg. 1999;16(1):9-13.

11. Michel P, Roques F, Nashef SA; EuroSCORE Project Group. Logistic or additive EuroSCORE for high-risk patients? Eur J Cardiothorac Surg. 2003;23(5):684-7; discussion 687

12. Chu D, Bakaeen FG, Wang XL, Dao TK, LeMaire SA, Coselli JS, Huh J. The impact of peripheral vascular disease on long-term survival after coronary artery bypass graft surgery. Ann Thorac Surg. 2008;86(4):1175-80

13. Gummert JF, Funkat A, Osswald B, Beckmann A, Schiller W, Krian A, Beyersdorf F, Haverich A, Cremer J. EuroSCORE overestimates the risk of cardiac surgery: results from the national registry of the German Society of Thoracic and Cardiovascular Surgery. Clin Res Cardiol. 2009;98(6):363-9.

14. Gersh BJ, Califf RM, Loop FD, Akins CW, Pryor DB, Takaro TC. Coronary bypass surgery in chronic stable angina. Circulation.1989;79(6 Pt 2):146-59.

15. Magovern JA, Sakert T, Magovern GJ, et al. A model that predicts morbidity and mortality after coronary artery bypass graft surgery. J Am Coll Cardiol. 1996;28(5):1147-53.

16. Rosenthal GE, Vaughan Sarrazin M, Hannan EL. In-hospital mortality following coronary artery bypass graft surgery in Veterans Health Administration and private sector hospitals. Med Care. 2003;41(4):522-35. 
Chapter 15

General discussion

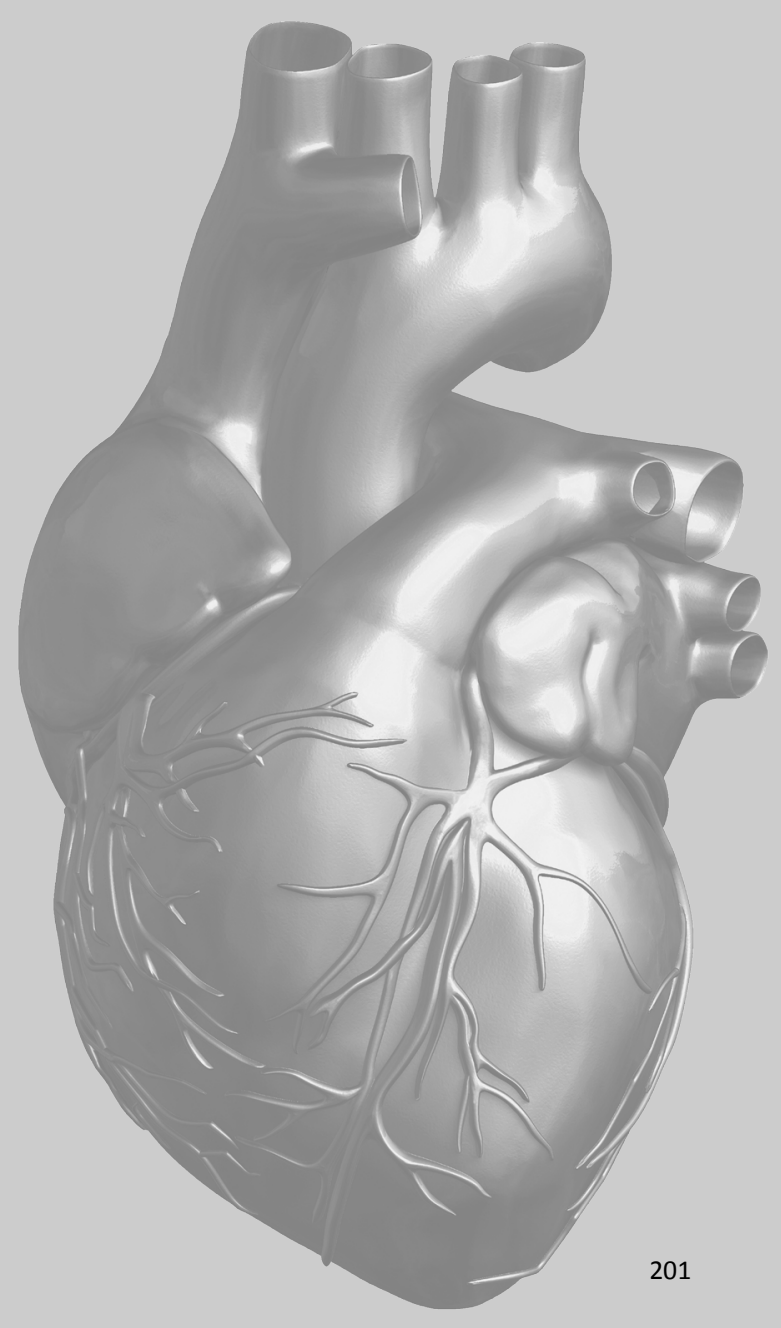




\section{General discussion}

The department of cardio-thoracic surgery of the Catharina hospital, Eindhoven, the Netherlands started collecting data of all patients who underwent cardiac surgery. Though the computerized data collection was incorporated in the daily practice, it still was a big effort to keep the database complete and accurate. Many surgeons, nursepractitioners, secretaries and residents contributed to this. By connecting our database to other hospital databases, an enormous amount of data came available for further analyses. By successfully retrieving long-term mortality data, we were able to study several perioperative risk factors for early and late mortality.

\section{The EuroSCORE as a risk scoring system}

Although the additive and the logistic EuroSCORE have a good discriminatory power in patients undergoing coronary artery bypass graft surgery (CABG) as is shown in chapter 2, both scores are overestimating the in-hospital mortality risk in lower risk CABG patients. The logistic EuroSCORE is more accurate in higher risk patients compared to the additive EurOSCORE. In order to compare the results of different centers using risk adjusted mortality rates, we need reliable and accurate risk stratification models. If the calculated risk score is not an accurate reflection of the mortality, this comparison may lead to wrong conclusions. If, for example the risk model underestimates the risk in high risk patients and overestimates the risk in low risk patients as is the case for the additive EUROscore in our CABG patients, the results of the comparison will be in favour of the centers that are performing operations with the lowest risk scores. The variable life-adjusted display (VLAD) curve will be more positive in centers with more low risk patients. Improvement of the VLAD curve can be easily accomplished by not performing operations on high risk patients. Especially when results of the VLAD curves are made public, this issue will become of interest. Re-evaluation of the variables used in the EuroSCORE and considering new ones in order to improve the accuracy of the scoring system is warranted. Only when a more accurate scoring system for CABG (and other cardiac operations) has been developed, publication of VLAD curves per centre can be done without the risk that hospitals, that are offering operations to the highest risk patients, will be unfairly accused of "bad quality".

When risk scores are inaccurate, wrong decisions can be made about the indication for a surgical procedure. Based on an estimated risk (EuroSCORE) which is twice the actual risk, a decision could be made to abstain from surgery and to choose another therapeutic option (medical therapy or percutaneous intervention). However, the result of these options might be inferior to the results of surgery. Of course the patient has to consent to the therapeutic option offered to him or her. Only when 
accurate information about early and late outcome and possible complications such as mortality and morbidity is given, the patient can give a true "informed consent". The EuroSCORE has only been validated for early mortality. To date no validated risk scoring system is available for late mortality.

\section{Renal function and CABG.}

Impaired renal function is a risk factor for early mortality as discussed in Chapter 3 and 5. Our study showed a non-linear relationship between renal function and early mortality. Renal function, estimated by the Cockroft-Gault formula, proved to have the best discriminatory power followed by the glomerular filtration rate estimated by the Modification of Diet in Renal Disease (MDRD) formula. The serum creatinine level had the worst discriminatory power. In the EuroSCORE the serum creatinine level with a cut-off point of $200 \mu \mathrm{mol} / \mathrm{L}$ is used as one of the variables. Any cut-off point will be inaccurate and due to the non-linear relationship, it will be difficult to create an accurate formula. If we want to improve the accuracy of the EuroSCORE we have to adjust this item considering the above findings. The postoperative renal function is a better predictor of early outcome than the preoperative one. Therefore it is obvious to preserve the renal function as much as possible. We therefore analyzed the risk factors for deterioration of the renal function as described in chapter 2. Most of the identified risk factors can not be influenced except for the preoperative C-reactive protein (CRP) level and haemoglobin level. Whether preoperative improvement of these two risk factors will lead to less renal deterioration remains to be investigated. In chapter 3 and 5, we described low creatinine clearance as a risk factor for impaired long term survival. We found that when compared to an age and sex matched general Dutch population, only severe renal impairment will lead to poor survival. Therefore impaired renal function should not be considered to be an absolute contraindication for surgical revascularisation of the coronary arteries.

\section{Blood transfusions and CABG}

Our studies demonstrated a strong correlation between the number of transfused Red Blood Cells (RBC) and early but not with late outcome (chapter 6). Therefore it seems advisable to avoid transfusion of RBC as much as possible. We analyzed risk factors for transfusion of RBC and found several risk factors that can influence transfusion. Low preoperative haemoglobin level can be corrected and the surgeon can choose to use blood instead of crystalloid cardioplegia (chapter 7). We used this analysis to identify patients with a low chance for transfusion of RBC. For these patients we introduced a 
separate blood supply protocol. No RBCs will be available anymore in the operating theatre. In this way we avoid deterioration of the quality of the RBC that is brought to the operating theatre and which is subsequently not used. Sometimes deterioration of the quality of the RBC prohibits future transfusion. We also save money by doing this, as for a large group of patients, preparation of RBC and cross-matching it to the patient's blood is no longer needed. We could not confirm the concern about the storage time of RBC, raised in 2008 (chapter 8). The withdrawal and storage protocol for RBC, used in the Netherlands does not give reason for concern, because we did not observe a higher mortality in patients who received RBC with a storage time exceeding 14 days. However, for fresh frozen plasma (FFP) we found a clear relationship between the storage time and early mortality (chapter 9). Until proven otherwise it seems advisable not to use older FFP anymore. The Dutch blood transfusion service (Sanquin) should reconsider their storage protocol for FFP.

\section{Preoperative laboratory results}

Apart from the serum creatinine level we identified elevated preoperative CRP and low haemoglobin levels to be important risk factors for early as well as late mortality (Chapter 10,11). It is important to be aware of these findings and in future risk stratification systems, preoperative CRP and haemoglobin levels should be incorporated. Whether postponement of the operation until the laboratory levels have improved will lead to improved outcome remains to be investigated. Until results of these studies are available we postpone patients with elevated levels of CRP more frequently in our practice. Whether the preoperative use of erythropoietin to increase the haemoglobin level will lead to improved outcome, remains to be investigated.

\section{Other patient related factors}

Low body mass index (BMI) imposes an increased risk for early mortality after CABG whereas morbid obesity is a risk factor for late mortality as is discussed in chapter 12 . Denying patients with morbid obesity an operation in fear of higher hospital mortality does not seem to be justified. Whether correction of body weight extremes will lead to better early and late outcome remains to be investigated. Low BMI should be incorporated in future risk scoring systems.

In chapter 13, it is shown that only non-insulin dependent diabetes is a risk factor for early mortality. Both insulin dependent and non-insulin dependent diabetes are risk factors for late mortality. When compared to an age and sex matched general Dutch 
population, insulin dependent as well as non-insulin dependent patients have a worse long-term survival. The difference for insulin-dependent diabetic patients is larger than for non-insulin dependent patients. Non-insulin dependent diabetes should be incorporated in future risk scoring systems for early mortality after CABG.

Peripheral vascular disease (PVD) is one of the variables used in the EuroSCORE and awarded two points. In chapter 14, we demonstrated that in CABG patients the presence of PVD does not lead to higher early mortality although it has a negative impact on late mortality. PVD as a variable in the EuroSCORE should also be reconsidered.

Long-term survival of patients undergoing CABG, who do not have other major risk factors for premature mortality such as impaired renal function, elevated CRP level, anemia, diabetes, PVD or impaired left ventricular function, have a survival rate which is similar or even better compared to the survival rate of an age and sex matched general Dutch population. Once their coronary problem is "cured" by the CABG, they should not be considered as "heart patients" anymore.

Combining several sources of patients' data and studying them together was a fascinating experience. It provided us new insights in several risk factors for early and late mortality and morbidity in patients undergoing CABG. The completion of this thesis does not coincide with the exhaustion of the writer of this thesis nor of data mining process of the yet readily available but so far unexplored data. We intend to expand our explorative journey to other patients groups such as aortic and mitral valve patients. Searching for improvements in patient care is a never ending story. 
Chapter 16

Abstract

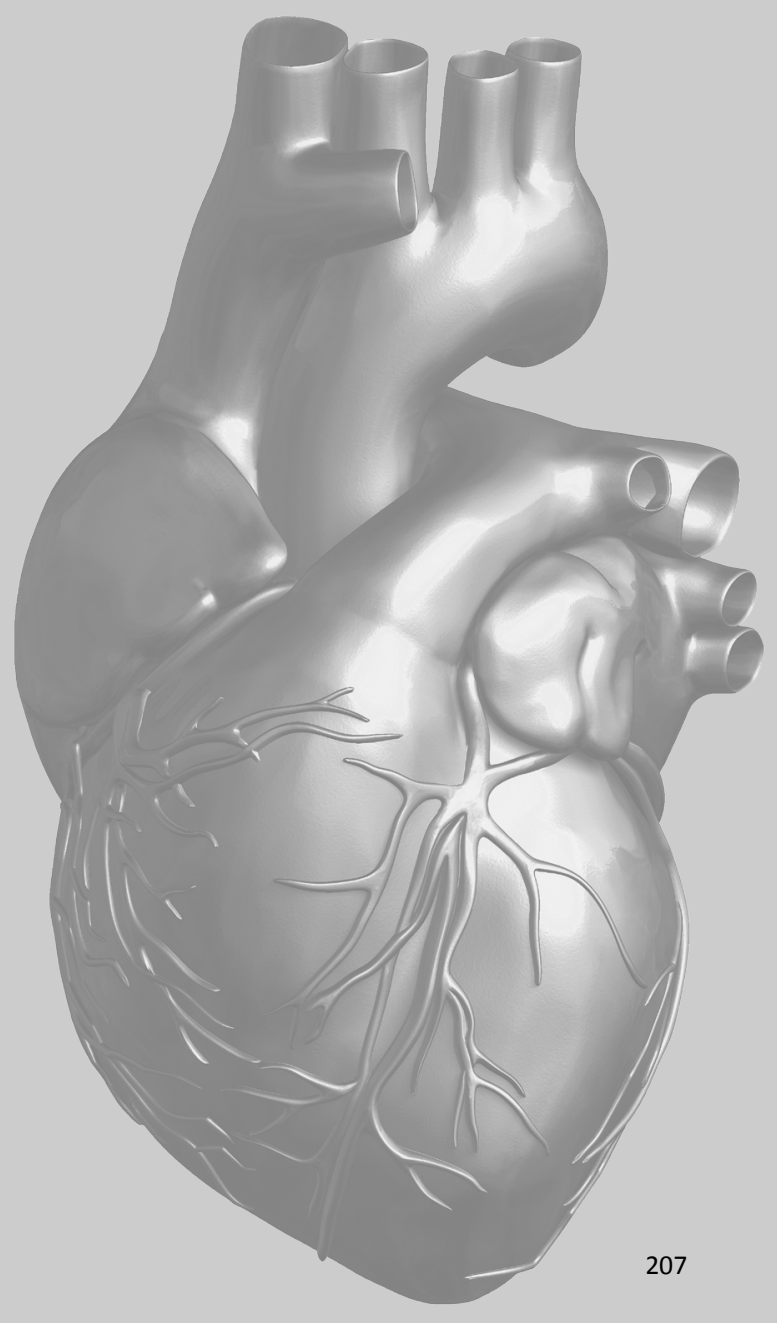





\section{Chapter 1 Introduction}

The first open heart operation in the Catharina Hospital in Eindhoven was performed in 1978. Since January 1992, preoperative, operative and postoperative data of all heart surgery patients are collected in a computerized database. In 1998 the database was restructured and made more comparable with the database of the Society of Thoracic Surgeons (STS). We prospectively calculate the additive and logistic EuroSCORE since January 2004. Since 2007 it was possible to make connections between our database and other databases in our hospital such as the laboratory database, the database of the hospital blood bank, the database from the ECHO lab, the database from the health insurance companies and recently the database from the pharmacological department. For comparison of our patients' survival with that of the general Dutch population, we used the mortality data of the Dutch Central Bureau of Statistics (CBS) which are available through the internet (www.CBS.nl).

The importance of accurate risk scoring models for patients

Only when the impact of risk factors on morbidity and early and late mortality is known, a balanced decision about the best therapeutic option can be made and a true informed consent of patients can be obtained.

The importance of accurate risk scoring models for doctors and institutions Nowadays, results of medical care given by different institutions and doctors are increasingly scrutinised, and the production of hospital league tables is widespread. Such league tables usually fail to account for case mix, and great caution should be exercised in their interpretation. Operative mortality is considered to be an indicator of the quality of cardiac surgery. Comparing different institutions or surgeons on the basis of crude mortality figures may be misleading as mortality is affected by various preoperative patient characteristics.

\section{Objectives of this thesis}

In patients undergoing CABG we tested the accuracy of the EuroSCORE. We investigated several risk factors for early and late mortality (ten years) as well as for morbidity. We compared the long-term survival of patient groups with the normal Dutch survival. We hope that better knowledge of risk factors will lead to better risk stratification and improved early and late outcome.

\section{Chapter 2 Evaluation of the EuroSCORE risk scoring model for patients undergoing coronary artery bypass graft surgery: a word of caution.}

Risk adjusted mortality rates are used to compare quality of care of different hospitals. We evaluated the EuroSCORE (European System for Cardiac Operative Risk Evaluation) in patients undergoing isolated CABG. Data of all consecutive CABG patients from Ja- 
nuary 2004 until December 2008 were analyzed. 5249 Patients underwent CABG of which $89(1,7 \%)$ died. Both the additive and the logistic EuroSCORE are overestimating the in-hospital mortality risk in low risk CABG patients. The logistic EuroSCORE is more accurate in high risk patients compared to the additive EuroSCORE. Until a more accurate risk scoring system is available, we suggest to be careful with comparing quality of care of different centres based on risk-adjusted mortality rates.

\section{Chapter 3 Preoperative Renal Function as a Predictor of Survival after Coronary Artery Bypass Grafting: Comparison with a Matched General Population}

Preoperative renal dysfunction is an established risk factor for early and late mortality after revascularization. We studied how renal function affects long-term survival of patients after CABG. After excluding 122 patients lost to follow-up, 10626 patients were studied; in 10359 patients, preoperative creatinine clearance could be calculated. Multivariate logistic regression and Cox regression analysis identified renal dysfunction as a predictor for early and late mortality. When long-term survival of patient groups were compared to expected survival, only patients with a creatinine clearance less than $30 \mathrm{~mL} \cdot \mathrm{min}^{-1}$ showed a worse outcome. Patients with a creatinine clearance between 60 and $90 \mathrm{~mL} \cdot \mathrm{min}^{-1}$ had a long-term survival exceeding the expected survival. Severity of renal dysfunction was related to poor survival.

\section{Chapter 4 Risk factors for deterioration of renal function after coronary artery bypass grafting}

Various definitions of impairment of renal function after CABG are used in the literature. Depending on the definition several risk factors are identified. We analysed our data to determine risk factors for deterioration of the creatinine clearance of $10 \%$ or more postoperatively. All patients undergoing isolated coronary surgery in our centre between January 1998 and December 2007 are included. In 10098 out of a total of 10626 patients, the preoperative as well as the postoperative creatinine clearance could be calculated. We could identify the following risk factors: advanced age, diabetes, chronic obstructive pulmonary disease, peripheral vascular disease, emergency operation, previous cardiac surgery, low preoperative hemoglobin level, high preoperative $\mathrm{C}$-reactive protein level, perioperative myocardial infarction, re-exploration and the number of blood transfusions.

\section{Chapter 5 Which method of estimating renal function is the best predictor of early and late mortality after coronary artery bypass surgery?}

Renal insufficiency is associated with an increased risk of complications and mortality after CABG. Definitions of renal function in CABG patients vary in the literature. Preop- 
erative and postoperative renal function was estimated using serum creatinine ( $\mathrm{SeCr}$ ) levels, creatinine clearance $(\mathrm{CrCl})$ determined by the Cockroft-Gault formula and the glomerular filtration rate (e-GFR) estimated by the Modification of Diet in Renal Disease (MDRD) formula. The relationship between the renal function parameters and mortality was determined. In 9,987 patients, $\mathrm{CrCl}$ had the best discriminatory power to predict early as well as late mortality, followed by e-GFR and finally SeCr. The relationship between renal function and mortality is non-linear. Any cut-off point used in a risk scoring system will be inaccurate. Renal function as a variable in risk scoring system such as the EuroSCORE needs to be reconsidered.

\section{Chapter 6 Transfusion of Red Blood Cells: The impact on short-term and long-term survival after coronary artery bypass grafting, a ten year follow-up.}

Transfusion of red blood cells and other blood products in patients undergoing coronary artery bypass grafting is associated with increased mortality and morbidity. We retrospectively analyzed data of patients who underwent CABG between January 1998 and December 2007. 8001 (76.7\%) Patients received no RBC, 1621 (15.2\%) received 1 to 2 units of red blood cells, $593(5.7 \%)$ received 3 to 5 units and $220(2.1 \%)$ received 6 to10 units. The number of transfused red blood cells was a predictor for early but not for late mortality. When compared to expected survival, survival of patients not receiving any blood product was better, while survival of patients receiving more than 3 units of red blood cells was worse. Transfusion of red blood cells is an independent, dose-dependent risk factor for early mortality after revascularization

\section{Chapter 7 Risk factors for red blood cell transfusion after coronary artery bypass grafting}

Perioperative transfusion of red blood cells is associated with increased morbidity and mortality. We investigated the correlation between pre- and operative risk factors and the number of red blood cell units received in patients undergoing CABG.

We studied the data of all patients who underwent isolated CABG between 1998 and 2007 ( $n=10626)$. The following independent risk factors for receiving red blood cell units were identified: age, female gender, low body surface area, low left ventricular ejection fraction $(<35 \%)$, emergency operation, previous cardiac surgery, low preoperative hemoglobin and low preoperative creatinine clearance. Perioperative risk factors were: use of extra-corporeal circulation, longer bypass time, use of crystalloid cardioplegia, the need for intra-aortic balloon pump counterpulsation, perioperative myocardial infarction and re-exploration for any cause. 
Chapter 8 Effect of duration of red blood cell storage on early and late mortality after coronary artery bypass grafting.

Recently, concern has been expressed about the transfusion of older red blood cells (RBCs) after cardiac surgery. We tested the hypothesis that longer storage of transfused RBCs increases the risk of early and late mortality in patients who undergo coronary artery bypass grafting.

We retrospectively analyzed data of patients who underwent isolated CABG between January 1998 and December 2007 in Catharina Hospital, Eindhoven, the Netherlands, and received up to $10 \mathrm{U}$ of RBCs intraoperatively or during the first 5 postoperative days. The patients were divided into 3 groups according to the storage time of the RBCs with a cutoff point of 14 days as follows: "only younger blood" ( $n=1422$ ), "only older blood" ( $n=1719)$, and at least $1 \mathrm{U}$ of older RBCs ("any older blood") ( $n=2175)$. Univariate and multivariate logistic regression analyses revealed that the number of transfused units but not the storage time of blood entered either as a continuous variable or as a dichotomous variable with a cutoff point of 14 days was a risk factor for early mortality. Neither the number of transfused units nor the storage time was an independent risk factor for late mortality.

\section{Chapter 9 Effect of storage time of transfused plasma on early and late mortality after coronary artery bypass grafting.}

To our knowledge, data on the relationship between the storage time of fresh-frozen plasma and early and late outcomes after coronary artery bypass grafting are not available. We therefore investigated whether a longer storage time of transfused plasma increases the risk for early or late mortality in patients who have undergone CABG. Patients who received at least $1 \mathrm{U}$ of plasma intraoperatively or during the first 5 postoperative days $(n=745)$ were studied. They were divided into 3 groups (the "only younger plasma" group, the "only older plasma" group, and the "any older plasma" group) according to the storage time of the plasma (cutoff point $=323$ days). The storage time of plasma, when entered as either a continuous variable or as a dichotomous variable, was a risk factor for early but not late mortality.

\section{Chapter 10 Preoperative C-Reactive Protein Levels to Predict Early and Late Mortality After Coronary Artery Bypass Surgery: 8 Years' Follow-up}

There is limited evidence that increased preoperative levels of C-reactive protein are associated with increased mortality after CABG. We retrospectively investigated the predictive value of preoperative C-reactive protein levels on early and late mortality after coronary artery bypass grafting in 5669 patients. Preoperative C-reactive protein levels of $>10 \mathrm{mg} / \mathrm{L}$ were an independent risk factor for early mortality, while preoperative C-reactive protein levels of $>5 \mathrm{mg} / \mathrm{L}$ were risk factors for late mortality. 


\section{Chapter 11 Preoperative Hemoglobin level as a Predictor of Survival after Coronary Artery Bypass Grafting, a Comparison with the Matched General Population}

The predictive value of preoperative hemoglobin value after coronary artery bypass grafting has not been well established. We studied how preoperative hemoglobin level affects survival of patients after coronary artery bypass grafting. Late mortality was compared to that of a general population. Patients were classified into 4 groups stratified by preoperative hemoglobin level. The cut-off point for anemia was $13 \mathrm{~g} / \mathrm{dL}$ for men and $12 \mathrm{~g} / \mathrm{dL}$ for women. Multivariate logistic regression analyses revealed anemia to be an independent risk factor for higher early mortality. Cox regression analyses revealed low hemoglobin level, both as a continuous variable and as a dichotomous variable (anemia), to be a predictor of higher late mortality. Compared to expected survival, patients with the lowest preoperative hemoglobin levels had a worse outcome, whereas patients with the highest hemoglobin levels had a better outcome.

\section{Chapter 12 Effect of Body Mass Index on Early and Late Mortality After Coronary Artery Bypass Grafting}

The effect of obesity on the long-term outcome after coronary artery bypass grafting (CABG) remains controversial. We analyzed data of patients undergoing CABG in a single center, to determine the predictive value of body mass index (BMI) in combination with comorbidities on both early and late mortality. Patients were classified into 5 groups according to preoperative BMI (underweight, normal weight, overweight, obesity, and morbid obesity). Multivariate logistic regression analyses showed that underweight was associated with higher early mortality. Multivariate Cox regression analyses did reveal morbid obesity as an independent predictor of late mortality.

\section{Chapter 13 Diabetes and Survival after Coronary Artery Bypass Grafting: Comparison with an Age and Sex Matched Population}

Long-term outcome after CABG is worse in diabetic patients than in non-diabetic patients. No data are currently available regarding survival rates of diabetic and nondiabetic patients after coronary revascularization compared to cohorts from the general population in the Netherlands, which were matched for age and sex (normal Dutch survival).

We retrospectively analyzed the data from 10626 patients who underwent coronary artery bypass grafting between January 1998 and December 2007. Of these, 8287 patients were non-diabetic, 1587 were non-insulin-dependent and 630 were insulindependent diabetic patients (122 patients were lost to follow-up). Survival of these patient groups was compared to the normal Dutch survival. Multivariate analyses revealed non-insulin-dependent diabetes to be a risk factor for early mortality and both 
insulin-dependent and non-insulin-dependent diabetes as risk factors for late mortality. One, 5- and 10-year survival rates for non-diabetic were better than the normal Dutch survival. For insulin-dependent diabetic patients, 1-, 5-, and 10-year survival rates worse than the normal Dutch survival.

\section{Chapter 14 Peripheral vascular disease as a predictor of survival after coronary artery bypass grafting: Comparison with a matched general population.}

The EuroSCORE, the most popular European scoring system in cardiac surgery, uses the extracardiac arteriopathy as a risk factor for early mortality. We studied the effect of peripheral vascular disease (PVD) on early and late mortality in a large group of patients undergoing isolated CABG. The primary endpoints of this study were early and late all-cause mortality. For each year of the study period, general population cohorts were matched with the patient groups for age and gender (expected survival). Out of patients included in the analysis, 1222 (11.63\%) patients had PVD. PVD was identified as an independent risk factor for late mortality, but not for early mortality. Patients without PVD had a better survival than patients with PVD and even a better survival compared to the normal Dutch population survival. PVD patients had a worse than expected survival.

\section{Chapter 15 General discussion}

Combining several sources of patients' data and studying them together was a fascinating experience. It provided us new insights in several risk factors for early and late mortality and morbidity in patients undergoing CABG. The EuroSCORE proved to be inaccurate in predicting hospital mortality in patients undergoing CABG. We hope that this thesis will contribute to better risk stratification in patients undergoing CABG and that treatment or modification of the risk factors will lead to improved outcomes. 
Chapter 17

Nederlandstalige samenvatting

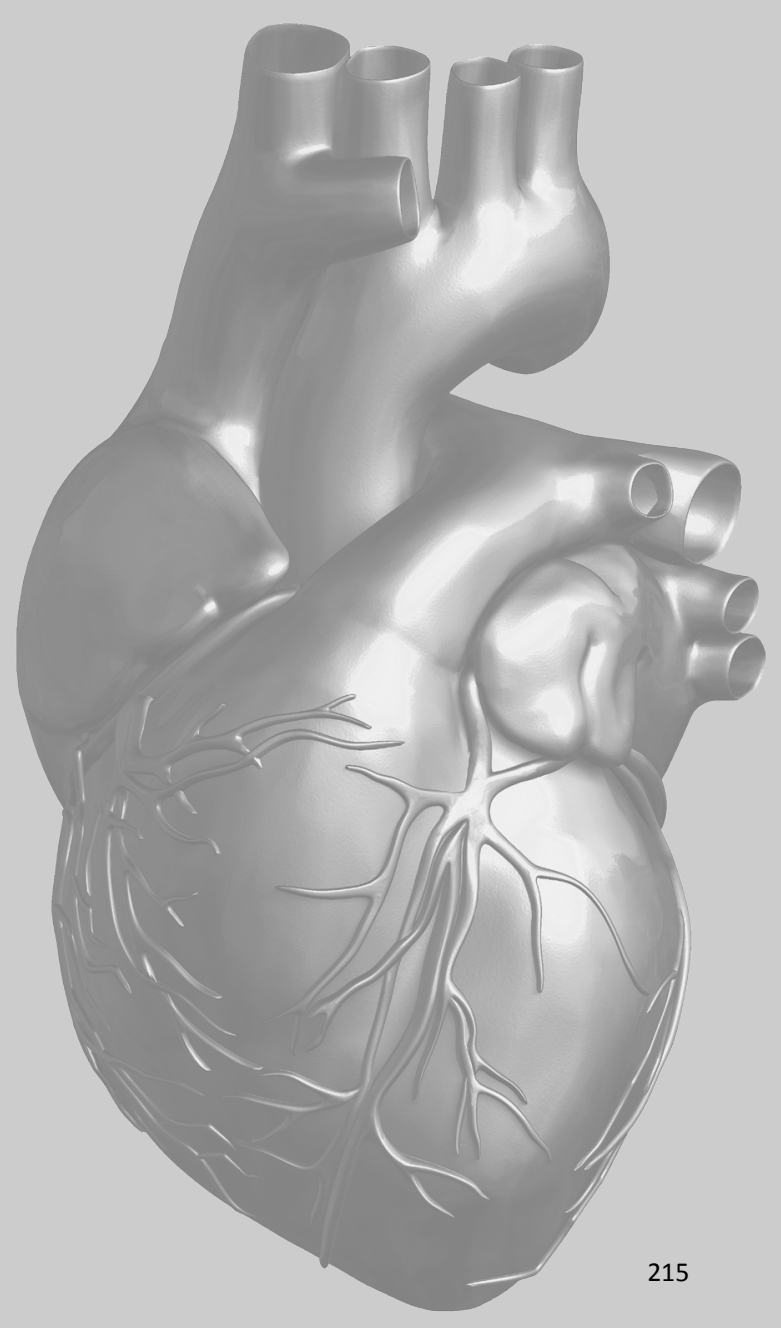





\section{Hoofdstuk 1 Inleiding}

De eerste open hart operatie in het Catharina Ziekenhuis in Eindhoven werd verricht 1978. Sinds januari 1992 werden preoperatieve, operatieve and postoperatieve gegevens van alle open hart operatie patienten verzameld in een computerdatabase. In 1998 werd de database aangepast zodat onze resultaten vergeleken zouden kunnen worden met de database van de Society of Thoracic Surgeons (STS). Dit is een database die de meeste patiënten gegevens ter wereld bevat. De additieve en logistische EuroSCORE (een risico scorings systeem voor patiënten die een open hart operatie moeten ondergaan) worden sinds januari 2004 voor iedere patient berekend en in de database opgeslagen. Sinds 2007 werd het mogelijk om een koppeling te maken tussen onze database en andere databases in ons ziekenhuis zoals, de database van het laboratorium, de database van de bloedbank en de database van de ziektekostenverzekeraars. Voor vergelijking van de overleving van onze patiënten met de overleving van een qua leeftijd en geslacht vergelijkbare groep uit de algemene Nederlandse bevolking, hebben we gebruik gemaakt van de cijfers van het Centraal Bureau voor Statistiek (CBS), die via hun website (www.CBS.nl) beschikbaar zijn.

\section{Waarom is een betrouwbare risico inschatting belangrijk voor de patient?}

Alleen wanneer de impact van alle risico factoren op morbiditeit en vroege en late mortaliteit bekend is, kan er een afgewogen advies gegeven worden over de beste therapeutische optie en kan de patiënt een bewuste keuze maken.

\section{Waarom is een betrouwbaar risico scorings systeem belangrijk voor dokters en ziekenhuizen?}

Tegenwoordig worden resultaten van medische zorg, geleverd door verschillende ziekenhuizen en dokters, steeds kritischer beschouwd. Er verschijnen steeds vaker ranglijsten voor ziekenhuizen. Zulke ranglijsten houden meestal geen rekening met de zwaarte van patienten die zijn behandeld. Zulke ranglijsten moeten dan ook met grote voorzichtigheid bekeken worden. Operatieve mortaliteit wordt beschouwd als een van de kwaliteits parameters in de hartchirurgie. Vergelijking van ziekenhuizen en dokters op basis van ruwe mortaliteitscijfers zou misleidend kunnen zijn omdat de operatieve mortaliteit niet alleen beïnvloed wordt door de kwaliteit van de dokters en ziekenhuizen maar ook door de patiënt zijn risico factoren. Zonder een betrouwbaar risico scorings systeem zouden dokters en ziekenhuizen, die bereid zijn om patiënten met een hoog operatie risico te opereren, onterecht beschuldigd kunnen worden van het leveren van slechte kwaliteit van zorg.

\section{Doelstelling van dit proefschrift.}

Onderzoek naar de betrouwbaarheid van de EuroSCORE bij patiënten die een CABG hebben ondergaan. Onderzoek naar verschillende risicofactoren om tot een betere risico inschatting te komen. Betere kennis van risicofactoren, in het bijzonder van risi- 
cofactoren die voor de operatie nog beïnvloed zouden kunnen worden leidt hopelijk tot betere patiënten zorg. Een betere risico inschatting zou ook moeten leiden tot een beter advies betreffende de therapeutische opties voor de patiënt. Ook zou dit moeten leiden tot een nauwkeurigere en dus objectievere meetlat voor dokters en ziekenhuizen. Onderzoek naar de vergelijking van de lange termijn overleving van onze patiënten met de overleving van een qua leeftijd en geslacht vergelijkbare algemene Nederlandse bevolking is gedaan om de patient beter te kunnen informeren over zijn of haar prognose.

\section{Hoofdstuk 2 Evaluatie van de EuroSCORE als risico score system voor patiënten die een coronary artery bypass graft operatie ondergaan: voorzichtigheid is geboden}

Risico gewogen mortaliteitscijfers worden gebruikt om die kwaliteit van zorg van verschillende ziekenhuizen met elkaar te vergelijken. Wij evalueerden de EuroSCORE (European System voor Cardiac Operative Risk Evaluation) bij patienten die een geisoleerde coronaire bypass ( $C A B G$ ) operatie ondergingen. Gegevens van alle opeenvolgende CABG patiënten, die geopereerd zijn vanaf januari 2004 tot en met december 2008 werden geanalyseerd. 5249 Patiënten ondergingen CABG van wie 89(1,7\%) zijn overleden. Zowel de additieve als de logistische EuroSCORE overschatten de ziekenhuismortaliteit bij laag risico CABG patienten. De logistische EuroSCORE is accurater bij hoge risico patiënten vergeleken met de additieve EuroSCORE. Totdat een accurater risico scoring systeem voorhanden is, stellen we voor om voorzichtig te zijn met het vergelijken van kwaliteit van zorg van verschillende ziekenhuizen wanneer deze gebaseerd is op een voor EuroSCORE gecorrigeerde mortaliteit.

\section{Hoofdstuk 3 Preoperatieve nierfunctie als voorspeller van overleving na coronaire bypass operaties: vergelijking met een gematchte algemene nederlandse populatie}

Preoperatieve nierfunctiestoornis is een bekende risico factor voor vroege en late mortaliteit na coronaire revascularisatie. We onderzochten hoe de nierfunctie de vroege en late overleving van patiënten na coronaire bypass operaties beïnvloedt. 10626 patiënten werden geanalyseerd; in 10359 patiënten kon de preoperatieve creatinine klaring worden berekend. Multivariate logistische regressie en Cox regressie analyse identificeerde nierfunctiestoornis als een voorspeller voor vroege en late mortaliteit. Wanneer lange termijn overleving van patiënten werd vergeleken met de verwachte overleving, toonden alleen patiënten met een creatinine klaring minder dan 30 $\mathrm{mL} \cdot \mathrm{min}^{-1}$ een slechtere overleving. Patiënten met een creatinine klaring tussen 60 en $90 \mathrm{~mL} \cdot \mathrm{min}^{-1}$ hadden een lange termijn overleving die beter was dan de verwachte overleving. 
Hoofdstuk 4 Risico factoren voor verslechtering van de nierfunctie na een coronaire bypass operatie

In de literatuur worden verschillende definities van verslechtering van nierfunctie na coronaire bypass operaties gebruikt. Afhankelijk van de definitie, zijn er verschillende risico factoren geidentificeerd. Wij analyseerden onze data om risico factoren vast te stellen voor verslechtering van de creatinine klaring van $10 \%$ of meer. Alle patiënten die een geïsoleerde coronaire bypass operatie ondergingen in ons ziekenhuis tussen januari 1998 en december 2007 werden geincludeerd. In 10098 van een totaal van 10626 patiënten, kon de preoperatieve en de postoperatieve creatinine klaring worden berekend. De volgende risico factoren werden gevonden: hogere leeftijd, diabetes, chronic obstructive pulmonary disease, perifeer vaatlijden, spoed operatie, eerdere hartoperatie, laag preoperatieve hemoglobin, hoge preoperatieve C-reactive protein waarde, perioperative myocard infarct, re-thoracotomie en het aantal bloed transfusies.

Hoofdstuk 5 Welke methode van bepalen van de nierfunctie is de beste voorspeller van vroege en late mortaliteit na coronaire bypass operaties?

Nierinsufficientie is geassocieerd met een verhoogd risico op complicaties en mortaliteit na coronaire bypass operatie (CABG). In de literatuur wordt de nierfunctie op verschillende manieren bepaald. We analyseerden preoperatieve en postoperatieve nierfunctie gegevens van alle patiënten die een geisoleerde CABG ondergingen vanaf januari 1998 tot en met december 2007. Preoperatieve en postoperatieve nierfunctie werd geschat op basis van de serum creatinine $(\mathrm{SeCr})$ waardes, de creatinine klaring $(\mathrm{CrCl})$ werd berekend met behulp van de Cockroft-Gault formule en de glomerular filtration rate (e-GFR) werd berekend door de Modification van Diet in Renal Disease (MDRD) formule. De relatie tussen de verschillende nierfunctie parameters en vroege en late mortaliteit werd bestudeerd. Bij 9987 patiënten, had de $\mathrm{CrCl}$ het beste discriminatoire vermogen om vroege en late mortaliteit te voorspellen, gevolgd door e-GFR en ten slotte door SeCr. De relatie tussen de nierfunctie en mortaliteit was niet lineair. leder afkap punt in een risico scoring systeem zal dan ook inaccuraat zijn. De nierfunctie als een variabele in risico scoring system zoals de EuroSCORE moet gereëvalueerd worden.

\section{Hoofdstuk 6 Transfusie van rode bloed cellen. de impact op korte en lange termijn overleving na een coronaire bypass operatie; een tien jaar follow-up studie}

Transfusie van Rode Bloed Cellen (RBC) en andere bloed producten in patiënten die een coronaire bypass operatie ondergaan, is geassocieerd met verhoogde mortaliteit en morbidity. 
We analyseerden retrospectief de gegevens van patiënten die een geisoleerde coronaire bypass operatie (CABG) ondergingen tussen January 1998 en December 2007. Van de geincludeerde patiënten, ontvingen 8001 geen RBC, 1621 1-2 eenheden RBC, 593 3-5 eenheden RBC en 220 6-10 units eenheden RBC. Het aantal getransfuseerde RBC was een voorspeller voor vroege maar niet voor late mortaliteit. Wanneer een vergelijking werd gemaakt met de verwachte overleving, was de overleving van patiënten die geen RBC kregen, beter, terwijl de overleving van patiënten die meer dan 3 eenheden RBC kregen slechter was. Transfusie van RBC is een onafhankelijke dosisafhankelijke risico factor voor vroege mortaliteit na CABG.

\section{Hoofdstuk 7 Risico factoren voor transfusie van rode bloed cellen na coronaire bypass operaties}

Perioperatieve transfusie van rode bloed cellen is geassocieerd met een verhoogde morbiditeit en mortaliteit. We onderzochten de correlatie tussen preoperatieve en peroperatieve risico factoren en het aantal getransfundeerde eenheden rode bloed cellen bij patiënten die een coronaire bypass operatie (CABG) ondergingen. We onderzochten de gegevens van alle patiënten die een geisoleerde CABG ondergingen tussen 1998 and 2007 ( $n=10626$ ). De volgende onafhankelijke risico factoren voor het krijgen van een of meer eenheden rode bloed cellen werden geidentificeed: leeftijd, vrouwelijk geslacht, gering lichaamsoppervlak, lage linker kamer ejectie fractie $(<35 \%)$, spoed operaties, eerdere hartchirurgie, laag preoperatief hemoglobine en lage preoperatieve creatinine klaring. Perioperatieve risico factoren waren: gebruik van extra-corporele circulatie, langere duur extra-corporele circulatie, gebruik van crystalloide cardioplegie, de noodzaak voor het gebruik van een intra-aortale ballon pomp, perioperatief hart infarct en een re-thoracotomie.

\section{Hoofdstuk 8 Effect van bewaarduur van rode bloed cellen op vroege en late mortaliteit na coronaire artery bypass operaties}

Recentelijk is er ongerustheid ontstaan over transfusie van oudere Rode Bloed Cellen (RBCs) na hart chirurgie. We onderzochten of langere bewaartijd van RBC heeft geleid tot een verhoogd risico op vroege en late mortaliteit bij patienten die een coronaire bypass operatie (CABG) ondergingen. We onderzochten retrospectief de gegevens van patiënten die een geisoleerde CABG ondergingen tussen januari 1998 en december 2007 in het Catharina Ziekenhuis, Eindhoven en die minder dan 11 eenheden RBC intraoperatief of tijdens de eerste 5 postoperatieve dagen getransfundeerd hebben gekregen. De patiënten werden onderverdeeld in 3 groepen afhankelijk van de bewaarduur van de RBCs met een afkap punt van 14 days: "alleen jonger bloed" ( $n=1422)$, "alleen ouder bloed" ( $n=1719)$, en tenminste 1 eenheid van ouder RBC ("enig ouder bloed") ( $n=2175)$. Univariate en multivariate logistische regressie analyses 
toonden aan dat het aantal van transfuseerde eenheden wel maar de bewaartijd van RBC zowal als een continue variabele of als een dichotome variabele met een afkap punt van 14 dagen geen risico factor voor vroege mortaliteit was. Noch het aantal eenheden RBC noch de bewaarduur was een onafhankelijke risico factor voor late mortaliteit

\section{Hoofdstuk 9 Effect van bewaartijd van getransfuseerd plasma op vroege en late mortaliteit na coronaire artery bypass operatie}

Voor zover wij weten zijn er geen gegevens beschikbaar over de relatie tussen de bewaarduur van van fresh-frozen plasma en vroege en late overleving na coronaire artery bypass operaties. Daarom onderzochten wij of een langere bewaartijd van getransfuseerd plasma tot een verhoogd risico op vroege of late mortaliteit bij patiënten die een coronaire bypass operatie (CABG) ondergingen heeft geleid. Patiënten die ten minste 1 eenheid van plasma intraoperatief of gedurende de eerste 5 postoperatieve dagen hebben gekregen $(n=745)$ werden geanalyseerd. De patiënten werden verdeeld in 3 groepen (de "alleen jonger plasma" groep, de "alleen ouder plasma" groep, en de "enige ouder plasma" groep) afhankelijk van de bewaartijd van het plasma (afkap punt = 323 days). Zowel gebruikt als een continue variabele als gebruikt als een dichotome variabele was de bewaartijd van plasma een risico factor voor vroege maar niet voor late mortaliteit.

\section{Hoofdstuk 10 Preoperatieve c-reactive protein als risico factor voor vroege en late mortaliteit na coronaire bypass operaties: 8 jaars' follow-up}

$\mathrm{Er}$ is een beperkte hoeveelheid aanwijzingen dat verhoogde preoperatieve waardes van C-reactive protein (CRP) geassocieerd zijn met een verhoogde mortaliteit na coronaire bypass operaties (CABG). We onderzochten retrospectief de voorspellende waarde van preoperatieve C-reactive proteïne waardes voor vroege en late mortaliteit na CABG in 5669 patiënten. Preoperatieve CRP waarde van > $10 \mathrm{mg} / \mathrm{L}$ was een onafhankelijke risico factor voor vroege mortaliteit, terwijl een preoperatieve CRP waarde van $>5 \mathrm{mg} / \mathrm{L}$ een risico factor was voor late mortaliteit. We vonden een hogere gemiddelde CRP waarde bij patiënten met een ejectie fractie $<35 \%$ ) vergeleken met patiënten met een ejectie fractie van $>35 \%$.

Conclusies: Preoperatieve CRP waardes kunnen gebruikt worden voor risico stratificatie bij patiënten die een CABG ondergaan. Een CRP waarde van $>10 \mathrm{mg} / \mathrm{L}$ is een risico factor voor vroege mortaliteit, terwijl een waarde van $>5 \mathrm{mg} / \mathrm{L}$ een risico factor is voor late mortaliteit. 
Hoofdstuk 11 Preoperatieve hemoglobin waarde als voorspeller van overleving na een coronaire bypass operatie, een vergelijking met een gematchte algemene populatie

De voorspellende waarde van de preoperatieve hemoglobine $(\mathrm{Hb})$ waarde voor mortaliteit na een coronaire bypass operatie $(A B G)$ is niet volledig bekend. We onderzochten hoe de preoperatieve $\mathrm{Hb}$ waarde de overleving van patiënten na coronaire artery bypass operatie beinvloedt. Late mortaliteit werd vergeleken met die van een algemene populatie. Patienten werden ingedeeld in 4 groepen op basis van hun preoperatieve $\mathrm{Hb}$ waarde. Het afkap punt voor anemia was $13 \mathrm{~g} / \mathrm{dL}$ voor mannen en $12 \mathrm{~g} / \mathrm{dL}$ voor vrouwen. Multivariate logistische regressie analyse toonde aan dat anemia een onafhankelijke risico factor was voor vroege mortaliteit. Cox regressie analyses toonden aan dat een laag $\mathrm{Hb}$, zowel geanalyseerd als een continue variabele als geanalyseerd als een dichotome variabele (anemia), een risico factor voor late mortaliteit was. Vergeleken met de overleving van een op leeftijd en geslacht gematchte algemene populatie hadden patiënten met de laagste preoperatieve $\mathrm{Hb}$ waarden een slechter overleving, terwijl patiënten met de hoogsgte $\mathrm{Hb}$ waardes een betere overleving hadden.

\section{Hoofdstuk 12 Effect van Body Mass Index op vroege en late mortaliteit na een coronaire bypass operatie}

Het effect van onder en overgewicht op de lange termijn overleving na een coronaire bypass operatie ( $C A B G$ ) is nog steeds controversieel. We onderzochten de gegevens van patiënten die een geïsoleerde CABG ondergingen in ons ziekenhuis om de voorspellende waarde van body mass index (BMI) in combination met comorbiditeit op zowel vroege ( $<31$ dagen) als late mortaliteit $(>30)$ vast te stellen. Patiënten werden onderverdeeld in 5 groepen afhankelijk van de preoperatieve BMI (ondergewicht, normaal gewicht, overgewicht, obesitas, en morbide obesitas). Multivariate logistische regressie analyses toonden dat ondergewicht geassocieerd was met hogere vroege. Multivariate Cox regressie analyses toonden aan dat morbide obesitas een onafhankelijke voorspeller van late mortaliteit was.

\section{Hoofdstuk 13 Diabetes mellitus en overleving na een coronaire bypass operatie: vergelijking met een op leeftijd en geslacht gematchte algemene populatie}

Lange termijn overleving na coronaire bypass operatie (CABG) is slechter bij patiënten met diabetes mellitus (diabetes) dan bij patiënten die geen diabetes hebben. Gegevens betreffende vergelijking van de overleving van diabetes en non-diabetes patiënten na CABG vergeleken met de algemene bevolking zijn niet voorhanden. We onderzochten retrospectief de gegevens van 10626 patienten die een geïsoleerde CABG ondergingen 
tussen januari 1998 en december 2007. Van deze hadden 8287 patiënten geen diabetes, 1587 hadden niet-insuline-afhankelijke diabetes en 630 hadden insulineafhankelijke diabetes (122 patiënten waren "lost to follow-up"). Overleving van deze patiënt groepen werd vergeleken met de overleving van de algemene Nederlandse bevolking gematcht op leeftijd en geslacht (verwachte overleving). Niet-insulineafhankelijke diabetes was een risico factor voor vroege mortaliteit en beide types van diabetes waren risico factoren voor late mortaliteit na CABG. Vergeleken met op leeftijd en geslacht gematchte cohorten van de algemene Nederlandse bevolking, was de 10 -jaar overleving van patiënten zonder diabetes beter, terwijl de overleving van patienten met een van beide types diabetes slechter was.

\section{Hoofdstuk 14 Perifeer vaatlijden als voorspeller van overleving na coronaire bypass operaties: Vergelijking met een gematchte algemene populatie}

Een van de onderdelen van de EuroSCORE, het meest gebruikte Europese risico scoring systeem voor hartchirurgie, is "extracardiac arteriopathy". Wij onderzochten de invloed van perifeer vaatlijden (PVD) op vroege en late mortaliteit in een grote groep patiënten die een geisoleerde coronaire bypass operatie (CABG) ondergingen. Van de bestudeerde patiënten hadden 1222 (11.63\%) PVD. PVD was een onafhankelijke risico factor voor late, maar niet voor vroege mortaliteit. Patiënten zonder PVD hadden een overleving, die beter was dan de overleving van patiënten met PVD en ze hadden zelfs een betere dan verwachte overleving. PVD patiënten hadden een slechtere dan verwachte overleving.

\section{Hoofdstuk 15 Algemene discussie}

Het combineren van verschillende bronnen van patiënteninformatie en het bestuderen daarvan was een fascinerende ervaring. Het heeft ons nieuwe inzichten verschaft in het effect dat verschillende risico factoren hebben op vroege en late stefte na CABG. Het tot nu toe gebruikte risico scorings systeem (EuroSCORE) voldoet niet. We hopen dat er met de gegevens van dit proefschrift gekomen kan worden tot betere een risicostratificatie van patiënten die een CABG moeten ondergaan en dat het behandelen en of modificeren van de risicofactoren zal leiden tot betere resultaten van de CABG operaties. 

Chapter 18

Conclusions and recommendations

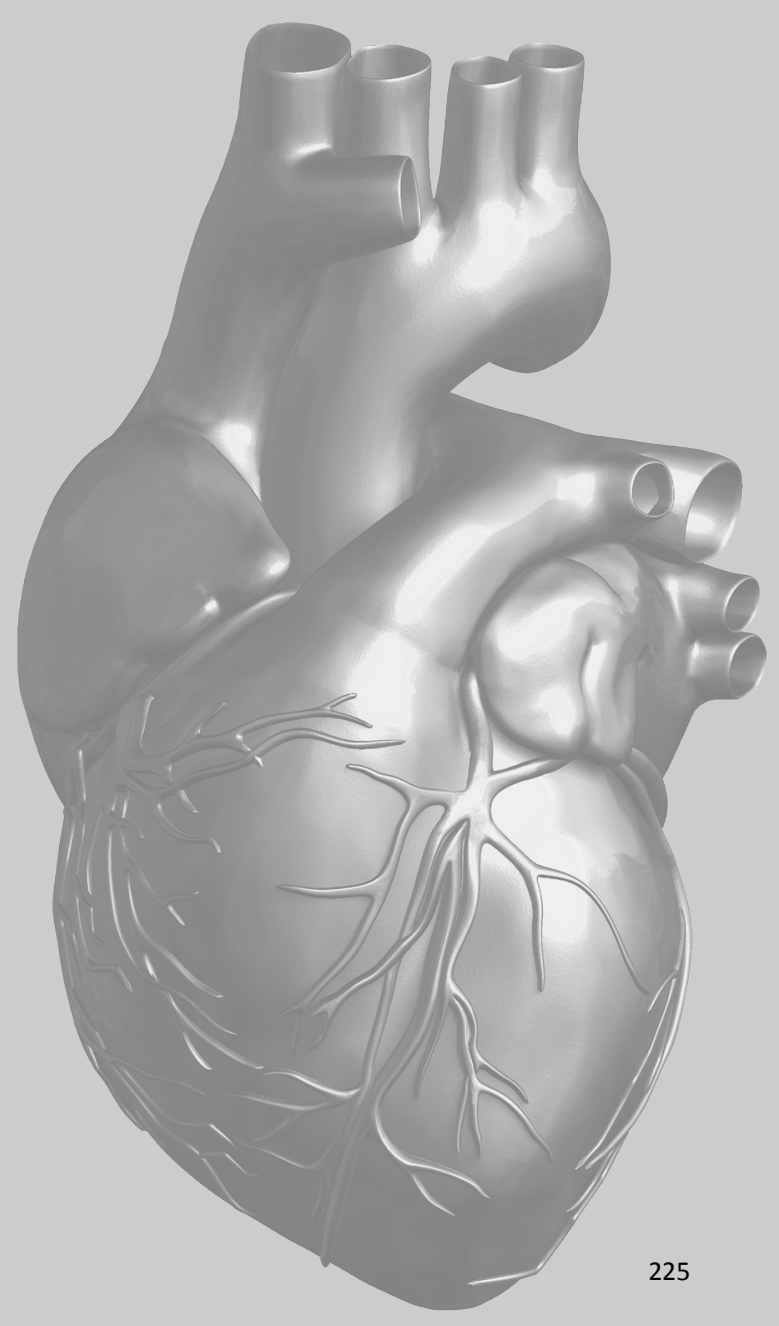



The EuroSCORE is inaccurate in predicting mortality in CABG patients en needs to be revised.

Until a more accurate risk scoring system is available comparison of institutions based risk-adjusted (EuroSCORE) mortality rates should be avoided.

The Cockroft-Gault formula should be used for estimation of the renal function when used as a risk factor in CABG .

The association between renal function en early mortality is non-linear. The EuroSCORE using serum creatinine level with a cut-off point of $200 \mu \mathrm{mol} / \mathrm{L}$ needs to be reconsidered.

Compared to an age and sex matched Dutch general population only severe renal impairment leads to worse outcome. One should be cautious in considering impaired renal function as a contraindication for surgical therapy.

Transfusion of Red Blood Cells is associated with increased early mortality. Every measure should be taken to avoid the need of transfusion of Red Blood Cells.

The use of crystalloid cardioplegia is associated with more transfusion of Red Blood Cells. One can consider using blood in instead of crystalloid cardioplegia in order to save Red Blood Cells.

Longer storage times of Red Blood Cells in the Netherlands are not associated with higher early mortality after CABG.

Longer storage times of fresh frozen plasma are associated with higher early mortality after CABG and the transfusion of older fresh frozen plasma should be avoided.

Elevated C-reactive protein levels are associated with worse early and late outcome after CABG. Postponement of the operation and more vigorous search for underlying diseases seems, whenever possible, advisable. Whether this will lead to improved outcome remains to be investigated.

Elevated C-reactive protein level should be incorporated in future risk scoring system.

Lower preoperative haemoglobin levels are associated with worse early en late outcome after CABG. Anemia should be incorporated in future risk scoring systems. Whether preoperative correction of low haemoglobin leads to improved outcome remains to be investigated.

Low Body Mass Index is associated with higher early mortality after CABG and should be incorporated in future risk scoring systems.

High Body Mass Index is associated with a poorer long-term outcome. Whether correction of body weight extremes lead to improved outcome, remains to be investigated.

Diabetic patients have a worse long-term outcome after CABG compared to nondiabetic patients. The long-term survival of insulin dependent diabetic patients differs more from the survival of an age en sex matched Dutch population than the survival of non-insulin dependent patients. 
Non-diabetic patients have a similar or even better long-term survival compared to an age en sex matched Dutch population.

Patients with peripheral vascular disease undergoing CABG are not at risk of increased early mortality. Peripheral vascular disease as a variable in the EuroSCORE should be reconsidered.

Peripheral vascular disease is a risk factor for late mortality. 
Chapter 19

Acknowledgements

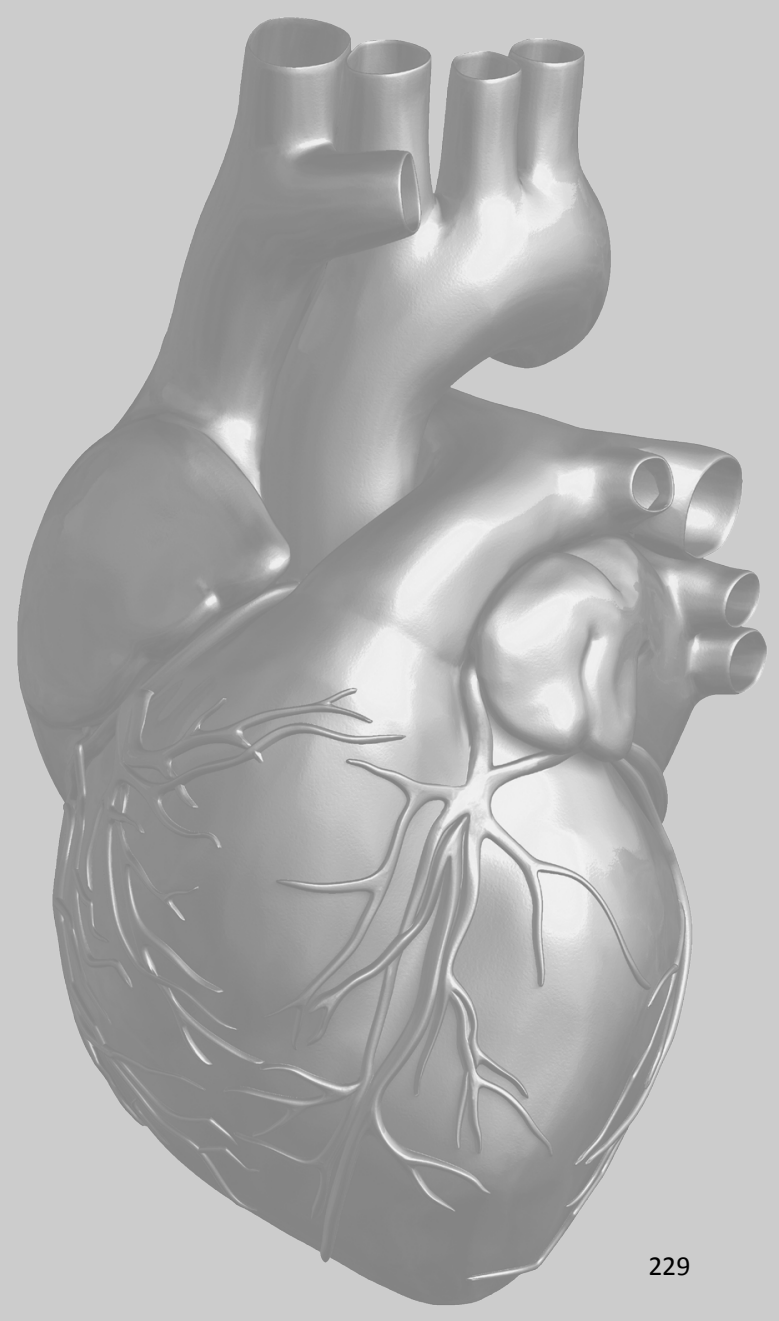



Many people contributed to the collection of the data of this thesis, such as the cardiothoracic surgeons from the Catharina Hospital, the residents, nurse-practitioners from the department of cardio-thoracic surgery, the secretaries. Thanks to their daily effort we have a large and complete database.

Some people deserve special acknowledgement.

\section{Brigitte de Wit}

Since the start of the database Brigitte is taking care of completing the database. For every patient, she controls after discharge the database for missing data and errors. She confronts the writer of this thesis almost daily with data that are unclear and together we decide to "score or not to score". Only thanks to her we can be confident that our database is complete and reliable.

\section{Toos van Straten}

When we decided to study the follow-up of our patients it was unclear what effort it would take to achieve this. Most of the follow-up data we could retrieve from the database from the health insurance companies but the data of some 1400 patients were still missing. Almost like a real detective, Toos succeeded in retrieving the data of most patients. She made a countless number of phone calls to referral cardiologists, home physicians, pharmacists and others. Thanks to her efforts only 177 patients (out of 16,000 ) were lost to follow-up.

\section{Elisabeth Martens}

When I started with the first studies I had very limited knowledge of statistics. By studying SPSS I learned to understand some of the simple statistical tests but only with the help from Lies I was able to performe the necessary statistical analyses described in this thesis.

\section{Jacques Schönberger}

Jacques helped me in writing most papers. The discussions with him about the findings in the different studies and the possible clinical implication were very inspiring and encouraged me to go on in times of despair.

\section{Andre de Wolf}

We have only met once but I am very glad that you offered me to help. Your contribution to most papers helped to improve them. 


\section{Mohamed Soliman}

Mohamed helped me enormously with the administrative burden that comes with submitting papers. Besides that, his critical remarks helped to improve the quality of the submitted papers. We were and still are a very good team.

\section{André van Zundert}

André is an exceptional experienced writer and has already helped a lot of people in their struggle to write papers and theses. I am very grateful that he has helped me in my struggle. Without his help I probably would not have come this far.

\section{Members of the Maatschap cardio-thoracale chirurgie of the Catharina Hospital}

I am grateful that the effort put in this thesis was supported by the members of the "maatschap". They did not only give me the mental support in times that I needed it, but also gave me the opportunity and time to accomplish this thesis. 
Chapter 20

Curriculum vitae

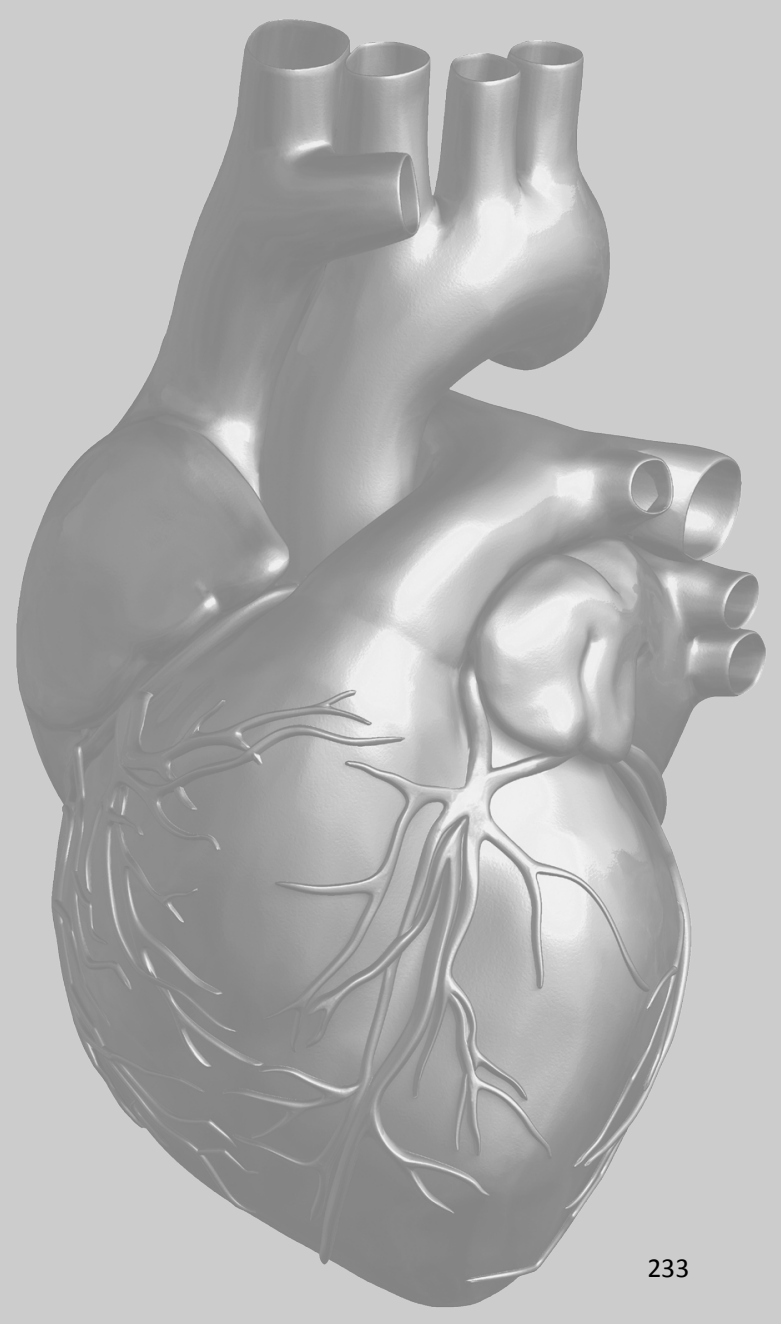





\title{
Curriculum vitae
}

\author{
Personalia \\ Name van Straten, Albert.H.M \\ First name Bart \\ Birth date 14 februari 1955 \\ Nationality Dutch \\ Hospital \\ Catharina Hospital \\ Michelangelolaan 2 \\ 5623 EJ Eindhoven \\ Phone: 0031402398680 \\ E-mail: bart.v.straten@cze.nl
}

Home Address

Het Kolkven 4

5688 XN Oirschot

The Netherlands

Phone : 0031499550155

Mobile: 0031653214729

E-mail : straten@chello.nl

Registrations

BIG registry: $\quad 79024138701$

\section{Education}

$1981-1982 \quad$ Military service

15 -01-1981 Graduation as a medical doctor in Rotterdam, The Netherlands

$1977-1981$ Medical School, University of Rotterdam, The Netherlands

$1974-1977$ Medical School, University of Antwerp, Belgium

$1973-1974$ Study physiotherapy, Breda, The Netherlands

1967-1973 Higher secondary school (gymnasium B), Eindhoven,

Clinical experience

2004 - now Chairman of the "sector Thorax" (including cardiology, pulmonology and cardio-pulmonary surgery, Catharina Hospital Eindhoven, The Netherlands

2002-2006 Member of the board of the medical staff Catharina Hospital 


2001-2007 $\begin{aligned} & \text { Chairman of the cardiothoracic department Catharina Hospital } \\ & \text { 1997-2002 }\end{aligned}$
$\begin{aligned} & \text { Chairman of the management team of the operating room de- } \\ & \text { partment Catharina Hospital } \\ & \text { Staffsurgeon at the department of cardio-thoracic surgery Ca- } \\ & \text { tharina hospital Eindhoven, The Netherlands }\end{aligned}$
Trainee for surgery for congenital cardiac disorders University
Hospital Leiden, The Netherlands
$1991-1991-1992 \quad \begin{aligned} & \text { Trainee cardio-pulmonary surgery Onze Lieve Vrouwe Gasthuis, } \\ & \text { Amsterdam, The Netherlands }\end{aligned}$
$\begin{aligned} & \text { Trainee general surgery St. Joseph hospital, Eindhoven, The Neth- } \\ & \text { erlands } \\ & \text { Resident cardio-pulmonary surgery Medisch centrum the Klok- } \\ & \text { kenberg, Breda, The Netherlands }\end{aligned}$




\section{List of publications}

Peripheral vascular disease as a predictor of survival after coronary artery bypass grafting: Comparison with an age and sex matched general population. Albert H. M. van Straten, Cristina Firanescu, M. A. Soliman Hamad, M. Erwin. S. H. Tan, Joost F. J. ter Woorst, Elisabeth J. Martens, André A. J. van Zundert. Ann Thorac Surg 2010;89:414-20

Diabetes and Survival after Coronary Artery Bypass Grafting: Comparison with an Age and Sex Matched Population. Albert H.M. van Straten, Mohamed A. Soliman Hamad, André A. J. van Zundert, Elisabeth J. Martens, Jacques P. A. M. Schönberger, Joost F. J. ter Woorst, Andre M. de Wolf. Eur J Cardio Thorac Surg 2009 dec. [epub ehead of print] PMID 20036136

Effect of Body Mass Index on Early and Late Mortality After Coronary Artery Bypass Grafting. Albert HM van Straten, Sander Bramer, Mohamed A. Soliman Hamad, André A.J. van Zundert, Elisabeth J. Martens, PhD; Jacques P. A. M. Schönberger, Andre M. de Wolf. Ann Thorac Surg 2010:89:30-37

Transfusion of Red Blood Cells: The impact on short-term and long-term survival after coronary artery bypass grafting, a ten year follow-up. Albert H. M. van Straten, Margreet W. A. Bekker, Mohamed A. Soliman Hamad, André A. J. van Zundert, Elisabeth J. Martens, Jacques P. A. M. Schönberger and Andre M. de Wolf. Interact Cardiovasc Thorac Surg.2010;10:37-42

Preoperative Renal Function as a Predictor of Survival after Coronary Artery Bypass Grafting: Comparison with a Matched General Population. Albert H. M. van Straten, $M^{1}$; Mohamed A. Soliman Hamad, $\mathrm{MD}^{1}$; André A. J. van Zundert, MD, PhD, FRCA ${ }^{2}$; Elisabeth J. Martens, $\mathrm{PhD}^{3}$; Jacques P. A. M. Schönberger, $\mathrm{MD}, \mathrm{PhD}^{1}$; and Andre $\mathrm{M}$. de Wolf, MD ${ }^{4}$. J Thorac Cardiovasc Surg. 2009 Oct;138(4):971-6.

Postoperative blood loss in patients undergoing coronary artery bypass surgery after preoperative treatment with clopidogrel. A prospective randomised controlled study.Firanescu CE, Martens EJ, Schönberger JP, Soliman Hamad MA, van Straten AH. Eur J Cardiothorac Surg. 2009 Nov;36(5):856-62. Epub 2009 Jul 17. 
Risk factors for deterioration of renal function after coronary artery bypass grafting . Albert H. M. van Straten, MD $^{1}$; Mohamed A. Soliman Hamad, MD $^{1}$; André J. van Zundert, MD, PhD, FRCA ${ }^{2}$; Elisabeth J. Martens, $\mathrm{PhD}^{3}$; Jacques P. A. M. Schönberger, MD, PhD ${ }^{1}$; Andre M. de Wolf, MD ${ }^{4}$. Eur J Cardiothorac Surg. 2010;37:106-111

Preoperative C-Reactive Protein Levels to Predict Early and Late Mortality After Coronary Artery Bypass Surgery: 8 Years' Follow-up. AHM van Straten, MD ${ }^{1}$; André J. van Zundert, MD, PhD, FRCA ${ }^{2}$; Mohamed A. Soliman Hamad, MD ${ }^{1}$; Elisabeth J. Martens, $\mathrm{PhD}^{3}$; Jacques P. A. M. Schönberger, MD, $\mathrm{PhD}^{1}$; and Andre M. de Wolf, MD, $\mathrm{PhD}^{4}$. J Thorac Cardiovasc Surg. 2009 Oct;138(4):954-8.

Intraoperative recognition of an intracavitary left anterior descending coronary artery.Sanders LH, Soliman Hamad MA, Newman MA, van Straten BH. J Thorac Cardiovasc Surg. 2009 Apr 7. [Epub ahead of print] No abstract available.

Management of right ventricular injury after localization of the left anterior descending coronary artery. Sanders LH, Soliman HM, van Straten BH. Ann Thorac Surg. 2009 Aug;88(2):665-7. Review.

Dissected biovalsalva prosthesis.Tan ME, ter Woorst FJ, Elenbaas TW, van Straten AH. Eur J Cardiothorac Surg. 2009 Aug;36(2):

Preoperative Hemoglobin level as a Predictor of Survival after Coronary Artery Bypass Grafting, a Comparison with the Matched General Population. Albert HM van Straten, $\mathrm{MD}^{1}$; Mohamed A. Soliman Hamad, MD ${ }^{1}$; André J. van Zundert, MD, PhD, FRCA $^{2}$; Elisabeth J. Martens, $\mathrm{PhD}^{3}$; Jacques P. A. M. Schönberger, MD, PhD ${ }^{1}$; Andre M. de Wolf, MD ${ }^{4}$ Circulation. 2009 Jul 14;120(2):118-25.

Acute hemodynamic effects of cardiac resynchronization therapy in patients with poor left ventricular function during cardiac surgery. Hamad MA, van Gelder BM, Bracke FA, van Zundert AA, van Straten AH. J Card Surg. 2009 Sep-Oct;24(5):585-90. Self management program improves anticoagulation control and quality of life: a prospective randomized study. Soliman Hamad MA, van Eekelen E, van Agt T, van Straten AH. Eur J Cardiothorac Surg. 2008 Nov 26.

Long-term results of coronary artery bypass grafting in patients with left ventricular dysfunction. Soliman Hamad MA, Tan ME, van Straten AH, van Zundert AA, Schönberger JP. Ann Thorac Surg. 2008 Feb;85(2):488-93. 
Antithrombotic therapy after bioprosthetic aortic valve replacement: ACTION Registry survey results. Colli A, Verhoye JP, Heijmen R, Strauch JT, Hyde JA, Pagano D, Antunes M, Koertke H, Ohri SK, Bail DH, Leprince P, Van Straten BH, Gherli T; ACTION Registry Investigators. Eur J Cardiothorac Surg. 2008 Apr;33(4):531-6. Epub 2008 Jan 18.

Coronary artery bypass surgery in patients with impaired left ventricular function. Predictors of hospital outcome. Soliman Hamad MA, Peels K, Van Straten A, Van Zundert A, Schönberger J. Acta Anaesthesiol Belg. 2007;58(1):37-44.

Influence of orientation of bi-leaflet valve prostheses on coronary perfusion pressure in humans. van't Veer M, van Straten B, vande Vosse F, Pijls N. Interact Cardiovasc Thorac Surg. 2007 Oct;6(5):588-92. Epub 2007 Jul 2.

Cardiac tamponade: an unusual, lifethreatening complication after transhiatal resection of the esophagus. Kats S, Nieuwenhuijzen GA, van Straten BH, Schönberger JP. Interact Cardiovasc Thorac Surg. 2007 Apr;6(2):238-9. Epub 2006 Dec 5.

Predictive models for thoracic aorta surgery. Is the Euroscore the optimal risk model in the Netherlands? Huijskes RV, Wesselink RM, Noyez L, Rosseel PM, Klok T, van Straten BH, Nesselaar A, Tijssen JG. Interact Cardiovasc Thorac Surg. 2005 Dec;4(6):538-42

Percutaneous coronary intervention or bypass surgery in multivessel disease? A tailored approach based on coronary pressure measurement. Botman KJ, Pijls NH, Bech JW, Aarnoudse W, Peels K, van Straten B, Penn O, Michels HR, Bonnier H, Koolen JJ. Catheter Cardiovasc Interv. 2004 Oct;63(2):184-91.

Surgical treatment of tumor metastases in the lungs, brain or liver. Sonnenberg AA, van den Borne BE, Smeenk FW, van Straten AH. Ned Tijdschr Geneeskd. 2003 Jul 12;147(28):1385; author reply 1385. Dutch.

Rapid hemodynamic deterioration because of acute rupture of an aneurysm of the sinus of Valsalva: the importance of echocardiography in early diagnosis. Pasteuning WH, Roukema JA, van Straten AH, van der MA, Wonnink-de Jonge WF. J Am Soc Echocardiogr. 2002 Oct;15(10 Pt 1):1108-10.

Acute right heart failure due to aortic aneurysm: 2 patients with an aortocaval shunt. Ansari Moein CM, Bellens L, Pasteuning WH, van Straten AH, Roukema JA. Ned Tijdschr Geneeskd. 2002 Aug 31;146(35):1653-6. Dutch. 
Clinical assessment of functional stenosis severity: use of coronary pressure measurements for the decision to bypass a lesion. Pijls NH, Bech GJ, De Bruyne B, van Straten A. Ann Thorac Surg. 1997 Jun;63(6 Suppl):S6-11.

Complications shortly after percutaneous transluminal angioplasty or after coronary surgery in 183 comparable patients with multi-vessel coronary disease. Berreklouw E, Mashhour YA, Schönberger JP, van Straten AH. Ned Tijdschr Geneeskd. 1994 Oct 8;138(41):2068-9. Dutch.

Accepted for publication

Evaluation of the EuroSCORE risk scoring model for patients undergoing coronary artery bypass graft surgery: a word of caution. Albert HM van Straten

Erwin MESH Tan, Mohamed A Soliman Hamad, Elisabeth J Martens, Andre AJ van Zundert.

Accepted for publication: Neth Heart J

Risk factors for red blood cell transfusion after coronary artery bypass grafting. Albert H.M. van Straten, Suzanne Kats, Margreet W.A. Bekker, Frank Verstappen, Joost F. J. ter Woorst, Mohamed A. Soliman Hamad, MD.

Accepted for publication: J Cardiothorac Vasc Anesth

Thrombocytopenia after aortic valve replacement: comparison between mechanical and biological valves. Albert H. M. van Straten, Mohamed A. Soliman Hamad, Eric Berreklouw, Joost F. Ter Woorst, Elisabeth J. Martens and M. Erwin S. H. Tan Accepted for publication J Heart Valve Disease

Preoperative atrial fibrillation and elevated C-reactive protein levels as predictors of deep sternal wound infections after coronary artery bypass grafting. Ted W. 0 . Elenbaas, Albert H.M. van Straten, Mohammed A. Soliman Hamad, Jacques P. A. M. Schönberger, Elisabeth J. Martens and André A.J. van Zundert Accepted for publication: Ann Thorac Surg 